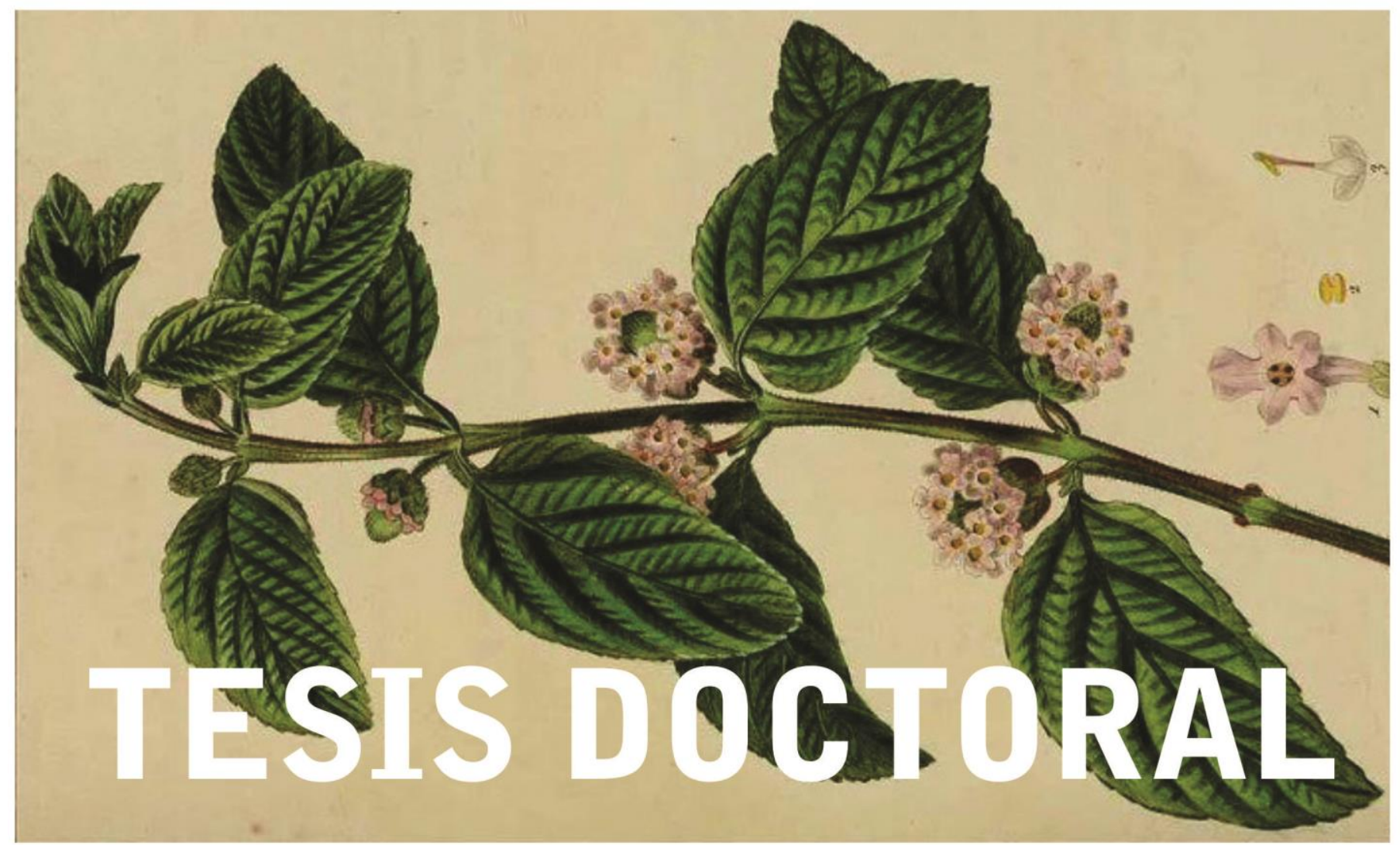

AÑO 2017

\title{
ESTUDIO DEL MECANISMO DE ACCIÓN DE DISTINTOS QUIMIOTIPOS DE Lippia alba SOBRE EL METABOLISMO LIPÍDICO Y LA PROLIFERACIÓN CELULAR
}

\section{SANDRA MONTERO VILLEGAS}
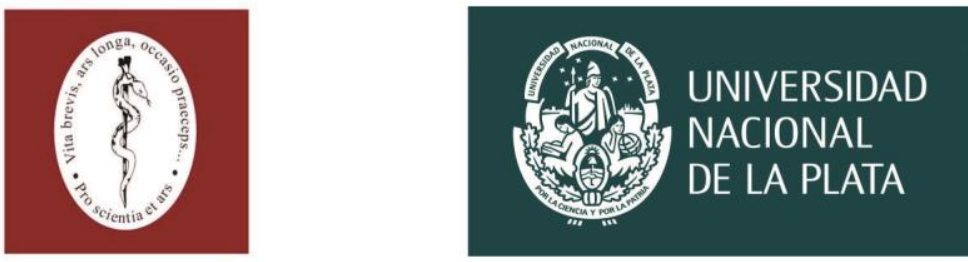


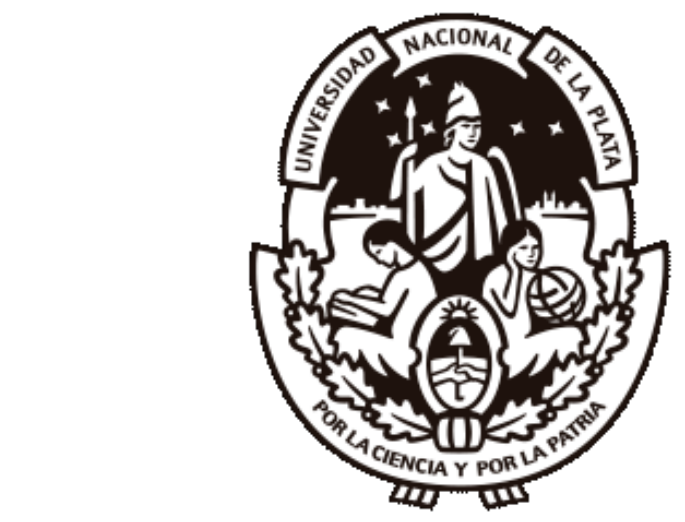

Universidad Nacional de La Plata

Facultad de Ciencias Médicas

Departamento de Posgrado

Trabajo de Tesis para optar al Título de Doctora en Medicina

\section{Estudio del mecanismo de acción de distintos quimiotipos de Lippia alba sobre el metabolismo lipídico y la proliferación celular}

Lic. Sandra Montero Villegas

Directora: Dra. Margarita García de Bravo Co-directora: Dra. Mónica Patricia Polo

La Plata, Buenos Aires, Argentina 
Dedicado a quienes me brindan su amor, me contagian su fortaleza, comparten mis alegrías y me dan aliento constante....

\section{A mis padres y hermanos}




\section{Reconocimientos}

Al Instituto de Investigaciones Bioquímicas de La Plata (INIBIOLP-UNLP-CONICET-CCT La Plata) y a la Facultad de Ciencias Médicas de la UNLP por haberme brindado el espacio y los medios para la ejecución de este trabajo.

Al apoyo económico de becas de Consejo Nacional de Investigaciones Científicas y Técnicas (CONICET), y subsidios de la Agencia Nacional de Promoción Científica y Tecnológica (ANPCYT), CONICET y de la Universidad Nacional de la Plata (UNLP) que me permitieron el desarrollo de este trabajo de investigación

Al M.Sc. José Francisco Cicció Alberti del Centro de Investigaciones en Productos Naturales (CIPRONA), Universidad de Costa Rica por proveer los aceites esenciales utilizados en la realización de este trabajo doctoral y su apoyo como co-director de beca.

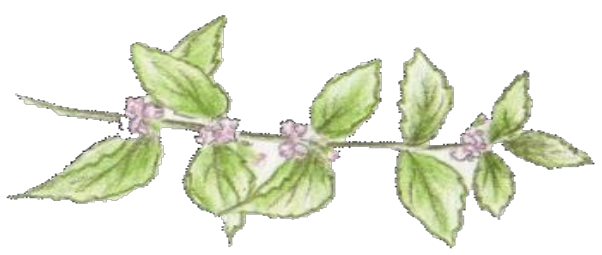




\section{Agradecimientos}

El trabajo realizado en esta tesis no hubiera sido posible sin el apoyo y la contención de muchas personas que han estado presentes durante estos años y que han sido determinantes en mi aprendizaje y crecimiento personal. No puedo más que agradecer a Dios por todas las personas especiales que puso en mi camino.

A Cecilia Díaz Oreiro y Ximena Cortes Bratti, por ser las primeras en creer en mí, ser mis guias en los primeros pasos y ofrecerme la oportunidad de emprender esta aventura.

A la JEFE por traerme al laboratorio, por abrirme las puertas de su casa, por su paciencia eterna, porque ser más que mi directora y maestra. Por cuidarme y guiarme en la vida, por ser mi madre suplente.

A Moni, miles de gracias por brindarme sus conocimientos, su tiempo y apoyo en el aprendizaje dentro del laboratorio. Por la gran ayuda durante estos años, por ser mi traductora y plasmar en palabras lo que mi cabeza piensa. Por brindarme un lugar tranquilo para escribir y siempre estar conmigo en el proceso y corregirme con amor y paciencia. A la familia de Moni, por prestármela para que me ayudara y a Don Carlos por ser tan amable conmigo.

A Ro, por toda su ayuda, enseñanza y apoyo tanto dentro como fuera del laboratorio. Por ser un ejemplo de trabajo y esfuerzo, por siempre estar a disposición para ayudarme, por hacer que siempre me esforzara más. Por pasarme a buscar, por llevarme a Doro y por muchas otras cosas más muchas gracias.

A Boris, gracias por ser mi compañero de laboratorio, por siempre brindarme una mano amiga, por apoyarme y estar un paso más adelante mío. Por hacer mi camino menos complejo al cederme tus conocimientos, técnicas, escritos o cualquier cosa que necesitara. Gracias por ser mi amigo.

Al B4, por ser grandes compañeros de trabajo. Por todas las experiencias vividas tanto fuera como dentro del laboratorio. Por ser cada uno especial a su manera.

A todos los del cuarto piso, y en especial a Moni H, Marisa, Santiago y Graciela, por toda la ayuda en la realización del trabajo para esta tesis, pero más importante por compartir conmigo este tiempo y hacerlo agradable.

A toda la gente del INIBIOLP por su apoyo, consejos y ayuda. A Annie, por muchos cafés, por sus consejos y por estar siempre pendiente de mí. A los Anicitos por ser mis compañeros de viaje y por toda la ayuda. A Lu, por ser mi compañera del grupo avesicular, por enseñarme de las gotas y por muchas pláticas de pasillo. A los Betinos por toda su ayuda, consejo y paciencia conmigo. 
A la familia Chaparro Aranda, por dejarme entrar en sus vidas, por apoyarme en estos años, dejarme formar parte de su familia y brindarme todo el amor, resguardo y cariño posible. Porque sé que en el cielo hay un ángel que nos cuida y en la tierra un hombre de hierro que es un ejemplo de vida.

A la familia Bravo, por abrirme la puerta de su casa y de su corazón. Por tratarme como una más de ustedes. A Don Rodolfo, por sus bromas, por ser mi paciente tutor de los asados y por ser tan especial conmigo. A Sole, Gra, Santi y Ceci por prestarme a ese ejemplo de personas que son sus padres y por todos los buenos momentos que me han dejado compartir con ustedes.

A mis padres, porque son mi pilar, por permitirme estudiar, volar y seguir mis sueños, porque les debo todo lo que soy. Porque esta etapa no hubiera sido posible sin su amor y apoyo incondicional. A mi madre por alentarme en la distancia y ser mi fortaleza, por enseñarme con su ejemplo a "ponerle pichón" a la vida.

A mis hermanos, por apoyarme y quererme, por estar ahí siempre. Por permitirme venirme a otro país sabiendo que ustedes están bien allá. Calo gracias por cuidarme y respetarme, por ser un gran hermano y de vez en cuando jalarme las orejas. Jose gracias por ser mi enlace con la familia y siempre estar pendiente de mí. Jesús y Angélica gracias por estar ahí. 


\section{Índice de Contenidos}

\section{Abreviaturas.}

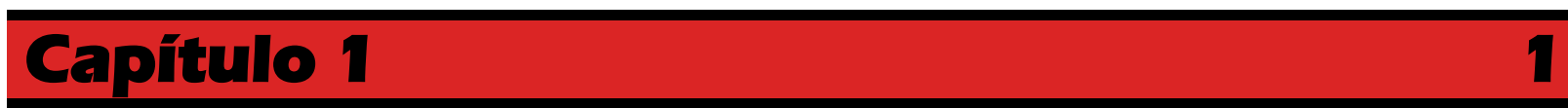

\section{Introducción}

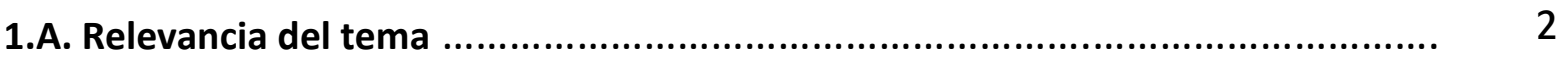

1.B. Síntesis de lípidos .................................................................................

1.B.1. Regulación del Metabolismo lipídico ....................................................... 8

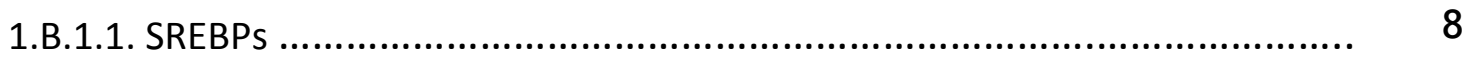

1.B.1.2. Receptores nucleares ............................................................. 11

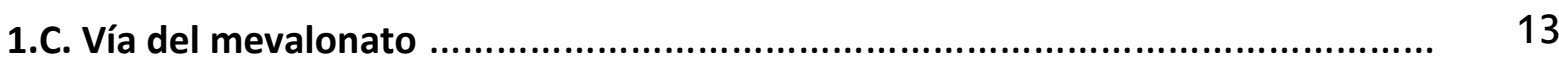

1.C.1. Productos de la vía del mevalonato ....................................................... 16

1.C.2. Regulación de la vía del mevalonato ....................................................... 19

1.C.3. Vía del mevalonato y cáncer ................................................................ 22

1.C.4. Drogas que inhiben la vía del mevalonato ............................................ 26

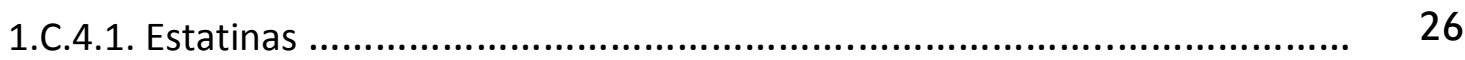

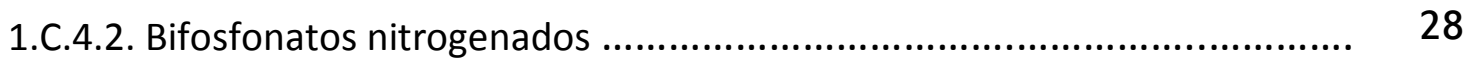

1.C.4.3. Inhibidores de farnesil transferasas .................................................. 29

1.C.4.4. Inhibidores de geranilgeranil transferasas ...................................... 29

1.C.4.5. Inhibidores de la escualeno sintasa ............................................. 30

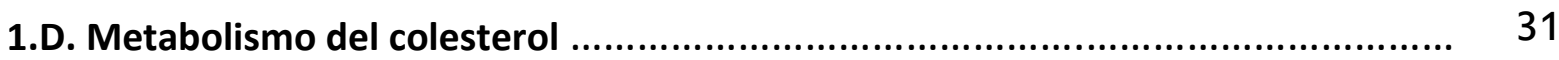

1.E. Dislipidemia y enfermedades cardiovasculares ............................................. 35

1.E.1. Manejo actual de las dislipidemias ........................................... 37

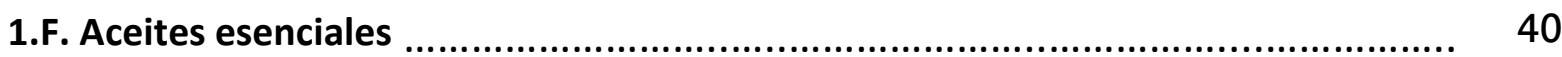

1.F.1. Isoprenoides: componentes mayoritarios de los aceites esenciales ............. 41

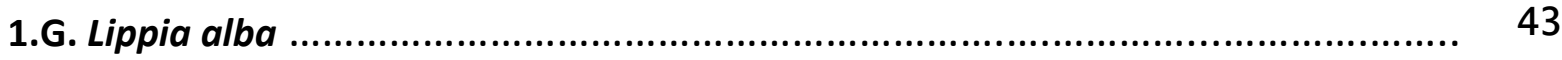

1.G.1. Usos tradicionales y actividades biológicas del aceite esencial de Lippia alba $\quad 47$

\section{Capítulo 2}

\section{Hipótesis y Objetivos}

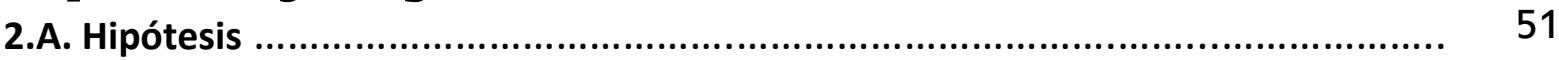

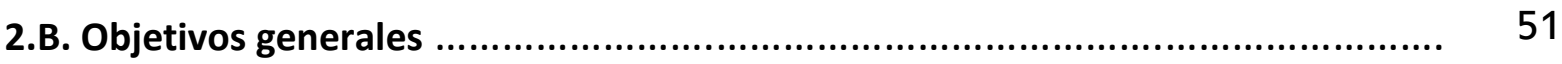




\section{Capítulo 3}

\section{Materiales y Métodos}

3.A. Materiales

3.A.1. Modelo experimental - Líneas celulares utilizadas

3.A.1.1. Células HepG2

3.A.1.2. Células A549

3.A.1.3. Células Vero

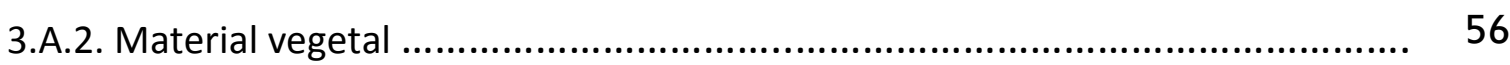

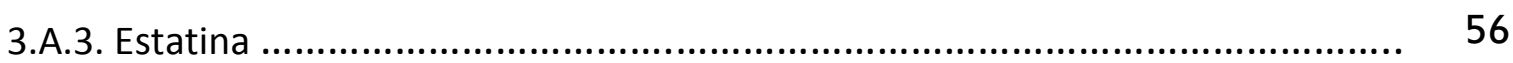

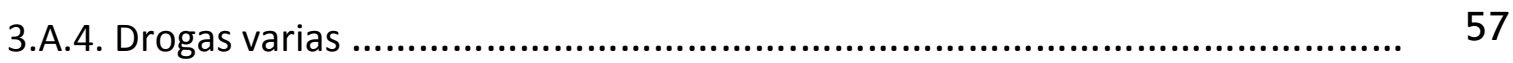

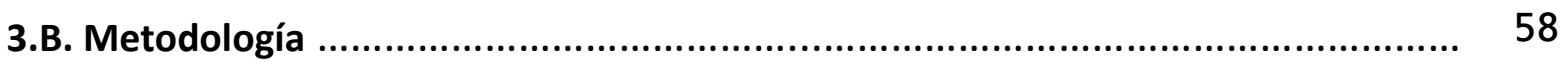

3.B.1. Obtención y análisis de los aceites esenciales ......................................... 58

3.B.1.1. Extracción de los aceites esenciales ............................................... 58

3.B.1.2. Análisis cromatográfico de los aceites esenciales ................................ 58

3.B.1.2.1. Cromatografía de gases acoplado a un detector de ionización de llama ................................................................................................ 58

3.B.1.2.2. Cromatografía de gases acoplada a espectrometría de masas .......... 59

3.B.1.2.3. Identificación de los constituyentes de los aceites esenciales ......... $\quad 59$

3.B.2. Obtención de sal sódica de simvastatina ............................................... 61

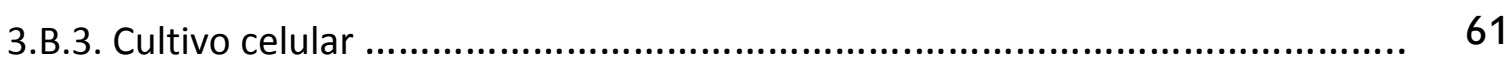

3.B.3.1. Condiciones de cultivo celular ..................................................... 61

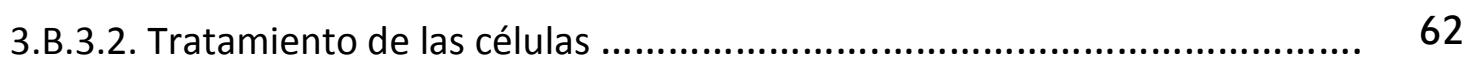

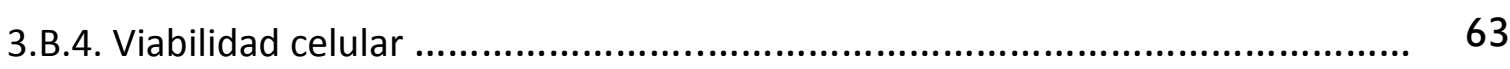

3.B.4.1. Ensayo de MTT ........................................................................ 63

3.B.4.2. Ensayo de captación de rojo neutro ............................................... 64

3.B.4.3. Ensayo de viabilidad/citotoxicidad utilizando calceína-AM/IP ............... 64

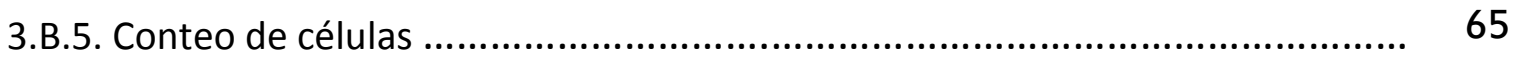

3.B.6. Análisis del ciclo celular por citometría de flujo .........................................6 66

3.B.7. Detección de apoptosis ....................................................................... 67

3.B.7.1. Marcaje in situ del ADN fragmentado o ensayo de TUNEL ..................... 67

3.B.7.2. Observación de morfología nuclear mediante microscopía de

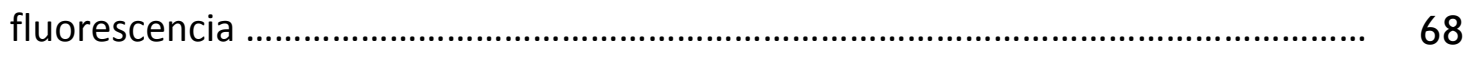

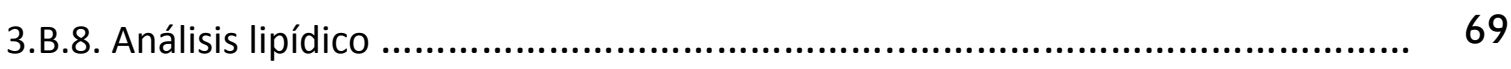

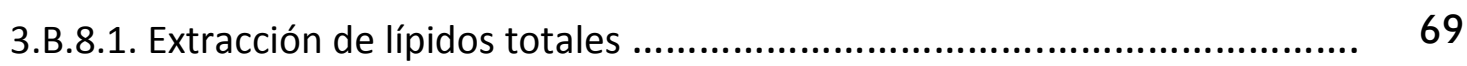


3.B.8.2. Separación de lípidos neutros ............................................. 70

3.B.8.3. Cuantificación de lípidos neutros y fosfolípidos .................................. 70

3.B.8.3.1. Cuantificación de triacilglicéridos ............................................. 70

3.B.8.3.2. Cuantificación de fosfolípidos .................................................. 71

3.B.8.3.3. Cuantificación de colesterol libre y esteres de colesterol ................. 71

3.B.8.4. Extracción de ácidos grasos y lípidos insaponificables ......................... 72

3.B.8.4.1. Composición de ácidos grasos por cromatografía gas-líquido (GLC)... 72

3.B.9. Incorporación de ${ }^{14} \mathrm{C}$-acetato en lípidos ................................................ 73

3.B.9.1. Cuantificación de ${ }^{14} \mathrm{C}$-acetato incorporado en lípidos neutros y polares... $\quad 73$

3.B.9.2. Cuantificación de ${ }^{14} \mathrm{C}$-acetato incorporado en lípidos insaponificables ... $\quad 74$

3.B.9.3. Distribución de ${ }^{14} \mathrm{C}$-acetato incorporado en ácidos grasos saturados e

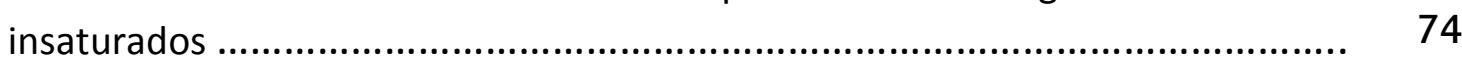

3.B.10. Cuantificación de gotas lipídicas por microscopía de fluorescencia ............. $\quad 75$

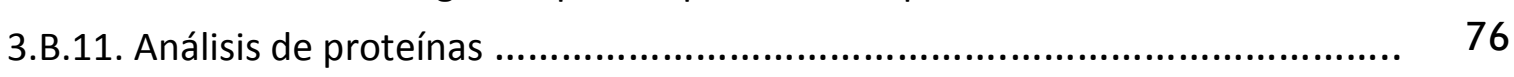

3.B.11.1. Cuantificación de proteínas totales ............................................... 76

3.B.11.1.1. Método de Lowry .................................................................. 76

3.B.11.1.2. Método de Bradford ............................................................. 76

3.B.11.2. Análisis de Proteínas por Western Blotting ................................... 77

3.B.11.2.1. Lisis de muestras celulares .................................................... 77

3.B.11.2.2. Electroforesis de proteínas en geles de poliacrilamida con SDS (SDS-PAGE) ............................................................................... 77

3.B.11.2.3. Western Blotting .............................................................. 78

3.B.12. Análisis de Interacción de Drogas .................................................... 79

3.B.13. Análisis estadístico ...................................................................... 80

\section{Capítulo 4 \\ Actividad antiproliferativa de aceites esenciales de Lippia alba en células neoplásicas humanas - Mecanismo de acción - Combinación con simvastatina}

4.A. Evaluación de citotoxicidad de quimiotipos del AEL en líneas celulares neoplásicas y no neoplásicas. Análisis de selectividad ...................................... 82

4.B. Efecto del AELta sobre la proliferación de células neoplásicas humanas ........... 86

4.C. Mecanismos involucrados en la actividad antiproliferativa de AELta .............. 88

4.C.1. Efectos sobre el ciclo celular ........................................................... 88

4.C.2. Detección de células apoptóticas ........................................................ 90

4.C.2.1. Ensayo de TUNEL ...................................................................... 90 
4.C.2.2. Análisis de la morfología nuclear por microscopía de fluorescencia en células teñidas con Hoechst 33258/IP

4.C.3. Efectos sobre la vía del mevalonato ...................................................... 95

4.C.3.1. Efecto sobre la síntesis de productos de la vía ................................... 95

4.C.3.2. Efecto sobre HMGCoA reductasa .................................................. 97

4.C.3.3. Efecto de la adición de mevalonato sobre la inhibición de la viabilidad

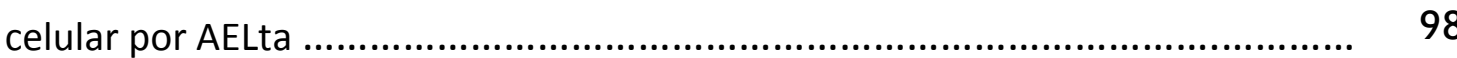

4.D. Efecto de la combinación de los AEs con simvastatina sobre la viabilidad celular 99

4.E. Discusión

\section{Capítulo 5}

Efectos de aceites esenciales de Lippia alba sobre el metabolismo lipídico celular - Combinación con simvastatina.

5.A. Vía del mevalonato y colesterogénesis en células HepG2 y A549 tratadas con simvastatina

5.B. Efectos de los AEs de $L$. alba sobre la vía del mevalonato y el contenido de lípidos mayoritarios de células HepG2 y A549

5.B.1. Vía del mevalonato y la colesterogénesis

5.B.1.1. Incorporación de ${ }^{14} \mathrm{C}$-acetato en intermediarios y productos finales de la VM

5.B.1.2. Actividad anticolesterogénica

5.B.2. Contenido de lípidos celulares mayoritarios

5.C. Efectos del AELta sobre el metabolismo lipídico en células HepG2

5.C.1. Incorporación de ${ }^{14} \mathrm{C}$-acetato en lípidos neutros y polares

5.C.1.1. Ácidos grasos y lípidos insaponificables

5.C.1.2. Lípidos neutros

5.C.1.3. Fosfolípidos

5.C.2. Impacto sobre la composición lipídica

5.C.2.1. Contenido de lípidos neutros y fosfolípidos

5.C.2.2. Composición de ácidos grasos

5.D. Análisis de los parámetros morfológicos de gotas lipídicas de células HepG2 tratadas con AELta

5.E. Efectos de la combinación de AELta y simvastatina

5.E.1. Vía del mevalonato y colesterogénesis. Incorporación de ${ }^{14} \mathrm{C}$-acetato en lípidos de la vía del mevalonato

5.E.2. Incorporación de ${ }^{14} \mathrm{C}$-acetato en lípidos neutros y polares 


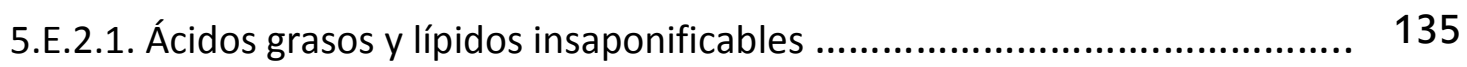

5.E.2.2. Lípidos neutros ....................................................................... 136

5.E.3. Contenido de lípidos neutros ............................................................ 138

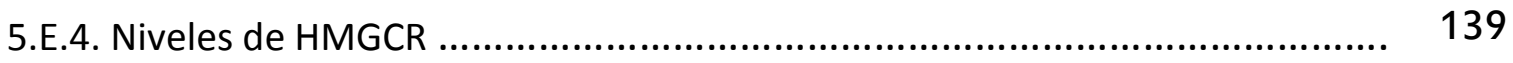

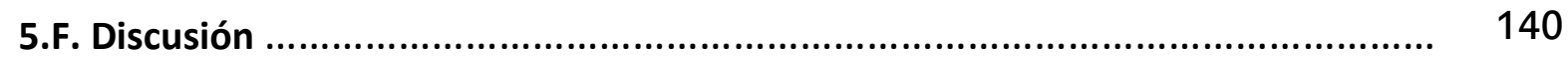

Capitulo $6 \quad 149$

\section{Conclusiones finales}

6.A. Conclusiones respecto a la proliferación celular ............................................ 150

6.B. Conclusiones respecto al metabolismo lipídico ........................................ 152

Referencias .................................................................... 157

\section{Apéndices}

I. Curvas dosis-respuesta de viabilidad celular

I.1 Ensayo de MTT en células tratadas con AELs .................................................... II

I.2 Ensayo de rojo neutro en células tratadas con AELs ........................................... V

I.3 Ensayo de MTT en células tratadas con simvastatina ........................................... VII

II. Determinación de apoptosis en células HepG2 por ensayo de TUNEL para 3 quimiotipos de Lippia alba ......................................................................... IX

\section{Índice de Tablas}

Tabla 1.1. Principales grupos de drogas utilizadas en el tratamiento de la dislipidemia...

Tabla 1.2. Opciones para tratar farmacológicamente las dislipidemias

Tabla 1.3. Nombres comunes de Lippia alba (Mill.) N.E. Br

Tabla 1.4. Clasificación de quimiotipos de Lippia alba

Tabla 3.1. Lista de reactivos utilizados

Tabla 3.2. Composición en porcentajes de los AEs extraídos de hojas de Lippia alba carvona, piperitona, tagetenona y citral cultivados en Costa Rica

Tabla 3.3. Lista de anticuerpos empleados y sus diluciones

Tabla 4.1. Valores de $\mathrm{IC}_{50}$ para aceites esenciales de Lippia alba obtenidos por MTT e índice de selectividad

Tabla 4.2. Valores de $\mathrm{IC}_{50}$ para aceites esenciales de Lippia alba obtenidos por RN ..... 
Tabla 4.3. Inducción de apoptosis en células HepG2 y A549 tratadas con AELta determinada por el ensayo de TUNEL

Tabla 4.4. Contenido de colesterol en células HepG2 y A549 tratadas con 1,0x IC 50 de AELta

Tabla 4.5. Viabilidad de células HepG2 y A549 tratadas con AELta en ausencia (-Mv) y presencia de $(+\mathrm{Mv})$ de mevalonato exógeno

Tabla 5.1. Composición lipídica de células A549 tratadas con AEs de 4 quimiotipos de Lippia alba

Tabla 5.2. Composición lipídica de células HepG2 tratadas con AEs de 4 quimiotipos de Lippia alba

Tabla 5.3. Composición de ácidos grasos de células HepG2 tratadas con AELta

Tabla A.1. Inducción de apoptosis en células HepG2 tratadas con quimiotipos de Lippia alba determinada por el ensayo TUNEL

\section{Îndice de Figuras}

Figura 1.1. Principales causas de muerte en las Américas

Figura 1.2. Esquema de las vías involucradas en la síntesis de ácidos grasos (AGs), colesterol, fosfoglicéridos, eicosanoides y esfingolípidos

Figura 1.3. Principales efectos de los reguladores del metabolismo lipídico

Figura 1.4. Genes regulados por proteínas de unión a elementos de repuesta a esteroides (SREBPS)

Figura 1.5. Activación de SREBPs por corte proteolítico

Figura 1.6. Vía del mevalonato

Figura 1.7. Isoprenilación de proteínas y reacciones post-prenilación

Figura 1.8. Estructura de la molécula de colesterol y su disposición en la membrana plasmática

Figura 1.9. Regulación de HMGCR a nivel transcripción y degradación

Figura 1.10. Vías de señalización de Ras

Figura 1.11. Acciones de las estatinas como quimioterapeúticos

Figura 1.12. Transporte de colesterol

Figura 1.13. Estructura de algunos monoterpenos presentes en aceites esenciales

Figura 1.14. Lippia alba (Mill.) N.E. Br.

Figura 3.1. Morfología típica de células HepG2 observadas al microscopio óptico en condiciones normales de cultivo

Figura 3.2. Morfología típica de células A549 observadas al microscopio óptico en condiciones normales de cultivo

Figura 3.3. Morfología típica de células Vero observadas al microscopio óptico en 


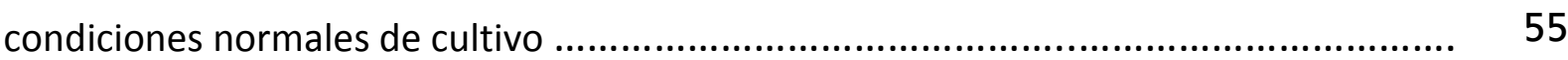

Figura 3.4. Transformación del MTT en formazán ...................................................... 63

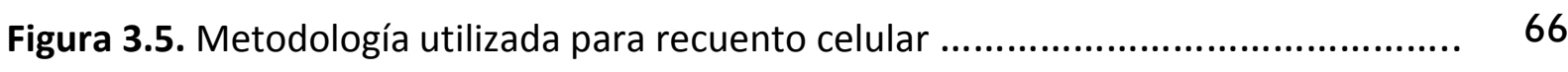

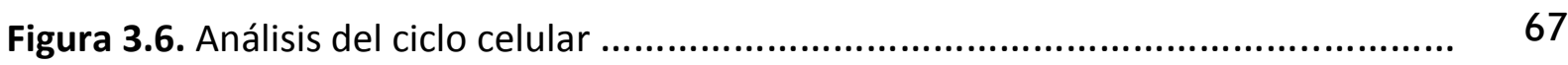

Figura 3.7. Determinación de contenido de lípidos en células HepG2 y A549 ............... 71

Figura 3.8. Electroforesis de proteínas ................................................................. 78

Figura 4.1. Efecto de AELta sobre la viabilidad en células tumorales humanas (HepG2 y A549) y no tumorales (Vero) ..................................................................... 84

Figura 4.2. Efecto de AELta sobre la viabilidad celular determinado por CAM/IP .......... 85

Figura 4.3. Inhibición de la proliferación de células HepG2 determinada por recuento celular

Figura 4.4. Inhibición de la proliferación de células A549 determinada por recuento celular

Figura 4.5. Análisis del ciclo celular de células HepG2 y A549 luego del tratamiento con AELta

Figura 4.6. Apoptósis determinada por ensayo de TUNEL en células HepG2 y A549 ......

Figura 4.7. Apoptosis determinada por observación de cambios morfológicos en el núcleo

Figura 4.8. Porcentaje de células apoptóticas y necróticas determinadas mediante ensayo morfológico por tinción de Hoechst e IP

Figura 4.9. Incorporación de ${ }^{14} \mathrm{C}$-acetato en colesterol y otros lípidos insaponificables de la vía del mevalonato en células HepG2 y A549

Figura 4.10. Efecto del AELta sobre los niveles de HMGCR en células HepG2 ...............

Figura 4.11. Efecto de la combinación de los AEs y simvastatina sobre la proliferación de células HepG2

Figura 4.12. Efecto de la combinación de los AEs y simvastatina sobre la proliferación de células A549

Figura 5.1. Incorporación de ${ }^{14} \mathrm{C}$-acetato en colesterol y otros lípidos insaponificables de la vía del mevalonato en células HepG2 y A549 tratadas con simvastatina

Figura 5.2. Incorporación de ${ }^{14} \mathrm{C}$-acetato en colesterol y otros lípidos insaponificables en células A549 tratadas con los AELs

Figura 5.3. Incorporación de ${ }^{14} \mathrm{C}$-acetato en colesterol y otros lípidos insaponificables en células HepG2 tratadas con los AELs.....

Figura 5.4. Lípidos insaponificables no identificados de la vía del mevalonato en células HepG2 y A549

Figura 5.5. Incorporación de ${ }^{14} \mathrm{C}$-acetato en colesterol y otros lípidos insaponificables en células A549 tratadas con los AELs 
Figura 5.6. Incorporación de ${ }^{14} \mathrm{C}$-acetato en colesterol y otros lípidos insaponificables en células HepG2 tratadas con los AELs

Figura 5.7. Curvas de dosis respuesta para A549 y HepG2 incubadas con los AEs con respecto a colesterogénesis

Figura 5.8. Incorporación ${ }^{14} \mathrm{C}$-acetato en colesterol en células HepG2 y A549 tratadas con $8 \mu \mathrm{g} / \mathrm{ml}$ de AELS

Figura. 5.9. Incorporación de ${ }^{14} \mathrm{C}$-acetato en ácidos grasos y lípidos insaponificables de células HepG2

Figura 5.10. Distribución radiactividad incorporada en ácidos grasos saturados e insaturados de células HepG2

Figura 5.11. Incorporación de ${ }^{14} \mathrm{C}$-acetato en lípidos neutros en células HepG2 tratadas con AELta

Figura 5.12. Incorporación de ${ }^{14} \mathrm{C}$-acetato en fosfolípidos en células HepG2 tratadas con AELta

Figura 5.13. Determinación del contenido lipídico de células HepG2 tratadas con AELta

Figura 5.14. Gotas lipídicas en células HepG2 incubadas con AELta

Figura 5.15. Diámetros de GL de células HepG2 tratadas con AELta

Figura 5.16. Distribución en porcentaje de GL clasificadas en pequeñas, medianas, y grandes

Figura 5.17. Cuantificación del número y volumen total de GL por célula

Figura 5.18. Efecto de la combinación entre AELta y simvastatina sobre la síntesis de colesterol en células HepG2

Figura 5.19. Efecto de la combinación entre AELta y simvastatina sobre la síntesis de productos finales de la vía del mevalonato en células A549

Figura 5.20. Incorporación de ${ }^{14} \mathrm{C}$-acetato en ácidos grasos y lípidos insaponificables de células HepG2

Figura 5.21. Incorporación de ${ }^{14} \mathrm{C}$-acetato en lípidos neutros

Figura 5.22. Efecto combinado de AELta y simvastatina sobre el contenido de colesterol y TAG en células HepG2

Figura 5.23. Efecto sobre los niveles de HMGCR en células HepG2 tratadas con AELta, simvastatina y su combinación

Figura 5.24. Activación de la expresión de genes regulados por SREBP-2 en respuesta a niveles bajos de colesterol intracelular

Figura 5.25. Modelo propuesto para describir el efecto de AELta sobre la VM en células HepG2 y su impacto sobre síntesis y degradación de HMGCR

Figura 5.26. Modelo propuesto para explicar el efecto hipolipogénico del AELta en células hepáticas

Figura 6.1. Modelo propuesto de la acción de AELta en la vía del mevalonato y sus efectos sobre la proliferación celular y el metabolismo de lípidos en células HepG2 ...... 
Figura A.1. Efecto de AELs sobre la viabilidad de células Vero determinada por el ensayo de MTT

Figura A.2. Efecto de AELs sobre la viabilidad de células HepG2 determinada por el ensayo de MTT

Figura A.3. Efecto de AELs sobre la viabilidad de células A549 determinada por el ensayo de MTT

Figura A.4. Inhibición de la viabilidad celular mediada por AELs determinada por el ensayo de RN en células HepG2

Figura A.5. Inhibición de la viabilidad celular mediada por AELs determinada por el ensayo de RN en células A549

Figura A.6. Efecto de simvastatina sobre la viabilidad de células HepG2 y A549 determinada por el ensayo de MTT

Figura A.7. Apoptósis determinada por ensayo de TUNEL en células HepG2 


\section{Abreviaturas}

24,25-EC: 24(S),25-epoxicolesterol

ABC: proteínas cassette de unión a ATP (del inglés ATP binding cassette)

ACAT: acetil-CoA acetil transferasa

ACAT2: acil-CoA: colesterol transferasa 2

ACC: acetil-CoA carboxilasa

ACLY: ATP-citrato liasa

ACV: enfermedades cerebrovasculares

AE: aceite esencial

AEL: aceite esencial de L. alba

AELca: aceite esencial de Lippia alba quimiotipo carvona

AELci: aceite esencial de Lippia alba quimiotipo citral

AELpi: aceite esencial de Lippia alba quimiotipo piperitona

AELta: aceite esencial de Lippia alba quimiotipo tagetenona

AG: ácido graso

AGPAT: 1-acilglicerol-3-fosfato O-aciltransferasa:

AMPK: protein quinasa activada por AMP (del inglés: AMP-activated protein kinase)

ANOVA: análisis de la varianza

BAS: secuestrador de ácidos biliares

BSA: albúmina sérica bovina (del inglés bovine serum albumin)

ca: carvona

CAM: calceína acetoximetilado

CARMELA: Cardiovascular Risk Factor Multiple Evaluation in Latin America

CDP-DAG: citidin difosfato diacilglicerol

CE: colesterol esterificado

CER: ceramida

CETP: proteína de transferencia de ésteres de colesterol (del inglés Cholesteryl ester transfer protein)

ci: citral

CINIBA: Centro de Investigaciones Inmunológicas Básicas y Aplicadas

CIPRONA: Centro de Investigaciones en Productos Naturales

CL: colesterol libre

COX1/2: cicloxigenasa1/2

CYP51: lanosterol 14 $\alpha$-demetilasa.

DAG: diacilglicéridos 
DAPI: 4',6-diamidino-2-fenilindol

DFG: difosfatidilglicerol

DGAT: diacilglicerol O-aciltransferasa

DHCR24: esterol- $\Delta 24$-reductasa

DMAPP: dimetilalil pirofosfato

DMBA: 7,12-Dimetilbenz(a)antraceno

DMSO: dimetilsulfóxido

DO: densidad óptica

DOS: 2,3;22,23-diepoxiescualeno

DPM: destellos por minuto

DS: desviacion estándar

dUTP: deoxinucleotidos tri-fosfato

ECV: enfermedades cardiovasculares

EDTA: ácido etilendiaminotetraacético

ELOVL: ácido graso elongasa

EMAG: ésteres metílicos de ácidos grasos

EUA: Estados Unidos de América

FADS: ácido graso desaturasa (del inglés fatty acid desaturase)

FAS: ácido graso sintasa (del inglés fatty acid synthase)

FC: fosfatidilcolina

FE: fosfatidiletanolamina

FG: fosfatilglicerol

FI: fosfatidilinositol

FL: fosfolípidos

FPP: farnesilpirofosfato

FS: fosfatidilserina

FTasa: farnesil transferasa

FXR: receptor $X$ activado por farnesoide (del inglés farnesoid $X$ receptor)

G6PD: glucosa-6-fosfohidrogenasa

GC-FID: cromatografía gaseosa con detector de ionización de llama

GC-MS: cromatografía gaseosa acoplada a espectrometría de masa

GGPP: geranilgeranilpirofosfato

GGTasa: geranilgeranil tranferasa

GL: gotas lipídicas

GLC: cromatografía gas-líquido

GPAT: glicerol-3-fosfato aciltransferasa 
GPP: geranilpirofosfato

HCC: hepatocarcinona celular

HDL: lipoproteína de alta densidad (del inglés high density lipoproteín)

HMG-CoA: 3-hidroxi-3-metilglutaril-CoA

HMGCR: HMG-CoA reductasa

HMGCS: HMG-CoA sintasa

HRP: peroxidasa del rábano (del inglés horseradish peroxidase)

IC $_{50}$ : concentración que inhibe en un 50 \% la proliferación celular

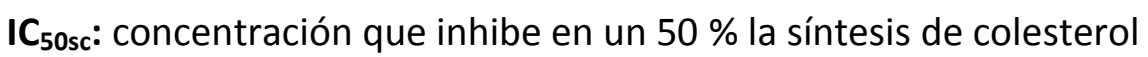

ICMT: isoprenilcisteina carboxil metiltransferasa

IDL: lipoproteína de intermedia densidad (del inglés intermediate density lipoprotein)

Insig: proteína de genes inducidos por insulina (del inglés insulin- induced gene protein)

IP: ioduro de propidio

IPP: isopentenilpirofosfato

IS: índice de selectividad

LCAT: lecitina-colesterol acetiltransferasa

LDL: lipoproteína de baja densidad (del íngles low density lipoprotein)

LDLR: receptor de LDL

LI: lípidos insaponificables

lisoFC: lisofosfatilcolina

LN: lípidos neutros

LOX-1: receptor 1 tipo lectina de LDL oxidadas

LP: lípidos polares

LPA: ácido lisofosfatídico

LPL: lipoprotein lipasa

LRP: proteína relacionada con el receptor de las LDL (del inglés LDL receptor-related protein)

LT: lípidos totales

LXRE: elementos de respuesta de LXR

LXR: receptor $X$ del hígado (del inglés liver $X$ receptor)

MAPK: protein quinasa activada por mitógenos (del inglés mitogen-activated protein kinase)

MEM: medio esencial mínimo de Eagle

MK: mevalonato quinasa (del inglés mevalonate kinase)

MOS: 2,3-monoxidoescualeno

MP: membrana plasmática

MPP: bifosfomevalonato

mSREBP: proteína madura del SREBP 
MTP: proteína microsomal transferidora de triacilglicéridos (del inglés microsomal triglyceride transfer protein)

MTT: bromuro de 3-(4,5-dimetiltiazol-2-il)-2,5-difenil- tetrazolio

Mv: mevalonato

NDEA: N-nitrosodietilanima

NIH: National Institute of Health

NIST: National Institute of Standards and Technology

NPC1L1: transportadores Niemann-Pick C1 Like1

OSC: 2,3-oxidoesqualeno:lanosterol ciclasa

oxLDL: LDL oxidadas

PA: ácido fosfatídico

PAGE: electroforesis de proteínas en geles de poliacrilamida (del inglés polyacrylamide gel electrophoresis)

PBS: solución tampón fosfato salino (del inglés phosphate-buffered saline)

PCT: proteína celular total

PGDH: 6-fosfogluconato deshidrogenasa

PGE2: prostaglandina E2

PGH2: prostaglandina $\mathrm{H} 2$

Pi: fósforo inorgánico

pi: piperitona

PIPx: fosfatidilinositol fosfato

PLTP: proteína de transferencia de fosfolípidos (del inglés phospholipid transfer protein)

PMK: fosfomevalonato quinasa

POPOP: 1,4-bis-(5-t-butilbezooxazol-2-il)-tiofeno

PP: pirofosfato

PPAP: ácido fosfatídico fosfatasa

PPAR: receptor activado por el factor proliferador de peroxisoma (del inglés peroxisome proliferator-activated receptor)

PPO: 2,5-difeniloxazol

pSREBP: proteína precursora de SREBP

PVDF: fluoruro de polivinilideno

Qm: quimilomicrones

Qmr: remanentes de quilomicrones

R: índice de sinergismo

RCE1: endopeptidasa convertidora de RAS (del inglés Ras converting enzime 1)

RE: retículo endoplásmico 
RI: índice de retención

RN: rojo neutro

RXR: receptor de ácido retinoico

S1P: esfingosina-1-fosfato

SAH: S-adenosil-homocisteína

SAM: S-adenosil-metionina

SCAP: proteína que activa SREBP mediante clivaje (del inglés SREBP cleavage activating protein)

SCD: estearoil-CoA desaturasa (del inglés stearoyl-CoA desaturase)

SDS: dodecil sulfato de sodio

SFB: suero fetal bovino

SM: esfingomielina

SHP: compañero pequeño de heterodímeros (del inglés small heterodimer partner)

SPHK: esfingosina-1-quinasa

SPN: esfingosina

SR-B1: receptor carroñero clase B tipo 1 (del inglés scavenger receptor class B type 1 )

SRE: elemento regulador de esterol (del inglés sterol regulator element)

SREBP: proteínas de unión a elementos reguladores de esteroles (del inglés sterol regulatory element-binding protein)

SS: escualeno sintasa

SSD: dominio sensor de esteroles

SSI: inhibidores de la escualeno sintasa

Sv: Simvastatina

$\mathrm{T}^{\circ} \mathrm{A}$ : temperatura ambiente

ta: tagetenona

TAG: triacilglicéridos

TCA: ácido tricarboxílico

TdT: desoxinucleotidil transferasa terminal

TICE: excreción del colesterol transintestinal

TLC: cromatografía en capa fina

TRC: transporte reverso de colesterol

TUNEL: TdT-mediated dUTP nick end labeling

US-NCI: Instituto Nacional del Cáncer de EUA

VLDL: lipoproteína de muy baja densidad (del inglés very low density liporprotein)

VLDLR: receptor de VLDL

VM: Vía del mevalonato. 


$$
\text { Resumen }
$$


Lippia alba (Miller) N.E. Brown es un arbusto aromático ampliamente utilizado en medicina tradicional. Esta planta presenta diversos quimiotipos (variantes químicas intraespecíficas dentro de una misma especie botánica) distribuidos a lo largo del continente americano que explican, en parte, la variedad de efectos biológicos que se le han asociado. Los aceites esenciales (AEs) extraídos de esta planta contienen una gran cantidad y variedad de monoterpenos, muchos de los cuales presentan actividad antiproliferativa en células tumorales tanto in vitro como in vivo. Este evento, así como el potencial efecto hipolipemiante, se asocia a las múltiples acciones que los monoterpenos presentan sobre la vía del mevalonato (VM), una ruta muy compleja en la cual se generan metabolitos que desempeñan funciones esenciales en el crecimiento, la proliferación y el mantenimiento de la homeostasis celular. En esta vía se generan diversos productos finales como el dolicol, ubiquinona y el colesterol, siendo este último el mayoritario. Adicionalmente, la VM provee intermediarios fundamentales para la prenilación de proteínas, como las pertenecientes a la superfamilia Ras, con funciones reguladoras de la proliferación y supervivencia celular.

Con el objetivo de analizar la utilidad de AEs de L. alba en el tratamiento de la hipercolesterolemia y prevención y tratamiento del cáncer, en este trabajo se evaluó la capacidad antiproliferativa, anticolesterogénica y los efectos sobre el metabolismo lipídico de cuatro quimiotipos -carvona (AELCa), citral (AELci), piperitona (AELpi), tagetenona (AELta)- utilizando células HepG2 (procedentes de un hepatocarcinoma humano) como modelo de célula hepática y A549 (provenientes de adenocarcinoma de pulmón humano) como tipo celular extra-hepático.

La citotoxicidad de los cuatro quimiotipos fue evaluada, tanto en líneas celulares neoplásicas (HepG2 y A549) como no neoplásicas (Vero), por medio de los ensayos de viabilidad MTT y rojo neutro. Los quimiotipos citral y tagetenona resultaron ser citotóxicamente activos en células tumorales, pero sólo AELta presentó una elevada selectividad por las células neoplásicas. Por recuento de células se determinó que AELta inhibe la proliferación celular en ambas líneas tumorales $y$, mediante el estudio de la distribución de las poblaciones en el ciclo celular y de la apoptosis por diferentes metodologías, se estableció que el arresto del ciclo celular y la inducción de apoptosis son dos de los mecanismos por los cuales ejerce su efecto antiproliferativo.

El efecto de concentraciones antiproliferativas de AELta sobre la VM se analizó a través de experimentos de incorporación de ${ }^{14} \mathrm{C}$-acetato en lípidos insaponificables y la cuantificación de 3-hidroxi-3-metilglutaril-CoA reductasa (HMGCR), enzima limitante de la vía, por Western Blotting. Se demostró que, a estas concentraciones, AELta inhibe la VM ocasionando una marcada disminución de la colesterogénesis y un descenso moderado de los niveles de HMGCR. Sin embargo, la inhibición de HMGCR por sí sola no es responsable del efecto antiproliferativo, dado que el agregado de mevalonato exógeno fue incapaz de revertir la inhibición de la proliferación promovida por este aceite.

A dosis que no afectan la proliferación celular, se observó que los AEs ejercen un efecto anticolesterogénico no hepatoselectivo que estaría relacionado, en la mayoría de los casos, con una inhibición de la escualeno sintasa con el redireccionamiento del intermediario FPP (principal punto de la ramificación de la VM) hacia la síntesis de ubiquinona. Las concentraciones efectivas en la inhibición de la síntesis de colesterol fueron considerablemente inferiores a las necesarias para ejercer un efecto antiproliferativo, siendo el quimiotipo tagetenona el más efectivo. 
Se demostró que concentraciones de AELta que inhiben la síntesis de colesterol sin afectar la proliferación, disminuyen la síntesis de ácidos grasos (determinada por incorporación de ${ }^{14} \mathrm{C}$-acetato) y el contenido de lípidos saponificables mayoritarios. Además, se evidenció una disminución en el tamaño de las gotas lipídicas citoplasmáticas teñidas con BODIPY 493/503 y observadas por medio de microscopía de florescencia. Estos efectos sobre el metabolismo de lípidos saponificables demuestran el potencial de este aceite como agente hipolipemiante. Los mismos pueden estar mediados por el FPP acumulado al inhibirse la VM, por algún componente específico del AE o por ambos, quienes podrían actuar como agonistas del receptor nuclear FXR e inducir a PPAR $\alpha$ (aumentando $\beta$-oxidación de AGs) y reprimir a SREBP-1c (disminuyendo síntesis de AGs y TAG).

Teniendo en cuenta que las estatinas -inhibidores competitivos de la HMGCR- afectan la VM a distintos niveles que los AEs de $L$. alba, se evaluó el potencial sinergismo entre éstos aceites y la simvastatina (Sv), una de las estatinas más utilizadas como hipolipemiante. Respecto a la proliferación, se observó un efecto antiproliferativo sinérgico entre simvastatina y cada uno de los aceites en ambas líneas celulares neoplásicas. De modo que, el tratamiento combinado permitiría disminuir las dosis antiproliferativas efectivas de ambos compuestos.

Respecto al efecto anticolesterogénico, se demostró que la combinación de concentraciones no antiproliferativas de AELta y Sv inhibe sinérgicamente la colesterogénesis. Esto permitiría disminuir la probabilidad de efectos indeseados y/o tóxicos asociados a la administración de altas dosis de Sv. El efecto inhibitorio es equivalente al que se obtiene con concentraciones 5 y 20 veces mayores de Sv como agente único en células HepG2 y A549, respectivamente. En células HepG2 el tratamiento combinado revirtió la inhibición de la síntesis de ubiquinona provocada por Sv, lo cual disminuiría uno de los efectos secundarios indeseables de esta estatina, manteniendo la disminución del contenido de lípidos de reserva ocasionada por el aceite, por lo que podría potencialmente mejorar la escasa capacidad de la Sv para disminuir niveles elevados de trigliceridemia.

Los resultados presentados a lo largo de este trabajo contribuyen a un mejor entendimiento de la acción de los aceites esenciales de $L$. alba y su combinación con estatinas sobre una vía metabólica tan compleja como lo es la VM. Además sugieren que el uso individual de aceites esenciales, y su combinación con estatinas, pueden aportar alternativas que resulten beneficiosas para la salud en el tratamiento del cáncer $\mathrm{y} / \mathrm{o}$ enfermedades cardiovasculares. 


\title{
Capítulo
}

\author{
INTRODUCCIÓN
}




\section{A. Relevancia del tema}

Los cambios en el estilo de vida como el aumento de la urbanización, del tabaquismo, de las dietas ricas en grasas y la inactividad física, conjuntamente con el envejecimiento de la población, han contribuido a que en los países latinoamericanos se dé una transición epidemiológica, donde la causalidad de la morbimortalidad pasa de enfermedades comunes transmisibles a enfermedades crónicas como enfermedades cardiovasculares (ECV), cáncer, diabetes mellitus y enfermedades respiratorias crónicas (1, 2) (Figura 1.1).

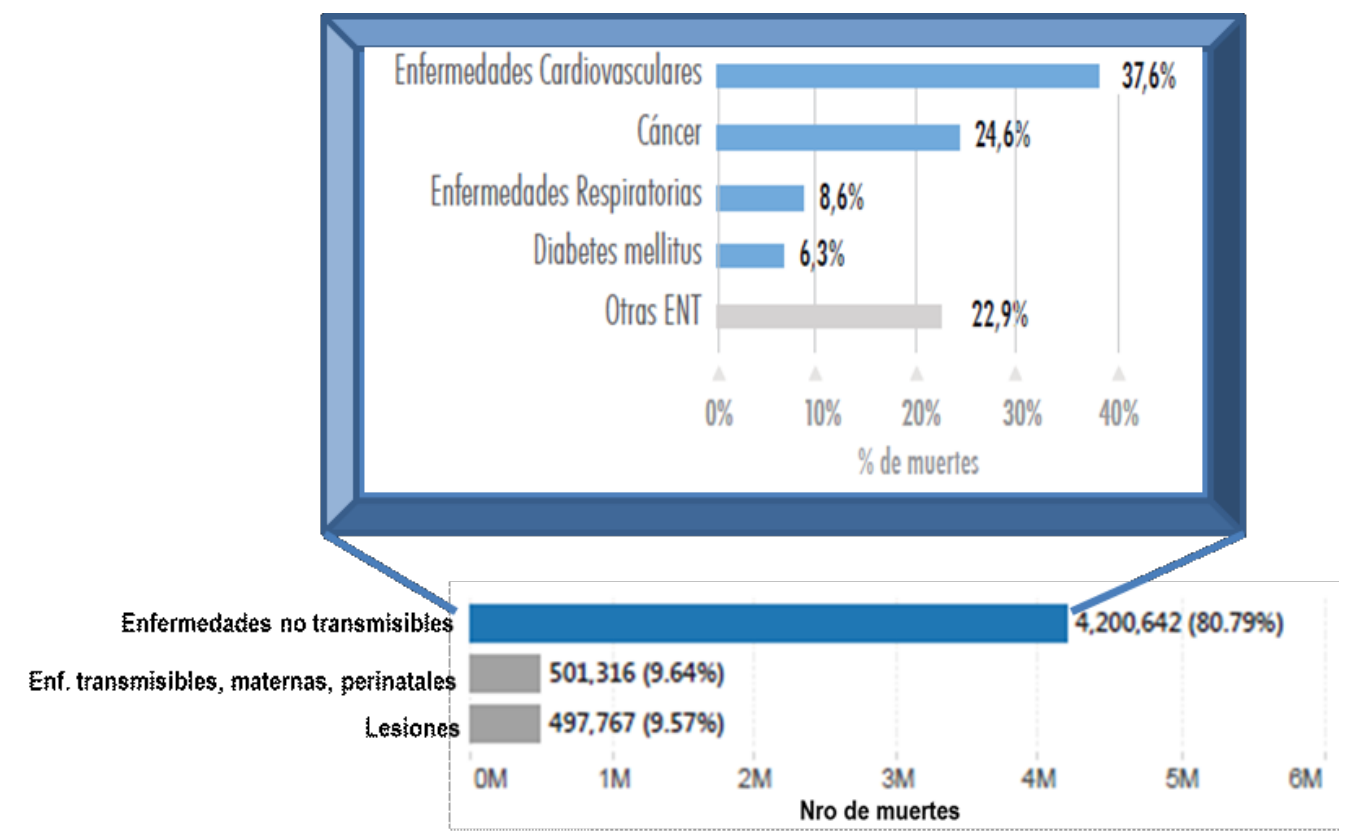

Figura 1.1. Principales causas de muerte en las Américas. Tomado de OPS/OMS Base de mortalidad Regional (3).

Las ECV son un grupo heterogéneo de enfermedades que afectan al sistema circulatorio dentro de las que se incluyen: las cardiopatías coronarias, las enfermedades cerebrovasculares (comúnmente conocidos como ACV), arteriopatías periféricas, cardiopatías reumáticas y congénitas, así como los eventos trombóticos (3).

Actualmente, a pesar de una amplia investigación básica y clínica y a la aparición de terapias más eficaces, las ECV siguen representando la principal causa de muerte tanto a nivel mundial como en las Américas (4-6) (Figura 1.1).El $80 \%$ de las muertes por ECV se deben a cardiopatías coronarias (42,3\%) y a ACV (38,3 \%) (3) y predicciones para las próximas dos décadas en Latinoamérica indican que se triplicará la mortalidad por estas 
patologías, que comparten como uno de los principales eventos fisiopatogénicos la formación y presencia de placas ateroescleróticas (7).

Los factores de riesgo cardiovascular son características biológicas o hábitos de vida que aumentan la probabilidad (riesgo) de padecer una ECV, mortal o no mortal, en aquellos individuos que los presentan (8). Dentro de los factores de riesgo encontramos los no modificables como edad, sexo y antecedentes hereditarios, y los modificables como el sobrepeso/obesidad, tabaquismo, sedentarismo, dieta aterogénica, etc. Las dislipidemias, niveles anormales de lipoproteínas en plasma, son uno de los factores de riesgo cardiovascular modificables que más peso tiene sobre la incidencia de las ECV, ya que juegan un rol predominante en la iniciación y desarrollo de lesiones ateroescleróticas. Por ejemplo, las dislipidemias están asociadas con el riesgo atribuible poblacional más alto $(49,2 \%)$ para la ocurrencia de infarto agudo de miocardio (9). En Latinoamérica, alrededor del $50 \%$ de la población presenta algún tipo de dislipidemia $(6,10)$; sin embargo, un alto porcentaje de los habitantes de estos países desconocen sus niveles lipídicos sanguíneos y/o no se benefician de programas de atención primaria integrados para la detección precoz y el tratamiento temprano de estos factores de riesgo. En el estudio CARMELA (Cardiovascular Risk Factor Multiple Evaluation in Latin America) se estimó que el 88 \% de los sujetos diagnosticados con dislipidemia no se encontraban bajo tratamiento farmacológico y que solo el $52 \%$ de las personas recibiendo alguna droga hipolipemiante logró alcanzar las metas propuestas (5). Esto hace que se mantenga vigente la búsqueda de nuevas terapéuticas tanto para el tratamiento de las dislipidemias como de las ECV que permitan obtener mejores resultados y sean económicamente accesibles para la población.

La obtención de medicamentos de origen natural que apoyen el tratamiento de las enfermedades crónicas no transmisibles como las dislipidemias, constituye una de las líneas de investigación de primer orden a nivel mundial. Actualmente, ya sea por el alto costo de los tratamientos convencionales o por los efectos secundarios de las actuales drogas hipolipemiantes, se ha incrementado la utilización de plantas medicinales y sus complementos en el tratamiento de dislipidemias, inclusive en países desarrollados $(11,12)$. La Fitoterapia constituye una alternativa farmacológica para resolver, de manera complementaria e incluso integral, las necesidades primarias de salud. Por este motivo, se considera importante evaluar plantas utilizadas en la etnofarmacología latinoamericana que presentan un potencial efecto hipolipemiante $(13,14)$. 
Por otro lado, los decesos ocasionados por tumores malignos representan la segunda causa de muerte en las Américas (Ver Figura 1.1). En América Latina, la mayoría de las muertes por cáncer en los hombres se deben a cáncer de próstata, seguido por pulmonar, gástrico y colorectal; mientras que, en las mujeres la mayor mortalidad se da por cáncer de mama, seguido por gástrico, pulmonar, cervical y colorectal (3). Cada vez es más fuerte la relación entre presentar dislipidemias, ya sea como factor de riesgo aislado o como parte del síndrome metabólico, y la aparición de los cánceres antes mencionados (15-19).

Las células tumorales presentan un elevado metabolismo lipídico, reflejado tanto en la incorporación de lípidos del torrente sanguíneo como en la maquinaria de síntesis endógena (20-22). Muchos de los tumores presentan alteraciones en las vías de señalización celular como la PI3K/AKT y MAPK, así como la activación de oncogenes como p53. Estas alteraciones generan la desregulación de la expresión y/o actividad de múltiples enzimas pertenecientes a vías metabólicas lipídicas $(23,24)$, por lo que nuevas dianas en el tratamiento de tumores están asociadas a la modulación de la lipogénesis ya sea a nivel de las enzimas de las vías afectadas como de los factores de transcripción que las regulan (20).

La vía del mevalonato es uno de los principales procesos de síntesis que se encuentra desregulado en la mayoría de las células tumorales e inclusive se ha asociado como una vía oncogénica (23). El colesterol, producto final mayoritario de esta vía, es un componente crucial de la biogénesis de membranas y es requerido para la proliferación celular. En condiciones normales, la síntesis de colesterol se encuentra altamente regulada a fin de conservar niveles apropiados del mismo manteniendo su homeostasis celular (25). Existen múltiples estudios donde se refiere que la proliferación de células tumorales es altamente dependiente de la biosíntesis de colesterol y sus derivados, y que la desregulación de esta vía registrada en células neoplásicas puede llevar a la promoción y resistencia de los tumores (26). Además, esta vía es la generadora de isoprenoides que son necesarios para la prenilación de proteínas que regulan el crecimiento y/o transformación celular; de modo que, la inhibición de la prenilación de estas proteínas se traduce en una disminución del crecimiento y proliferación celular (27-29).

En diversos estudios preclínicos y clínicos se ha demostrado que fármacos que inhiben la vía del mevalonato presentan un potencial efecto preventivo de tumores (30-32) y estudios prospectivos de su utilización en pacientes con cáncer evidencian una disminución de la mortalidad así como la presencia de tumores más diferenciados (32-34). De modo que, 
ésta clase de fármacos se consideran promisorios en el tratamiento de tumores $(35,36)$, en especial en combinación con otros quimioterapéuticos $(32,37-40)$. Sin embargo, una de las principales encrucijadas en el uso de estos fármacos es que se requieren concentraciones elevadas para alcanzar el efecto antitumoral con el consiguiente incremento del riesgo de presentar efectos secundarios adversos.

Una alternativa viable en la investigación de nuevas terapéuticas para el cáncer es el estudio de aceites esenciales de plantas aromáticas. Estos aceites contienen diversos isoprenoides naturales que son capaces de modular la vía del mevalonato ejerciendo un efecto antitumoral (41-44). Además, los aceites esenciales poseen las características ideales que se buscan en los agentes quimiopreventivos y quimioterapéuticos: eficaz actividad antitumoral, disponibilidad comercial, bajo costo, buena biodisponibilidad oral y baja toxicidad.

Por estas razones, el estudio de aceites esenciales como agentes con propiedades antihiperlipidémicas y antiproliferativas, así como su combinación con otros fármacos que modulan la vía del mevalonato se ha convertido en un área de gran interés y creciente estudio.

\section{B. Síntesis de lípidos.}

Los lípidos desempeñan diversas funciones en el organismo de los animales actuando como fuente de energía, componentes de las membranas celulares y precursores de moléculas que están involucradas en múltiples procesos biológicos como las hormonas esteroideas, vitaminas, ácidos biliares y eicosanoides. Los lípidos presentes en el organismo provienen de dos fuentes: la dieta y la síntesis endógena.

La síntesis de ácidos grasos (AGs) y colesterol (quienes a su vez dan origen a múltiples compuestos lipídicos) tiene lugar en prácticamente todas las células de animales

vertebrados pero estas vías son particularmente importantes en el hígado y el tejido adiposo, órganos especializados en la exportación y almacenaje de lípidos (45).

Tanto la síntesis de colesterol como de AGs se realiza a partir de unidades de dos carbonos en la forma de acetil-CoA. La mayoría del acetil-CoA citosólico que se utiliza en la síntesis lipídica es generado a partir de citrato en una reacción catalizada por la enzima ATPcitrato liasa (ACLY). El citrato que es generado en el ciclo del ácido tricarboxílico (TCA) proviene mayoritariamente del metabolismo de la glucosa. También se puede generar 
citrato, especialmente en células tumorales, por el metabolismo reductor de la glutamina $(21,46)$. Por otra parte, las células pueden aumentar el pool citoplasmático de acetil-CoA que es utilizado en la biosíntesis lipídica por medio de la incorporación directa de acetato (47) (Ver Figura 1.2 A).

En la síntesis de AGs, la enzima acetil-CoA carboxilasa (ACC) cataliza la carboxilación del acetil-CoA para dar malonil-CoA, sustrato indispensable para este proceso. Posteriormente, la síntesis es catalizada por el complejo de la ácido graso sintasa (FAS) en una serie de reacciones que generan palmitato, un AG saturado de 16 carbonos. Por medio de desaturaciones y/o elongaciones, el palmitato es utilizado para generar todo el amplio espectro de AGs saturados e insaturados (Figura 1.2 B) que son sintetizados por la célula (21).

Los AGs sintetizados por la célula y aquellos provenientes de la dieta, pueden ser utilizados para generar diferentes tipos de lípidos. Por medio de la vía del glicerol fosfato, pueden dar origen a diacilgliceridos (DAG) y triacilglicéridos (TAG). Además, intermediarios de esta vía pueden ser convertidos en diferentes fosfoglicéridos (Figura 1C), componentes mayoritarios de las membranas biológicas, como lo son la fosfatidilcolina (FC), fosfatidiletanolamina (FE), fosfatilglicerol (FG), fosfatidilinositol (FI) y fosfatidilserina (FS).

Otros lípidos que se generan a partir de los AGs son los esfingolípidos, fosfoinosítidos y eicosanoides (Figura 1.2 D,E,F), los cuales tienen importantes funciones de señalización en células y tejidos $(48,49)$.

La otra clase de lípidos que se genera a partir del acetil-CoA son los isoprenoides/ esteroles, los cuales son generados por medio de la vía del mevalonato (VM) (Figura 1.2 G). 


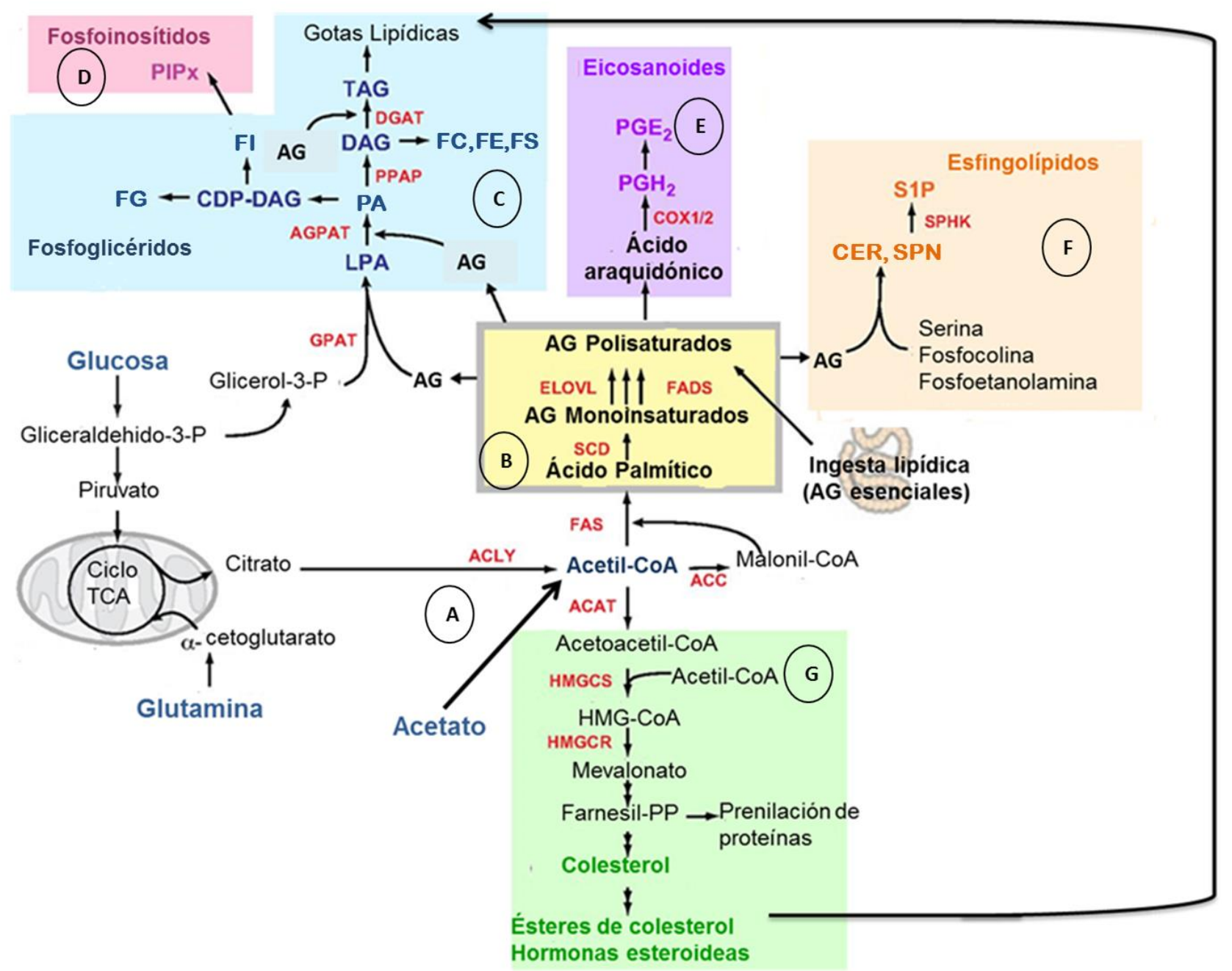

Figura 1.2. Esquema de las vías involucradas en la síntesis de ácidos grasos (AGs), colesterol, fosfoglicéridos, eicosanoides y esfingolípidos. (A) Fuentes a partir de los cuales se genera acetil-CoA. (B) Biosíntesis, elongación y desaturación de AGs a partir de acetil-CoA. AGs saturados e insaturados son combinados con glicerol-3-fosfato para generar (C) fosfoglicéridos y (D) fosfoinosítidos. (E) El ácido araquidónico es usado en la síntesis de eicosanoides. (F) A partir de AGs y grupos de cabeza polar derivados de la serina, fosfocolina y fosfoetanolamina se generan los esfingolípidos. (G) Vía del mevalonato Abreviaturas de enzimas: ACAT, acetil-CoA acetiltransferasa; ACC, acetil-CoA carboxilasa; ACLY, ATP-citrato liasa, AGPAT, 1-acilglicerol-3-fosfato O-aciltransferasa: COX1/2, cicloxigenasa1/2; DGAT, diacilglicerol Oaciltransferasa; ELOVL, AG elongasa; FADS, AG desaturasa; FAS, AG sintasa; GPAT, glicerol-3-fosfato aciltransferasa; HMGCR, 3-hydroxi-3-metilglutaril-CoA reductasa; HMGCS, 3-hidroxi-3-metilglutaril-CoA sintasa; PPAP, ácido fosfatídico fosfatasa; SCD, estearoil-CoA desaturasa; SPHK, esfingosina-1-quinasa. Abreviaturas de metabolitos: CDP-DAG, citidin difosfato-diacilglicerol; CER, ceramida; DAG, diacilglicerol; LPA, ácido lisofosfatídico; PA, ácido fosfatídico; FC, fosfatidilcolina; FE, fosfatidiletanolamina; FG, fosfatilglicerol; PGE2, prostaglandina E2; PGH2, prostaglandina $\mathrm{H2}$; $\mathrm{Fl}$, fosfatidilinositol; PIPx, fosfatidilinositol fosfato; FS, fosfatidilserina; S1P, esfingosina-1-fosfato; SPN, esfingosina; TAG, triacilglicéridos. Adaptado de Baenke et al. (21). 


\section{B.1. Regulación del metabolismo lipídico.}

El metabolismo lipídico se halla regulado por una serie de factores de transcripción, pertenecientes a diferentes familias. Estos factores son activados en respuesta a modificaciones en los niveles celulares de productos finales $y / 0$ intermediarios de distintas vías lipogénicas, induciendo respuestas compensatorias que permiten el mantenimiento de la homeostasis lipídica (Figura 1.3).

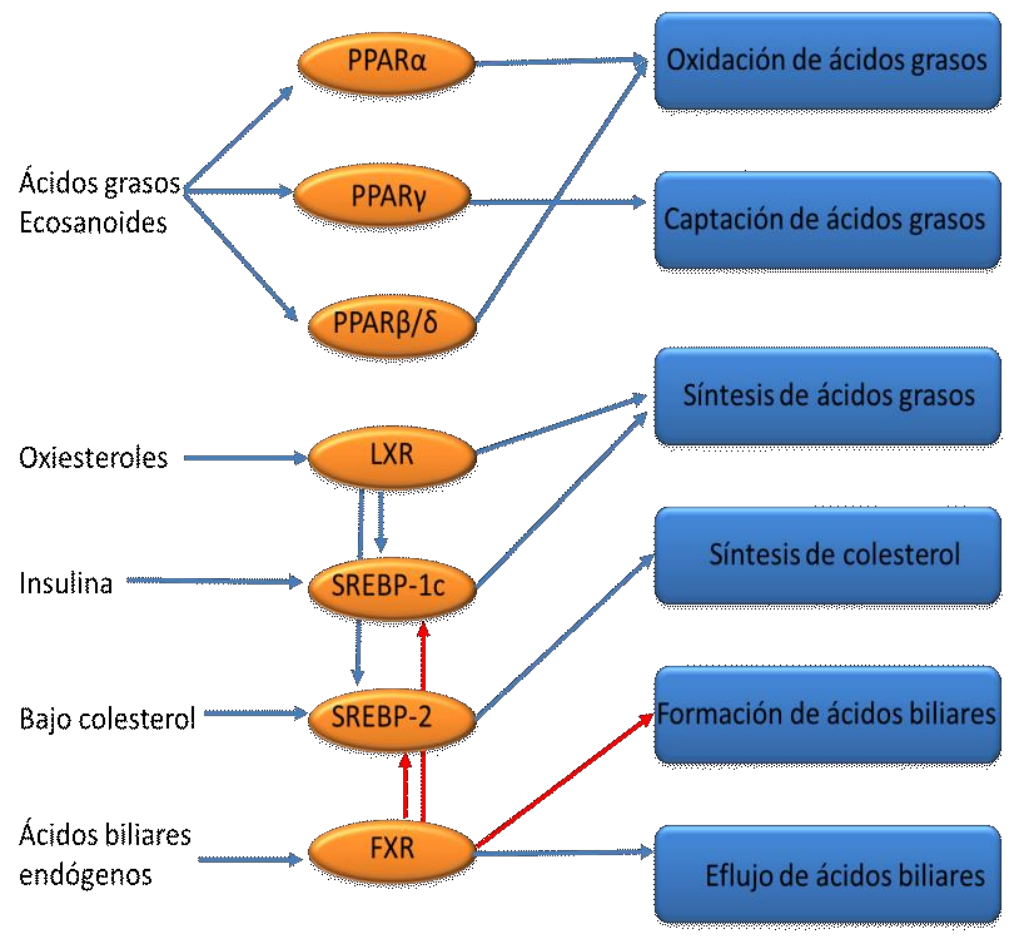

Figura 1.3. Principales efectos de los reguladores del metabolismo lipídico. Inducen actividad: flechas azules. Inhiben actividad: flechas rojas. FXR: receptor $X$ farnesoide; LXR: receptor $X$ del hígado; PPAR: receptor activado por factor proliferador de peroxisoma; SREBP: proteína de unión a elementos reguladores de esteroles. Adaptado de Serviddio et al. (65).

\section{B.1.1. SREBPS}

La biosíntesis de colesterol, AGs y otros lípidos generados a partir de ellos es controlada por una familia de factores de transcripción denominados proteínas de unión a elementos reguladores de esteroles (SREBPs, sterol regulatory element-binding protein). En el núcleo, las SREBPS se unen al elemento regulador de esterol (SRE) presente en más de 30 genes involucrados en la síntesis y captación de colesterol, AGs, triglicéridos y fosfolípidos (45, 50-52).

Existe tres isoformas de SREBPs $(-1 a,-1 c$ y -2$)$ que difieren en su expresión en diversos tejidos y sus genes blanco (52). SREBP-1a es un potente activador de todos los genes SREBPsensibles, incluyendo aquellos que median en la síntesis de colesterol, ácidos grasos y triacilglicéridos. Las isoformas SREBP-1c y SREBP-2 predominan en el hígado y sus funciones 
son más restringidas (50). SREBP-1c induce principalmente la transcripción de genes necesarios para la síntesis de ácidos grasos [ATP citrato liasa (ACLY), acetil-CoA carboxilasa (ACC), ácido graso sintasa (FAS) y estearoil-CoA desaturasa (SCD)] y glicerolípidos [glicerol-3fosfato aciltransferasa (GPAT)], pero no para la síntesis de colesterol. Por el contrario, SREBP-2 activa preferentemente la expresión de proteínas involucradas en el metabolismo del colesterol: todas las enzimas colesterogénicas desde acetil-CoA y el receptor de la lipoproteína de baja densidad (LDLR, low density lipoprotein receptor) $(50,51,53)$ (Figura 1.4).

Las SREBPs se encuentran retenidas en la membrana del retículo endoplásmico (RE) en forma de precursores inactivos (pSREBP). Tras su activación son trasladados al aparato de Golgi donde sufren dos cortes secuenciales liberando al citosol su dominio N-terminal, la forma madura del SREBP (mSREBP), que ingresa al núcleo para unirse a los SRE e inducir la transcripción de los genes diana (Ver Figura 1.5).

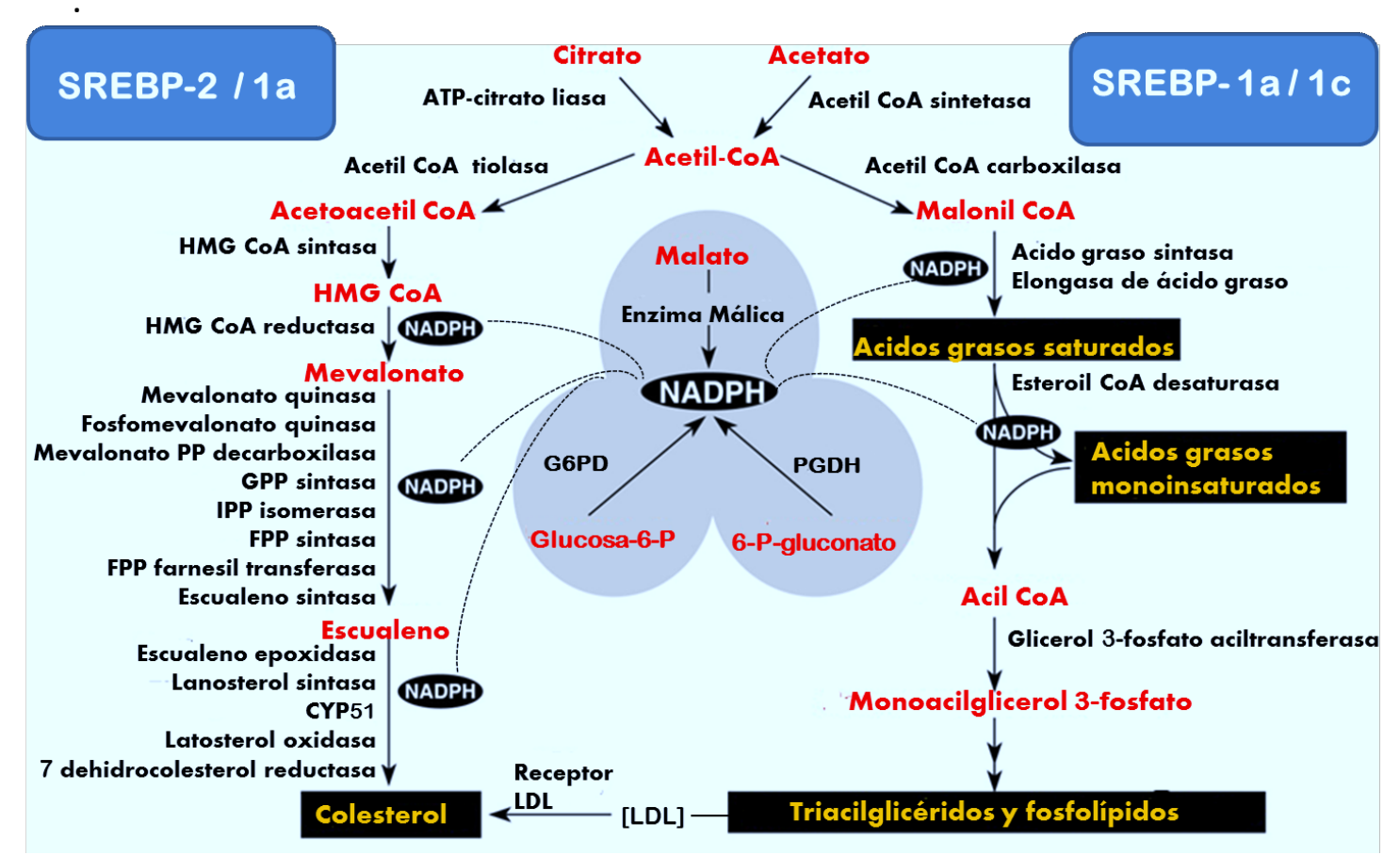

Figura 1.4. Genes regulados por proteínas de unión a elementos de repuesta a esteroides (SREBPs). El diagrama muestra los principales intermediarios metabólicos en las vías de síntesis de colesterol, ácidos grasos y triglicéridos (letra roja). SREBP-1c es un factor de transcripción que activa genes que codifican enzimas relacionadas con la síntesis de ácidos grasos y la formación de triglicéridos y fosfolípidos. En contraste SREBP-2 estimula la transcripción de genes que codifican enzimas para la síntesis de colesterol y receptores de LDL. Estas dos vías requieren de la generación de NADPH, provistas por las reacciones que se muestran en la figura del medio; todas las SREBPs regulan positivamente las tres enzimas que participan en estas reacciones. G6PD, glucosa-6-fosfohidrogenasa; PGDH, 6-fosfogluconato deshidrogenasa; CYP51, lanosterol 14ademetilasa. Adaptado de Horton et al. (50). 
Estos factores de transcripción están regulados en tres niveles: (1) transcripción, (2) corte proteolítico de PSREBP y (3) modificaciones postraduccionales de mSREBP. El principal mecanismo de regulación de SREBP-1c es a nivel transcripcional; mientras que, SREBP-1a y SREBP-2 son regulados principalmente a nivel del corte de pSREBP.

La expresión de SREBP-1c está disminuida durante el ayuno y se incrementa con las dietas altas en calorías. La insulina induce la transcripción de SREBP-1c conduciendo a un aumento paralelo tanto del precursor unido a RE (pSREBP-1c) como de la forma madura del factor de transcripción (mSREBP-1c) $(45,54)$. Las otras isoformas de SREBP no se afectan por el ayuno o la ingesta. Otra de las señales que activa la transcripción SREBP-1c es el factor nuclear LXR $\alpha$ (liver $X$ receptor $\alpha$ ), el cual se describirá más adelante. La transcripción de SREBP-1a y SREBP-2 esta inducida por la misma activación del factor de transcripción (45).

La traducción de los ARNm de estas proteínas genera los pSREBP que se encuentran retenidos en la membrana del RE a través de la fuerte asociación con la proteína SCAP (SREBP cleavage activating protein) y una proteína de la familia Insig (Insulin-induced gene protein), la cual se une a un dominio sensor de esteroles (SSD) de SCAP. Bajo las condiciones de activación, niveles bajos de esteroles para SREBP-2 o activación por insulina o LXR $\alpha$ para SREBP 1c, el complejo SREBP-SCAP se disocia de Insig y es transportado al aparato de Golgi por vesículas revestidas de COPII. En el aparato de Golgi residen dos proteasas específicas unidas a membrana (S1P y S2P) que producen dos eventos proteolíticos secuenciales en el complejo SREBP-SCAP, liberando la forma madura de los SREBPs (mSREBP) en el citoplasma para que se transloque al núcleo y active la transcripción génica.(51, 55-57) (Ver Figura 1.5). 


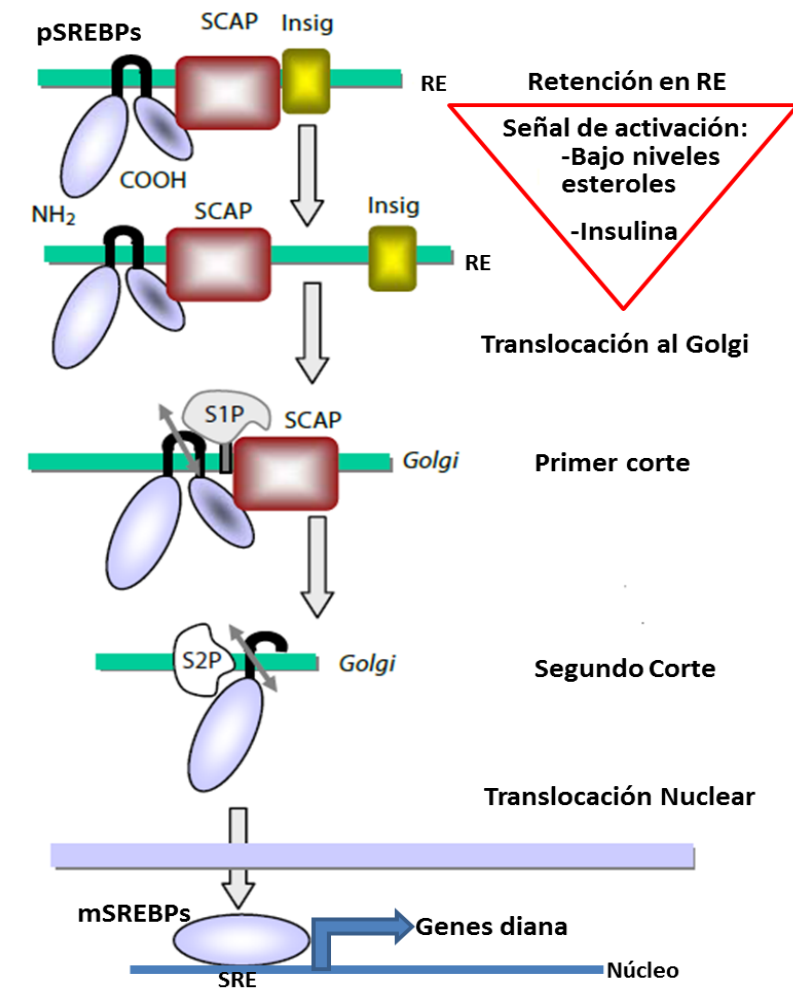

Figura 1.5. Activación de SREBPs por corte proteolítico. Los SREBPs en la membrana del retículo endoplásmico (RE) se encuentran altamente asociados con la proteína SCAP. SCAP a su vez interacciona con las proteínas Insig, que retienen el complejo SCAP/SREBP en el RE. Bajo apropiadas condiciones (niveles bajos de esteroles o activación por insulina), la interacción entre Insig y SCAP disminuye y permite que SCAP escolte a SREBP al aparato de Golgi donde S1P corta SREBP en un sitio luminal. Luego S2P corta liberando el dominio $\mathrm{N}$-terminal de SREBP. Este dominio es traslocado al núcleo donde se une a los genes diana en secuencias SRE como un homodímero. Adaptado de Ferré y Foufelle (54).

Dentro del núcleo, la actividad transcripcional de mSREBP está regulada por modificaciones covalentes o interacciones con otras proteínas. Por ejemplo, se ha visto que la insulina puede aumentar la actividad transcripcional al fosforilar los mSREBPs por medio de la vía MAPK (mitogen-activated protein kinase) $(45,58,59)$.

\section{B.1.2. Receptores nucleares}

La superfamilia de receptores nucleares comprende una serie de factores de transcripción que son fundamentales en la organogénesis, la regulación del metabolismo, la proliferación celular, la diferenciación celular y el cáncer. En los humanos, esta familia tiene 48 miembros e incluye los receptores de ácido retinoico (RXR), hormonas sexuales, vitamina D y el tiroideo, entre otros $(60,61)$. Algunos miembros de esta superfamilia son factores de transcripción sensores de lípidos, que traducen señales del entorno lipídico constantemente variable a cambios en la expresión génica (62). Estos receptores se pueden unir a moléculas que son sustratos, intermediarios o productos finales de rutas metabólicas como lo son los AGs, eicosanoides y oxiesteroles (63). 
Uno de los primeros receptores nucleares sensores del metabolismo lipídico en conocerse fueron los receptores activados por el factor proliferador de peroxisoma (PPARs; peroxisome proliferator-activated receptors). Existen tres isoformas de estos receptores nucleares (PPAR $\alpha$, PPAR $y$ y PPAR $\beta / \delta$ ), los cuales funcionan como heterodímeros obligatorios con RXR. PPARa, cuyos ligandos naturales son lípidos endógenos (ácidos grasos, eicosanoides, fosfolípidos oxidados), es un potente regulador del metabolismo lipídico, especialmente del catabolismo lipídico, al inducir la expresión de enzimas involucradas en la captación, esterificación y $\beta$-oxidación de ácidos grasos (61). PPAR $\alpha$ regula también la distribución sistémica de lípidos del hígado a otros órganos por su papel en el metabolismo de lipoproteínas, complejos macromoleculares encargados del transporte de lípidos en plasma, al modular la expresión de componentes de las mismas como son las apolipoproteínas $(60,61)$. PPARy es un potente modulador del metabolismo de la glucosa y un regulador maestro de la adipogénesis; mientras que, PPAR $\beta / \delta$ es un potente sensibilizador de insulina, altamente presente en músculo esquelético, que promueve la captura de AGs y $\beta$-oxidación de estos (62).

Los LXRs (liver $X$ receptors) son otros miembros de la superfamilia de receptores nucleares que regulan la homeostasis de lípidos como el colesterol y los AGs. Se han identificado 2 isoformas denominadas LXR $\alpha$ y LXRß, que difieren en el patrón de distribución tisular. La expresión de LXRa se limita al riñón, intestino, tejido graso, macrófagos, pulmón e hígado, donde la misma es la más elevada. En cambio, LXR $\beta$ se expresa en casi todos los tejidos y órganos. Sus ligandos endógenos son metabolitos del colesterol conocidos como oxiesteroles, así como también intermediarios de la colesterogénesis como el demosterol. Tras su activación, forman heterodímeros con RXR y regulan la expresión de genes al unirse a regiones denominadas elementos de respuesta de LXR (LXRE). Estos factores de transcripción participan en el proceso de detección de colesterol y proveen la base de un circuito de control homeostático para el mantenimiento de los niveles celulares del mismo $(62,63)$. Los LXRs inducen la expresión de una gran variedad de genes relacionados con el eflujo de colesterol, por ejemplo transportadores ABC (ATP binding cassette) como ABCA1 y $A B C G 1$, y también incrementan el aclaramiento de colesterol al aumentar los niveles plasmáticos de las lipoproteínas HDL (high density lipoprotein) (64).

LXR $\alpha$ puede activar genes de enzimas lipogénicas (ACC, FAS, SCD), ya sea directamente o por medio de la activación de SREBP-1c $(45,65)$. Se cree que LXR $\alpha$ induce la 
expresión de SREBP-1c a los efectos de generar AGs necesarios para la formación de ésteres de colesterol, que sirven de tampón a la concentración de colesterol libre (45). Al estimularse la lipogénesis por la activación de LXR se eleva los niveles plasmáticos y hepáticos de triglicéridos (66).

Otro receptor nuclear que regula el metabolismo lipídico es el receptor $X$ farnesoide (FXR; farnesoid $X$ receptor), el cual es un sensor de ácidos biliares. Este receptor, que esta expresado principalmente en hígado, intestino, riñón y glándulas adrenales, también funciona como un heterodímero con RXR y su activación modula la expresión de genes relacionados con la regulación de la homeostasis de ácidos biliares y colesterol y el metabolismo de lipoproteínas. A diferencia de LXR la activación de FXR reprime la expresión de SREBP-1c. FXR puede inducir a PPAR $\alpha$ el cual, como se mencionó anteriormente, es un potente promotor de vías de $\beta$-oxidación de lípidos $(61,67)$.

\section{C. Vía del mevalonato}

La vía del mevalonato (VM), también conocida como la vía de biosíntesis de isoprenos-colesterol, es una ruta metabólica muy ramificada. A través de ella, se generan diversas moléculas bioactivas que participan en múltiples procesos celulares como crecimiento y diferenciación celular, glicosilación de proteínas, transporte de electrones mitocondrial y vías de transducción de señales $(68,69)$ (Ver Figura 1.6).

Esta vía consta de múltiples reacciones secuenciales que se llevan a cabo en las fracciones microsomal y soluble del citoplasma. Comienza en el citosol con la síntesis de acetoacetil-CoA a partir de la condensación de 2 moléculas de acetil-CoA, en una reacción catalizada por la enzima acetoacetil-CoA tiolasa. Por acción de la HMG-CoA sintasa (HMGCS), el acetoacetil-CoA se combina con otra molécula de acetil-CoA para generar 3-hidroxi-3metilglutaril-CoA (HMG-CoA). Posteriormente, el HMG-CoA es convertido en mevalonato a través de una reacción catalizada por la HMG-CoA reductasa (HMGCR), una proteína integral de RE que es la enzima limitante de la velocidad de la vía y una de las más reguladas en la naturaleza $(70,71)$. La mevalonato quinasa (MK), que cataliza la fosforilación del mevalonato para dar fosfomevalonato en la siguiente etapa de esta vía, es otra enzima importante en la regulación de la ruta de biosíntesis de isoprenoides/colesterol. Aunque la MK no es la enzima limitante de la velocidad de la vía, se demostró que su actividad está regulada por 
intermediarios de la VM, a través de la inhibición por retroalimentación (72). En una reacción posterior de la vía se produce una nueva fosforilación, en la cual la fosfomevalonato quinasa (PMK) cataliza la conversión del fosfomevalonato en bifosfomevalonato (MPP), quien luego es decarboxilado para formar isopentenilpirofosfato (IPP) por acción de la MPP decarboxilasa. EL IPP es la unidad isoprénica (5 carbonos) básica a partir de la cual se generan todos los otros intermediarios de la VM. Una isomerasa cataliza la interconversión de IPP en su isómero dimetilalil pirofosfato (DMAPP), el cual sirve como donador de grupo isopreno en la producción de isopenteniladenina, requerida para la síntesis de ARN de transferencia $(73,74)$.

La geranilpirofosfato sintasa cataliza la condensación de IPP y DMAPP para dar geranilpirofosfato (GPP). Este compuesto, por medio de la farnesilpirofosfato sintasa, se une a un IPP para generar farnesilpirofosfato (FPP), una molécula de 15 carbonos $(75,76)$. Luego de la síntesis de FPP la VM diverge en múltiples ramas. La FPP sintasa es una enzima clave de esta vía dado que cataliza la última etapa común (Figura 1.6. Panel A).

La primera etapa comprometida específicamente con la colesterogénesis corresponde a la síntesis de escualeno a partir de la condensación de dos moléculas de FPP, reacción catalizada por la enzima escualeno sintasa (SS). El escualeno es convertido en lanosterol, el primer intermediario cíclico, en una serie de dos reacciones. En una primera instancia, el escualeno es convertido a 2,3-monoxidoescualeno (MOS) por acción de la enzima escualeno monoxigenasa/epoxidasa. En la segunda reacción el MOS es transformado en lanosterol a partir de la enzima 2,3-oxidoesqualeno:lanosterol ciclasa (OSC) o simplemente lanosterol sintasa. La síntesis avanza con una serie de reacciones de demetilación, deshidrogenación e isomerización del lanosterol para dar finalmente colesterol. Este proceso se lleva a cabo a través de dos ramificaciones de la vía postlanosterol, que dan lugar a las denominadas vía de Bloch y vía de Kandutsch-Russell $(70,77)$. En la vía de Bloch, la reacción final es la conversión de desmosterol a colesterol por la enzima esterol- $\Delta 24$-reductasa (DHCR24), de modo que todos los intermediarios entre lanosterol y desmosterol contienen un doble enlace $\Delta 24$. En la vía de Kandutsch-Russell, DHCR24 actúa sobre lanosterol y por ende todos los intermediarios desde 24,25hidrolanosterol hasta 7-dehidrocolesterol contienen una cadena lateral saturada. Dado que la enzima DHCR24 puede en principio metabolizar cualquier intermediario de lanosterol en adelante, ambas vías no pueden ser tratadas de forma separada (Figura 1.6, Panel C). 


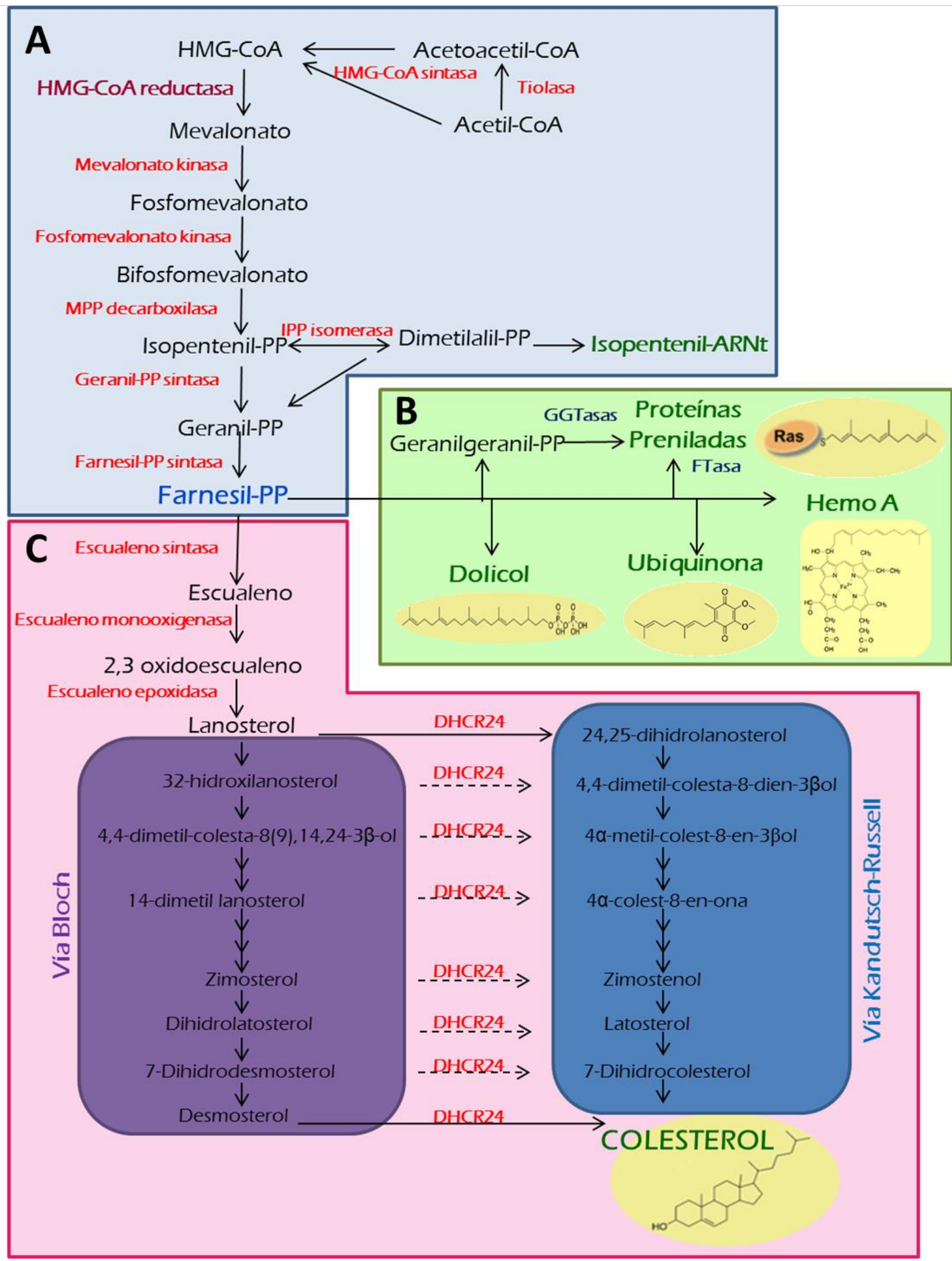

Figura 1.6. Vía del mevalonato. Esquema que representa los intermediarios y productos finales (letra verde) de la VM y las enzimas que las catalizan. (A) Reacciones comunes a todos los productos de la vía (celeste). (B) Productos no esteroideos (verde). (C) Reacciones específicas de la síntesis de colesterol (rosa). Se destaca además la HMGCR (letra borgoña), enzima reguladora de la velocidad de la $\mathrm{VM}$, y el principal punto de ramificación a nivel de farnesilpirofosfato (letra azul). Abreviaturas: PP: pirofosfato; DHCR24: esterol- $\Delta 24$-reductasa. 


\section{C.1. Productos de la vía del mevalonato}

Uno de los productos finales de la VM a partir del FPP es el dolicol, un alcohol poliisoprenoide de cadena larga. Este se genera a través de una serie de adiciones de 16 residuos de isopentenilo. En esta serie de condensaciones se producen dobles enlaces cis en la cadena del poliisopreno, algo característico del dolicol (78-80). El dolicol, ubicado en la membrana del RE, funciona como transportador de oligosacáridos durante la N-glicosilación de proteínas (73).

En otra de las ramas de la VM, el FPP puede unirse con otros grupos IPP o con cadenas cortas de poliprenoles para formar largas cadenas de poliprenoles con todos sus dobles enlaces en configuración trans. En humanos, cuando estas cadenas alcanzan las 10 unidades de isopreno, el grupo poliprenilo es transferido a un anillo aromático derivado de la tirosina para iniciar la síntesis de ubiquinona $(81,82)$. La ubiquinona es uno de los componentes de la cadena transportadora de electrones mitocondrial y el único antioxidante liposoluble sintetizado endógenamente que previene eficientemente la oxidación de proteínas, lípidos y ADN (82). En los últimos años se le han asignado a este compuesto un número creciente de funciones, entre las que se destacan la prevención de apoptosis (83) y propiedades antiinflamatorias y antiaterogénicas $(84,85)$.

El FPP es utilizado para modificar el grupo vinílico C2 del hemo B a un grupo hidroxietilfarnesil del hemo 0 , en una reacción catalizada por la hemo 0 sintasa. Luego la hemo A sintasa monooxigena el grupo metil $\mathrm{C} 8 \mathrm{del}$ hemo $\mathrm{O}$ y genera hemo $\mathrm{A}$, una porfirina que es grupo prostético del citocromo a, componente del último complejo de la cadena respiratoria donde el oxígeno es reducido a agua (86).

La condensación de FPP e IPP genera geranilgeranilpirofosfato (GGPP), un isoprenoide de 20 carbonos. FPP y GGPP pueden ser utilizados como grupos prostéticos en la prenilación de proteínas. Esta es una modificación postraduccional en la cual se unen covalentemente estos isoprenoides a proteínas que tienen una repetición CAAX en la región carboxiterminal. La repetición CAAX está compuesta por un residuo de cisteína, dos de aminoácidos alifáticos y un residuo terminal X. Las tres enzimas que pueden catalizar esta reacción son la farnesil transferasa (FTasa) y las geranilgeranil tranferasas (GGTasa) I y II (28). Si el residuo $\mathrm{X}$ es serina, alanina, metionina o glutamina la prenilación será catalizada por FTasa (farnesilación), pero si es una leucina la prenilación será mediada por una GGTasa 
(geranilgeranilación) $(87,88)$. Curiosamente se ha observado que la especificidad de sustrato de estas enzimas no es absolutamente estricta y que puede darse prenilación transversal (89). Una vez preniladas, las proteínas se dirigen al RE donde se produce la eliminación proteolítica del tripéptido AAX a cargo de la endopeptidasa RCE1 (Ras converting enzime 1) y la carboximetilación en el residuo de cisteína isoprenilado por la enzima ICMT (isoprenilcistein carboxil metiltransferasa) $(90,91)$ (Ver Figura 1.7).

Entre las proteínas que se prenilan se destacan proteínas de la lámina nuclear, la subunidad $\gamma$ de proteínas $G$ heterotrimétricas y de pequeñas GTPasas de la superfamilia Ras (Rho, Rac, Rab, Rap, Ras) que cumplen un importante papel en muchas cascadas de señalización dentro de la célula (92). La prenilación aporta un dominio hidrofóbico que juega un rol preponderante en la unión de estas proteínas a la cara citosólica de las membranas celulares, requisito esencial para cumplir su función biológica.

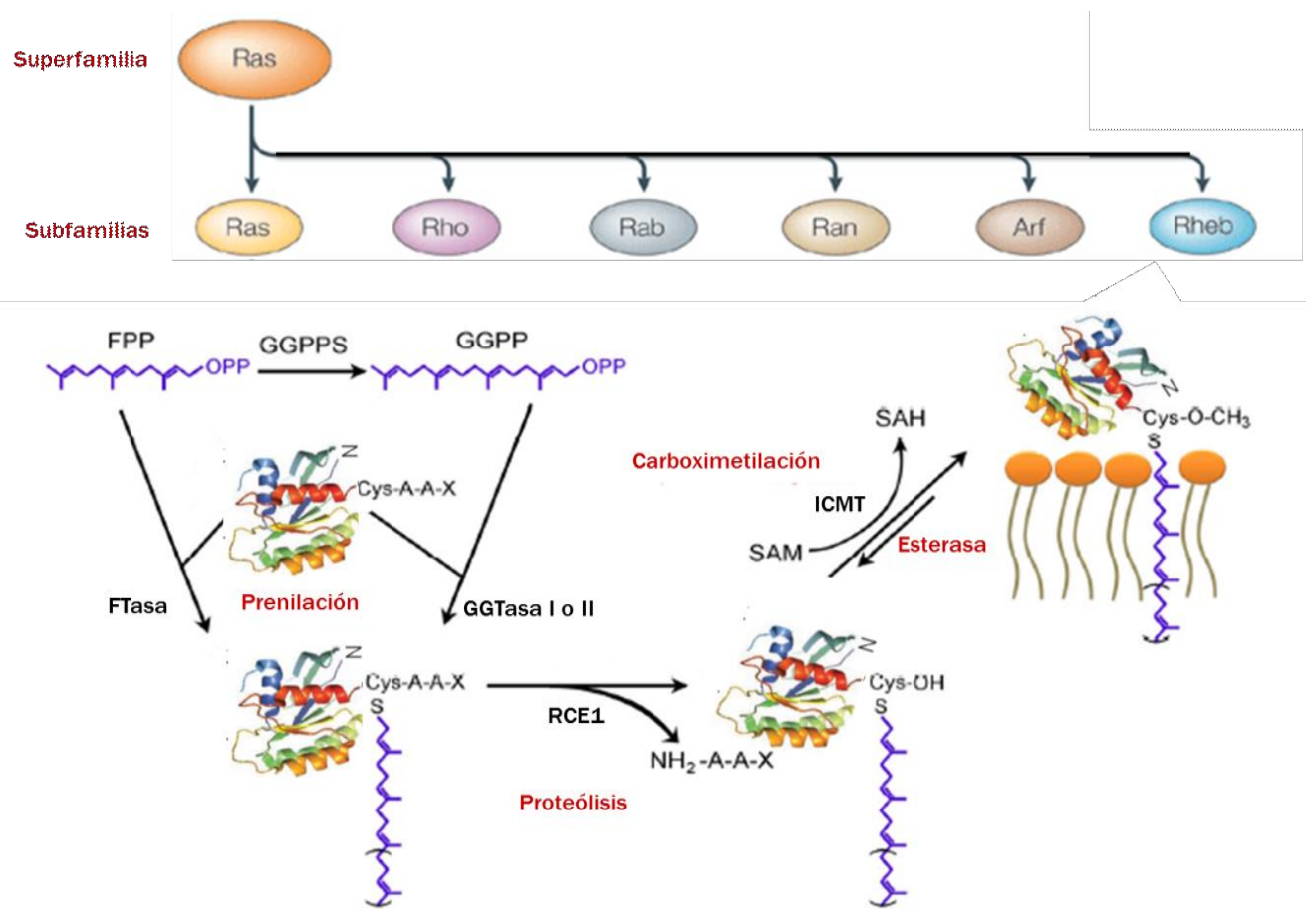

Figura 1.7. Isoprenilación de proteínas y reacciones post-prenilación. Proteínas de la superfamilia RAS entre otras, se isoprenilan en el residuo de cisteína dentro de la secuencia C-terminal CAAX. Seguido por la eliminación proteolítica del tripéptido AAX a cargo de la endopeptidasa RCE1 y por la carboximetilacion en el residuo de cisteína isoprenilado por la ICMT. Esta metilación es reversible debido a su actividad esterasa. Esta modificación incrementa la hidrofobicidad de la proteína y facilita su interacción con las membranas. Algunas de la GTPasas, como H-Ras y K-Ras, son palmitoiladas en el Golgi. SAM, S-adenosil-metionina; SAH, S-adenosil-homocisteína. Adaptado de Xu et al. (88). 
El producto final mayoritario de la VM es el colesterol, un isoprenoide de 27 carbonos perteneciente al subgrupo de los esteroides. El colesterol fue descubierto en el año 1815 por el químico francés M.E. Chevreul como un componente de los cálculos biliares y originalmente lo llamó colesterina (cole= bilis, stereos= sólido). Está formado por cuatro anillos fusionados (A, B, C, D) con dos grupos metilos angulares en las posiciones C10 y C13, un doble enlace entre $\mathrm{C} 5$ y $\mathrm{C} 6$, una cadena lateral isooctilo en $\mathrm{C} 17$ y un grupo $3 \beta-\mathrm{OH}$ en el anillo A, que lo convierte en una molécula anfipática (Figura 1.8, Panel A) $(93,94)$.

El colesterol es un componente estructural importante de las membranas celulares que modula la fluidez y permeabilidad de las mismas. Actualmente se considera que la interacción del colesterol con los fosfolípidos de membrana es predominantemente de tipo biofísica (Figura 1.8, Panel B) mientras que con las proteínas es de tipo estereoespecífica (95). Este lípido de membrana es necesario para la formación de caveolas y balsas lipídicas, cumpliendo un rol importante en el tráfico vesicular, en procesos de señalización transmembrana y en la viabilidad y proliferación celular $(96,97)$. Su distribución en membranas a nivel subcelular es muy heterogénea. Su principal destino es la membrana plasmática (60-80 \%) mientras que en el RE solo se encuentra el 0,5-1 \% del colesterol total (94).

A

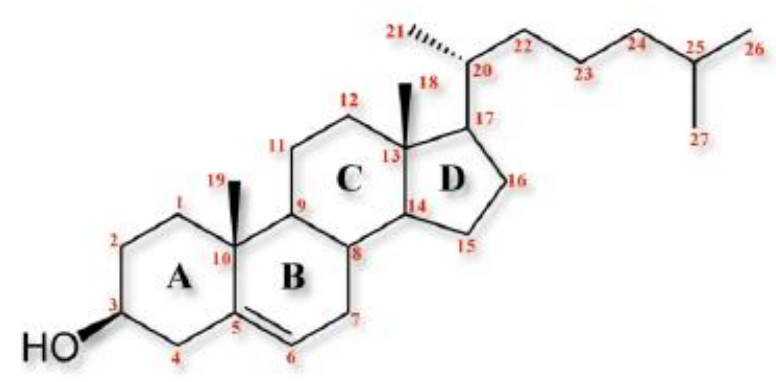

B

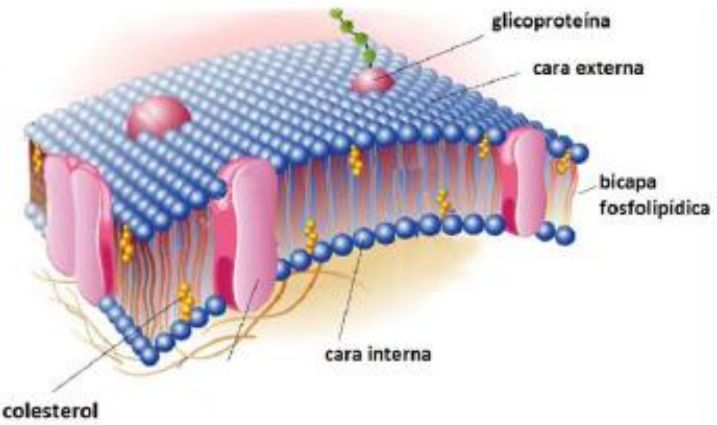

Figura 1.8. Estructura de la molécula de colesterol y su disposición en la membrana plasmática. (A) La estructura de colesterol consiste en cuatro anillos $(A, B, C, D)$, con dos grupos metilo angulares situados en $\mathrm{C} 10$ y $\mathrm{C} 13$, un grupo $3 \beta-\mathrm{OH}$ en el anillo $A$, un doble enlace entre $\mathrm{C} 5$ y $\mathrm{C} 6$ y una cadena lateral (isooctilo) en C17. (B) El colesterol se orienta con su hidroxilo 3-OH próximo a las cabezas polares de los fosfolípidos de membrana, mientras que la porción apolar (anillos fusionados y cola alifática) se encuentra sumergida en la bicapa lipídica interaccionando con la primer porción de las cadenas alifáticas de los fosfolípidos. Tomado de Rodenak Kladniew (445) 
Además de su función como constituyente de membranas celulares, el colesterol es precursor de numerosas sustancias como ácidos y sales biliares, vitamina $D$, hormonas esteroideas y oxiesteroles. Estos últimos participan en la regulación de la expresión de genes asociados a la biosíntesis del propio colesterol y de ácidos grasos y triglicéridos $(75,98)$.

Los mamíferos carecen de las enzimas necesarias para degradar el núcleo de la molécula del colesterol y sólo algunas células especializadas de estos animales pueden transformarlo en otros productos esteroideos, tales como los ácidos biliares y las hormonas esteroideas. Dado que en elevadas concentraciones el colesterol puede ser tóxico para la célula, tanto la biosíntesis como la captura de colesterol por la célula están altamente reguladas y el principal mediador de esta regulación es el mismo colesterol (35).

\section{C.2. Regulación de la vía del mevalonato.}

Una sofisticada regulación de la VM permite a las células asegurar la provisión de colesterol e isoprenoides necesaria para garantizar el adecuado funcionamiento y proliferación celular, y a la vez evitar la acumulación de productos esteroides que son potencialmente tóxicos $(35,71)$. La regulación se lleva a cabo mediante complejos mecanismos de control ejercidos sobre distintas enzimas de la vía.

El principal punto de regulación de la VM se encuentra a nivel de la HMGCR, una proteína integral de la membrana del RE que cataliza una reacción irreversible al comienzo de la vía. La principal isoforma de la HMGCR presente en humanos (isoforma 1) posee 888 aminoácidos de longitud. Se trata de una proteína transmembrana politópica que contiene dos dominios principales (99):

- Un dominio N-terminal (correspondiente al intervalo de aminoácidos del 88 al 218) o dominio sensor de esteroles (SSD, sterol-sensing domain) que atraviesa múltiples veces la membrana y es clave en la regulación por retroalimentación ejercida por el colesterol.

- Un dominio C-terminal (correspondiente al intervalo de aminoácidos del 489 al 871) o dominio catalítico que se extiende hacia el citoplasma y contiene al sitio activo de la enzima.

La regulación de la HMGCR se lleva a cabo a diversos niveles: transcripción, traducción, degradación y fosforilación $(51,71)$.

El control del inicio de la transcripción es el principal mecanismo de regulación de la HMGCR. Como se ha mencionado previamente, este control es mediado por SREBP-2, un 
regulador maestro de genes implicados tanto en la síntesis de colesterol como en la endocitosis de lipoproteínas de baja densidad (LDL) que permite mantener la homeostasis de esteroles $(45,50)$ (Ver Figura 1.9). En presencia de colesterol, pSREBP-2 asociado con SCAP es retenido en el RE debido a la unión de Insig al dominio SSD de SCAP. La disminución del contenido de colesterol ocasiona un cambio conformacional en SCAP que permite la disociación de Insig y el transporte del complejo pSREBP-SCAP hacia el aparato de Golgi donde por procesamiento proteolítico se libera el fragmento amino-terminal soluble de la proteína (mSREBP-2). mSREBP-2 se transloca al núcleo, se une a SREs en los genes diana y activa la transcripción de los mismos (100). Los genes diana incluyen aquellos que codifican enzimas de la VM, en especial HMGCR donde el promotor tiene dos SREs, el receptor de lipoproteína de baja densidad que facilita la endocitosis de LDL, y el propio SREBP-2 (50, 101).

La regulación a la baja por medio de la vía de SREBP es lenta y requiere de varias horas para disminuir los ARNm de los genes diana (102). Para lograr un rápido apagado de la síntesis de colesterol, HMGCR está muy regulada a nivel traduccional y post-traduccional.

HMGCR está regulada a nivel post-transcripcional por splicing alternativo del exón 13, produciendo un transcripto más corto que codifica para una enzima inactiva (102). Este mecanismo en el hígado está regulado por esteroles (colesterol y 25-hidroxicolesterol) y es más rápido que la inhibición que el colesterol genera en la transcripción (101). El mevalonato, el geraniol y ciertos derivados como el dioxidolanosterol (un intermediario de una derivación de la VM) pueden reducir la velocidad de traducción o su inicio (101).

Dependiendo del estado metabólico de la célula, la HMGCR también es regulada por un mecanismo que contribuiría a optimizar la disponibilidad de ATP en condiciones de estrés celular. Cuando los niveles intracelulares de ATP son bajos, y por ende la relación AMP/ATP es alta, aumenta la actividad catalítica de la enzima AMPK (AMP-activated protein kinase). En estas condiciones, la enzima fosforila HMGCR e inhibe su actividad por un mecanismo no del todo dilucidado. La defosforilación de la HMGCR, mediada principalmente por la proteína fosfatasa 2 A, restablece completamente su actividad (103-105).

El mecanismo más conocido de regulación post-traduccional de la HMGCR es la ubiquitinización mediada por esteroles para su posterior degradación proteosomal (Ver Figura 1.9). Insig puede unirse al SSD de la HMGCR y reclutar enzimas que la conjugan con ubiquitina cuando abundan los esteroles celulares (106-108). Se ha visto que oxiesteroles 
como el 25-epoxicolesterol y el 24-hidroxicolesterol, así como el intermediario 24,25dihidrolanosterol, pueden unirse a Insig e inducir la degradación de HMGCR. Además, se ha observado que tanto farnesol (FOH) como geranilgeraniol (GGOH), alcoholes derivados de intermediarios de la vía, pueden estimular la degradación de HMGCR por un mecanismo diferente a la unión de Insig (101).

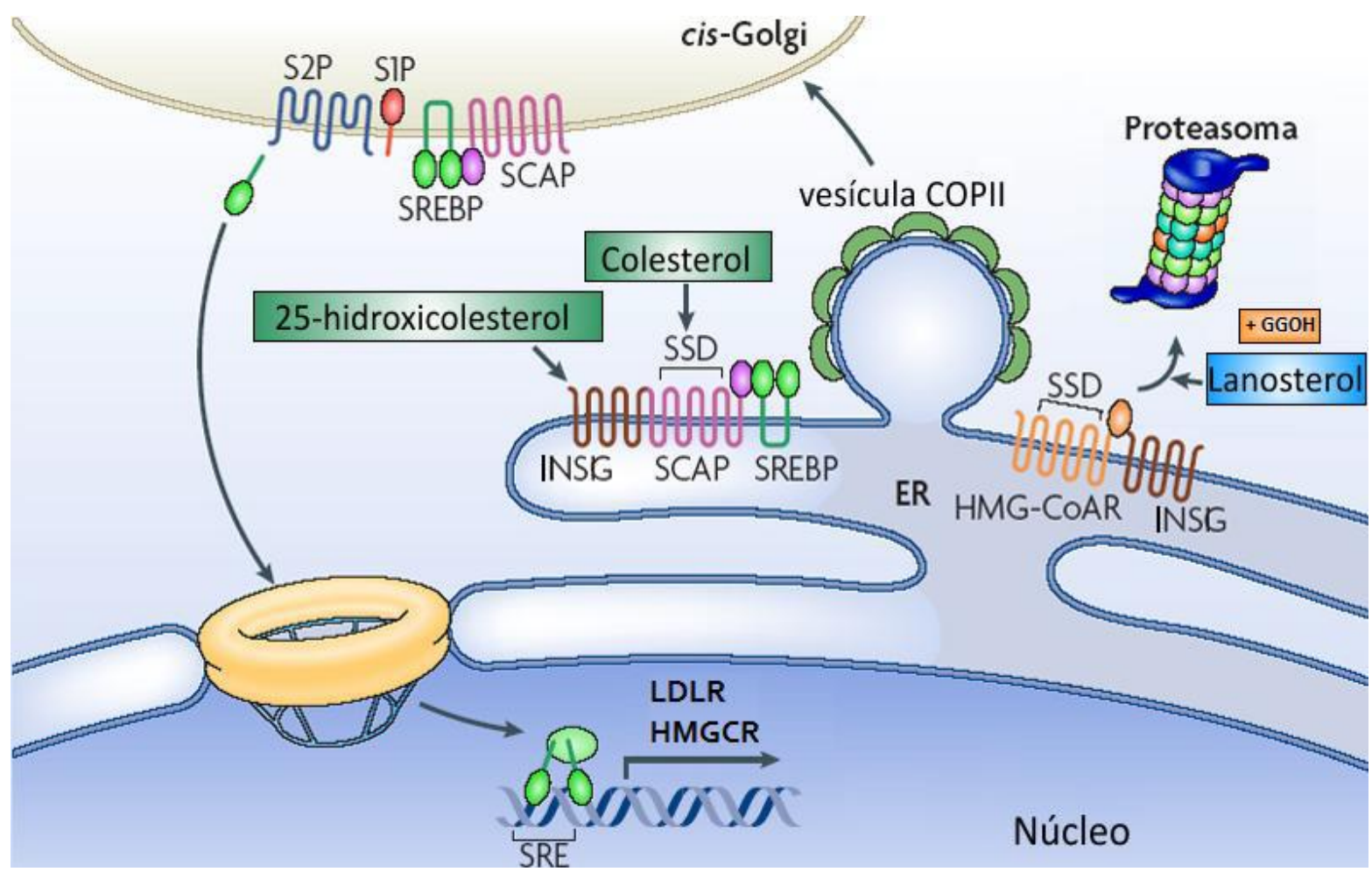

Figura 1.9. Regulación de HMGCR a nivel transcripcional y degradación. SREBP controla la transcripción de la HMGCR y de LDLR. SREBP-SCAP reside inactivo en la membrana del RE. Cuando el colesterol celular es escaso, lo cual es detectado a nivel del dominio sensor de esteroles (SSD) de SCAP, el complejo se transporta al aparato de Golgi en vesículas COPII. En el aparato de Golgi, SREBP es activado por dos eventos proteolíticos secuenciales que escinden el dominio $\mathrm{N}$-terminal del factor de transcripción de la membrana, lo que le permite entrar en el núcleo y activar la transcripción de la HMGCR y de LDLR. Insig se une a SCAP en condiciones celulares donde los esteroles son abundantes haciendo que su secuencia de reconocimiento de COPII sea inaccesible. Insig también regula la degradación de la HMGCR. En condiciones de niveles elevados de esteroles, la acumulación de lanosterol favorece que Insig se una a la región N-terminal de la HMGCR y recluta enzimas que conjugan con ubiquitina a HMGCR. Adaptado de Ikonen (57). 


\section{C.3. Vía del mevalonato y cáncer}

El cáncer es una patología que se caracteriza por un crecimiento celular descontrolado. Se produce por la presencia continua de señales proliferativas, la evasión de mecanismos supresores del crecimiento, la disminución de apoptosis, la capacidad de inducir angiogénesis y la exacerbación del comportamiento migratorio de las células que le permite invadir tejidos adyacentes o provocar metástasis en tejidos no adyacentes (109). Dado que durante la proliferación es necesaria la duplicación de todos sus componentes en cada división celular, resulta claro que las células cancerosas requieren un metabolismo muy activo. Actualmente se reconoce que un metabolismo lipídico aberrante es una de las características clave en estas células. La lipogénesis de novo provee una amplia variedad de moléculas lipídicas que cumplen diferentes funciones de señalización, modificación postraduccional de proteínas y aporte energético para sostener la continua división celular y facilitar la metástasis $(22,24,110)$.

Diferentes líneas de evidencia proponen que la VM es capaz de favorecer el desarrollo y progresión del cáncer. Se han encontrado variedad de tumores que presentan una expresión y actividad aumentada de la HMGCR respecto de las células normales, o bien, que son deficientes en el control por retroalimentación de la transcripción de la reductasa aunque su regulación postraduccional se mantiene intacta (111-113). Estudios epidemiológicos sobre pacientes que consumen regularmente inhibidores de HMGCR, como las estatinas, mostraron un menor riesgo de contraer ciertos tipos de cáncer $(114,115)$. Por último, se ha visto que la forma mutante de p53 (que en condiciones normales es considerado un gen supresor de tumores), presente en más del $50 \%$ de los cánceres humanos, es capaz de estimular la actividad de la VM en las células cancerígenas. Esto favorece la prenilación de proteínas y por ende el mantenimiento del fenotipo maligno (28). El análisis de todos estos resultados sugiere que HMGCR tendría un rol clave en la transformación, desarrollo y/o mantenimiento de las células malignas y se la propone como un posible oncogén (116).

Al presentarse hiperactividad de VM se facilita la prenilación de pequeñas GTPasas y el anclaje de estas a membranas celulares. Las GTPasas pequeñas son proteínas que hidrolizan GTP para dar GDP. Cuando unen GTP (forma activa), estas proteínas adoptan una conformación que les permite interaccionar con moléculas efectoras y disparar la cascada de 
transducción de señales a la cual se acopla. Las proteínas más estudiadas son de la superfamilia Ras. Ésta se compone de seis familias: Ras, Rho, Rab, Arf, Rheb y Ran (92, 117119). Estas proteínas están involucradas en la transducción de señales que regulan el crecimiento, morfología, tráfico vesicular así como la diferenciación y supervivencia celular $(76,120)$.

De todas ellas, Ras y Rho son las familias principalmente asociadas a distintos procesos biológicos pro-oncogénicos. Las proteínas de la familia Ras son preferentemente farnesiladas mientras que las de la familia Rho son geranilgeraniladas. Las proteínas Ras en citoplasma son mitogénicamente inactivas y su prenilación, la cual es indispensable para el anclaje a membrana, es requerida para su actividad ya que estas proteínas solo pueden interactuar con receptores de membrana $(29,90,121,122)$. Algunas mutaciones específicas resultan en una activación continua de las proteínas de la familia Ras $(29,90,122)$. La presencia de mutaciones en la familia Ras está asociada con transformación y malignidad debido a la estimulación anómala de las vías de señalización moduladas por ella, como por ejemplo las vías PI3K/Akt y Raf/MEK/MAPK/ERK, involucradas con apoptosis y progresión del ciclo celular $(90,123,124)$. Otros blancos incluyen los inhibidores de quinasa dependiente de ciclina (CDKI) como p21 y p27 (Ver Figura 1.10)(29, 125). Se estima que existen mutaciones activadoras de Ras en un $30 \%$ de los tumores humanos.

Las proteínas de la familia Rho rara vez presentan mutaciones que promuevan su actividad constitutiva, pero en una gran cantidad de tumores se observa una notable sobreexpresión de las mismas $(119,126)$. Las proteínas de la familia Rho son bien conocidas como reguladores de la migración celular a través de sus efectos sobre la reorganización del citoesqueleto de actina, la adherencia célula-célula y la adherencia célula-sustrato. En general se piensa que las proteínas Rho contribuyen al cáncer principalmente a través de sus efectos sobre la migración celular, lo que influye en la invasión y metástasis (119, 126-128).

Tanto Ras como Rho son capaces de estimular la angiogénesis (surgimiento de nuevos capilares sanguíneos a partir de los ya preexistentes), lo que favorece en gran medida el crecimiento tumoral $(123,129)$. 


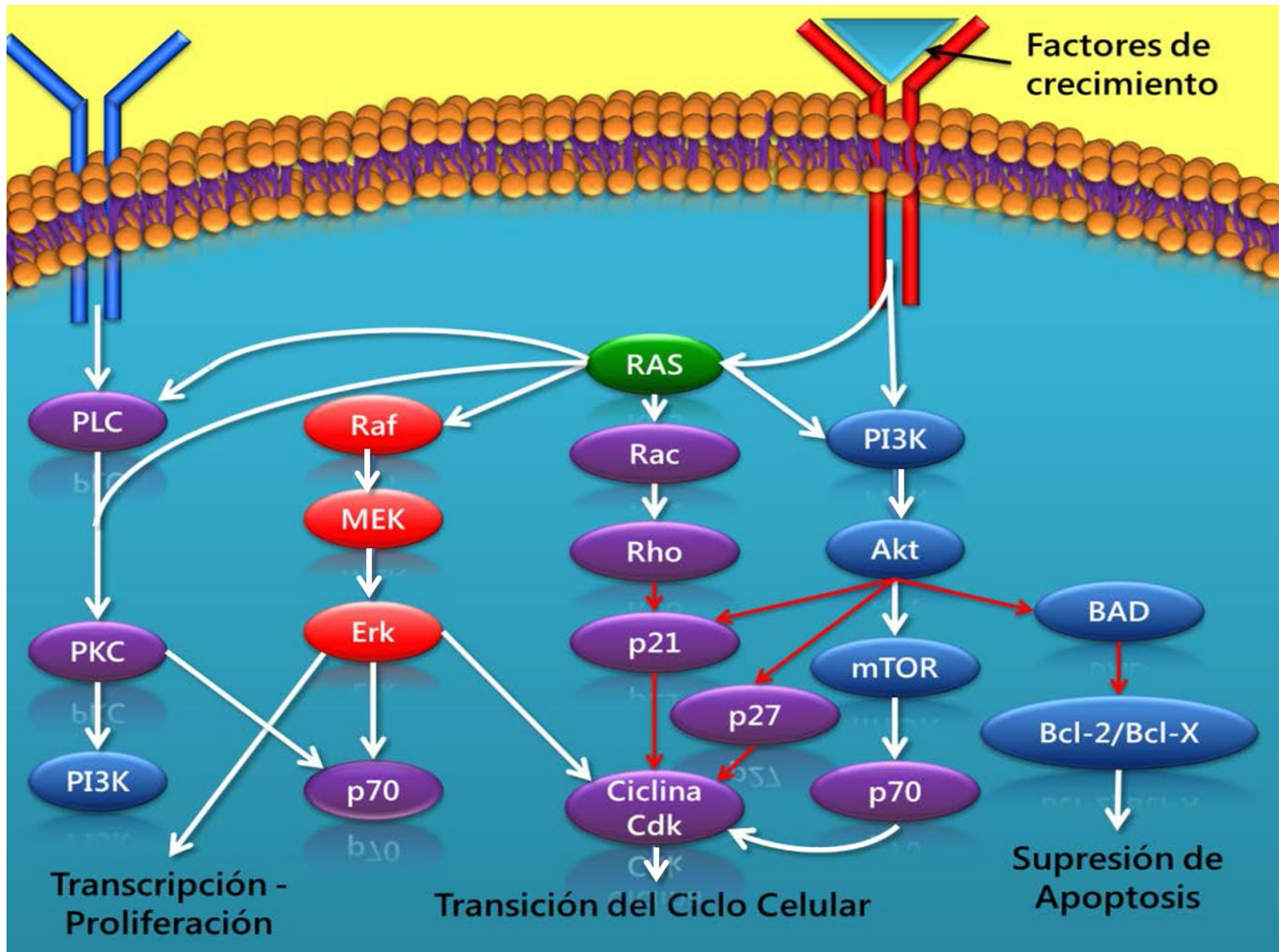

Figura 1.10. Vías de señalización de Ras. Receptores de tipo tirosin-quinasa se activan frente a un estímulo mitogénico y actúan sobre moléculas adaptadoras que interaccionan con Ras promoviendo su activación (Ras-GTP). En el esquema se simplifican las principales vías moduladas por Ras y las proteínas efectoras que habitualmente se ven afectadas por mutaciones en desórdenes del desarrollo y cáncer. Las vías Raf/MEK/ERK y PI3K/Akt son las principales vías desreguladas en células tumorales. Flechas blancas: estimulación; flechas rojas: inhibición. Tomado de Sandoval Usme (124).

Al inhibirse la VM en etapas tempranas, como a nivel de la HMGCR, no solo se inhibe la prenilación de proteínas sino que también la generación de otros productos finales importantes. Por ejemplo, la inhibición de la síntesis de dolicol se asocia con una disminución en la $\mathrm{N}$-glicosilación de receptores de factores de crecimiento como el IGFR y EGFR (130). La inhibición de la N-glicosilación de IGF-1R por fármacos que inhiben la HMGCR se ha asociado a una disminución de la síntesis de DNA y disminución del crecimiento celular (131).

La inhibición de la VM tiene un efecto inmunomodulatorio. Se ha observado que la acumulación de metabolitos del mevalonato en células tumorales pueden estimular a linfocitos $T$ (75) y que inhibiciones de enzimas corriente abajo en la VM, como la farnesilpirofosfato sintasa, producen la acumulación de IPP que genera la activación de 
linfocitos citotóxicos del sistema inmune innato que contribuye a la vigilancia de tumores $(132,133)$.

En células tumorales, el metabolismo de colesterol se encuentra generalmente desregulado, siendo los niveles celulares de colesterol mayores a los de células normales. Además, se encuentra alterada la distribución y cantidad de balsas lipídicas en la membrana plasmática que presentan estas células. Las balsas lipídicas son pequeños dominios heterogéneos, altamente dinámicos, enriquecidos en colesterol y esfingolípidos que compartimentalizan ciertos procesos celulares $(134,135)$. Las mismas son conocidas por presentar abundantes cantidades de moléculas de señalización. Receptores de crecimiento, receptores de células T, H-Ras, Akt y Src son ejemplos de proteínas que se encuentran en estos microdominios involucrados en múltiples funciones celulares, incluyendo regulación de la apoptosis, proliferación celular, tráfico de membrana, fenómenos de adhesión y migración celular. El colesterol juega un papel muy importante en el mantenimiento de la organización, estructura y función de estos microdominios. La depleción de colesterol en las balsas lipídicas genera cambios en la distribución de las proteínas residentes que da como resultado la pérdida de la función de los receptores o interrupción de los eventos de señalización. Se ha visto que la inhibición de la escualeno sintasa y por ende la síntesis de colesterol, merma principalmente a las balsas lipídicas de colesterol y en menor medida al colesterol fuera de estos dominios (135). El hecho de que las células tumorales presenten un incremento de estos microdominios respecto a las normales ha suscitado gran interés en apuntar hacia la regulación de la vía del mevalonato y síntesis de colesterol como una forma de modular a las balsas lipídicas y así prevenir y tratar el cáncer $(134,136,137)$.

Por último el colesterol es el precursor de hormonas esteroideas como los estrógenos y la testosterona, que tienen efectos de promoción tumoral en cáncer de mama y en cáncer de próstata bien conocidos $(26,33)$.

De este modo, queda claramente establecida la relación entre la vía del mevalonato y la proliferación, migración, angiogénesis y supervivencia celular. Esto la convierte en un muy atractivo objeto de estudio para profundizar el conocimiento de los mecanismos implicados y para el descubrimiento y/o desarrollo de nuevas terapias contra el cáncer. 


\section{C.4. Drogas que inhiben la vía del mevalonato.}

\section{C.4.1. Estatinas}

La familia de las estatinas está constituida por drogas naturales (de origen fúngico), semisintéticas (obtenidas por modificaciones de las anteriores) y sintéticas. Estos compuestos son estructuralmente similares a la mevalonolactona, característica que les posibilita actuar como inhibidores competitivos de la HMGCR (138). Las estatinas se utilizan con éxito en el tratamiento de la hipercolesterolemia, ya que ocasionan una disminución del contenido de colesterol celular que se traduce, vía SREBP-2, en un incremento del número de receptores para LDL con el concomitante aumento de la captación de LDL-colesterol del plasma $(71,100)$. También incrementan levemente los niveles de HDL mejorando así los perfiles de colesterol sanguíneo y reduciendo la morbi-mortalidad cardiovascular en pacientes dislipidémicos $(139,140)$.

La dosis recomendada en terapias hipocolesterolemiantes en humanos depende de la naturaleza de la estatina. Si bien a dosis terapéuticas en general son bien toleradas por el organismo, la administración de estatinas pueden ocasionar la aparición de efectos secundarios indeseables como disfunción hepática, progresión de cataratas, disfunción eréctil, miopatías, sensibilidad al tacto o debilidad con niveles elevados de creatina quinasa (141-143).

Se describen efectos pleiotrópicos de las estatinas que no siempre dependen de sus efectos en la reducción de los niveles de colesterol. Las estatinas se han relacionado con reducción de lesiones de tejido en modelos de isquemia y reperfusión en varios órganos, incluyendo corazón, pulmón, cerebro, riñón e intestinos. Adicionalmente, se ha demostrado que las estatinas atenúan la vasoconstricción incrementando la actividad del óxido nítrico (NO) endotelial. Además, la inhibición de la prenilación de proteínas se asocia a efectos como la reducción en la migración y proliferación de células musculares lisas vasculares, la inhibición de la adhesión y activación plaquetaria, la reducción de la acumulación de colesterol, inhibición de proliferación y activación de monocitos/macrófagos atraídos al sitio de injuria endotelial y la reducción en la producción de factores quimiotácticos (i.e. MCP-1) y de metaloproteinasas. Los efectos pleiotrópicos independientes de la reducción de 
colesterol les da una mayor versatilidad como anti-ateroscleróticos, anti-trombótico y antinflamatorio directos (144-147).

Aunque las estatinas se han aprobado para el tratamiento de desórdenes lipídicos, diversas evidencias señalan su potencial utilidad en el tratamiento de otras enfermedades como Alzheimer, osteoporosis y cáncer (148). En los últimos años se ha evaluado a las estatinas como potenciales agentes antitumorales ya que, al inhibir la HMGCR, producen una depleción de los precursores isoprenoides de la VM que limita la prenilación de proteínas como Ras y Rho, y por ende reduce su actividad, además de disminuir la disponibilidad de colesterol en las células (120). De este modo, las estatinas afectan procesos críticos en la génesis y progresión del cáncer como la movilidad y adhesión celular, reorganización del citoesqueleto, progresión del ciclo celular, angiogénesis y supervivencia entre otros $(40,149-151)$.

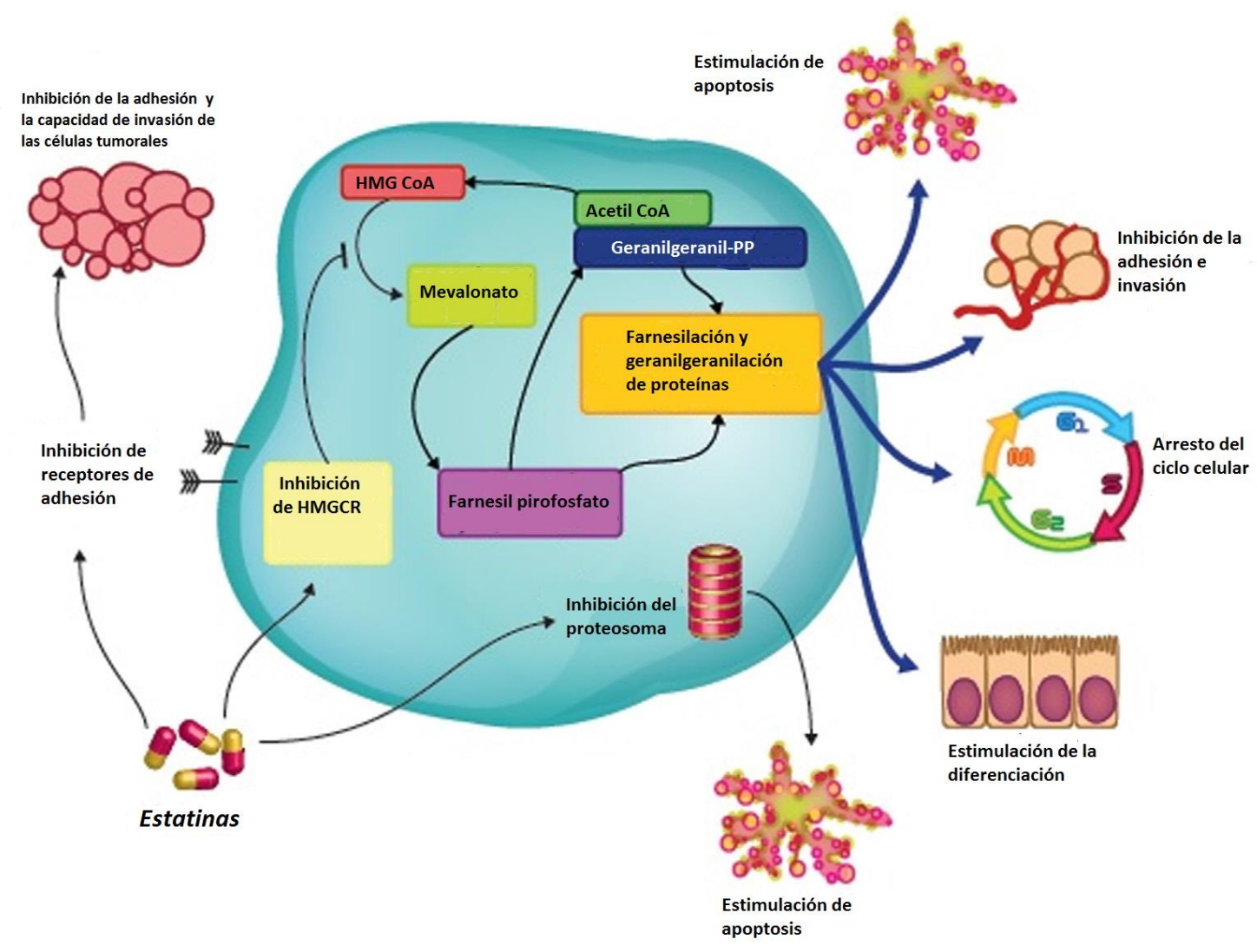

Figura 1.11. Acciones de las estatinas como quimioterapéuticos. Flechas negras: acciones directas de las estatinas. Flechas azules: acciones indirectas. Adaptado de Kubatka et al. (31). 
Se han realizado alrededor de media centena de estudios clínicos con estatinas en diferentes tumores. En estadíos tempranos de tumores de mama e intestinales, estudios con estatinas como monoterapia indican que estas drogas podrian reducir la morbilidad post cirugía (152). En estadios tardíos los estudios como monoterapia no han mostrado resultados promisorios, sin embargo, algunos ensayos utilizando estatinas en combinación con otros quimioterapéuticos han demostrado un incremento de la sensibilidad al quimioterapéutico, un aumento en la sobrevida o menor incidencia de recidivas $(34,152)$. Aunque estos resultados parecen prometedores aún estan pendientes estudios más robustos y con mayor duración para determinar el efecto de las estatinas en el tratamiento del cáncer.

\section{C.4.2. Bifosfonatos nitrogenados}

Los bifosfonatos son drogas que previenen la resorción ósea, y son utilizados en el tratamiento de osteoporosis y enfermedades similares $(36,153)$. Debido a su estructura (fósforo-carbón-fósforo) y la habilidad de quelar iones de calcio, estos agentes se direccionan rápidamente hacia el mineral óseo (154). Estos compuestos inhiben la FPP sintasa y su elevada afinidad por el tejido óseo hace que sean los osteoclastos los principales afectados del bloqueo de la VM. De este modo, disminuyen la disponibilidad de FPP y GGPP para la prenilación de proteínas y por ende el anclaje y actividad de muchas de las proteínas necesarias para que los osteoclastos puedan resorber hueso $(154,155)$.

Por sus efectos sobre la VM estos fármacos presentan, a nivel preclínico, un gran potencial en el tratamiento de diversos tumores. Conducen a la inhibición de la prenilación de proteínas vinculadas al crecimiento y proliferación celular. Adicionalmente, ocasionan un acumulo de IPP que permitiría la activación inicial de células inmunes citotóxicas y en altas cantidades la formación y acumulación del metabolitos que induce la apoptosis de las células tumorales $(35,75)$. Los bifosfonatos están aprobados para la prevención de afectación ósea y/o el tratamiento de enfermedad ósea metastásica en tumores hematopoyéticos como el mieloma múltiple y de tumores no hematopoyéticos como el cáncer de mama y de próstata $(36,156)$.

Se ha propuesto que los bifosfonatos pueden tener un efecto inhibidor de la ateroesclerosis actuando a través de varios mecanismos: inhibición de la mineralización y calcificación de las lesiones ateroescleróticas, inhibición del metabolismo en macrófagos de 
las LDL modificadas, disminución de la formación de células espumosas, reducción LDLs y aumento de HDLs en plasma (157).

Dentro de los efectos adversos de los bifosfonatos se encuentran trastornos gastrointestinales, reacción de fase aguda, dolor musculoesquelético severo, hipocalcemia y a largo plazo y en dosis elevadas aumentan el riesgo de osteonecrosis de mandíbula (158).

\section{C.4.3. Inhibidores de farnesil transferasas}

Los inhibidores de farnesil transferasas (FTIs) son un tipo de inhibidores de transducción de señales, originalmente diseñados para actuar en la inhibición de la prenilación de proteínas Ras. Estos incluyen compuestos que actúan competitivamente con FPP, competitivamente con el dominio CAAX o tienen ambas actividades. Los FTI no tienen especificidad solamente por Ras, sino que también afectan las funciones de diferentes proteínas que necesitan la farnesilación para su anclaje y actividad $(35,75)$. Pese a estar originalmente ideados para disminuir la actividad de Ras mutadas, no han tenido los resultados esperados en estudios preclínicos y clínicos. Esto se asocia a la posibilidad de que se dé prenilación cruzada, lo cual permitiría la geranilgeranilación de Ras al estar la farnesilación comprometida. En la actualidad se han realizado múltiples ensayos clínicos con FTIs, sin embargo, en ensayos fase III la respuesta a estos fármacos ha sido pobre, siendo los tumores hematológicos, en especial leucemia mieloide aguda, donde mejor respuesta se ha obtenido (159). En estudios clínicos, la combinación de FTIs con otros quimioterapéuticos han demostrado resultados mixtos $(131,160)$.

\section{C.4.4. Inhibidores de geranilgeranil transferasas.}

Estos inhibidores son una clase nueva de drogas que tienen como diana la geranilgeranil transferasa. Pueden ser inhibidores peptidomiméticos o inhibidores de moléculas pequeñas, con propiedades antitumorales promisorias (35). Estos compuestos, tanto en líneas celulares como en modelos animales, inducen apoptosis e inhiben el crecimiento de células tumorales. Tienen la habilidad de inducir arresto del ciclo celular al aumentar la expresión de inhibidores de ciclinas p21 y p27 (160). Recientemente se ha realizado un ensayo clínico con estos inhibidores, en el cual la tolerancia fue buena y en dos de las nueve personas evaluadas se logró mantener la enfermedad estable (159). 
En estudios preclínicos, se ha visto que la combinación de FTIs con GGTIs tiene un efecto inhibitorio sinérgico de la prenilación de K-Ras, generando un gran aumento de la respuesta apoptótica que con los tratamientos individuales $(35,75)$. Se considera que la combinación de inhibidores de transferasas, con ellos mismos o con otros inhibidores de la VM, tiene un considerable potencial como agente quimioterapéutico (160).

\section{C.4.5. Inhibidores de la escualeno sintasa.}

La escualeno sintasa (SS) cataliza la reacción de condensación de dos moléculas de FPP para la generar escualeno, el primer paso comprometido específicamente en la biosíntesis de colesterol. La inhibición de la SS no afecta directamente la síntesis de otros productos finales de la VM distintos del colesterol, por lo que los efectos musculares adversos asociados a la depleción mitocondrial de ubiquinona, que pueden ocasionar las estatinas, no se producirían con estos fármacos (161-163).

En estudios preclínicos, se ha observado que los inhibidores de la escualeno sintasa (SSI) disminuyen la colesterogénesis, aumentan la cantidad de ARNm de los receptores de LDL e inhiben la biosíntesis de triglicéridos. Esto se traduce, en modelos animales, en la disminución de los niveles de tanto triglicéridos como colesterol plasmático $(163,164)$.

Un SSI -el lapaquistat- ha avanzado hasta la fase III de ensayo clínico obteniéndose buenos resultados respecto a su efecto sobre el perfil de lípidos plasmáticos, con disminución de los niveles de LDL y triglicéridos. Además, se observó que este compuesto combinado con estatinas tiene un efecto sinérgico en la modulación de las lipoproteínas. Pese a estos resultados iniciales alentadores respecto al mejoramiento del perfil lipídico plasmático, la aparición de dos casos de elevación severa de enzimas hepáticas motivó la interrupción del estudio $(162,165)$. Actualmente se están realizando estudios preclínicos con nuevos SSIs que, además de ocasionar disminución de los lípidos plasmáticos y tener mejor hepatoselectividad y tolerancia, pueden presentar otros efectos como por ejemplo antioxidantes, antiparasitarios, antivirales y antitumorales (135, 166-169). 


\section{D. Metabolismo del colesterol}

En los seres humanos, y en mamíferos en general, el colesterol del que dispone el organismo proviene tanto de la síntesis endógena como de la dieta en una relación 70/30. En individuos alimentados con una dieta occidental típica, la biosíntesis a partir de acetil-CoA oscila entre $800-1000 \mathrm{mg} / \mathrm{día}$, mientras que el colesterol proveniente de la absorción intestinal ronda los 400-500 mg/día. Este último resulta del aporte de colesterol presente tanto en los alimentos ingeridos (300-500 mg/día) como del que se secreta formando parte de la bilis (800-1200 mg/día), teniendo en cuenta que se absorbe un 30-60 \% del colesterol disponible a nivel intestinal $(97,170,171)$.

Dado que el colesterol es una molécula muy hidrofóbica, su absorción intestinal requiere previa emulsificación, hidrólisis del colesterol esterificado (CE) de la dieta, solubilización micelar por sales biliares y posterior captación por parte de los enterocitos (97). La incorporación de colesterol estaría mediada por transportadores NPC1L1 (NiemannPick C1 Like1), localizados en el borde en cepillo de la membrana apical de los enterocitos del intestino delgado. Estos receptores colocalizan con dos transportadores de la familia $A B C$ (ATP-binding cassette), ABCG5/G8, los cuales promueven la expulsión del colesterol libre (no esterificado) al lumen intestinal, regulando así los niveles de absorción del mismo $(96,171)$. El colesterol intracelular que no es expulsado por ABCG5/G8, es esterificado en RE por acción de la enzima acil-CoA: colesterol transferasa 2 (ACAT2). Una vez esterificado, el colesterol es empaquetado en quilomicrones $(\mathrm{Qm})$ junto con fosfolípidos y triacilglicéridos (TAG), su principal componente. De allí es enviado al sistema linfático para luego alcanzar el torrente sanguíneo $(97,170,172)$

Una vez en circulación, algunos de los TAG de los Qm son hidrolizados por la lipoprotein lipasa (LPL) de los lechos capilares, generando los remanentes de Qm (Qmr). Los Qmr son capturados por los hepatocitos, los cuales utilizan sus lípidos para producir las partículas de muy baja densidad (VLDL, very low density lipoprotein)(96, 172).

Las VLDL son ricas en TAG y contienen entre 10-15\% de colesterol. Son transportadas en sangre hacia los tejidos adiposo y muscular, donde la LPL se activa hidrolizando los TAG y liberando ácidos grasos que pueden ser utilizados como fuente energética principalmente en el músculo, o ser almacenados en adipocitos. Las IDL (intermediate density lipoprotein) o VLDL remanentes pueden seguir diferentes caminos. Una proporción es captada del plasma 
por el hígado a través de diversos receptores, otra es transformada en LDL mediante un proceso dependiente de la actividad de la LPL y de la transferencia del exceso de apolipoproteínas a las HDL mediante la proteína de transferencia de fosfolípidos (PLTP, phospholipid transfer protein) (153). Las LDL, ricas en colesterol y fosfolípidos, son las principales lipoproteínas que distribuyen el colesterol en los tejidos periféricos y sus niveles en sangre están íntimamente relacionados a los acontecimientos pro-aterogénicos y al desarrollo de enfermedades coronarias $(94,171)$. La captación de LDL a partir del LDLR, ubicado en la superficie celular, es un caso típico de endocitosis mediada por receptor. Una vez que la partícula de LDL se una al LDLR, el complejo formado es endocitado en vesículas recubiertas de clatrina y transportado a los compartimentos endocíticos ácidos donde el CE es hidrolizado por lipasas. EI LDLR se disocia de la LDL en los endosomas tempranos y es devuelto a la membrana plasmática (MP) en un ciclo de reciclaje mediado por vesículas. EI colesterol continúa por la vía endocítica hacia endosomas tardíos, lisosomas y luego es liberado a otras membranas como la MP, RE y mitocondria. Este transporte puede darse por mecanismos vesiculares mediados por GTPasas de la familia Rab, o no vesiculares, a partir de la acción de las proteínas NPC1 y NPC2 (Niemann-Pick C1 y C2)(57, 96).

Dado que las células no son capaces de degradar el colesterol, cuando los tejidos extra-hepáticos poseen un exceso del mismo, éste se transfiere a través de trasportadores ABCA1/G1 hacia partículas de HDL, las cuales son sintetizadas como HDL nacientes en el hígado y en la mucosa intestinal (153). Las HDL nacientes pobres en lípidos se convierten en HDL esféricas (HDL madura) gracias a la acción de la lecitina-colesterol acetiltransferasa (LCAT), que esterifica el colesterol adquirido. En la circulación sanguínea los ésteres de colesterol de las HDL pueden ser intercambiados por medio de la proteína transferidora de ésteres de colesterol (CETP) por triglicéridos de las VLDL, IDL y LDL (173), pueden ser transportados a tejidos esteroidogénicos, que utilizan el colesterol como precursor biosintético, o trasladados nuevamente al hígado, donde el colesterol es eliminado en un proceso que se conoce como transporte reverso de colesterol (TRC). El colesterol de las HDL se internaliza al hígado mediante un receptor específico denominado SR-B1 (scavenger receptor class $B$ type1). Desde los hepatocitos, el colesterol es secretado en la bilis, ya sea como colesterol libre (a partir de los transportadores ABCG5/G8) o modificado, en forma de ácidos biliares. Posteriormente, la bilis se vuelca al intestino delgado, desde donde el colesterol y sales biliares pueden ser re-absorbidos o eliminados en las heces $(96,97,172)$. 
En los últimos años se ha sugerido que la tradicional vía hepatobiliar no sería la única vía de eliminación del colesterol. Se ha demostrado en ratones, y se cree que también existe en humanos, una eliminación directa del colesterol en sangre hacia el intestino en un mecanismo denominado excreción del colesterol transintestinal (TICE) $(174,175)$. Actualmente se desconoce los mecanismos y actores que participan en este proceso (97).

Se excreta alrededor de $1100 \mathrm{mg} /$ día de colesterol en pérdidas fecales como sales biliares, colesterol no absorbido y células descamadas del intestino $(173,176)$.

La Figura 1.12 esquematiza de forma simplificada los mecanismos mencionados en esta sección para el transporte y metabolismo del colesterol.

La cantidad de colesterol de la dieta varía notablemente de un día a otro, lo que obliga a la existencia de mecanismos de control que permitan mantener el equilibrio entre las velocidades de síntesis y excreción en relación con el que es absorbido. Tales mecanismos de control suelen funcionar correctamente, y garantizar la disponibilidad de cantidades adecuadas de colesterol que satisfacen las necesidades de los distintos tejidos.

El hígado desempeña un rol central en el mantenimiento de la homeostasis del colesterol corporal. Este órgano es el encargado de regular los niveles plasmáticos del mismo a través de la producción, secreción y captación de lipoproteínas, la formación de ésteres de colesterol y su almacenamiento en gotas lipídicas citoplasmáticas, así como su eliminación a través de la bilis. El intestino también cumple un papel determinante regulando su absorción y excreción en las heces $(94,177,178)$.

En situaciones patológicas tiene lugar un desequilibrio entre los procesos de síntesis, absorción y eliminación del colesterol que conllevan a elevados niveles de colesterol en circulación sanguínea o a un exceso de su eliminación por vía biliar. En el primer caso se ve favorecida la acumulación de CE en las paredes arteriales que promueve la formación de placas de ateroma (97). En el segundo, la sobresaturación de colesterol en las sales biliares facilita su precipitación promoviendo la formación de cálculos biliares (179). 


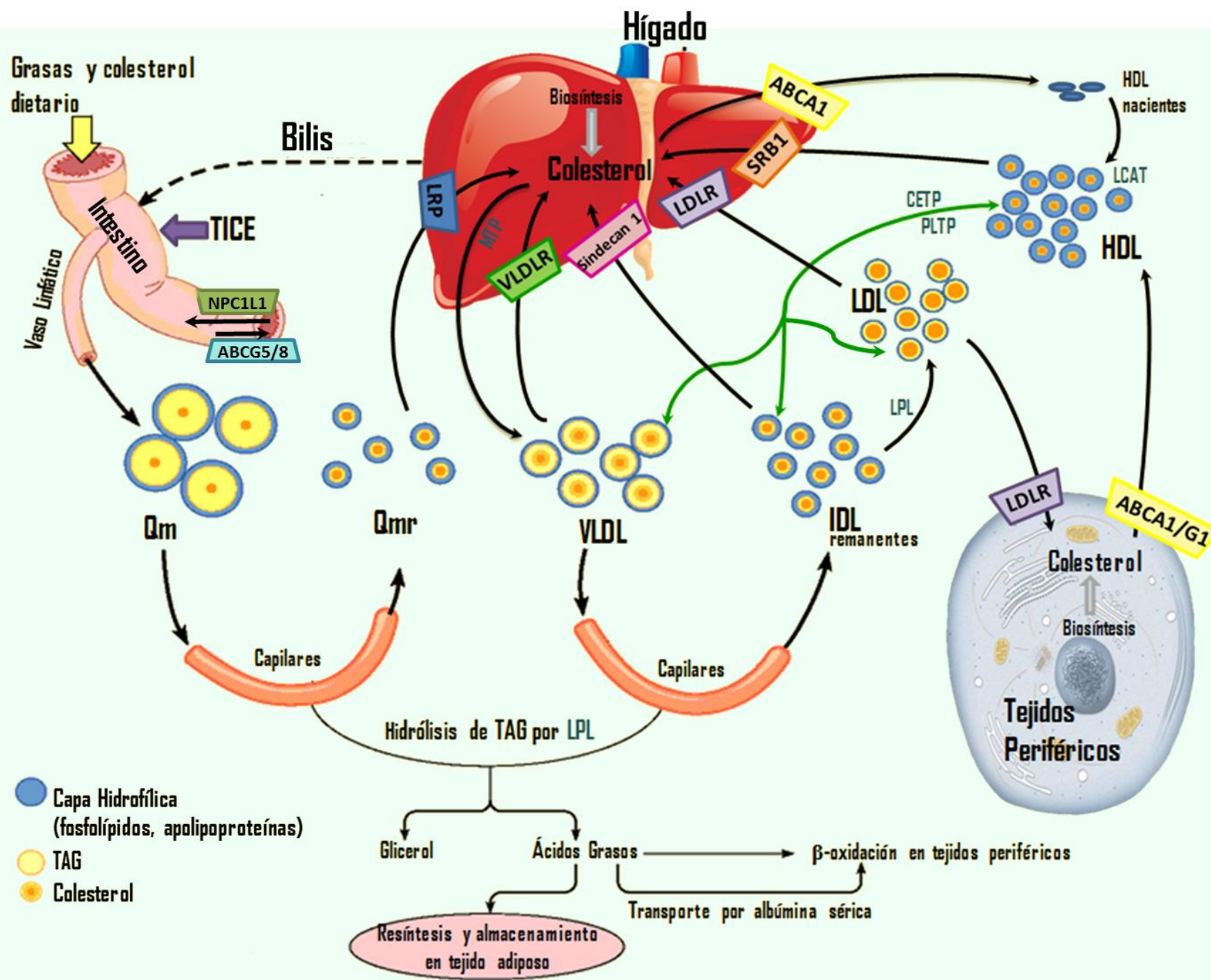

Figura 1.12. Transporte de colesterol. El colesterol y los triacilglicéridos (TAG) dietéticos son absorbidos por los enterocitos del intestino delgado para formar los quilomicrones (Qm). Algunos de los TAG se hidrolizan en la circulación por la lipoprotein lipasa (LPL) dando lugar a los remanentes de quilomicrones (Qmr) que son tomados por los hepatocitos. Por medio de la proteína de transferencia de triglicéridos microsomal (MTP) el hígado sintetiza VLDL que son metabolizadas en el torrente sanguíneo con la remoción de una extensa porción de TAG por los tejidos periféricos, convirtiéndose en IDL y luego en LDL. Las células de los mamíferos adquieren el colesterol exógeno principalmente a partir de las LDL, a través del receptor de LDLR (LDLR). Cuando los tejidos extra hepáticos tienen exceso de colesterol, este se transfiere a las HDL. Las HDL pueden intercambiar ésteres de colesterol por triglicéridos con otras lipoproteínas por medio de la proteína de transferencia de ésteres de colesterol (CETP) y recibir de estas fosfolípidos y apolipoproteínas por medio de la proteína de transferencia de fosfolípidos (PLTP). Diferentes receptores en el hígado captan las lipoproteínas del torrente sanguíneo, en especial LDL y HDL, en un proceso llamado transporte reverso del colesterol (TRC). Desde el hígado, el colesterol se excreta en la bilis (ya sea como colesterol libre o como ácidos biliares), la cual se vuelca en el intestino delgado. Además, el colesterol puede ser eliminado directamente desde el torrente sanguíneo a la luz intestinal por una vía alternativa a la hepatobiliar, en un mecanismo denominado excreción transintestinal del colesterol (TICE). A partir de ahí, colesterol y sales biliares se reabsorben (ciclo entero-hepático) o son excretados en las heces. 


\section{E. Dislipidemia y enfermedades cardiovasculares}

El término dislipidemia se refiere a todas las posibles alteraciones en las subfracciones de las lipoproteínas, reconociendo tanto la importancia de la elevación de LDL como la disminución de HDL (60). Clínicamente un individuo padece una dislipidemia si se presenta una o más de las siguientes condiciones: Triglicéridos $\geq 200 \mathrm{mg} / \mathrm{dl}$, Colesterol total $\geq 240 \mathrm{mg} / \mathrm{dl}, \mathrm{HDL}<40 \mathrm{mg} / \mathrm{dl}$, LDL mayor de $160 \mathrm{mg} / \mathrm{dl}$ o la persona se encuentra tomando agentes antilipidémicos (10).

Según estudios epidemiológicos, las dislipidemias más prevalentes en Latinoamérica, a diferencia de Europa y EUA, son aquellas en donde se presentan niveles bajos de $\operatorname{HDL}(53,3$ $\%)$, seguidas por las hipertrigliceridemias $(26,5 \%)$, y solo un 9-14 \% de la población presentan niveles elevados de colesterol total o $\operatorname{LDL}(1,6)$.

Pese a que existen dislipidemias primarias por trastornos genéticos, en las sociedades occidentales la mayoría de las dislipidemias son secundarias. Estas últimas estan asociadas fundamentalmente a la dieta moderna alta en el consumo de grasa y estilos de vida no saludables como consumo de tabaco, obesidad y sedentarismo, entre otros (180).

Las dislipidemias son importantes factores de riesgo cardiovascular, intimamente asociados con la acelerada progresión de la ateroesclerosis (181). En este sentido, muchos son los estudios donde se confirma la correlación lineal entre los altos niveles de LDL y la generación de ateroesclerosis $(100,182,183)$. Cuando los niveles de LDL son elevados, estas lipoproteínas se acumulan en el intersticio de la pared vascular, donde pueden darse modificaciones (oxidación, agregación, acomplejamiento con inmunoglobulinas, modificación enzimática) que impiden su reconocimiento por el LDLR (184). Las LDL oxidadas (oxLDL), como se refiere a las LDL modificadas, son en cambio captadas por receptores carroñeros (scavenger) [CD36, SR-A/B, receptor 1 tipo lectina de LDL oxidadas (LOX-1)] presentes en macrófagos y células musculares lisas $(185,186)$. Los receptores carroñeros, a diferencia de los LDLR, no tienen retrocontrol por lo que las células persisten tomando colesterol y terminan convirtiéndose en células espumosas (187). Esto desencadena una cascada de procesos inflamatorios y de remodelación de la pared vascular que resultan en la formación de estrías lipídicas. Estos procesos se autoperpetúan progresivamente y generan lesiones más extensas y más friables que conllevan a eventos cardiovasculares $(186,188)$. En las últimas décadas, diversos trabajos han documentado los beneficios de disminuir los 
niveles plasmáticos de LDL-colesterol para la prevención primaria y secundaria de ECVs y la reducción del riesgo de mortalidad por enfermedad ECV (189).

El incremento de los niveles plasmáticos de LDL-colesterol se mantiene como el principal "villano" en la generación de la lesión ateroesclerótica. Sin embargo, conforme avanza la investigación en aterogénesis, alteraciones en las otras fracciones lipoproteicas cada vez toman más protagonismo como contribuyentes del riesgo aterogénico. Actualmente estas alteraciones son factores de riesgo de ECV independientes, lo que ha llevado a repensar las estrategias en el tratamiento de las dislipidemias en los últimos años $(181-183,190)$.

Elevados niveles de triglicéridos séricos pueden causar disfunción de las células endoteliales y promover una respuesta inflamatoria que incrementa la adhesión y migración de monocitos, contribuyendo a la formación de la placa aterosclerótica $(186,191)$. Estos eventos han sido asociados a remanentes de lipoproteínas ricas en triglicéridos, como las pequeñas VLDL, IDL y los Qmr, que pueden ingresar en la pared vascular y tienen una elevada cantidad de apo CIII (una apolipoproteína particularmente aterogénica). Además, elevadas concentraciones de lipoproteínas ricas en triglicéridos resultan en niveles bajos de HDL-colesterol como consecuencia del intercambio de triglicéridos por colesterol que se da entre estas partícula y las HDL, el cual esta mediado por la CETP. Adicionalmente, las partículas de HDL enriquecidas en triglicéridos presentan una reducida capacidad de eflujo de colesterol desde los macrófagos (192-194).

Estudios epidemiológicos han demostrado extensamente la relación inversa entre niveles bajos de HDL-colesterol y un elevado riesgo de ECV (195-197). Dentro de las propiedades antiaterogénicas que se le asocian a las HDL se incluyen: el eflujo de colesterol de los macrófagos en la pared vascular por el TRC, la inhibición de la inflamación vascular, el mantenimiento de la función endotelial, el efecto antioxidante y el mantenimiento de la baja viscosidad sanguínea, entre otros $(186,187,194,195)$. Sin embargo, los estudios donde se analiza la capacidad de disminuir los eventos cardiovasculares al incrementar el HDLcolesterol por medio farmacológico no han arrojado resultados promisorios $(181,195,198)$. Esto ha llevado a la búsqueda de medicamentos y/o medidas que, más allá de elevar los niveles de HDL, mejoren la "capacidad de eflujo de colesterol", un biomarcador que al encontrarse en el cuartil más alto ha demostrado una reducción de hasta el 67 \% en el riesgo de eventos cardiovasculares $(199,200)$. 


\section{E.1. Manejo actual de las dislipidemias}

Las dislipidemias aisladas son poco comunes, presentándose frecuentemente asociadas a diabetes, síndrome metabólico, obesidad, hipertensión, etc., con su correspondiente tratamiento farmacológico (180). Por este motivo, se buscan terapéuticas eficientes y que presenten escasos efectos adversos, evitando interacciones medicamentosas.

La dieta es la base del tratamiento de las dislipidemias. La American Heart Association sugiere la reducción de la ingesta de grasa a menos del $30 \%$ de las calorías totales, con menos del $10 \%$ de grasas saturadas y la reducción de la ingesta de colesterol a menos de $300 \mathrm{mg} /$ día. Además de la modificación de la dieta, el aumento de ejercicio aeróbico es una medida terapéutica no farmacológica fundamental en el manejo de las dislipidemias. Se ha observado que luego de un plan de ejercicio constante disminuyen los niveles de TAG y colesterol y aumentan los de $\operatorname{HDL}(201,202)$.

Sólo si las medidas anteriores no logran el objetivo propuesto, y luego de analizar cuidadosamente los demás factores de riesgo cardiovascular, debe recurrirse a drogas hipolipemiantes. Los principales grupos de estos fármacos se presentan en la Tabla 1.1.

Tabla 1.1. Principales grupos de drogas utilizadas en el tratamiento de dislipidemias

\begin{tabular}{|c|c|c|c|}
\hline $\begin{array}{l}\text { Clase de } \\
\text { Droga }\end{array}$ & $\begin{array}{l}\text { Ejemplo de } \\
\text { Agentes }\end{array}$ & Mecanismo de acción & Efectos secundarios \\
\hline Estatinas & $\begin{array}{l}\text { Lovastatina, } \\
\text { Simvastatina, } \\
\text { Pravastatina, } \\
\text { Atorvastatina, } \\
\text { Rosuvastatina }\end{array}$ & Inhibidores de la HMGCR & $\begin{array}{l}\text { Miopatías, elevación de las } \\
\text { enzimas hepáticas }\end{array}$ \\
\hline Ezetimiba & & $\begin{array}{l}\text { Inhibidores de la proteína Niemann-Pick C1. } \\
\text { Inhiben la absorción de colesterol en el } \\
\text { borde en cepillo yeyunal. }\end{array}$ & Diarrea, fatiga, sinusitis, artralgias \\
\hline Niacina & $\begin{array}{l}\text { De liberación inmediata } \\
\text { De liberación extendida }\end{array}$ & $\begin{array}{l}\text { Inhibición de la liberación de ácidos grasos } \\
\text { del tejido periférico }\end{array}$ & $\begin{array}{l}\text { Arritmias, palpitaciones, } \\
\text { rubicundez, prurito, hiperglicemia, } \\
\text { hiperuricemia, mareos, cefaleas, } \\
\text { diarrea, mialgias. }\end{array}$ \\
\hline $\begin{array}{l}\text { Secuestradores } \\
\text { de ácidos } \\
\text { biliares (BAS) }\end{array}$ & $\begin{array}{l}\text { Colestiramina, } \\
\text { Colestipol, Colesevelam }\end{array}$ & $\begin{array}{l}\text { Resinas de intercambio iónico que } \\
\text { previenen la reabsorción de ácidos biliares. } \\
\text { Las LDL son aclaradas del plasma para } \\
\text { generar ácidos biliares }\end{array}$ & $\begin{array}{l}\text { Malestar abdominal, } \\
\text { estreñimiento, flatulencia, } \\
\text { hemorroides, impostación } \\
\text { fecal, fisuras anales y } \\
\text { transaminasas altas }\end{array}$ \\
\hline $\begin{array}{l}\text { Derivados del } \\
\text { ácido fíbrico } \\
\text { (fibratos) }\end{array}$ & $\begin{array}{l}\text { Gemfibrocil, Fenofibrato, } \\
\text { Clofibrato }\end{array}$ & $\begin{array}{l}\text { Agonistas de receptores PPARa. } \\
\text { Incrementan la afinidad de las LDL al LDLR }\end{array}$ & $\begin{array}{l}\text { Dispepsia, colelitiasis, toxicidad } \\
\text { muscular, mialgias }\end{array}$ \\
\hline
\end{tabular}

Adaptado de Gonzalez et al. (204). 
Las estatinas, medicamentos de primer uso en hipercolesterolemias, y los fibratos, de primer uso en hipertrigliceridemias, son los más utilizados y estudiados en la prevención de la enfermedad cardiovascular (203). Un gran número de estudios han demostrado que disminuyen el riesgo de morbimortalidad cardiovascular, tanto en la prevención primaria como en la secundaria $(203,204)$. En la Tabla 1.2 se muestra la capacidad que tienen estos medicamentos para modular las distintas fracciones de lipoproteínas ya sea como monoterapia o en combinación.

\section{Tabla 1.2. Opciones para el tratamiento farmacológico de dislipidemias}

\begin{tabular}{|c|c|c|c|c|c|c|c|c|}
\hline Trastorno lipídico & Monoterapia & $\%$ LDL & $\% \mathrm{HDL}$ & $\%$ TAG & Terapia combinada & $\% \mathrm{LDL}^{*}$ & $\% \mathrm{HDL}^{*}$ & $\%$ TAG \\
\hline \multirow{5}{*}{$\begin{array}{l}\text { Hipercolesterolemia } \\
\text { LDL altas } \\
\text { TAG normales } \\
\text { HDL normales }\end{array}$} & Estatinas & $25-63 \downarrow$ & - & - & Estatina + ezetimiba & $46-61 \downarrow$ & - & - \\
\hline & Ezetimiba & $18 \downarrow$ & - & - & Estatina + niacina & $36-42 \downarrow$ & $16-27 \uparrow$ & \\
\hline & Niacina & $6-25 \downarrow$ & - & - & Estatina + BAS & $45-64 \downarrow$ & - & - \\
\hline & BAS & $15-30 \downarrow$ & - & - & Estatina + niacina + BAS & $66 \downarrow$ & $16-27 \uparrow$ & - \\
\hline & & & & & Niacina + BAS & $25-55 \downarrow$ & $16-27 \uparrow$ & - \\
\hline \multirow{4}{*}{$\begin{array}{l}\text { Hiperlipidemia mixta } \\
\text { LDL altas } \\
\text { TAG altos } \\
\text { HDL normales o bajas }\end{array}$} & Estatinas & $25-45 \downarrow$ & $5-15 \uparrow$ & $5-37 \downarrow$ & Estatina + ácido fíbrico & $20-35 \downarrow$ & & $35 \downarrow$ \\
\hline & Ácido fíbrico & $10-28 \downarrow$ & $5-35 \uparrow$ & $10-50 \downarrow$ & Niacina + estatina & $36-42 \downarrow$ & $16-27 \uparrow$ & $15-45 \downarrow$ \\
\hline & Niacina & $6-25 \downarrow$ & $8-38 \uparrow$ & $30-50 \downarrow$ & Niacina + ácido fíbrico & - & $16-27 \uparrow$ & $20-37 \downarrow$ \\
\hline & & & & & Niacina + BAS & $25-55 \downarrow$ & $16-27 \uparrow$ & - \\
\hline \multirow{3}{*}{ Hipertrigliceridemia } & Estatinas & - & - & $5-10 \downarrow$ & Niacina + ácido fíbrico & - & $16-27 \uparrow$ & $20-37 \downarrow$ \\
\hline & Ácido fíbrico & - & - & $30-50 \downarrow$ & & & & \\
\hline & Niacina & & - & $10-50 \downarrow$ & & & & \\
\hline \multirow{3}{*}{ HDL baja aislada } & Ácido fíbrico & - & $6-12 \uparrow$ & - & & & & \\
\hline & Estatina & - & $5-10 \uparrow$ & - & & & & \\
\hline & Niacina & - & $5-35 \uparrow$ & - & & & & \\
\hline
\end{tabular}

* Los cambios en el porcentaje son aproximados. LDL = lipoproteínas de baja densidad, $\mathrm{TAG}=$ triglicéridos, $\mathrm{HDL}=$ lipoproteínas de alta densidad, BAS = secuestrador de ácidos biliares

Tomado de Canalizo Miranda et al. (203).

$\mathrm{Si}$ bien los medicamentos anteriormente descritos han disminuido considerablemente la morbimortalidad cardiovascular, no siempre son efectivos en alcanzar los objetivos del tratamiento y presentan diversos efectos adversos (Ver Tabla 1.1) que pueden potenciarse al combinarlos. Además, en general son tratamientos crónicos que tienen costos elevados ya sea para el individuo o para el sistema de salud. Esto hace que se busquen nuevas terapéuticas más seguras y eficientes. Actualmente, fármacos con diferentes dianas se encuentran en desarrollo o en fase clínica de ensayo: nuevos SSIs (205, 206) e inhibidores de PCSK9, una proteína que estimula la degradación lisosomal de los LDLR 
hepáticos y por ende modula los niveles plasmáticos de $\operatorname{LDL}(4,207)$. También se han desarrollado inhibidores de CETP que elevan considerablemente las HDL, en teoría con menos efectos secundarios que la niacina, sin embargo estos se encuentran todavía en fase clínica III y está pendiente determinar sus efectos sobre la enfermedad cardiovascular (4, 204, 208).

Los productos naturales que presentan efecto hipolipemiante son una opción cada vez más utilizada en el mundo occidental para complementar con los cambios en el estilo de vida y eventualmente administrar en conjunto con los fármacos previamente descritos. El interés de encontrar alternativas no farmacológicas, en particular para pacientes con hiperlipidemias moderadas, riesgo cardiovascular bajo o que son intolerantes a los tratamientos farmacológicos tradicionales, ha llevado a la comunidad científica a probar muchos fitoquímicos con propiedades hipolipemiantes en estudios preclínicos y clínicos (11, $13,209)$ y a incentivar la investigación en la identificación de los componentes activos y el mecanismo bioquímico por el que actúan (12).

Se han estudiado más de 40 plantas o productos derivados de estas que han demostrado sus beneficios en el metabolismo lipídico y en marcadores de riesgo cardiovascular, lo que valida el uso de estas sustancias en el manejo diario de las dislipidemias $(11,210-212)$. Los alimentos funcionales o nutraceúticos pueden disminuir el colesterol y triglicéridos plasmáticos por uno o más mecanismos, ya sea la inhibición de la absorción de colesterol, la inhibición de HMGCR, la activación de LDLR y la activación de las enzimas que generan ácidos biliares, entre otros mecanismos (209).

Productos como la fibra dietaria, fitoesteroles, frijol de soya, té verde y negro, policosanoles, ajo, levadura roja de arroz, almendras, linaza, trigo negro y regaliz, entre otros, han demostrado tener actividad hipocolesterolemiante por diversos mecanismos. Actualmente se considera de gran utilidad el estudio y comercialización de asociaciones de dos o más fitofármacos, buscando sinergismos que permitan dosis más bajas de los elementos individuales y disminuir el riesgo de efectos adversos (13). Además, en múltiples casos se ha estudiado la asociación de productos naturales con fármacos hipolipemiantes, en especial estatinas, observándose efectos sinérgicos prometedores y menor aparición de efectos adversos (213-216). 


\section{F. Aceites esenciales}

Muchas de las drogas modernas tienen su origen en la medicina tradicional y se estima que el 25-30 \% de las drogas disponibles en el mercado mundial son provenientes de productos vegetales. En los últimos tiempos, luego de décadas apostando a la química industrial y sintética, en el mundo occidental se ha hecho un retorno a la etnofarmacología y a la búsqueda de sustancias químicas de origen vegetal con las cuales desarrollar medicamentos, elaborar cosméticos y obtener productos para las industrias de bebidas y alimentos (217-219). Hoy se acepta que las plantas, en especial las aromáticas, contienen valiosos compuestos terapéuticos con estructuras químicas muy efectivas que han sido seleccionadas por mecanismos evolutivos durante millones de años (220-222).

Los aceites esenciales (AEs) de plantas aromáticas -pertenecientes fundamentalmente a las familias Apiaceae, Lauraceae, Myristicaceae, Lamiaceae, Asteraceae, Myrtaceae, Rosaceae, Piperaceae, Verbenaceae y Rutaceae (223)tradicionalmente tienen gran utilidad como sustancias medicinales, suplementos alimenticios, perfumería, cosmética y aromaterapia (217). En la actualidad, estos aceites son una de las principales fuentes en la búsqueda de nuevos compuestos con actividad terapéutica.

Los AEs (también llamados aceites volátiles o etéreos) se caracterizan por ser una mezcla compleja de varias sustancias químicas volátiles, pudiendo presentar más de 60 componentes individuales diferentes. Generalmente son líquidos oleosos aromáticos a temperatura ambiente, presentan una densidad menor al agua y son solubles en solventes orgánicos. Debido a su volatilidad son extraíbles del material vegetal por destilación por arrastre de vapor de agua, por hidrodestilación y en el caso de frutas del género Citrus por un proceso mecánico como el prensado en frio (224-226).

Los constituyentes de los AEs pueden agruparse fundamentalmente en dos clases de compuestos: los terpenos o isoprenoides (componentes mayoritarios) y los fenilpropenos o taninos (presentes en escasa concentración). Estos constituyentes provienen fundamentalmente del metabolismo secundario de los vegetales superiores y pueden ser sintetizados por todos los órganos de la planta: flores, hojas, tallo, semillas, frutos o su corteza (pericarpio)(217). Estos metabolitos son almacenados en células secretoras, cavidades, canales, células epidérmicas o tricomas glandulares (como el caso de Lippia alba) 
y están implicados en las diversas interacciones entre las plantas, plantas con animales y/o plantas con microorganismos (227). Las plantas utilizan los componentes de los AEs en la defensa de plagas, de enfermedades, de la invasión de otras plantas, así como en la atracción de insectos y aves (polinizantes). Funcionan también como hormonas, como moléculas de señalización, de expresión de genes, en vías de transducción de señales, transporte de electrones o dentro de la maquinaria fotosintética $(74,228)$.

La composición química del $A E$ depende de numerosos factores, entre los que pueden destacarse: condiciones climáticas, estacionales, geográficas, de crecimiento, lugar de origen, momento de la recolección y técnica de obtención $(217,229)$. Además, la existencia de diversos quimiotipos (variantes químicas intraespecíficas dentro de una misma especie botánica debido a condiciones geobotánicas, fisiológicas y genéticas) (217) pueden afectar drásticamente la composición del mismo (230).

Se han publicado numerosos trabajos donde se evidencia la actividad biológica de los AEs dentro de las que se describen actividad antimicótica (231), antibacteriana (232) y antiviral (233), efecto repelente de insectos (234), antisépticos (235), antioxidante $(236,237)$ y antihiperlipidémicos $(210,233)$. Una de las actividades más estudiadas de los AEs es la antitumoral, tanto a nivel de prevención como de tratamiento $(224,233,238$, 239), atribuida a las capacidades antimutagénicas, antiproliferativas, de inducción de la detoxificación y del sistema inmune y de modulación de la resistencia multidroga, reportadas para muchos de estos aceites.

Al analizar la actividad biológica de los AEs, debe tenerse en cuenta que se trata de una mezcla compleja de numerosas moléculas bioactivas que pueden presentar actividad sinérgica entre ellas $(224,235)$, de modo que sus efectos biológicos no siempre resultan de la simple sumatoria de los efectos individuales de cada constituyente (225).

\section{F.1. Isoprenoides: componentes mayoritarios de los aceites esenciales.}

Los isoprenoides, también conocidos como terpenoides, son los componentes mayoritarios de los AEs de las plantas y los principales responsables de la actividad biológica que presentan estos aceites (236). Estos más de 20000 compuestos derivan de los precursores de 5 carbonos IPP y DMAPP, denominados unidades de isopreno, y son generados en la VM o la vía de la metileritritol-4-fosfato de las plantas, sin poder ser producidos por mamíferos u hongos $(74,240,241)$. Los isoprenoides presentes en plantas se 
clasifican en 2 grupos principales: metabolitos primarios (hormonas, ubiquinona y compuestos relacionados a la fotosíntesis, entre otros) y metabolitos secundarios [monoterpenos (C10), sesquiterpenos (C15), diterpenos (C20), triterpenos (C30), tetraterpenos (C40) y politerpenos (>C40)] $(228,241)$.

Los monoterpenos son los isoprenoides mayoritarios de los AEs, seguido de los sesquiterpenos y en menor cantidad diterpenos (236). Los monoterpenos pueden ser alifáticos, cíclicos o aromáticos, y según los grupos funcionales que tengan se denominan como: alcoholes, fenoles, aldehídos, cetonas, ésteres, éteres e hidrocarburos (236) (Ver Figura 1.13). En el caso de los sesquiterpenos, que es el grupo más diverso de terpenos, también se encuentran componentes acíclicos como los farnesoles y aquellos ciclados dentro de los cuales se encuentran el alfa y el beta-cariofileno.

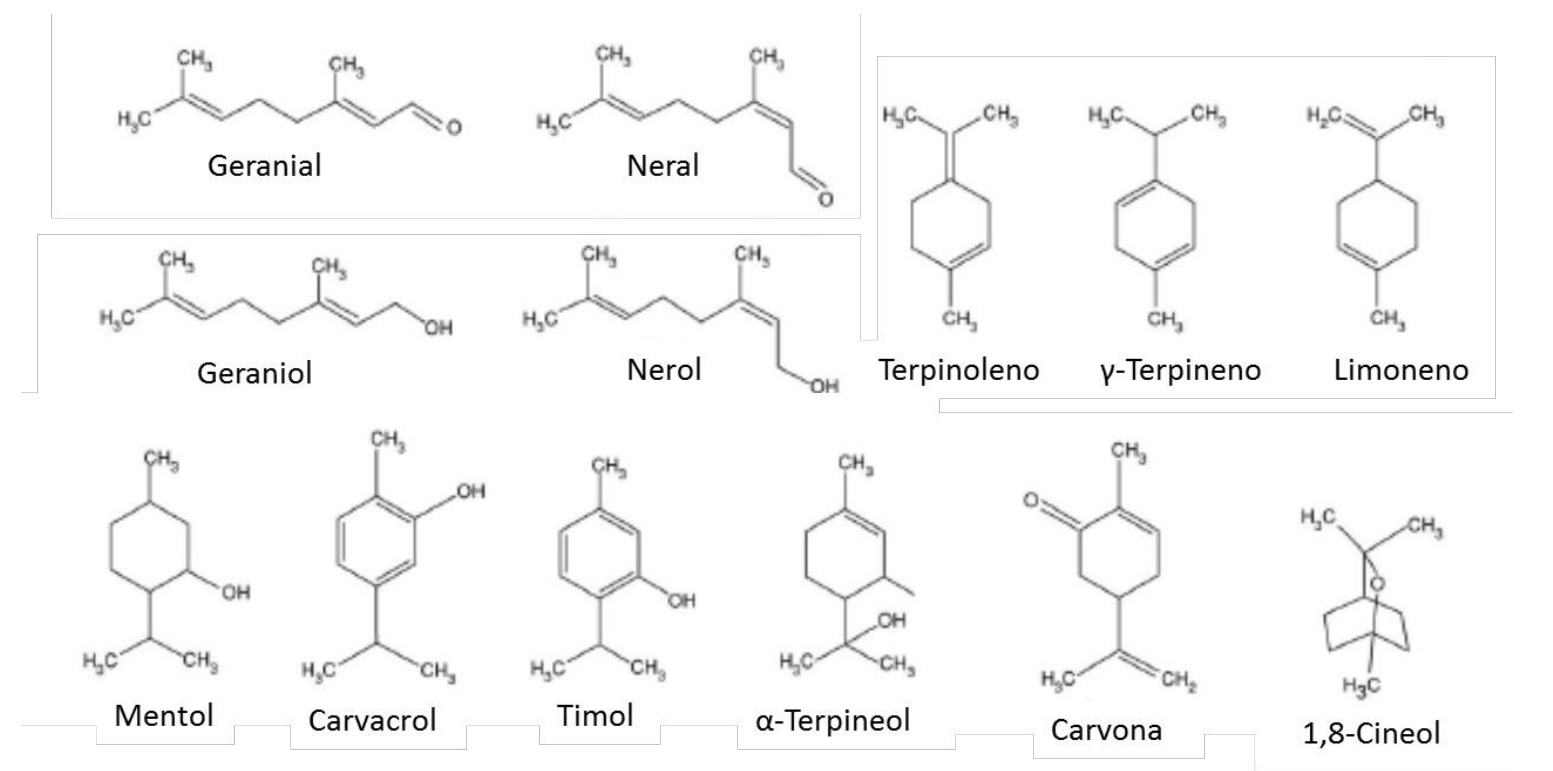

Figura 1.13. Estructura de algunos monoterpenos presentes en aceites esenciales. Tomado de Grassmann (236)

Los monoterpenos presentan diversas actividades biológicas entre las que se destacan: actividad analgésica, ansiolítica, antimicrobiana, antiparasitaria, antioxidante, antiinflamatoria e hipoglucemiante, entre otras $(228,236,240,242,243)$. La amplia exposición de los seres humanos a los monoterpenos, los cuales tienen un alto grado de biodisponibilidad oral, se produce tanto a través de la dieta como del medio ambiente. Están presentes en numerosos alimentos y hierbas, y algunos de ellos son usados como saborizantes de bebidas o aromatizantes de cosméticos, jabones y otros productos de limpieza. 
Diversos monoterpenos tienen la capacidad de ejercer múltiples efectos sobre la VM: inhiben la actividad HMGCR (244), en especial a nivel postranscripcional disminuyendo la velocidad de traducción del $A R N m$ de la reductasa y aumentando la velocidad de degradación de la enzima (245-247); inhiben alguna enzima involucrada en la conversión de lanosterol en colesterol (248-250) e inhiben la isoprenilación de proteínas $(43,251)$, ya sea por disminución de la cantidad de isoprenoides disponibles para realizar esta modificación postranscripcional o interfiriendo a nivel de las farnesil y geranilgeranil transferasas $(42,44$, $113,252,253)$.

Los efectos sobre la VM difieren de un isoprenoide a otro y se han asociado con la actividad antilipogénica observada tanto in vitro (254) como in vivo (255-259). También se ha atribuido a estos efectos, al menos en parte, la actividad antitumoral reportada para muchos monoterpenos, capaces de inhibir la proliferación de diversas líneas neoplásicas in vitro (44, $112,249,260,261)$ y ocasionar la regresión de distintos tumores in vivo (262-268). Numerosos trabajos realizados en modelos animales reportan la actividad antitumoral de distintos monoterpenos, como linalool, 1,8-cineole, geraniol y perillil-alcohol, utilizando dosis para las cuales no se evidencia daño tisular en tejidos normales ni signos de toxicidad en general (269-272). Además, se ha demostrado capacidad quimiopreventiva en presencia de inductores de carcinogénesis como el 7,12-Dimetilbenz(a)antraceno (DMBA) (263) o el NNitrosodietilanima (NDEA) (273) en modelos in vivo.

\section{G. Lippia alba}

Lippia alba (Mill.) N.E. Br. ex Britton \& P. Wilson es una planta que pertenece a la familia Verbenaceae. Esta familia, con gran interés económico como fuente de productos ornamentales y medicinales, incluye cerca de 70 géneros y 2000 especies que se distribuyen en casi todas las regiones del planeta, siendo particularmente abundantes en las regiones tropicales y subtropicales $(274,275)$. Dentro de esta familia, el género Lippia está constituido por cerca de 200 especies, que incluyen hierbas, arbustos y pequeños árboles, encontradas principalmente en América Central, América del Sur y África tropical $(276,277)$.

Lippia alba (Mill.) N.E. Br es una especie originaria del bosque tropical y subtropical americano. Se encuentra ampliamente distribuida en el continente, encontrándose en regiones secas de América del Norte -sur de EUA (Texas) y México-, Centroamérica y el Cono 
Sur, así como en las regiones húmedas del Caribe y de América del Sur, como la región del Amazonas (278). Además, se ha reportado su presencia en otras partes del mundo como India (279), Bangladesh (280) y Australia (281).

Debido a su gran distribución en el continente americano, su nombre vulgar varía según el país donde se encuentre (Ver Tabla 1.3).

Tabla 1.3. Nombres comunes de Lippia alba (Mill.) N.E. Br

\begin{tabular}{l|l}
\hline EUA & Bushy matgrass, bushy Lippia, Oaxaca lemon verbana, melissa \\
México & Hierba del negro, mirto, sonora o mastranto. \\
Guatemala & Salvia santa, salvia sija, orozus \\
Honduras & Juanilama, orégano de monte, salvia santa \\
Nicaragua & Juanilama, guanislama, mastranto \\
Costa Rica & Juanilama \\
Panamá & Oroazul, mastrento \\
Cuba & Quitadolor, menta americana, anís de España, salvia americana, toronjil isleño. \\
Jamaica & Colie mint \\
Colombia & Pronto alivio, cidrón llanero, quita dolor \\
Venezuela & Cidrón \\
Perú & Pampa orégano \\
Brasil & Falsa melissa, erva cidreira; \\
Argentina & Salvia Morada \\
Información adaptada de Hennebelle et al. (282); (278); Linde et al. (295).
\end{tabular}

Es un arbusto aromático ramificado, con largas ramas cuadrangulares que caen al suelo (Ver Figura 1.14 A). Su altura varía de acuerdo con la región, pero puede alcanzar 1,7-2 metros. Las hojas son membranosas, pecioladas y pubescentes, pequeñas $(2-7 \mathrm{~cm})$, aromáticas, de color verde por encima y gris por debajo. Las mismas se disponen de manera opuesta o algunas veces alternada, sus formas pueden ser oblongas, lanceoladas o cuneadas y los bordes aserrados o crenados $(278,282,283)$ (Ver Figura 1.14 D). Sus flores son axilares, generalmente solitarias, color lila pálido, rosado o blanco, de $3-5 \mathrm{~mm}$ y dispuestas en ramas principales, secundarias y terciarias $(275,284)$ (Ver Figura $1.14 \mathrm{C})$. 

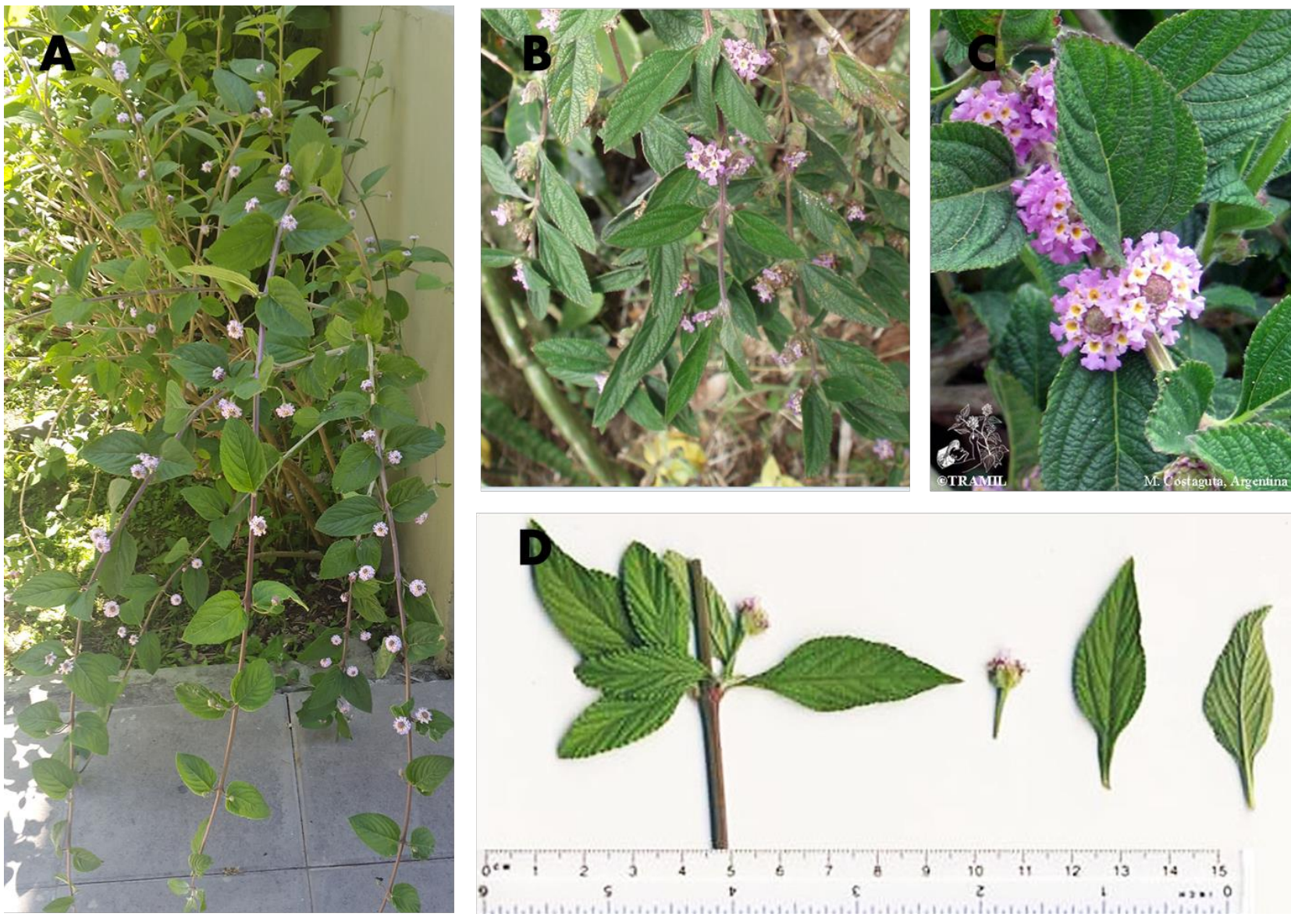

Figura 1.14. Lippia alba (Mill.) N.E. Br. Panel A: Arbusto de L. alba en jardín. La Plata, Buenos Aires. Fuente propia. Panel B: Ramas de planta cultivada en un jardín en San Rafael, Heredia, Costa Rica. Fuente Propia. Panel C: Flores L. alba. Argentina. Tomado de TRAMILoteca (284). Panel D: Tamaño y forma de hojas y flores. Guadeloupe. Tomado de TRAMILoteca (284).

L. alba es una especie perenne que en estado silvestre crece, desde el nivel del mar hasta $1.900 \mathrm{~m}$, en laderas, a la orilla de caminos y riberas de los ríos (283). Sin embargo, debido a la desaparición de la cobertura boscosa, se ha observado el deterioro de poblaciones naturales y actualmente es común que se presente como una planta domesticada en patios y jardines. En varios países se ha empezado a promover su cultivo agrícola que predominantemente se da en forma vegetativa, por estacas, el cual se desarrolla mejor en suelos francos o francos arenosos, entre 15 y $25^{\circ} \mathrm{C}$, y precipitación entre 700 y $1.500 \mathrm{~mm}$ anuales (278). Actualmente se está prestando más atención al desarrollo de cultivos comerciales y a gran escala, debido al potencial económico que tiene esa planta 
como alternativa de extracción de sustancias utilizadas en la industria química y cosmética, así como en el ámbito de la medicina tradicional $(285,286)$.

Gracias a la amplia distribución geográfica de L. alba en nuestro continente y su popularidad en la medicina tradicional, se han reportado múltiples estudios sobre la composición química de los AEs extraídos de ella (287-291). Esta composición puede variar según el origen geográfico, las condiciones de cultivo, la edad, la parte de la planta empleada para la extracción y de algunos otros factores geobotánicos (289). En función de esa variabilidad en la composición química de los AEs se han propuesto diversos quimiotipos de L. alba.

La distribución biogeográfica de los quimiotipos de L. alba, en América y el Caribe, responden en parte a factores ecológicos, que se evidencia por la existencia de quimiotipos por región biogeográfica, y por otra parte a factores genéticos, siendo estos posiblemente más determinantes en la composición química del AE de L. alba que los factores ambientales. Evidencia de esto es que, cuando se cultiva plantas de un quimiotipo en ambientes o condiciones edafoclimáticas diferentes a su zona de origen, la composición del aceite esencial se mantiene conservada $(278,287,291)$.

Para simplificar la distribución de los quimiotipos, Hennebelle et al. propusieron una clasificación para los AEs de L. alba basándose en los componentes mayoritarios, las vías biosintéticas de los terpenos que presentan y las variaciones estacionales, entre otros (287). En la Tabla 1.4 se resumen los quimiotipos. 
Tabla 1.4. Clasificación de quimiotipos de Lippia alba

\begin{tabular}{|c|c|c|c|}
\hline Tipo & Subtipo & Componente mayoritario & Lugares donde ha sido descrito \\
\hline \multirow[t]{4}{*}{1} & la & $\begin{array}{l}\text { Citral (mezcla isómeros neral y } \\
\text { geranial) todo el año }\end{array}$ & $\begin{array}{l}\text { Argentina, Brasil, Colombia, India, } \\
\text { Martinica, Isla Guadalupe, } \\
\text { Curaçao }\end{array}$ \\
\hline & $\mathrm{Ib}$ & Linalool todo el año & Argentina, Uruguay, Brasil, India, \\
\hline & Ic & $\begin{array}{l}\text { Citral o Linalool según época del } \\
\text { año }\end{array}$ & Argentina \\
\hline & Id & $\beta$-cariofileno & Brasil \\
\hline II & & $\begin{array}{l}\text { Tagetenona (mezcla de isómeros } \\
\text { mircenona y ocimenona) }\end{array}$ & $\begin{array}{l}\text { México, Guatemala, Costa Rica, } \\
\text { Argentina. }\end{array}$ \\
\hline \multirow[t]{2}{*}{ III } & IIla & Limoneno y carvona & $\begin{array}{l}\text { Brasil, Colombia, Costa Rica, } \\
\text { Cuba, Perú, Guyana Francesa, } \\
\text { Martinica. }\end{array}$ \\
\hline & IIIb & $\begin{array}{l}\text { Limoneno y alguna de las siguientes } \\
\text { cetonas cíclicas: dihidrocarvona, } \\
\text { piperitona, piperitenona, lippiona. }\end{array}$ & Argentina, Guatemala \\
\hline IV & & Mirceno & Argentina, India \\
\hline $\mathrm{V}$ & & $\checkmark$ - Terpineno & Brasil \\
\hline VI & & Alcanfor, 1,8 cineol & Uruguay \\
\hline VII & & Estragol (metilchavicol) & EUA, México \\
\hline
\end{tabular}

Adaptado de Hennebelle et al. (287); Cicció y Ocampo (275); y (278).

\section{G.1. Usos tradicionales y actividades biológicas del aceite esencial de Lippia alba.}

Los usos que se reportan a lo largo del continente americano para Lippia alba son tan variados como las diversas formas con las que se denomina al arbusto. Lo que generalmente se consume es la infusión de las partes aéreas de esta planta, en especial de hojas y flores; también se puede utilizar en forma de compresas y macerada o en alcohol para realizar fricciones (292). Es comúnmente utilizada para trastornos digestivos o gastrointestinales, como antiespasmódico, antiemético, emenagogo y para la disminución de la distención abdominal (282, 293-295). A nivel respiratorio, es utilizada como un complemento en el tratamiento de infecciones de vías respiratorias superiores, tanto como infusión como en forma de jarabe (282). A nivel cardiovascular se reporta su uso como antihipertensivo y en el tratamiento de niveles elevados de colesterol $(295,296)$. Además, se describe su uso en el 
tratamiento de anemias, cefaleas, de enfermedades reumáticas y, como un macerado, para tratar enfermedades de la piel.

Numerosos estudios realizados utilizando AEs y extractos de L. alba dan cuenta de sus múltiples actividades biológicas. Gran cantidad de ellos refieren a su efecto antimicrobiano, ya sea como antibacteriano (297-300), antiviral (301-303), antifúngico (304306) y antiprotozoario (307-310), siendo los quimiotipos citral y carvona los más estudiados. Además de las propiedades antimicrobianas, se ha demostrado el efecto analgésico y antiinflamatorio de AEs de esta planta (311-313), así como efectos sobre el sistema nervioso central como antimigrañoso (314), anticonvulsivante $(315,316)$, ansiolítico (317) y sedante (318-320).

En relación a las acciones sobre el tracto gastrointestinal, se ha demostrado el efecto anti-ulceroso de la planta (321), así como su capacidad de inhibir el crecimiento de la Helicobacter pylori (322), uno de los principales agentes asociados tanto a úlceras como al cáncer gástrico. Adicionalmente, Blanco et al. (294) han evaluado la acción antiespasmódica de AEs de $L$. alba en duodenos aislados de rata para los quimiotipos citral y linalool.

A nivel cardiovascular se ha observado que AEs de esta planta tienen efecto vasodilatador $(323,324)$ e inhiben la frecuencia cardiaca en corazones aislados (325), eventos que derivarían en una acción hipotensora.

Con respecto al potencial efecto anticancerogénico y quimiopreventivo, se han realizado estudios donde se demuestra la capacidad antioxidante de los AEs de L. alba, tanto in vitro $(280,326-328)$ como in vivo $(329,330)$. Además, se evidenció el efecto antigenotóxico de AEs de quimiotipos citral y carvona, al encontrarse disminución de la inducción de lesiones del ADN de bacterias coincubadas con el mutágeno bleomicina (331). Si bien la actividad citotóxica de los AEs de algunos quimiotipos y sus componentes mayoritarios se ha demostrado en diversas líneas celulares neoplásicas (304, 332-334), la mayoría de estos estudios presentan solo datos preliminares y no describen ningún posible mecanismo de acción.

Es posible pensar que la variedad de usos y actividades biológicas que se han descrito para L. alba estan asociadas a la presencia de diversos quimiotipos, con diferentes composiciones de monoterpenos, iridoides y flavonoides, que presentan a nivel farmacológico esa gran variedad de efectos (296, 335-338). Además, es importante recordar 
que la actividad biológica de un AE no es la simple sumatoria de los efectos individuales de sus componentes pudiendo presentarse sinergismo entre ellos.

Cabe destacar que, si bien puede considerarse que los AEs (ricos en monoterpenos con actividades anticolesterogénicas y antiproliferativas) poseen algunas de las características ideales para actuar como agentes cardioprotectores, quimiopreventivos y quimioterapéuticos (capacidad de inhibir síntesis de colesterol hepática, potencial antitumoral, disponibilidad comercial, bajo costo, biodisponibilidad oral y baja toxicidad), la evaluación de la actividad antitumoral de los AEs de L. alba ha sido escasa y prácticamente no se han estudiado sus efectos sobre el metabolismo lipídico. 


\section{Capítulo}

Hipótesis y Objetivos 


\section{A. Hipótesis}

Los isoprenoides presentes en los aceites esenciales ejercen múltiples efectos inhibitorios sobre la vía del mevalonato que dan por resultado la disminución de la síntesis de colesterol y de la proliferación celular.

La capacidad anticolesterogénica y antiproliferativa depende de la composición de cada aceite, donde los monoterpenos mayoritarios pueden interactuar entre sí o con componentes minoritarios potenciando su actividad biológica.

Los isoprenoides de los aceites esenciales inhiben a la HMG-CoA reductasa a través de mecanismos diferentes del empleado por las estatinas.

El uso combinado de aceites esenciales naturales con estatinas permite incrementar la eficacia antitumoral de ambos compuestos y disminuir la dosis efectiva de las estatinas en el tratamiento de hipercolesterolemias hasta valores en los cuales los efectos secundarios indeseables sean prácticamente nulos.

\section{B. Objetivos generales}

Analizar la utilidad de aceites esenciales en el tratamiento de hipercolesterolemia y prevención y tratamiento del cáncer, estudiando su eficiencia y mecanismos de acción.

Estudiar el potencial sinergismo de aceites esenciales con estatinas como una alternativa para disminuir las dosis efectivas y la probabilidad de efectos indeseados y/o tóxicos de estas últimas.

Aportar conocimientos que resulten útiles en el desarrollo de nuevos compuestos terapéuticos naturales de amplia disponibilidad y bajo costo para la población. 


\section{B.1. Objetivos específicos}

Utilizando células HepG2 (provenientes de un hepatocarcinoma humano) como modelo de célula hepática y células A549 (provenientes de un adenocarcinoma de pulmón humano) como modelo de células extrahepáticas, los objetivos específicos fueron:

1) Estudiar los efectos de aceites esenciales de $L$. alba pertenecientes a 4 quimiotipos diferentes (carvona, citral, piperitona y tagetenona) sobre:

- la proliferación celular, analizando algunos de los mecanismos de acción implicados (alteraciones del ciclo celular e inducción de apoptosis).

- el metabolismo lipídico en general, prestando particular atención a la síntesis de colesterol y de otros lípidos de la vía del mevalonato, analizando los posibles mecanismos involucrados.

2) Evaluar el efecto combinado de aceites esenciales de $L$. alba con simvastatina sobre los parámetros mencionados anteriormente (proliferación y metabolismo lipídico) analizando el posible efecto aditivo o sinérgico en la interacción entre ellos. 


\section{Capítulo}

Materiales y Métodos 


\section{A. Materiales}

\section{A.1. Modelo experimental - Líneas celulares utilizadas}

\section{A.1.1. Células HepG2}

La línea celular HepG2, proveniente de un carcinoma hepatocelular (HCC) extirpado a un varón caucásico de 15 años en 1975, fue obtenida de la American Type Culture Collection (ATCC HB 8065) (Virginia, EUA). Estas células son altamente diferenciadas, comparten muchas de las características genotípicas y fenotípicas de los hepatocitos normales y conservan gran parte de las propiedades bioquímicas de las células del parénquima hepático $(339,340)$. Al igual que en hepatocitos normales, la HMGCR de estas células puede ser regulada tanto a nivel de actividad enzimática (341) como a nivel transcripcional $(246,342)$. Se consideran un sistema útil y confiable para evaluar tanto el metabolismo, como el efecto citoprotector, o citotoxicidad de diferentes químicos y fármacos en el hígado humano (343). También son ampliamente utilizadas como modelo de $\operatorname{HCC}(344,345)$.
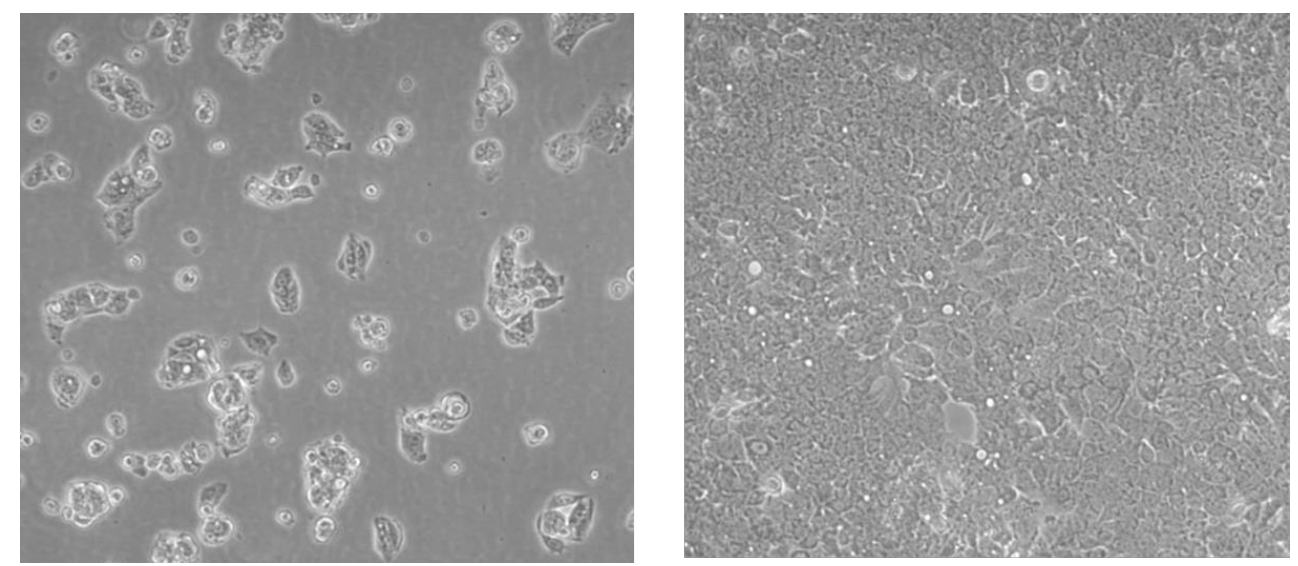

Figura 3.1. Morfología típica de células HepG2 observadas al microscopio óptico en condiciones normales de cultivo. (Izq.) Células HepG2 adheridas a baja confluencia. (Der.) Células a mayor porcentaje de confluencia. Magnificación $400 \mathrm{X}$

\section{A.1.2. Células A549}

La línea celular A549 fue gentilmente donada por la Dra. Amada Segal-Eiras (CINIBA, UNLP, Argentina). Estas células, cuya morfología es de tipo epitelial, provienen de un adenocarcinoma bronco-alveolar de pulmón extirpado de un hombre caucásico de 58 años en 1972 (346). Las células son capaces de sintetizar lecitina y poseen un alto porcentaje de ácidos grasos insaturados, importantes en el mantenimiento de la membrana celular. Es ampliamente utilizada como modelo de célula tumoral pulmonar no pequeña $(347,348)$. 
Presentan una elevada actividad de HMGCR y en ellas la vía del mevalonato puede ser modulada por múltiples productos (349). Al ser un modelo de epitelio alveolar tipo II, se mantiene la batería enzimática necesaria para evaluar el metabolismo oxidativo de drogas en pulmón, por lo que son muy utilizadas para el estudio del metabolismo y direccionamiento de drogas (350).
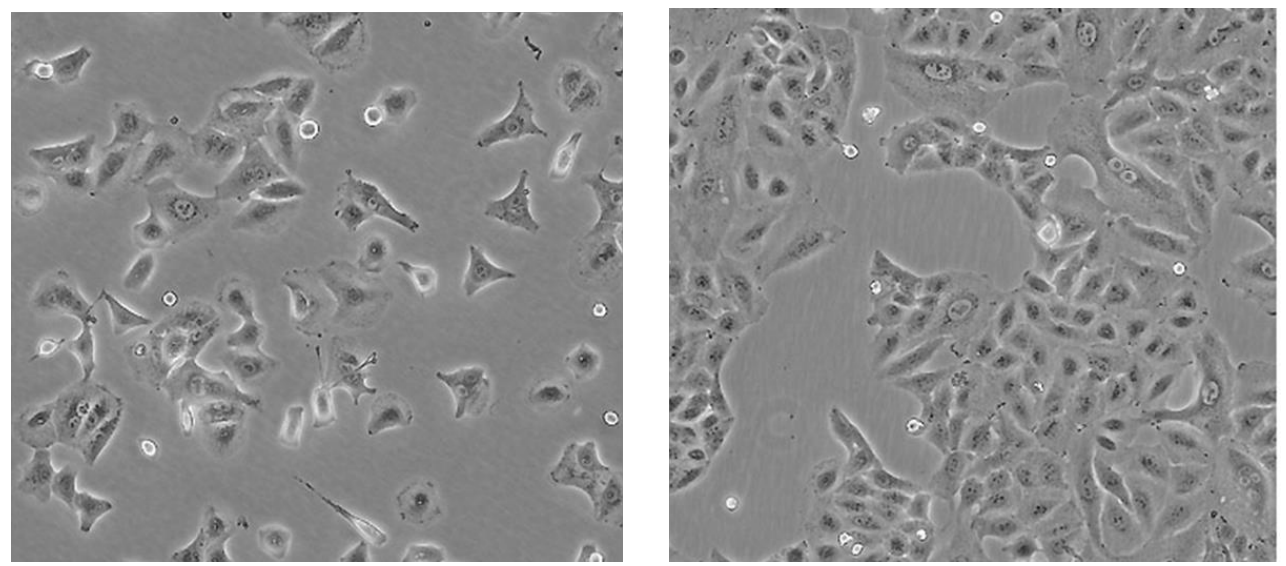

Figura 3.2. Morfología típica de células A549 observadas al microscopio óptico en condiciones normales de cultivo. (Izq.) Células A549 adheridas a baja confluencia. (Der.) Células a mayor porcentaje de confluencia. Magnificación $400 x$

\section{A.1.3. Células Vero}

La línea celular Vero, proveniente de células no tumorales de riñón de mono verde africano Cercopithecus aethiops, fue obtenida de la American Type Culture Collection (ATCC CCL-81). Estas células de morfología epitelial son ampliamente utilizadas como modelo en ensayos de detoxificación, como sustrato para el crecimiento de virus y en especial como modelo de células no cancerosas de mamíferos en ensayos de citotoxicidad y comparativos con líneas celulares tumorales $(302,304,351)$
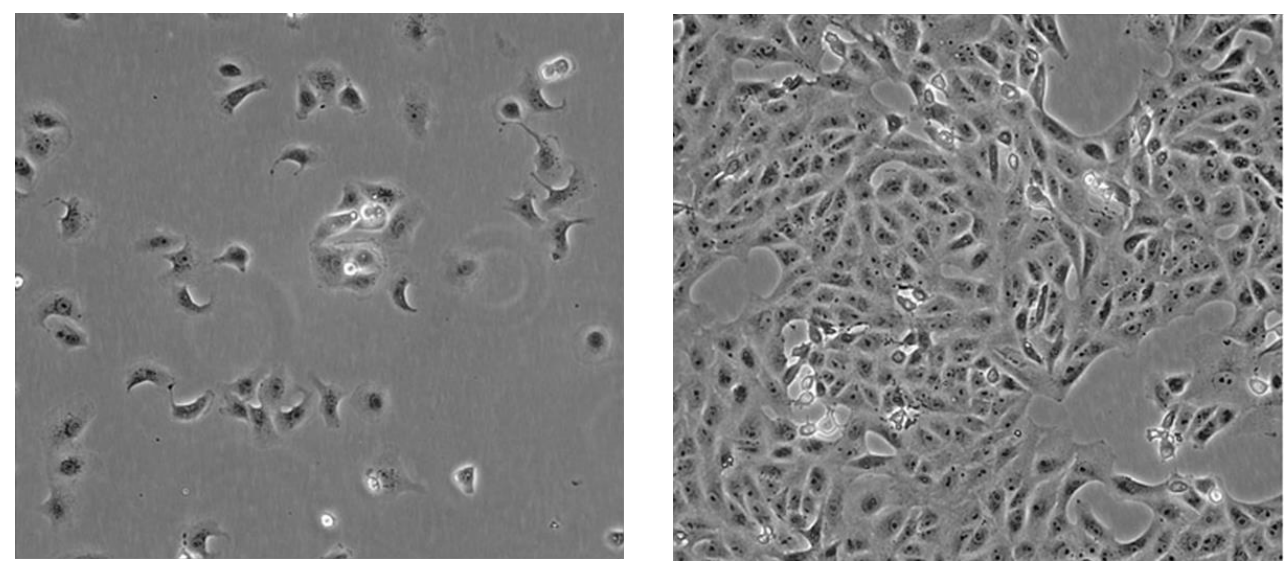

Figura 3.3. Morfología típica de células Vero observadas al microscopio óptico en condiciones normales de cultivo. (Izq.) Células Vero adheridas a baja confluencia. (Der.) Células a mayor porcentaje de confluencia. Magnificación 400X 


\section{A.2. Material vegetal}

El material vegetal fresco se obtuvo de plantas pertenecientes a cuatro quimiotipos (carvona, piperitona, tagetenona y citral) de Lippia alba (Mill.) N.E. Br cultivados en Costa Rica. Las plantas pertenecientes a los quimiotipos carvona (originario de Costa Rica) y piperitona (originario de Argentina) fueron cultivadas en Baltimore, Matina, Provincia de Limón (trópico húmedo de Costa Rica) por Bougainvillea S.A. Las plantas de los quimiotipos tagetenona (originario de Costa Rica) y citral (originario de Argentina) fueron cultivadas en un jardín privado próximo a la ciudad de San José, provincia de San José (en el valle central de Costa Rica). La identificación de las plantas fue realizada por R. Ocampo y J.F. Cicció. Un voucher para cada espécimen se guardó en el Herbario de la Escuela de Biología, Universidad de Costa Rica. (L. alba quimiotipo carvona: USJ 70741, L. alba quimiotipo piperitona: USJ 93918, L. alba quimiotipo tagetenona: y USJ 70698 y L. alba quimiotipo citral USJ 100626).

\section{A.3. Estatina}

Para la evaluación de los efectos de las estatinas, se utilizó como droga modelo a la simvastatina (Sv), una estatina semisintética derivada de un producto de fermentación del Aspergillus terreus. (352). La selección fue realizada atendiendo a que este fármaco es uno de los más ampliamente utilizados en el tratamiento de la hipercolesterolemia, debido a que por su naturaleza hidrofóbica ingresa por difusión simple a través de membranas tanto de hepatocitos como de células no hepáticas (353), y a que es la estatina frecuentemente utilizada en estudios donde se evalúa la capacidad antiproliferativa de este tipo de compuestos en células tumorales (120).

La simvastatina fue proporcionada gentilmente por Merck, Sharp y Dohme (Buenos Aires, Argentina). 


\section{A.4. Drogas varias}

Los reactivos utilizados y su origen se detallan en la siguiente tabla:

\section{Tabla 3.1. Lista de reactivos utilizados.}

\begin{tabular}{|c|c|}
\hline Reactivo & Empresa Proveedora \\
\hline Solventes orgánicos (calidad pro-análisis) & Carlo Erba Reagents (Milán, Italia) \\
\hline Sales inorgánicas & Carlo Erba Reagents (Milán, Italia) \\
\hline Folin- Ciocalteu & Carlo Erba Reagents (Milán, Italia) \\
\hline Tris (hidroximetil) aminometano (Tris) & Carlo Erba Reagents (Milán, Italia) \\
\hline Estándares lipídicos & Sigma-Aldrich (Missouri, EUA) \\
\hline $\begin{array}{l}\text { Bromuro de 3-(4,5-dimetiltiazol-2-il)-2,5- } \\
\text { difenil- tetrazolio (MTT) }\end{array}$ & Sigma-Aldrich (Missouri, EUA) \\
\hline Mevalonolactona $97 \%$ & Sigma-Aldrich (Missouri, EUA) \\
\hline Ácido etilendiaminotetracético (EDTA) & Sigma-Aldrich (Missouri, EUA) \\
\hline Tween-20 & Sigma-Aldrich (Missouri, EUA) \\
\hline Triton X-100 & Sigma-Aldrich (Missouri, EUA) \\
\hline Dodecil sulfato de sodio (SDS) & Sigma-Aldrich (Missouri, EUA) \\
\hline 2-mercaptoetanol & Sigma-Aldrich (Missouri, EUA) \\
\hline Azul de bromofenol & Sigma-Aldrich (Missouri, EUA) \\
\hline Acrilamida y N, N'-metilen-bis-acrilamida & Sigma-Aldrich (Missouri, EUA) \\
\hline 2,5-difeniloxazol (PPO) & DuPont Medical Products (Delaware, EUA) \\
\hline $\begin{array}{l}\text { 1,4-bis-(5-t-butilbezooxazol-2-il)-tiofeno } \\
\text { (POPOP) }\end{array}$ & DuPont Medical Products (Delaware, EUA) \\
\hline$\left[4{ }^{14} \mathrm{C}\right]$ - colesterol $(49,78 \mathrm{mCi} / \mathrm{mmol})$ & Perkin Elmer Life Sciences Inc. (Boston, EUA). \\
\hline $\begin{array}{l}{\left[1-{ }^{14} \mathrm{C}\right] \text {-ácido acético (sal sódica, 55,3 }} \\
\mathrm{mCi} / \mathrm{mmol} \text { ) }\end{array}$ & Perkin Elmer Life Sciences Inc. (Boston, EUA). \\
\hline Rojo neutro (RN) & Anedra (Buenos Aires, Argentina) \\
\hline Azul tripán & Anedra (Buenos Aires, Argentina) \\
\hline Calceína-AM & Invitrogen (California, EUA) \\
\hline loduro de propidio (IP) & Sigma-Aldrich (Missouri, EUA) \\
\hline 4',6-diamidino-2-fenilindol (DAPI) & Thermo Fisher Scientific (Pennsylvania, EUA) \\
\hline Hoechst 33258 & Sigma-Aldrich (S Missouri, EUA ) \\
\hline BODIPY 493/503 & Invitrogen (Buenos Aires, Argentina) \\
\hline
\end{tabular}




\section{B. Metodología}

\section{B.1. Obtención y análisis de los aceites esenciales}

La extracción e identificación de los componentes de los aceites esenciales fue realizada por el M.Sc. José Francisco Cicció Alberti en el Centro de Investigaciones en Productos Naturales (CIPRONA), Universidad de Costa Rica. A continuación se describe brevemente el procedimiento seguido.

\section{B.1.1. Extracción de los aceites esenciales}

Para la extracción de los aceites esenciales de L. alba (AELs), flores y hojas frescas de los quimiotipos carvona (ca), piperitona (pi), tagetenona (ta) y citral (ci) fueron sujetas a hidrodestilación a presión atmosférica durante 3 horas utilizando un equipo de vidrio Clevenger modificado. Los aceites fueron colectados, secados sobre sulfato de sodio anhidro, filtrados y guardados $0-10{ }^{\circ} \mathrm{C}$ en oscuridad hasta su posterior análisis cromatográfico. Luego fueron almacenados a $-20^{\circ} \mathrm{C}$ en la oscuridad hasta ser utilizados en los ensayos.

\section{B.1.2. Análisis cromatográfico de los aceites esenciales.}

Los aceites de los 4 quimiotipos de Lippia alba fueron analizados por cromatografía gaseosa con detector de ionización de llama (GC-FID) y por cromatografía gaseosa acoplada a espectrometría de masa (GC-MS).

\section{B.1.2.1. Cromatografía de gases acoplado a un detector de ionización de llama.}

La GC analítica fue realizada en un cromatógrafo de gases Shimadzu GC-2014 (Kioto, Japón) equipado con un detector de ionización de llama (FID). Se utilizó una columna capilar de sílice fundido MDN-5S (30 m x 0,25 d.i.; grosor de película 0,25 $\mu \mathrm{m}$ ) con recubrimiento interno de $5 \%$ fenil-95 \% metilpolisiloxano (Supelco, Pensilvania, EUA). Las condiciones de operación fueron: gas portador $\mathrm{N}_{2}$, flujo 1,0 $\mathrm{ml} / \mathrm{min}$; programa de temperatura del horno: $60-280{ }^{\circ} \mathrm{C}$ a $3{ }^{\circ} \mathrm{C} / \mathrm{min}, 280{ }^{\circ} \mathrm{C}$ ( $2 \mathrm{~min}$ ); temperatura del puerto de inyección de muestra: 250 ${ }^{\circ} \mathrm{C}$; temperatura del detector: $280{ }^{\circ} \mathrm{C}$; split 1:60. Los datos fueron obtenidos utilizando el software LabSolutions, Shimadzu GC Solution, Chromatography Data System, versión 2.3. Los 
porcentajes de los constituyentes se calcularon mediante integración electrónica del área de los picos del FID sin uso de factor de corrección.

\section{B.1.2.2. Cromatografía de gases acoplada a espectrometría de masas}

El análisis GC-MS fue realizado con un cromatógrafo de gases Shimadzu GC-17A acoplado a un espectrómetro de masa GCMS-QP5050 y utilizando el software CLASS 5000 con las bases de datos Wiley 139 y del National Institute of Standards and Technology (NIST) (EUA). Los análisis fueron realizados utilizando una columna capilar de sílice fundido MDN-5S (30 $\mathrm{m} \times$ 0,25 d.i.; grosor de película 0,25 $\mu \mathrm{m}$ ) con recubrimiento interno de $5 \%$ fenil-95\% metilpolisiloxano. Las condiciones de operación fueron: gas portador He, flujo 1,0 ml/min; programa de temperatura del horno: $60-280{ }^{\circ} \mathrm{C}$ a $3{ }^{\circ} \mathrm{C} / \mathrm{min}$; temperatura del puerto de inyección de muestra: $250{ }^{\circ} \mathrm{C}$; temperatura del detector: $260^{\circ} \mathrm{C}$; voltaje de ionización: $70 \mathrm{eV}$; corriente de ionización $60 \mu \mathrm{A}$; velocidad de barrido 0,5 s sobre un rango de masas de 38-400 amu; split 1:70.

\section{B.1.2.3. Identificación de los constituyentes de los aceites esenciales.}

Los constituyentes de los aceites se identificaron utilizando sus índices de retención (RI) en una columna de tipo DB-5 (354), y por comparación de sus espectros de masas con los publicados en la literatura (355) o de las bases de datos. Con el objetivo de obtener el RI para cada pico, se inyectó 0,1 $\mu \mathrm{l}$ de una mezcla de n-alcanos (mezcla estándar C8-C32; Sigma, Saint Louis, Missouri, EUA) bajo las mismas condiciones experimentales previamente descritas. Para obtener información cuantitativa de la composición se hizo una integración del total del cromatograma (CG-FID), expresado como área-porcentaje.

En la siguiente tabla se muestran los componentes principales de cada aceite: 
Tabla 3.2. Composición en porcentajes de los AEs extraídos de hojas de Lippia alba carvona, piperitona, tagetenona y citral cultivados en Costa Rica.

\begin{tabular}{|c|c|c|c|c|c|c|}
\hline Compuesto & $\mathbf{R I}^{\mathbf{a}}$ & $I A^{b}$ & \multicolumn{4}{|c|}{ Quimiotipoc $^{c}$} \\
\hline & & & ca & pi & ta & ci \\
\hline \multicolumn{7}{|c|}{ Monoterpenos Hidrocarburos } \\
\hline$\alpha$-Pineno & 936 & $1 ; 2 ; 3$ & - & - & 0,6 & - \\
\hline Sabineno & 971 & $1 ; 2$ & - & - & 4,3 & - \\
\hline Mirceno & 990 & $1 ; 2$ & 0,2 & 0,1 & 11,0 & 0,1 \\
\hline Limoneno & 1024 & $1 ; 2 ; 3$ & 13,6 & 9,0 & 2,0 & 0,4 \\
\hline$(E)$ - $\beta$-Ocimeno & 1049 & $1 ; 2$ & 0,1 & 0,1 & 1,9 & 0,2 \\
\hline \multicolumn{7}{|l|}{ Monoterpenos oxigenados } \\
\hline 1,8-cineol & 1033 & $1 ; 2 ; 3$ & - & - & 21,4 & - \\
\hline Linalool & 1096 & $1 ; 2$ & 0,5 & 0,4 & 1,4 & 1,6 \\
\hline Mircenona & 1147 & $1 ; 2$ & - & - & 20,6 & - \\
\hline Citronelal & 1157 & $1 ; 2 ; 3$ & - & - & - & 0,8 \\
\hline Borneol & 1165 & $1 ; 2$ & 0,5 & - & 0,5 & 0,2 \\
\hline trans-Dihidrocarvona & 1200 & $1 ; 2$ & 0,2 & - & - & - \\
\hline Nerol & 1229 & $1 ; 2$ & - & - & - & 3,5 \\
\hline Neral & 1235 & $1 ; 2 ; 3$ & - & - & - & 14,1 \\
\hline (Z)-Ocimenona & 1239 & $1 ; 2$ & - & - & 7,1 & - \\
\hline (E)-Ocimenona & 1243 & $1 ; 2$ & - & - & 11,7 & - \\
\hline Carvona & 1244 & $1 ; 2 ; 3$ & 58,6 & 0,2 & - & - \\
\hline Geraniol & 1252 & $1 ; 2$ & - & - & - & 17,6 \\
\hline Piperitona & 1253 & $1 ; 2$ & 1,5 & 52,4 & 1,9 & - \\
\hline Geranial & 1267 & $1 ; 2$ & - & - & - & 22,9 \\
\hline Piperitenona & 1343 & $1 ; 2$ & 3,0 & 0,8 & - & - \\
\hline \multicolumn{7}{|c|}{ Sesquiterpenos hidrocarburos } \\
\hline$\beta$-Bourboneno & 1388 & $1 ; 2$ & 1,0 & 0,5 & 0,1 & - \\
\hline$\beta$-Cubebeno & 1384 & $1 ; 2$ & 0,1 & 0,2 & 0,2 & 0,2 \\
\hline$\beta$-Elemeno & 1389 & $1 ; 2$ & 0,7 & 0,3 & 0,9 & 1,6 \\
\hline$\beta$-Carofileno & 1421 & $1 ; 2 ; 3$ & 0,3 & 3,0 & 0,9 & 3,7 \\
\hline (Z)- $\beta$-Farneseno & 1442 & $1 ; 2$ & 0,6 & - & - & - \\
\hline$\alpha$-Humuleno & 1453 & $1 ; 2$ & - & 0,2 & - & 0,4 \\
\hline
\end{tabular}




\begin{tabular}{|c|c|c|c|c|c|c|}
\hline Germacreno-D & 1484 & $1 ; 2$ & 10,1 & 1,9 & 3,2 & 4,2 \\
\hline Biciclogermacreno & 1505 & $1 ; 2$ & 0,6 & - & - & 0,2 \\
\hline a-Muuroleno & 1507 & $1 ; 2$ & 0,1 & 3,1 & - & 0,2 \\
\hline Germacreno A & 1511 & $1 ; 2$ & 0,3 & - & - & 0,6 \\
\hline$\delta$-Cadineno & 1525 & $1 ; 2$ & 0,1 & 4,1 & - & - \\
\hline \multicolumn{7}{|c|}{ Sesquiterpenos oxigenados } \\
\hline Neril acetato & 1361 & $1 ; 2$ & - & - & - & 0,3 \\
\hline Geranil acetato & 1381 & $1 ; 2$ & - & - & - & 2,5 \\
\hline epi-Cubebol & 1494 & $1 ; 2$ & - & 0,5 & - & - \\
\hline Cubebol & 1519 & $1 ; 2$ & 0,7 & & & \\
\hline Hedicariol & 1548 & $1 ; 2$ & - & - & 4,2 & - \\
\hline Germacrene D-4-ol & 1570 & $1 ; 2$ & 0,4 & 8,5 & 0,4 & - \\
\hline Óxido de Cariofileno & 1590 & $1 ; 2$ & - & & & 1,2 \\
\hline epi- $\alpha-M u u r o l o l$ & 1642 & $1 ; 2$ & - & 3,1 & - & - \\
\hline$\alpha$-Cadinol & 1652 & $1 ; 2$ & - & 3,4 & - & - \\
\hline \multicolumn{7}{|l|}{ Alifáticos } \\
\hline 6-Metil-5-hepten-2-ona & 982 & $1 ; 2$ & - & - & - & 12,5 \\
\hline
\end{tabular}

Notas: ${ }^{a}$ Índices de retención calculados contra series homologas de $n$-alcanos en una columna de poli(5\% fenil-95\% metilsiloxano). ${ }^{b}$ Método de asignación de identidad: índice de retención en una columna de poli(5 \% fenil-95 \% metilsiloxano) (1); espectro de espectometría de masas (2); estándar (3). 'Quimiotipos de Lippia alba: carvona (ca), piperitona (pi), tagetenona (ta) y citral (ci)

\section{B.2. Obtención de sal sódica de simvastatina}

La sal sódica de simvastatina (forma activa) fue preparada disolviendo la droga en etanol absoluto a la que se le agregó $\mathrm{NaOH} 0,1 \mathrm{M}$ y se incubó a $50{ }^{\circ} \mathrm{C}$ durante 2 horas. Se neutralizó con cantidades equimolares de $\mathrm{HCl}$ hasta $\mathrm{pH}$ 7,2. La sal sódica de simvastatina se disolvió en agua destilada a concentración final de 5 mM (356).

\section{B.3. Cultivo celular}

\section{B.3.1. Condiciones de cultivo celular}

El mantenimiento de las líneas celulares se realizó utilizando técnicas estándar de cultivo celular para células animales $(357,358)$. Las células se cultivaron rutinariamente en placas de $100 \mathrm{~mm}^{2}$ o botellas plásticas de cultivo de $25 \circ 75 \mathrm{~cm}^{2}$ con medio de 
mantenimiento compuesto por medio esencial mínimo de Eagle (MEM) (EMEVE Medios, Buenos Aires, Argentina) suplementado con 0,1 mg/l de estreptomicina (Richet, Buenos Aires, Argentina), $\mathrm{NaHCO}_{3} 2,2 \mathrm{~g} / \mathrm{l}$ y 10 \% de suero fetal bovino (SFB, Natocor, Córdoba, Argentina) (v/v). El medio de cultivo fue esterilizado por filtración en membranas de nylon con un diámetro del poro de 0,22 nm (Osmonics, South Dakota, EUA). La incubación se realizó en una estufa gaseada Forma Scientific (Massachusetts, EUA) a $37^{\circ} \mathrm{C}$ y en atmósfera con $5 \% \mathrm{CO}_{2}$ y $100 \%$ de humedad. Todas las operaciones de cultivo se efectuaron en ambiente estéril en una cámara de flujo laminar Dwyer Instruments (Indiana, EUA).

Las células fueron subcultivadas antes de que los cultivos alcanzaran una confluencia mayor al 90 \% (cada 3-5 días). Para ello, se eliminó el medio de las botellas y se lavó 2 veces con solución tampón fosfato salino (PBS) estéril [137 mM NaCl, 2,7 mM KCl, 8,8 mM Na2HPO4, 1,8 mM KH2PO4]. Luego se separó las células de la superficie por digestión de proteínas de adhesión durante 5-10 minutos con una solución al 0,25 \% de tripsina (SigmaAldrich, Missouri, EUA) en EDTA 1 mM. La tripsinización se detuvo por agregado de MEM con $10 \%$ de SFB y de la suspensión celular resultante se realizó la transferencia a placas y/o botellas estériles en diluciones dependientes del objetivo posterior, ya sea mantenimiento de la línea o experimentación.

Parte de las células fueron almacenadas por crionización en $\mathrm{N}_{2}$ líquido, utilizándose MEM con $20 \%$ de SFB y glicerol al $10 \%$ como agente anticongelante.

\section{B.3.2. Tratamiento de las células}

Dado que las líneas celulares utilizadas tienen diferentes velocidades de crecimiento, el inóculo celular inicial sembrado para los ensayos fue ajustado a una densidad tal que las células alcanzaran la fase de crecimiento exponencial antes de empezar el tratamiento y se mantuvieran en esta fase hasta finalizar el mismo. Las células HepG2, A549 y Vero fueron sembradas de acuerdo a las densidades de 20000, 10000 y 45000 células $/ \mathrm{cm}^{2}$, respectivamente e incubadas en condiciones estándar hasta alcanzar fase exponencial de crecimiento (48 horas).

En los ensayos realizados en este trabajo, salvo que se indique lo contrario, células en fase exponencial de crecimiento fueron tratadas con AEs o Sv adicionados (individualmente o combinados) al MEM con $10 \%$ de SFB durante 24 horas a $37{ }^{\circ} \mathrm{C}$. Luego, el medio fue reemplazado por medio sin suero suplementado con las mismas concentraciones de los 
diferentes compuestos utilizadas antes y las células se incubaron durante otras 24 horas a 37 ${ }^{\circ} \mathrm{C}$.

Los AEs fueron disueltos en dimetilsulfóxido (DMSO) previo a su adición al medio de cultivo, asegurándose que la concentración final de este vehículo en los controles y en los tratamientos no supere el 0,2 \% (v/v). La solución madre de Sv 5 mM se diluyó directamente en el medio de cultivo.

\section{B.4. Viabilidad celular}

\section{B.4.1. Ensayo de MTT}

Este es un ensayo colorimétrico analítico-cuantitativo que se basa en la reducción metabólica del bromuro de 3-(4,5-dimetiltiazol-2-ilo)-2,5-difeniltetrazol (MTT), un compuesto soluble de color amarillento. Por acción de la succinato deshidrogenasa este compuesto se reduce generando formazán, una sal insoluble de color azul-violáceo oscuro que se acumula en las células. Dado que esta reacción solo puede llevarse a cabo en células viables, la cantidad de formazán producido es proporcional al número de las mismas (359, 360).

Las células se incubaron con una solución de MTT $(0,5 \mathrm{mg} / \mathrm{ml}$ en PBS) durante 2-3 horas. Luego del período de incubación se realizó la extracción del sobrenadante y las sales de formazán producidas fueron disueltas en isopropanol/HCl 0,04 M. La lectura de densidad óptica (DO) se realizó en un lector de placas Beckman Coulter DTX 880 Multimode Detector (California, EUA) a $560 \mathrm{~nm}$.

A

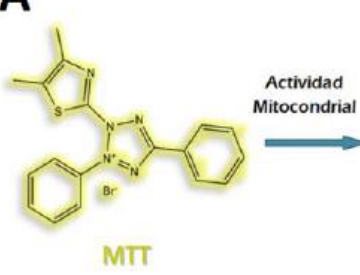

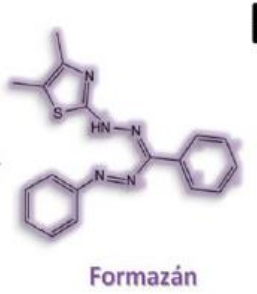

B

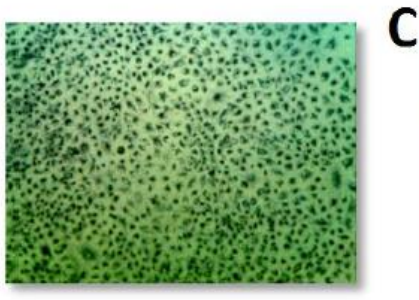

C

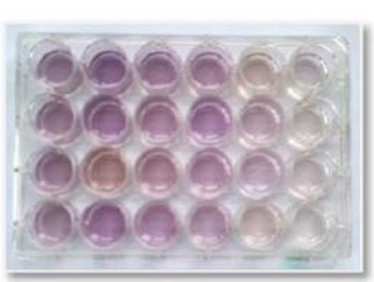

Figura 3.4. Transformación del MTT en formazán. Esta reacción se lleva a cabo a partir de la actividad de las enzimas mitocondriales en células viables. (A) Reacción catalizada por las enzimas mitocondriales. (B) Imagen de células A549 al microscopio óptico (10X) conteniendo el formazán insoluble. (C) El colorante es liberado con una solución ácida de isopropanol y la absorbancia leída a $560 \mathrm{~nm}$. Tomado de Rodenak Kladniew (445). 


\section{B.4.2. Ensayo de captación de rojo neutro.}

Otro método ampliamente utilizado para evaluar la viabilidad celular se fundamenta en la capacidad de las células viables, con compartimento endosomal funcional, de captar el colorante rojo neutro $(\mathrm{RN})$ y almacenarlo en lisosomas. A pH fisiológico, este colorante supravital débilmente catiónico presenta una carga neta cercana a cero, lo que le permite ingresar a las células por difusión simple. En células viables el colorante se concentra en los lisosomas donde, al pH ácido de estas organelas, el $\mathrm{RN}$ presenta carga positiva y se une por enlaces electrostáticos a grupos aniónicos y/o fosfatos de la matriz lisosomal, permaneciendo ahí retenido. El colorante puede ser liberado luego de las células viables utilizando una solución ácida etanólica y la absorbancia de la solución coloreada es medida por espectrofotometría (361).

Las células fueron incubadas durante 3 horas en medio de cultivo conteniendo RN $(0,05 \mathrm{mg} / \mathrm{ml})$. Luego, se extrajo el sobrenadante y se lavaron las células con PBS. El colorante retenido en las células viables se liberó mediante solución de extracción (50 \% etanol en solución acuosa de ácido acético al 2 \%). La absorbancia de las suspensiones coloreadas se midió a 540 nm en lector de placas Beckman Coulter DTX 880 Multimode Detector.

\section{B.4.3. Ensayo de viabilidad/citotoxicidad utilizando calceína-AM/IP.}

La calceína es un colorante polianiónico intensamente fluorescente (fluorescencia verde). Su derivado éster acetoximetilado (calceína-AM; CAM), que no es fluorescente, puede difundir libremente a través de la membrana al interior celular. Una vez que la sonda ingresa, la actividad de las enzimas esterasas citoplasmáticas (únicamente activas en células vivas) transforma la CAM en calceína que queda atrapada en el interior celular. La fluorescencia verde uniforme en células vivas es cuantificable dentro del espectro de emisión 495 nm- excitación $515 \mathrm{~nm}$ (362). En comparación con otros indicadores de esterasas, CAM genera mucha fluorescencia, tiene reducido blanqueamiento, reducida salida y es insensible a cambios de pH entre 5,5 y 10 (363).

El ioduro de propidio (IP) es excluido en células vivas con membrana plasmática integra. Al perderse la integridad de la membrana se pierde la estructura de la célula, el contenido intracelular, los gradientes iónicos y el potencial eléctrico siendo la muerte celular el resultado inevitable. EI IP entra en células muertas, se intercala en los ácidos nucleicos, 
especialmente de doble cadena, y su fluorescencia se incrementa 40 veces produciendo una fluorescencia brillante roja medible a 495nm de emisión, $635 \mathrm{~nm}$ de excitación. En este ensayo la fluorescencia de fondo es realmente baja porque los colorantes son virtualmente no fluorescentes previo a la interacción con células.

Las sondas fueron adicionadas a los cultivos celulares en cantidades que permitieron obtener concentraciones finales de CAM $2 \mu \mathrm{M}$ y de IP $4 \mu \mathrm{M}$. Se incubó durante 30 minutos a $37^{\circ} \mathrm{C}$, al resguardo de la luz, y se lavaron las células con medio de cultivo fresco. El número de células CAM (vivas) y IP (muertas) positivas se determinó por microscopía de florescencia empleando el filtro B/G (emisión 460-495 nm y 530-550 nm, excitación 510 nm y 575 nm) de una magnificación de 400X, utilizando el microscopio invertido Olympus IX71 (Tokio, Japón) que posee acoplado una cámara de fotos Olympus DP70 CCD. Se tomaron imágenes de 5 campos que presentaran de 200/300 células. Las imágenes se analizaron utilizando el software de análisis de imágenes Image J versión 1.48 [National Institute of Health (NIH), EUA] (364).

Además se escaneó la fluorescencia superficial para cada colorante en el lector de placas Beckman Coulter DTX 880 Multimode Detector con filtros $485 \mathrm{~nm}-535 \mathrm{~nm}$ para CAM y $535 \mathrm{~nm}-595 \mathrm{~nm}$ para IP.

\section{B.5. Conteo de células}

El conteo de células totales se realizó en cámara de Neubauer, un portaobjetos especializado de superficie y profundidad conocidas que posee una retícula grabada con láser, de modo que permite cuantificar número de células por unidad de volumen (hemocitómetro, Figura 3.5). Para visualizar las células muertas se utilizó el colorante azul tripán, un colorante derivado de la toluidina, que no es captado por las células viables pero que sí ingresa en las células muertas debido a una alteración de la membrana plasmática $(365,366)$.

Las células fueron despegadas de la superficie de adhesión por tripsinización (como se describe en el ítem 3.B.3.1.) y una alícuota de la suspensión celular obtenida se mezcló con una solución de azul tripán 0,4 \% (v/v) en PBS (generalmente en proporciones 1:2). Con la mezcla se cargó la cámara y se realizó el recuento de las células totales observadas al microscopio óptico modelo Carl Zeiss 2064189 (Oberkochen, Alemania), tanto las que 
incorporaron el colorante como las que no, procurando que el número de células por cuadrante de $4 \times 4$ no supere las 50 unidades.

En caso contrario, se procedió a realizar una mezcla de proporciones 1:3 o 1:4 hasta lograr dicho propósito.
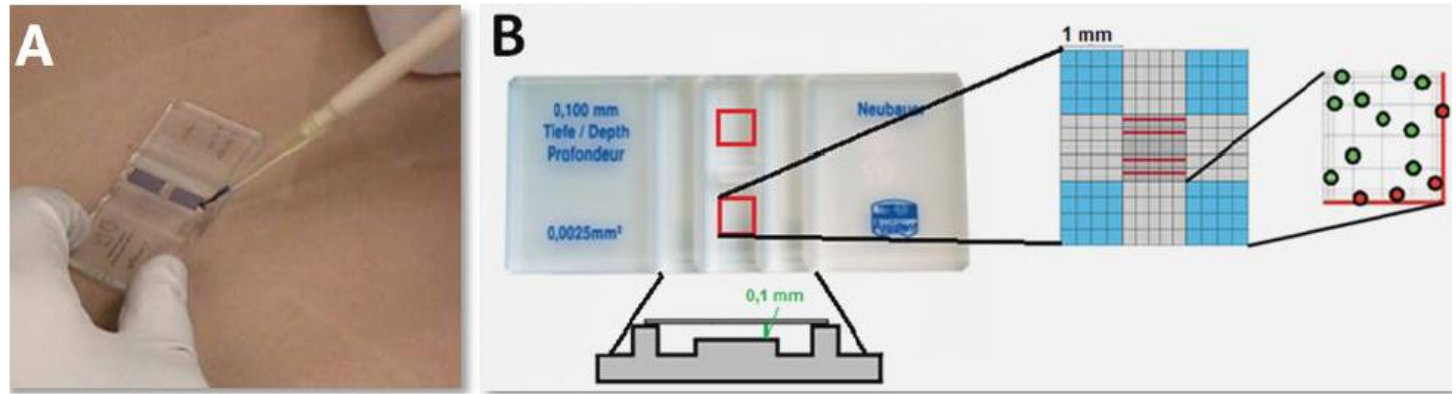

Figura 3.5. Metodología utilizada para recuento celular. La mezcla de la suspensión celular y solución de azul tripán se coloca en la cámara de Neubauer (A). Luego de 1-2 minutos se observa al microscopio y se cuenta el número de células totales presentes en cada cuadrante (en celeste) de los 8 cuadrantes que posee el hemocitómetro (B), y se calcula el promedio de los mismos. Tomado de Rodenak Kladniew (445).

\section{B.6. Análisis del ciclo celular por citometría de flujo}

El ciclo celular se estudió por medición del contenido celular de ADN en un solo punto de tiempo (single time-point measurement). La tinción del ADN se realizó con IP, basado en el hecho de que el IP se incorpora de manera proporcional a la cantidad de ADN presente en la célula, la cual depende de la fase del ciclo en la que se encuentre (G0/G1, S o G2/M). La cantidad de IP presente en cada célula individual puede ser cuantificada por citometría de flujo, permitiendo determinar la proporción de células de una población que se encuentran en cada una de las fases del ciclo celular (367).

Las células fueron tripsinizadas, recolectadas en tubos cónicos tipo Falcon de $15 \mathrm{ml}$, lavadas con PBS, centrifugadas a $300 \mathrm{xg}$ en centrifuga Presvac DCS 16 RVT Plus (Buenos Aires, Argentina) y resuspendidas en PBS frío para lograr una suspensión de $10^{6}$ células $/ \mathrm{ml}$. Las células se fijaron por agregado gota a gota de etanol $70^{\circ}$ frío ( 9 partes de etanol por cada parte de suspensión celular) con agitación moderada en agitador vorticial, para evitar la formación de agregados, y luego se mantuvieron a $4{ }^{\circ} \mathrm{C}$ por lo menos 4 horas. En caso de no hacerse el análisis en el mismo día, la suspensión de células fijadas se almacenó a $-20{ }^{\circ} \mathrm{C}$.

Para el análisis, las células fueron centrifugadas a 800 xg durante 10 minutos a $4{ }^{\circ} \mathrm{C}$, se eliminó el sobrenadante, se resuspendieron en $3 \mathrm{ml}$ de PBS y se incubaron durante 15 
minutos a temperatura ambiente $\left(\mathrm{T}^{\circ} \mathrm{A}\right)$ para su rehidratación. Después de una nueva centrifugación, se eliminó el sobrenadante y el pellet celular se resuspendió en $500 \mu l$ de una solución de IP/RNasa A [IP 25 mg/ml, RNasa A 100 U/ml, Triton X-100 0,1% (v/v) en PBS] (Biodinamics, Buenos Aires, Argentina) y se incubó durante al menos 30 minutos a $\mathrm{T}^{\circ} \mathrm{A}$ en oscuridad. Las muestras se analizaron en un citómetro de flujo FACS Aria II (BD Biosciences, New Jersey, EUA) y los resultados fueron procesados con el software Flow Jo 7.6.2 (Tree Star, Oregon, EUA).
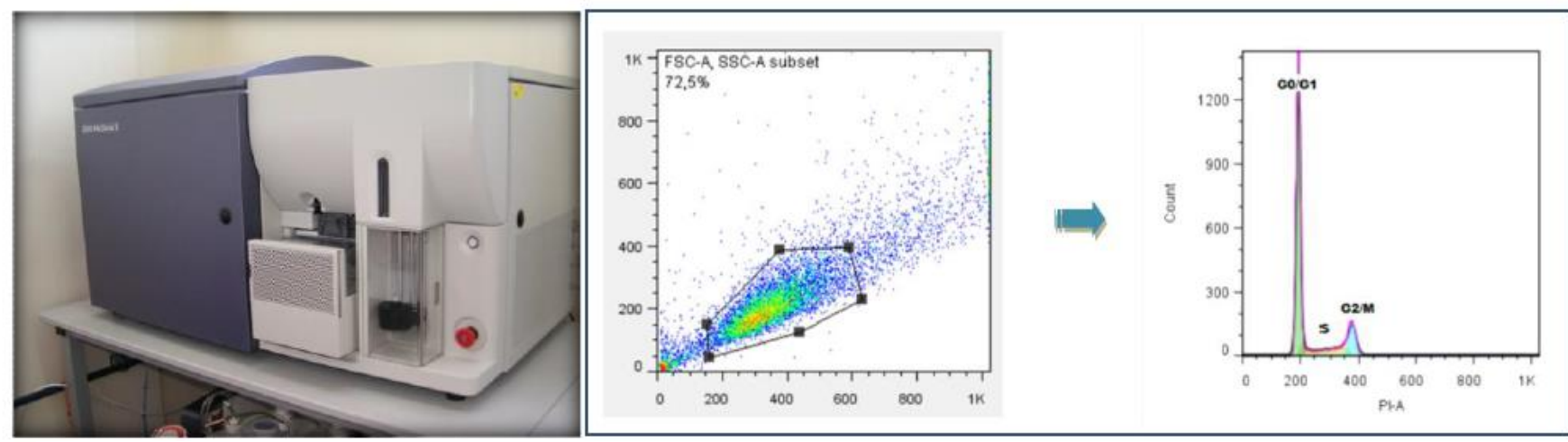

Figura 3.6. Análisis del ciclo celular. Las muestras se analizaron en un citómetro de flujo FACS Aria II y los resultados se procesaron con el software Flow Jo 7.6.2.

\section{B.7. Detección de apoptosis}

\section{B.7.1. Marcaje in situ del ADN fragmentado o ensayo de TUNEL.}

La valoración de la apoptosis por el método de marcaje in-situ o técnica de TUNEL (TdT-mediated dUTP nick end labeling) tiene su fundamento en la detección de la rotura de ADN internucleosomal, característico de este tipo de muerte celular programada (368). Durante la apoptosis, por acción de las endonucleasas, se generan gran número de pequeños fragmentos de ADN con extremos 3'-OH libres. Por medio de la enzima desoxinucleotidil transferasa terminal (TdT) se adosan deoxinucleotidos trifosfato (dUTP) marcados con el fluorocromo rodamina a estos fragmentos, lo que permite observar los núcleos apoptóticos por microscopia de fluorescencia (369).

Las células, cultivadas sobre cubreobjetos de vidrio contenidos en placas de 6 pocillos, fueron lavadas 2 veces con PBS y fijadas con $1,5 \mathrm{ml}$ de una solución de paraformaldehído al $4 \%(\mathrm{v} / \mathrm{v})$ en PBS durante 1 hora a $\mathrm{T}^{\circ} \mathrm{A}$. Luego de 3 lavados con $2 \mathrm{ml}$ de PBS durante 10 minutos, se agregaron $1,5 \mathrm{ml}$ de solución de permeabilización [Triton X-100 
0,1 \% (v/v) y citrato de sodio 0,1\% (p/v) en PBS], se colocó a $4^{\circ} \mathrm{C}$ durante 2 minutos y se lavó nuevamente 3 veces con PBS. Como control positivo de la reacción se incubó una de las muestras control ya fijadas con DNasa (Fermentas, Massachusetts, EUA) durante 30 minutos a $37{ }^{\circ} \mathrm{C}$, se detuvo la reacción por adición de solución de EDTA 0,5 M y se lavó con PBS. Finalmente se incubaron todas las muestras durante $1 \mathrm{~h}$ a $37{ }^{\circ} \mathrm{C}$ con la enzima y los dUTP marcados provistos por el kit comercial para detección in situ de muerte celular (Roche, Mannein, Alemania) según las instrucciones del vendedor. Al terminar la reacción, los cubreobjetos se lavaron nuevamente con PBS y se montaron en medio de montaje con el colorante fluorescente diclorhidrato de 4',6-diamidino-2-fenilindol (DAPI). Este colorante fluorescente al unirse selectivamente al ADN de doble cadena, por intercalación, permite funcionar como marcador nuclear.

Las células TUNEL positivas se observaron utilizando el microscopio de fluorescencia Olympus BX51 (Tokio, Japón), adosado a una cámara digital Olympus DP70. Para la cuantificación, se tomaron aleatoriamente imágenes (a un aumento de 400X) de diez campos para cada tratamiento y se analizaron con el software Image Pro Plus versión 5.1 (Media Cynernetics, Massachusetts, EUA). La proporción de células apoptóticas se determinó calculando el número de núcleos apoptóticos (TUNEL positivos) respecto de los núcleos totales (teñidos con DAPI).

\section{B.7.2. Observación de morfología nuclear mediante microscopía de fluorescencia.}

La morfología nuclear fue analizada por microscopía de fluorescencia luego de una doble tinción del ADN con Hoechst 33328 (fluorescente azul) e IP (fluorescente rojo). EI Hoechst 33258 es un colorante de ácidos nucleicos que atraviesa libremente las membranas celulares y es usualmente utilizado para identificar condensación y fragmentación de la cromatina por tinción de los núcleos condensados de las células apoptóticas. EI IP es un colorante de ácidos nucleicos que no atraviesa libremente las membranas celulares y por lo tanto solo puede teñir núcleos de células deterioradas, en situaciones en las que hay un aumento en la permeabilidad y/o pérdida de integridad de la membrana de plasma.

Las células cultivadas sobre cubreobjetos de vidrio contenidos en placas de 6 pocillos fueron lavadas 2 veces con PBS, se agregó MEM con la solución de tinción Hoechst 33328 (5 $\mu \mathrm{g} / \mathrm{ml}$ ) y se incubaron a $37{ }^{\circ} \mathrm{C}$ durante 20 minutos. Posteriormente se realizó una contratinción incubando las células con IP $(25 \mu \mathrm{g} / \mathrm{ml})$ en oscuridad a $4{ }^{\circ} \mathrm{C}$ durante 15 
minutos. Finalmente, las células fueron lavadas con PBS dos veces y observadas bajo el microscopio de florescencia Olympus BX51 adosado a una cámara digital Olympus DP70 a 400X de magnificación (370).

Para el análisis cuantitativo, las células se separaron en 4 categorías: Viable/normal (VN) [cromatina azul con estructura organizada], Viable/apoptótico (VA) [cromatina azul brillante que está altamente condensada o fragmentada], No viable/normal (NVN) [cromatina roja sin características nucleares apoptóticas] y No viable/apoptótico (NVA) [cromatina roja condensada o fragmentada]. Se contaron al menos 200 células por campo. Los porcentajes de células apoptóticas y necróticas fueron determinadas de acuerdo a la siguiente fórmula (371):

Porcentaje de células apoptóticas $=\frac{\mathrm{VA}+\mathrm{NVA}}{\mathrm{VN}+\mathrm{VA}+\mathrm{NVA}+\mathrm{NVN}} \mathrm{X} 100$

Porcentaje de células necróticas $=\frac{\text { NVN }}{V N+V A+N V A+N V N} \times 100$

\section{B.8. Análisis lipídico}

\section{B.8.1. Extracción de lípidos totales.}

Los lípidos totales (LT) presentes en las células se extrajeron por el método de Folch (372). Para ello, se eliminó el medio de las botellas, se lavaron las células con PBS y por raspado con espátula de silicona se obtuvo una suspensión celular en PBS. Se separó una alícuota para determinación de proteínas y el resto de la suspensión se centrifugó a 500 xg por 10 minutos en centrífuga Presvac DCS 16 RVT Plus, se descartó el sobrenadante y se obtuvo el pellet celular.

El pellet celular se puso en contacto con la mezcla de solventes de extracción [cloroformo: metanol en relación $2: 1 \mathrm{v} / \mathrm{v}$ ] y se dejó a $4{ }^{\circ} \mathrm{C}$ durante toda la noche. Luego se agregó un 20 \% de su volumen de agua, se agitó y se dejó en reposo para permitir la separación de las fases acuosa (metanólica) y orgánica (clorofórmica). Se descartó la fase acuosa por succión. La fase clorofórmica, con el extracto lipídico, se filtró con papel de filtro en presencia de $\mathrm{Na}_{2} \mathrm{SO}_{4}$ anhidro recogiéndose en tubos cónicos con tapa esmerilada. Los tubos fueron gaseados con nitrógeno y almacenados a $-20^{\circ} \mathrm{C}$ para su posterior análisis. 


\section{B.8.2. Separación de lípidos neutros}

Los lípidos neutros (LN), presentes en los LT, se separaron por cromatografía en capa fina (TLC), utilizando, como fase estacionaria, placas de vidrio de $20 \times 20 \mathrm{~cm}$ recubiertas con 0,25 mm de silicagel G 60 (Merck, Darmstadt, Alemania). Las placas se activaron previamente durante 1 hora a $120^{\circ} \mathrm{C}$. Se utilizó como fase móvil una mezcla compuesta de éter de petróleo, éter etílico y ácido acético en proporciones 80:20:1 (v/v/v) (373). Los lípidos se separaron en función de su polaridad, los más polares son afines a la fase estacionaria (agua retenida en la placa de sílica) y los menos polares son afines a la fase móvil. La fracción correspondiente a lípidos polares (LP), como los fosfolípidos (FL), permaneció en el punto de siembra, mientras que los $L N$, como colesterol libre $(C L)$, triacilglicéridos (TAG) y colesterol esterificado (CE), corrieron en mayor o menor medida con la fase móvil según su polaridad. Finalizada la cromatografía, las placas desarrolladas y secas se expusieron a una atmósfera de vapores de yodo en una cuba que contenía yodo bisublimado. El yodo forma complejos inespecíficos color pardo con compuestos orgánicos de manera reversible, lo que permite la localización de las distintas especies lipídicas comparando con los estándares que se siembran en forma simultánea en la placa.

\section{B.8.3. Cuantificación de lípidos neutros y fosfolípidos}

Los niveles de $\mathrm{CL}, \mathrm{CE}$, TAG y FL se cuantificaron a partir de los diferentes métodos detallados a continuación. El contenido de los diferentes lípidos se normalizó en función de la proteína celular total (PCT) correspondiente.

\section{B.8.3.1. Cuantificación de triacilglicéridos}

La sílica de la zona correspondiente a los TAG fue raspada de la placa y extraída con cloroformo. El extracto clorofórmico se centrifugó a 500 xg para precipitar la sílica y se evaporó a seco con corriente de $\mathrm{N}_{2}$. Los TAG así extraídos se cuantificaron colorimétricamente utilizando un kit enzimático (Wiener Lab, Rosario, Argentina), basado en la cuantificación del glicerol liberado por la acción de una triacilgliceridolipasa. Los cálculos se efectuaron mediante un coeficiente de calibración obtenido de la pendiente de una curva 
construida a partir de estándares de trimiristina $(10-100 \mu \mathrm{g})$ tratados de manera idéntica que las muestras.

\section{B.8.3.2. Cuantificación de fosfolípidos}

Los FL se cuantificaron midiendo el contenido de fósforo en la muestra mediante el método de Chen (374). Se raspó la sílica del punto de siembra de la TLC, conteniendo los FL, y se recogió en tubos de mineralización. Las muestras se mineralizaron con $\mathrm{HClO}_{4} 70$ \% (p/v) a $160{ }^{\circ} \mathrm{C}$ hasta cenizas blancas. El fósforo inorgánico (Pi) liberado por este procedimiento se cuantificó mediante una reacción colorimétrica en presencia de molibdato de amonio $\left[\left(\mathrm{NH}_{4}\right)_{2} \mathrm{MoO}_{4}\right.$ 0,44 \% p/v en $\mathrm{H}_{2} \mathrm{SO}_{4}$ al 2,8 \% v/v] y ácido ascórbico $10 \%$ (p/v) que se desarrolló a $45^{\circ} \mathrm{C}$ durante 20 min. Esta reacción genera la formación de un complejo entre el $\mathrm{Pi}$ y $\mathrm{MoO}_{4}$ color verde-azulado, que fue determinado colorimétricamente a $820 \mathrm{~nm}$. Los cálculos se realizaron construyendo una curva de calibración con estándares de $\mathrm{KH}_{2} \mathrm{PO}_{4}$ tratados de manera idéntica a las muestras.

\section{B.8.3.3. Cuantificación de colesterol libre y esteres de colesterol}

Las bandas correspondientes a colesterol libre y esterificado fueron reveladas aplicando en forma de spray una solución ácida de cloruro férrico con posterior carbonización a $220^{\circ} \mathrm{C}$ (375). La aparición de coloración rojo-violácea indica la presencia de CL y CE (373). La intensidad de las manchas se cuantificó utilizando el software de análisis de imágenes Image J versión 1.48. La cantidad de CL y CE se calculó utilizando un coeficiente de calibración obtenido de la pendiente de una curva construida a partir de estándares de $\mathrm{CL}$ (4-10 $\mu \mathrm{g}$ ) y CE (colesteril-palmitato, $2-8 \mu \mathrm{g}$ ) resueltas en la misma TLC que las muestras.

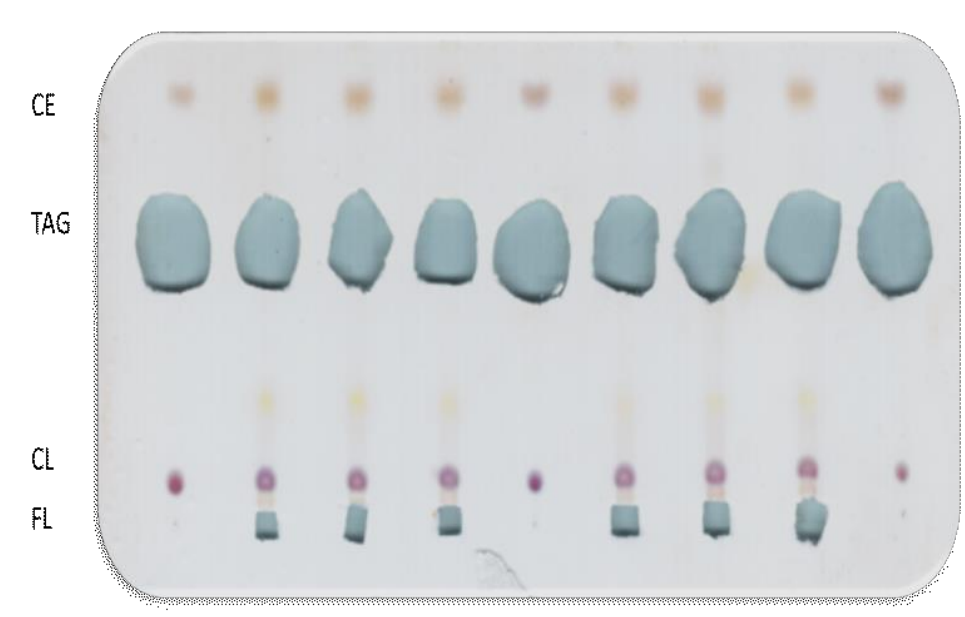

Figura 3.7. Determinación de contenido de lípidos en células HepG2 y A549. Se extrajeron LT que posteriormente fueron resueltos por TLC. El CL y CE presente en las placas se reveló aplicando una solución ácida de cloruro férrico en forma de espray sobre la placa con posterior carbonización a $180{ }^{\circ} \mathrm{C}$ para luego cuantificarse por densitometría. Los TAG se determinaron por un kit comercial y los FL por el método de Chen. 


\section{B.8.4. Extracción de ácidos grasos y lípidos insaponificables}

La obtención de los lípidos insaponificables (LI) y los ácidos grasos (AGs) totales requiere la saponificación previa de las muestras tratándolas con álcali para hidrolizar los AGs de los ésteres de colesterol, acilglicéridos, glicerofosfolípidos y esfingolípidos. Para ello, se agregó una solución de $\mathrm{KOH}$ al 10 \% (p/v) en metanol a alícuotas de LT evaporadas a seco, se gasearon con $\mathrm{N}_{2}$ para evitar oxidaciones y se calentaron en tubos de vidrio cónicos tapados a $80^{\circ} \mathrm{C}$ durante 1 hora. Los LI se extrajeron por agitación de la fase alcohólica con 2 $\mathrm{ml}$ de hexano, repitiendo esta operación tres veces. Los LI fueron trasvasados a tubos esmerilados para su posterior análisis, y la fase metanólica se acidificó con $\mathrm{HCl}$ para desplazar el equilibrio hacia la formación de AGs, los cuales fueron extraídos por agitación con $2 \mathrm{ml}$ de hexano repitiéndose la operación tres veces (373).

\section{B.8.4.1. Composición de ácidos grasos por cromatografía gas-líquido}

La composición de AGs se determinó por cromatografía gas-líquido (GLC) de los respectivos ésteres metílicos. Los AGs libres provenientes de la saponificación de los LT se metilaron de acuerdo a la metodología desarrollada por Morrison y Smith (376). Para ello, las muestras se colocaron en tubos de vidrio con tapa esmerilada y fueron evaporadas a seco; se les agregó $\mathrm{BF}_{3} 10 \% \mathrm{p} / \mathrm{v}$ en metanol, se gasearon con $\mathrm{N}_{2}$ y se calentaron a $80^{\circ} \mathrm{C}$ durante $45 \mathrm{~min}$. Una vez que los tubos estuvieron fríos se realizaron tres extracciones con hexano. Los ésteres metílicos de ácidos grasos (EMAGs) se conservaron a $-20{ }^{\circ} \mathrm{C}$, bajo atmósfera de $\mathrm{N}_{2}$, hasta el momento de ser utilizados.

Los EMAGs se analizaron en un cromatógrafo gas-líquido Hewlett Packard modelo 6890 (Willmingtone, Delaware, EUA) con FID. Las muestras fueron inyectadas en una columna capilar Supelco 11090-02, con relleno OMEGA WAX, de $30 \mathrm{~m} \times 0.25 \mathrm{~mm}$ d. i. x 0,25 $\mu \mathrm{m}$ film. La temperatura fue programada para obtener un aumento lineal de $3^{\circ} \mathrm{C} / \mathrm{min}$ desde $175^{\circ} \mathrm{C}$ a $230{ }^{\circ} \mathrm{C}$; el gas portador fue helio a $1.0 \mathrm{ml} / \mathrm{min}$ de flujo constante.

El método de identificación de los EMAGs se basó en los tiempos de retención relativos de cada $A G$ respecto al tiempo de retención del ácido esteárico (18:0), comparando estos con los de una mezcla de estándares de EMAGs conocidos procesados por el mismo método. 


\section{B.9. Incorporación de ${ }^{14} \mathrm{C}$-acetato en lípidos.}

Las células fueron incubadas durante 3 horas en presencia ${ }^{14} \mathrm{C}$-acetato $(1 \mu \mathrm{Ci} / \mathrm{ml})$ adicionado al medio de cultivo sin suero. Luego se descartó el medio, se lavaron las células repetidas veces con PBS y se extrajeron los LT con una mezcla de hexano: isopropanol (3:2 v/v) durante 30 minutos en agitación moderada, se realizó dos veces esta operación, recolectándose la solución con los LT en tubos con tapa esmerilada (377). El pellet celular remanente se disolvió en una solución alcalina $\left[\mathrm{Na}_{2} \mathrm{CO}_{3} 2 \%\right.$ en $\mathrm{NaOH} 0,1 \mathrm{M}$, tartrato de $\mathrm{Na}$ y $\mathrm{K} 2 \%$ en $\mathrm{H}_{2} \mathrm{O}$ y $\mathrm{CuSO}_{4} 1 \%$ en $\mathrm{H}_{2} \mathrm{O}(100: 1: 1, \mathrm{v} / \mathrm{v} / \mathrm{v})$ ] para la determinación de PCT. La fracción orgánica conteniendo los LT se transvasó a tubos de vidrio con tapa esmerilada, se evaporó completamente el solvente bajo corriente de $\mathrm{N}_{2}$ y se resuspendieron los LT en $1 \mathrm{ml}$ de cloroformo. Se tomó una alícuota de $10 \mu \mathrm{l}$ a la que se le agregó 2,5 ml de líquido de centelleo para determinar la radiactividad total incorporada en los LT, utilizando un contador de centelleo Wallac 1214 Rackbeta liquid scintillation counter (Pharmacia, Turku, Finland).

\section{B.9.1. Cuantificación de ${ }^{14} \mathrm{C}$-acetato incorporado en lípidos neutros y polares}

Alícuotas de LT en cloroformo fueron sembradas en placas para TLC de sílica-gel G 60 previamente activadas. Las muestras sembradas en las placas se sometieron a dos corridas cromatográficas secuenciales utilizando distintos sistemas de solventes como fase móvil. En una primera instancia se resolvieron los FL colocando la placa de TLC en una cuba saturada con un sistema de solventes compuesto por cloroformo, metanol, ácido acético y agua en proporciones 50:37,5:3,5:2 (v/v/v/v) De esta manera se procedió a la separación de los FL en el siguiente orden desde el punto de siembra: lisofosfatidilcolina (lisoFC), esfingomielina (SM), fosfatidilcolina (FC), fosfatidilserina (FS), fosfatidilinositol (FI) y fosfatidiletanolamina (FE) (378)

La cromatografía se detuvo cuando el frente de corrida, en el cual se encuentran los LN, alcanzó la mitad de la placa (25-30 minutos). Las placas se retiraron de la cuba y se colocaron en atmósfera de $\mathrm{N}_{2}$ hasta la completa evaporación de los solventes remanentes. Posteriormente se realizó una segunda cromatografía, que permitió la separación de los lípidos neutros, utilizando una mezcla de éter de petróleo, éter etílico y ácido acético en proporciones 80:20:1 (v/v/v) como fase móvil. La corrida se desarrolló hasta que el frente de la misma alcanzara $1 \mathrm{~cm}$ por debajo del límite de la placa. 
La incorporación de radiactividad en las distintas especies de FL y $L N$ se cuantificó por análisis densitométrico de las bandas detectadas por autorradiografía. Para ello se expusieron las placas sobre una pantalla Storage Phosphor Screen, GE Healthcare. (Amersham, Inglaterra) y se examinaron utilizando el equipo Storm 840 Phosphorlmager (Amersham Pharmacia Biotech; Amersham, Inglaterra). La cuantificación se realizó utilizando el software Image J versión 1.48 y las clases lipídicas presentes se identificaron por comparación con una mezcla de estándares separados en las mismas condiciones. Se utilizaron estándares de los FL: FC, FE, FS y difosfatidilglicerol (DFG, cardiolipina), además se sembró estándares de CL, CE y trimiristina. En todos los casos, los resultados se normalizaron con los respectivos niveles de PCT para cada muestra.

\section{B.9.2. Cuantificación de ${ }^{14} \mathrm{C}$-acetato incorporado en lípidos insaponificables.}

Los LI fueron extraídos desde alícuotas de los LT previamente saponificadas según se describió en la sección 3.B.7.4. Una vez realizadas las extracciones, los tubos conteniendo los LI se llevaron a seco, se resuspendieron en $1 \mathrm{ml}$ de hexano y se tomaron alícuotas de $10 \mu \mathrm{l}$ para determinar la radioactividad total incorporada en esta fracción por centelleo líquido.

Las distintas especies lipídicas presentes en la fracción insaponificable se separaron por TLC en placas de sílica-gel G 60 (activadas previamente a $120{ }^{\circ} \mathrm{C}$ durante 1 hora) utilizando cloroformo 100 \% como fase móvil (249). La cromatografía se desarrolló hasta que el frente de la fase móvil alcanzara $1 \mathrm{~cm}$ por debajo del borde superior de la placa. La incorporación de radiactividad en las distintas especies de la fracción insaponificable se detectó por autorradiografía según se describió en la sección anterior. El análisis densitométrico de las bandas se realizó utilizando el software Image J versión 1.48 y las clases lipídicas presentes se identificaron por comparación con una mezcla de estándares (colesterol, lanosterol, ubiquinona, dolicol y escualeno) desarrollada en la misma TLC. En todos los casos, los resultados se normalizaron con los respectivos niveles de PCT para cada muestra.

\section{B.9.3. Distribución de ${ }^{14} \mathrm{C}$-acetato incorporado en ácidos grasos saturados e insaturados.}

La obtención de los EMAGs se realizó como se describió anteriormente en la sección 3.B.7.4.1. Una vez realizadas las extracciones, los tubos se llevaron a seco, se resuspendieron 
en $1 \mathrm{ml}$ de hexano y se tomaron alícuotas de $10 \mu \mathrm{l}$ para determinar la radioactividad total incorporada por centelleo líquido.

Los ácidos grasos saturados e insaturados se separaron por TLC en placas de sílica-gel G 60 impregnadas con $\mathrm{AgNO}_{3}$. Para ello las placas (preactivadas a $120{ }^{\circ} \mathrm{C}$ durante una hora) fueron impregnadas con una solución de $2 \mathrm{~g} \mathrm{AgNO}_{3}$ en $20 \mathrm{ml}$ de acetonitrilo (379), se dejaron secar en oscuridad para luego activarlas a $120{ }^{\circ} \mathrm{C}$ por 20 minutos. Se utilizó como fase móvil una solución compuesta por hexano, éter etílico, ácido acético en proporciones 94:4:2 (380) y se realizó un doble desarrollo. En una primera instancia la corrida cromatográfica se detuvo cuando el frente de solvente se encontraba $3 \mathrm{~cm}$ por debajo del borde superior de la placa y luego de secar la placa se realizó un segundo desarrollo (con el mismo solvente de corrida) hasta que el frente de la fase móvil alcanzó $1 \mathrm{~cm}$ por debajo del borde superior de la placa. La incorporación de radiactividad en las distintas especies se detectó por autorradiografía, exponiendo las placas sobre una pantalla Storage Phosphor Screen. El análisis densitométrico de las bandas se realizó utilizando el software Image J versión 1.48. Se determinó el porcentaje de EMAGs saturados y EMAGs insaturados.

\section{B.10. Cuantificación de gotas lipídicas por microscopía de fluorescencia.}

Las células cultivadas sobre cubreobjetos contenidos en placas de 6 pocillos fueron lavadas con PBS y fijadas con una solución de paraformaldehído $4 \%(v / v)$ en frío durante la noche. Luego de remover la solución de fijado y de realizar múltiples lavados con PBS, se permeabilizaron con una solución de permeabilización [Triton X-100 0,008 \% (v/v) en PBS] durante 30 minutos a $4{ }^{\circ} \mathrm{C}$. Posteriormente, las células fueron lavadas e incubadas durante 24 horas con DAPI (marcador de ADN) y BODIPY 493/503 (marcador de lípidos neutros), ambos disueltos en albúmina sérica bovina (BSA) $3 \%$ en PBS a una concentración final de 1 $\mu \mathrm{g} / \mathrm{ml}$. Finalmente, los preparados se lavaron nuevamente con PBS, se montaron sobre portaobjetos y se observaron en el microscopio de fluorescencia Olympus BX51 adosado a una cámara digital Olympus DP70. Tanto para la captura de las imágenes como para realizar el análisis de las imágenes se utilizó el software Image Pro plus versión 5.1. 


\section{B.11. Análisis de proteínas}

\section{B.11.1. Cuantificación de proteínas totales}

\section{B.11.1.1. Método de Lowry}

La cantidad de PCT, se determinó por la microtécnica de Lowry, la cual se basa en el desarrollo de un cromóforo de color azul-violáceo cuando reacciona el complejo cobregrupos aromáticos derivados de los aminoácidos con el reactivo de Folin en medio fuertemente alcalino (381). Las alícuotas se incubaron durante 15 minutos en una solución de $\mathrm{Na}_{2} \mathrm{CO}_{3} 2 \%$ en $\mathrm{NaOH} 0,1 \mathrm{M}$, tartrato de $\mathrm{Na}$ y $\mathrm{K} 2 \%$ en $\mathrm{H}_{2} \mathrm{O}$ y CuSO 1 \% en $\mathrm{H}_{2} \mathrm{O}$ (100:1:1, $\mathrm{v} / \mathrm{v} / \mathrm{v}$ ) a $\mathrm{T}^{\circ} \mathrm{A}$, lográndose así la digestión proteica y la generación del complejo entre el Cu (II) y los enlaces peptídicos en medio alcalino. Posteriormente se adicionó solución de reactivo Folin-Ciocalteu en $\mathrm{H}_{2} \mathrm{O}$ bidestilada $(1: 1 \mathrm{v} / \mathrm{v})$, manteniendo las muestras en agitación durante 30 minutos, produciéndose la reducción del reactivo de Folin-Ciocalteu por acción del complejo cupro-proteínico y generando color. La DO se determinó a $750 \mathrm{~nm}$ en un espectrofotómetro GBC UV-Visible Cintra 10/20/40 (Sydney, Australia). En todos los casos, los cálculos se efectuaron mediante un coeficiente de calibración obtenido de la pendiente de una curva estándar. Como solución estándar de proteína se utilizó BSA (fracción V) en $\mathrm{NaOH} 0,10 \mathrm{~N}$.

\section{B.11.1.2. Método de Bradford}

El contenido de proteínas de los lisados y homogenados celulares se determinó utilizando el método de Bradford (382). En contacto con proteínas, el cromóforo Coomassie Brillant Blue G-250 (absorción a 465 nm) genera un complejo-proteína que convierte el color de rojo a azul (absorción a $595 \mathrm{~nm}$ ). El complejo es formado rápidamente y posee un coeficiente de extinción tal que le aporta gran sensibilidad al método aunque su dispersión en solución es estable solo por 1 hora. En este caso se utilizó un método adaptado a micrométodo en placas de 96 pocillos (383). Se colocó una alícuota de $5 \mu \mathrm{l}$ de muestra en cada pocillo y se agregaron $250 \mu \mathrm{l}$ de reactivo Coomassie Brillant Blue G-250 [0,01 \% (p/v) en etanol 4,70 \% (p/v) y H3PO4 8,50 \% (p/v)] y el color azul generado se midió espectrofotométricamente a $595 \mathrm{~nm}$ en el lector de placas Beckman Coulter DTX 880. La 
calibración del método colorimétrico se realizó utilizando una curva patrón de BSA sometida al mismo procedimiento que las muestras.

\section{B.11.2. Análisis de proteínas por Western Blotting}

\section{B.11.2.1. Lisis de muestras celulares}

Con el propósito de obtener un homogenado, las células cultivadas en placas de Petri fueron lavadas con PBS, se les adicionó buffer de lisis $[$ Tris- $\mathrm{HCl} 50 \mathrm{mM}-\mathrm{pH}=7.4, \mathrm{NaCl} 150$

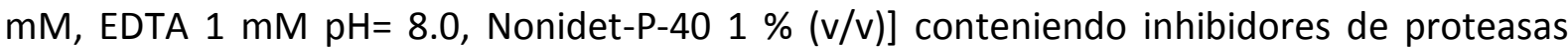
(Cóctel, MPBio, № Cat: 158837) y se las incubó a $4{ }^{\circ} \mathrm{C}$ durante 30 minutos. El homogenado celular resultante se recolectó por raspado con espátula de silicona, se centrifugó a 15.000 xg durante 15 minutos a $4{ }^{\circ} \mathrm{C}$ y el sobrenadante se almacenó a $-70{ }^{\circ} \mathrm{C}$ hasta su uso.

\section{B.11.2.2. Electroforesis de proteínas en geles de poliacrilamida con SDS (SDS-PAGE)}

La electroforesis de proteínas es una técnica que se emplea para analizar una mezcla de proteínas compleja o para caracterizar una proteína. Debido a que las proteínas poseen coeficientes electroforéticos muy variados y que dependen de la conformación, así como, del pH del buffer en el que se encuentran, es fundamental fijar algunas variables para poder realizar comparaciones. Se fija el $\mathrm{pH}$ del gel y de los buffer de corrida; y se recurre a un agente desnaturalizante que permite desplegar los péptidos de forma que la conformación de cada proteína no influya en la corrida. En la mayoría de los casos la electroforesis en geles de poliacrilamida se realizó según el método glicina-SDS-PAGE de Laemmli (384), en la cual el agregado de SDS permite tanto desnaturalizar las muestras como dotarlas de una relación carga/masa prácticamente uniforme y, de este modo, se logra una separación en base al tamaño molecular de los péptidos.

Se incubaron muestras de homogenado celular con buffer de carga [Tris- $\mathrm{HCl}$ 0,5 M$\mathrm{pH}=6.8$, SDS $10 \%(\mathrm{p} / \mathrm{v}), \beta$-mercaptoetanol $1 \%(\mathrm{p} / \mathrm{v})$, azul de bromofenol 0,5\% (p/v) y glicerol $15 \%(\mathrm{v} / \mathrm{v})]$ a $100{ }^{\circ} \mathrm{C}$ durante 5 minutos para desnaturalizar completamente las proteínas. El agregado de $\beta$-mercaptoetanol en el buffer muestra permite romper los enlaces disulfuro. Las muestras de homogenado celular (20-60 $\mu \mathrm{g}$ proteína) se sembraron en geles de 10 calles de poliacrilamida al $12,5 \%$ y se separaron durante 2 horas a $120 \mathrm{~V}$ en buffer de corrida [Tris 0,025 M - pH=8.3, Glicina 0,2 M y SDS 3,5 mM] en una celda de 
electroforesis Mini Protean II (BioRad, EUA). Junto con las muestras se siembra también el estándar de peso molecular ColorBurst ${ }^{\mathrm{TM}}$ Electrophoresis Marker (Sigma, Missouri, EUA) como referencia y para la comparación de los pesos moleculares de las bandas.

La tinción de los geles se realizó en una solución 0.1 \% Coomasie Blue R-250 en $\mathrm{H}_{2} \mathrm{O}$ :metanol:ácido acético (5:5:2 v/v/v). La decoloración se efectuó con una solución acuosa al $10 \%$ ácido acético $30 \%$ metanol. Los geles fueron digitalizados utilizando el programa Image J versión 1.48 .
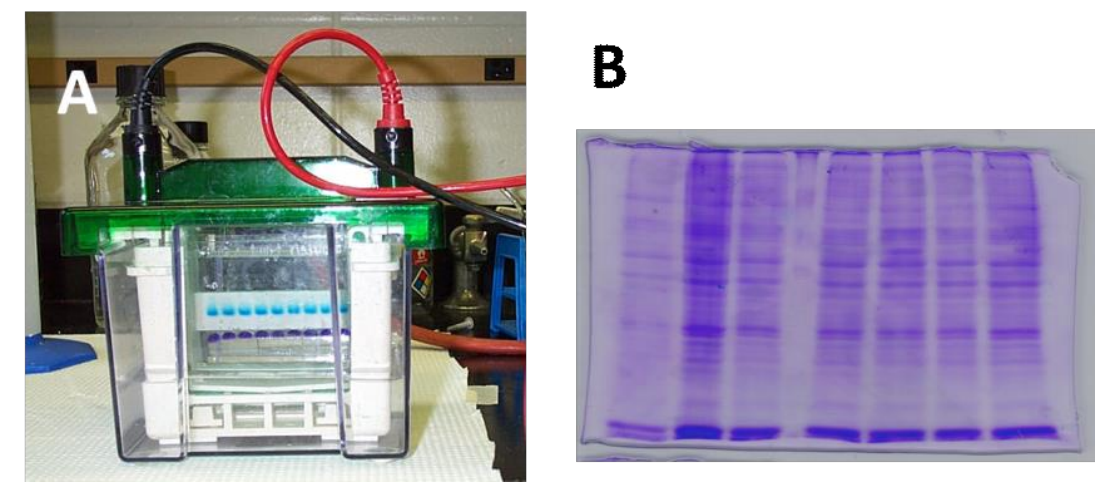

Figura 3.8. Electroforesis de proteínas. A) Corrida electroforética. B) Tinción de proteínas con solución de Coomasie Blue R-250

\section{B.11.2.3. Western Blotting}

Las proteínas, separadas por electroforesis desnaturalizante, se transfirieron desde los geles a membranas de fluoruro de polivinilideno (PVDF, Amersham-GE, Buckinghamshire, Inglaterra) utilizando buffer de transferencia [Tris 0,05 M, glicina 0,04 M, metanol 0,2\% $(p / v)$ ] en un equipo de transferencia semi-seca Trans-Blot SD de Bio-Rad (385). La transferencia se realizó a $10 \mathrm{~V}$ durante 40 minutos.

Al finalizar, la membranas se incubaron hasta el día siguiente a $4{ }^{\circ} \mathrm{C}$ con leche descremada al 5 \% en buffer PBST [ $\mathrm{NaCl} 137$ mM; KCl 2,7 mM; Na2HPO4 10,0 mM; KH2PO4 2,0 mM; Tween-20 0,05 M; pH=7.4] para bloquear los sitios de unión no específicos en la membrana.

Las membranas se incubaron con cada anticuerpo primario durante 1 hora a $\mathrm{T}^{\circ} \mathrm{A}$ con agitación suave. Posteriormente, se lavaron las membranas 3 veces durante 10 minutos con PBST y se incubaron durante 1 hora a $\mathrm{T}^{\circ} \mathrm{A}$, en agitación leve, con el correspondiente anticuerpo secundario conjugado a la enzima peroxidasa (HRP). Tanto los anticuerpos primarios como secundarios fueron preparados en leche descremada al $2 \%$ en PBST a las respectivas diluciones, que se muestran en la Tabla 3.3. 


\begin{tabular}{|l|l|l|l|l|}
\hline \multicolumn{6}{|l|}{ Tabla 3.3. Lista de anticuerpos empleados y sus diluciones } \\
\hline Anticuerpo & Origen & Código & Dilución & Proveedor \\
\hline Anti-HMGCR & Conejo & sc-33827 & $1: 200$ & Santa Cruz \\
\hline Anti- $\beta$ actina & Ratón & AC-15 & $1: 10.000$ & Sigma Aldrich \\
\hline Anti-Conejo (HRP) & Cabra & sc-2004 & $1: 3000$ & Santa Cruz \\
\hline Anti-Ratón (HRP) & Cabra & ab-6789 & $1: 2000$ & Abcam \\
\hline
\end{tabular}

Terminada la incubación con el anticuerpo secundario, las membranas se lavaron repetidas veces con PBST y se reveló la actividad peroxidasa de las bandas inmunoreactivas utilizando los reactivos de luminol y ácido p-cumárico (386). La quimioluminiscencia emitida fue detectada utilizando el filtro de quimioluminiscencia del equipo ImageQuant 350 (GE Healthcare, Buckinghamshire, Inglaterra) o por exposición a placas autorradiográficas.

Las bandas se cuantifican por densitometría utilizando el programa Image J versión 1.48, y la señal correspondiente al HMGCR se normalizó con la correspondiente a $\beta$-actina, que funciona como control interno.

\section{B.12. Análisis de interacción de drogas}

Pese a que hay múltiples métodos propuestos para evaluar la interacción entre drogas (387) como los isobologramas de Steel y Peckhams, isobologramas modificados de Kano, el principio del efecto medio de Chou-Talalay y otros; la mayoría de estos no son aplicables a drogas con efecto citotóxico bajo como los aceites esenciales o las estatinas. Por esta razón se decidió utilizar el método de Kern (388) modificado por Romanelli (389). Este método se ha utilizado tanto para la evaluación de estatinas (390) como sustancias que interactúan en la VM (391).

Se utiliza el siguiente índice sinérgico: $\quad \mathbf{R}={ }^{\mathbf{P} \operatorname{esp}} / \mathbf{P}$ obs $\quad$ donde:

- P esp corresponde al valor esperado del proceso en consideración (por ejemplo proliferación o colesterogénesis), calculado como el producto del porcentaje remanente luego del tratamiento con la droga A sola multiplicado por el porcentaje remanente del tratamiento con la droga B sola dividido por 100. 
- P obs corresponde al porcentaje remanente real observado luego del tratamiento combinado de las drogas $A$ y $B$.

De esta forma se define sinergismo como cualquier valor de $R>1$, mientras que un $R=1$ (efecto aditivo) o inferior indica la ausencia de una interacción sinérgica entre las drogas A y $B$.

\section{B.13. Análisis estadístico}

Los experimentos se realizaron como mínimo 2 veces en forma independiente, realizados cada uno como mínimo por triplicado. Se utilizó el test de Kolmogorov-Smirnov con correcciones de Lilliefors para probar la normalidad.

Los resultados donde se presenta normalidad se expresan como las medias con sus respectivas desviaciones estándar (DS). El análisis estadístico se realizó mediante el análisis de la varianza (ANOVA) seguido del test de comparación de medias de Tuckey $(p<0,05)$, o utilizando el test " $\mathrm{t}$ " de Student, según corresponda, utilizando el software IBM SPSS stadistics V.22 (IBM Corp, New York, EUA). El análisis estadístico no paramétrico se realizó mediante el uso de la prueba de Krustal Wallis y la prueba de Chi cuadrado seguidos de la prueba post hoc de Bonferroni. Los límites de confianza utilizados se señalan para cada experimento, pero nunca fueron menores al $95 \%$. Las curvas de ajuste por mínimos cuadrados, correlación paramétrica y la graficación científica se efectuaron mediante SigmaPlot v. 10 (Systat Software, Inc., California, EUA). El análisis de las imágenes se llevó a cabo a partir de los programas Image J versión 1.48 (NIH, EUA) o Image Pro Plus versión 5.1 (Media Cybernetics Inc, Maryland, EUA) según corresponda. 


\title{
Capítulo \\ Actividad antiproliferativa de ACEITES \\ ESENCIALES DE Lippia alba EN CÉLULAS NEOPLÁSICAS HUMANAS
}

\author{
Mecanismo de acción
}

Combinación con simvastatina 


\section{A. Evaluación de citotoxicidad de quimiotipos del AEL en líneas celulares neoplásicas y no neoplásicas. Análisis de selectividad.}

Para analizar la citotoxicidad de los distintos quimiotipos de AEL, células neoplásicas (HepG2 y A549) y no neoplásicas (Vero) sembradas en placas de 24 pocillos fueron tratadas con concentraciones crecientes de los AEs y se evaluó la viabilidad celular por medio del ensayo de reducción metabólica del MTT. El efecto de los fitoquímicos fue expresado como porcentaje del control y las concentraciones que inhiben la viabilidad un $50 \%\left(I_{50}\right)$ calculadas por regresión no lineal a partir de las curvas dosis-respuesta (Ver Apéndice I.1)- se utilizaron como parámetro de análisis de citotoxicidad.

La Tabla 4.1 muestra los valores de $I_{50}$ obtenidos para las distintas líneas celulares tratadas con cada uno de los quimiotipos de AEL. LOS AEs de los quimiotipos citral y tagetenona fueron los más efectivos en la reducción de la viabilidad de todas las líneas celulares ensayadas, siendo las células tumorales más sensibles a los efectos citotóxicos de estos aceites que las células Vero.

Para evaluar el grado de toxicidad selectiva de cada uno de estos AEs sobre las células cancerosas probadas respecto a la línea no maligna, se calculó el índice de selectividad (IS) definido como: $\mathrm{IC}_{50}$ en células Vero/ $\mathrm{IC}_{50}$ en células cancerosas y se consideró que muestras con un IS mayor a 3 presentan alta selectividad $(392,393)$. Los valores obtenidos se presentan entre paréntesis en la Tabla 4.1. Allí puede observarse que, si bien los valores de $\mathrm{IC}_{50}$ en la línea celular no cancerosa Vero fueron mayores que en las células tumorales para todos los aceites ensayados, sólo el quimiotipo tagetenona presentó una alta selectividad (IS>3) para ambas líneas cancerosas. 
Tabla 4.1. Valores de $I_{50}$ para aceites esenciales de Lippia alba obtenidos por MTT e índice de selectividad.

\begin{tabular}{|c|c|c|c|c|}
\hline & \multicolumn{4}{|c|}{$I C_{50}^{a}(I S)^{b}$} \\
\hline Línea celular & AELca & AELpi & AELci & AELta \\
\hline HepG2 & $\begin{array}{c}347,2 \pm 28,3 \\
(1,3)\end{array}$ & $\begin{array}{c}412,2 \pm 30,8 \\
(1,4)\end{array}$ & $\begin{array}{c}34,4 \pm 3,1 \\
(2,6)\end{array}$ & $\begin{array}{c}33,6 \pm 4,0 \\
(6,7)\end{array}$ \\
\hline A549 & $\begin{array}{c}275,2 \pm 18,7 \\
(1,6)\end{array}$ & $\begin{array}{c}304,4 \pm 23,7 \\
(1,9)\end{array}$ & $\begin{array}{c}36,1 \pm 3,4 \\
(2,5)\end{array}$ & $\begin{array}{c}30,4 \pm 3,2 \\
(7,4)\end{array}$ \\
\hline Vero & $452,1 \pm 37,4$ & $592,3 \pm 41,5$ & $88,8 \pm 7,8$ & $225,6 \pm 15,2$ \\
\hline \multicolumn{5}{|c|}{$\begin{array}{l}{ }^{a} \text { Valores } \mathrm{IC}_{50}(\mu \mathrm{g} / \mathrm{ml}) \text { obtenidos de curvas de viabilidad dosis respuesta por medio de } \\
\text { análisis de regresión no lineal. Los valores se expresan como el promedio } \pm \mathrm{DS} \text {, } \\
\text { determinados de } 3 \text { ensayos por cuadruplicado de MTT. } \\
{ }^{\mathrm{b}} \mathrm{IS} \text { refiere al índice de selectividad, calculado como la razón entre el IC } \mathrm{C}_{50} \text { de células Vero/ } \\
\mathrm{IC}_{50} \text { células tumorales. Un IS cuyo valor es }>3 \text { indica alta selectividad. }\end{array}$} \\
\hline
\end{tabular}

La Figura 4.1 muestra las curvas representativas de la viabilidad celular en respuesta al tratamiento con concentraciones crecientes de AELta (el quimiotipo de AEL más efectivo y selectivo). En ambas líneas de células tumorales, se requieren concentraciones próximas a los $20 \mu \mathrm{g} / \mathrm{ml}$ de AELta para alcanzar una inhibición de la viabilidad estadísticamente significativa. A partir de allí y hasta concentraciones del orden de los $70 \mu \mathrm{g} / \mathrm{ml}$ de AELta el tratamiento ocasionó una disminución progresiva de la viabilidad celular dosis dependiente. Por encima de este valor la curva alcanzó una meseta hasta la concentración máxima ensayada $(100 \mu \mathrm{g} / \mathrm{ml})$ donde se registró una inhibición de la viabilidad superior al $95 \%$ (Figura 4.1, Panel A). En la línea no tumoral Vero, el tratamiento con AELta no produjo una inhibición estadísticamente significativa de la viabilidad celular en el intervalo de concentración ensayado para las células malignas (Figura 4.1, Panel A) y fueron requeridas concentraciones superiores a los $200 \mu \mathrm{g} / \mathrm{ml}$ para registrar una disminución dosis dependiente de la viabilidad (Figura 4.1, Panel B), alcanzando una inhibición del 82 \% en la concentración más alta probada $(800 \mu \mathrm{g} / \mathrm{ml})$. 


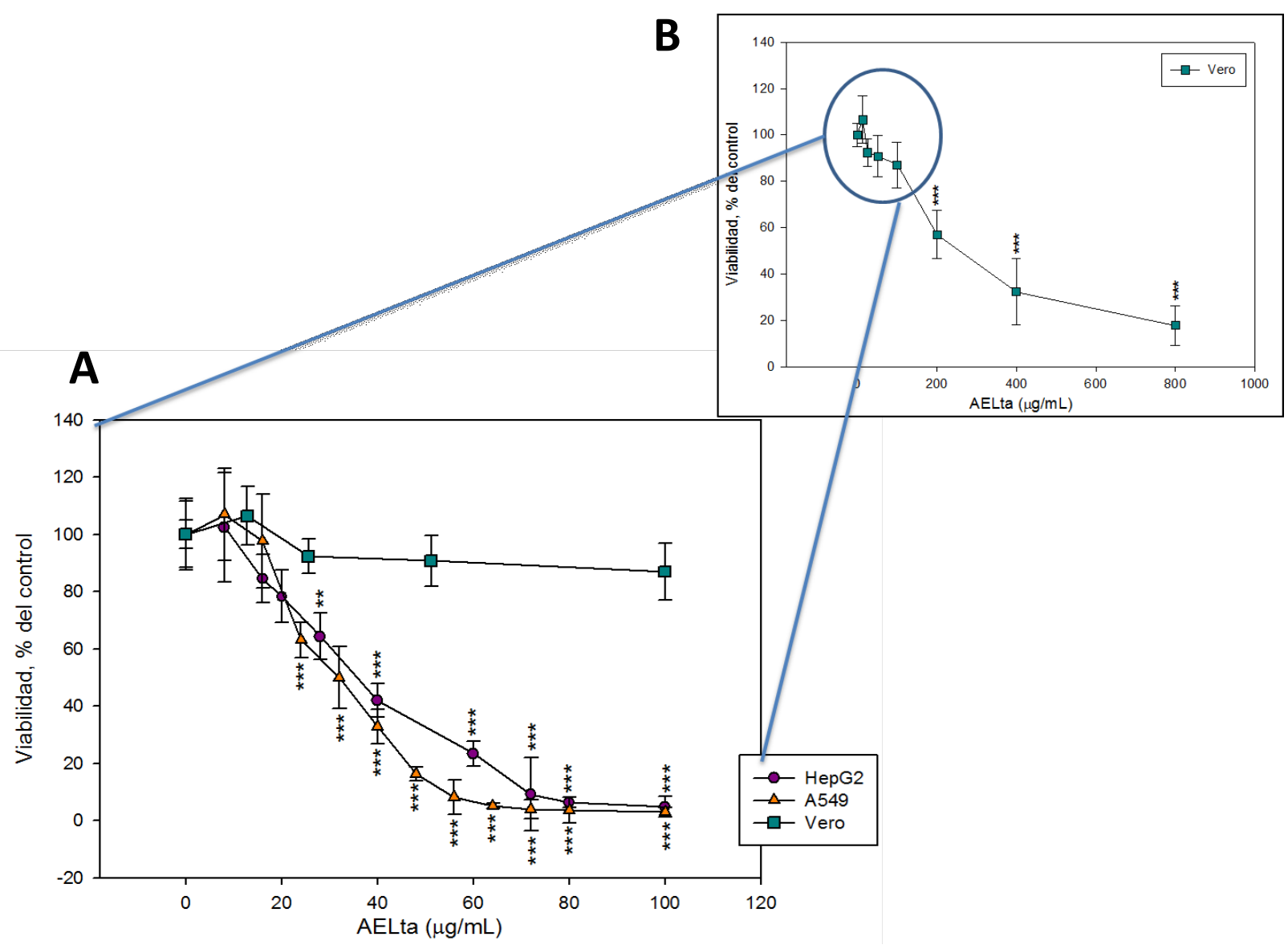

Figura 4.1. Efecto de AELta sobre la viabilidad en células tumorales humanas (HepG2 y A549) y no tumorales (Vero). Las células se trataron con las concentraciones indicadas de AELta por 48 horas. La viabilidad fue determinada por el ensayo de MTT y se expresó como el porcentaje del control. A: Concentraciones en el rango de AELta que disminuyen viabilidad en células tumorales; B: rango extendido de AELta que produce disminución de la viabilidad celular en células no tumorales Vero. Se muestra los datos como el promedio \pm DS de tres experimentos independientes realizados por cuadruplicado; * $<<0,05 ;{ }^{* *} \mathrm{p}<0,01 ; * * * \mathrm{p}<0,001$.

La viabilidad de las células tumorales (HepG2 y A549) sembradas en placas de 24 pocillos y tratadas con concentraciones crecientes de los 4 quimiotipos del AEL fue evaluada adicionalmente por ensayo de incorporación de rojo neutro (RN). Las curvas de inhibición de la viabilidad en función de la concentración de los AEs (Ver Apéndice I.2) y los valores de IC 50 calculados a partir de las mismas (Tabla 4.2) fueron comparables a los obtenidos mediante el ensayo de MTT tanto para A549 como para HepG2 y permitieron corroborar los datos indicativos de citotoxicidad obtenidos previamente. 
Tabla 4.2. Valores de $I C_{50}$ para aceites esenciales de Lippia alba obtenidos por rojo neutro

\begin{tabular}{lcccc}
\hline & \multicolumn{3}{c}{ IC $_{50}$} \\
\hline Línea celular & AELca & AELpi & AELci & AELta \\
HepG2 & 264,8 & 325,6 & 32,0 & 28,0 \\
A549 & 240,0 & 336,0 & 28,0 & 30,4 \\
\hline
\end{tabular}

Valores $\mathrm{IC}_{50}(\mathrm{\mu g} / \mathrm{ml})$ obtenidos de curvas de viabilidad dosis respuesta por medio de análisis de regresión no linear. Los valores se expresan como el promedio \pm DS, determinados de tres ensayos por cuadruplicado.

La citotoxicidad del quimiotipo tagetenona -el más eficaz y selectivo- fue evaluada en células HepG2 por medio de un tercer ensayo que permite identificar células vivas y muertas utilizando microscopía de fluorescencia. Para ello, las células sembradas en placas de 24 pocillos fueron tratadas durante 48 horas con concentraciones crecientes de AELta adicionando en la última media hora la CAM y el IP, según se describe en sección 3.B.4.4. Se tomaron 5 campos de cada pocillo y se contaron las células viables (verdes). A partir de esos datos se construyó una curva de inhibición de la viabilidad en función de la concentración y se calculó el valor de IC $\mathrm{C}_{50}$, que concordó con los resultados anteriores (Figura 4.2, panel C).
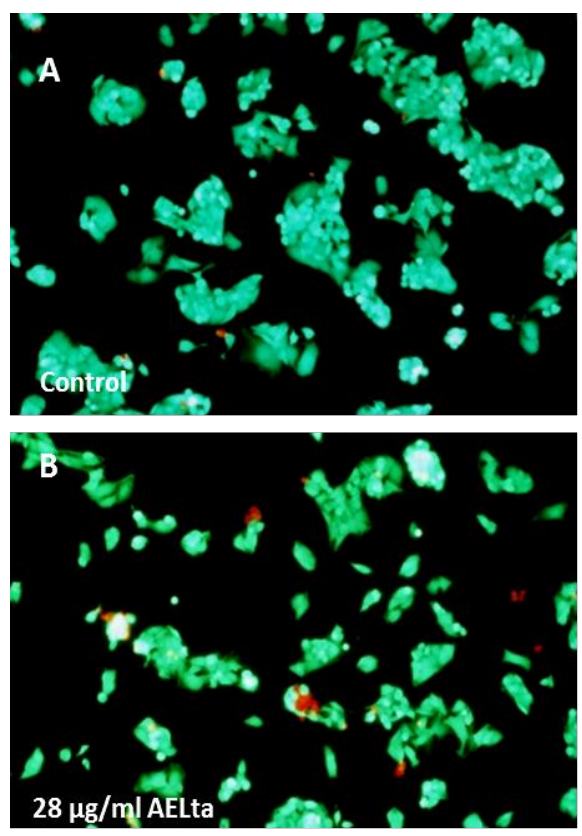

C

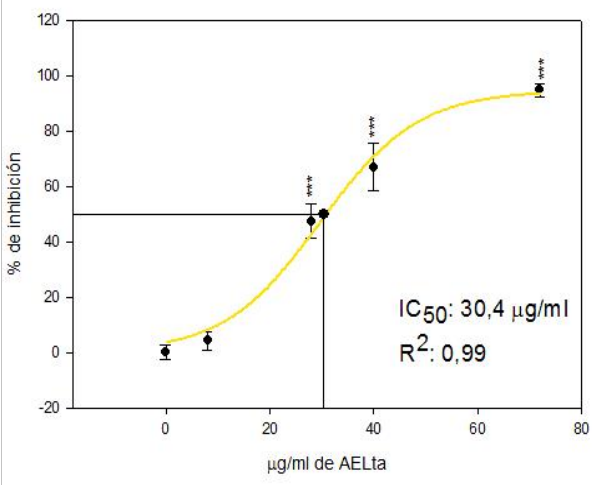

Figura 4.2. Efecto de AELta sobre la viabilidad celular determinado por CAM/IP. Las células creciendo exponencialmente fueron tratadas con concentraciones crecientes de AELta durante 48 horas. Se muestra imágenes representativas de células control y tratadas con AELta cercano al IC $C_{50}(A, B)$. La curva de inhibición de la viabilidad celular se determinó por el recuento de células HepG2 vivas (verdes) y excluyendo a las células muertas (rojas) (C). Los datos se expresan como el promedio \pm DS $(\mathrm{n}=3) ;{ }^{*} \mathrm{p}<0,05 ;{ }^{* *} \mathrm{p}<0,01 ; * * * \mathrm{p}<0,001$ 


\section{B. Efecto del AELta sobre la proliferación de células neoplásicas humanas.}

Para investigar el efecto de AELta -el quimiotipo con menor $\mathrm{IC}_{50}$ y mayor IS- sobre la proliferación celular, células HepG2 y A549 sembradas en placas de 6 pocillos fueron tratadas con concentraciones crecientes de AELta $(0-80 \mu \mathrm{g} / \mathrm{ml})$ y el número de células se determinó por conteo en cámara de Neubauer utilizando la exclusión del azul tripán como indicador de viabilidad según se describe en Materiales y Métodos.

El tratamiento con AELta dentro de este rango reduce la proliferación de las dos líneas celulares de manera dosis-dependiente, registrándose una inhibición de la proliferación celular del $50 \%$ con concentraciones de $36 \mu \mathrm{g} / \mathrm{ml}$ en HepG2 (Fig. 4.2-E) y $40 \mu \mathrm{g} / \mathrm{ml}$ en A549 (Fig. 4.3-E).

Las fotomicrografías presentadas en las Figuras 4.2 y 4.3 (Paneles A-D) ilustran los cambios morfológicos que acompañan a la supresión de la proliferación producida en ambas líneas celulares luego del tratamiento con AELta durante $48 \mathrm{~h}$.
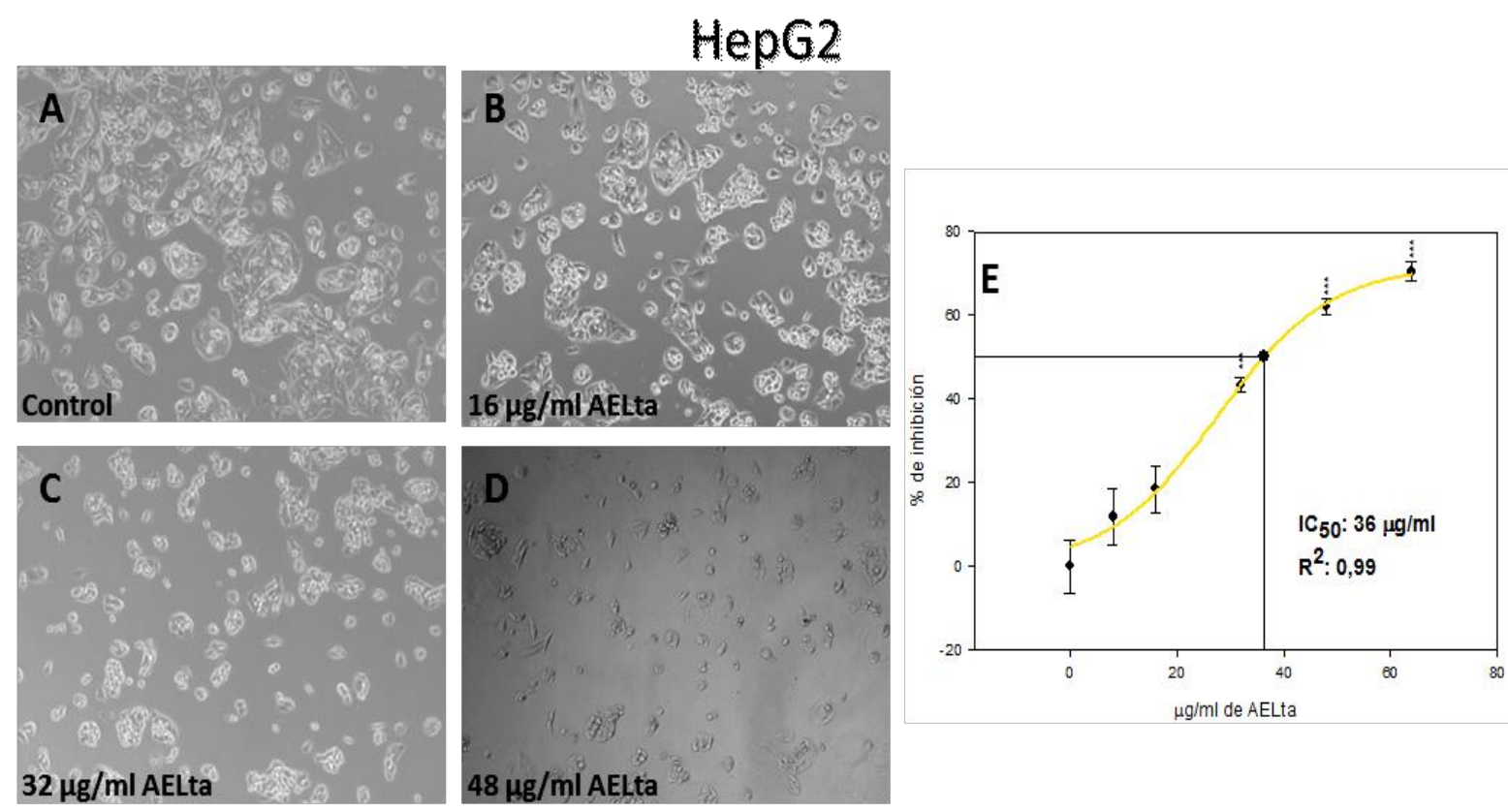

Figura 4.3. Inhibición de la proliferación de células HepG2 determinada por recuento celular. Las células creciendo exponencialmente fueron tratadas con concentraciones crecientes de AELta durante 48 horas. Paneles A-D: Imágenes representativas de células tratadas con concentraciones en aumento de AELta de tres experimentos independientes con resultados similares. Panel E: El número de células, determinado por conteo en cámara de Neubauer, se expresó como porcentaje respecto al control generándose una curva de inhibición de proliferación. Los datos representan el promedio $\pm D S(n=3)$; ${ }^{*} p<0,05 ; * * p<0,01 ; * * *<<0,001$. 

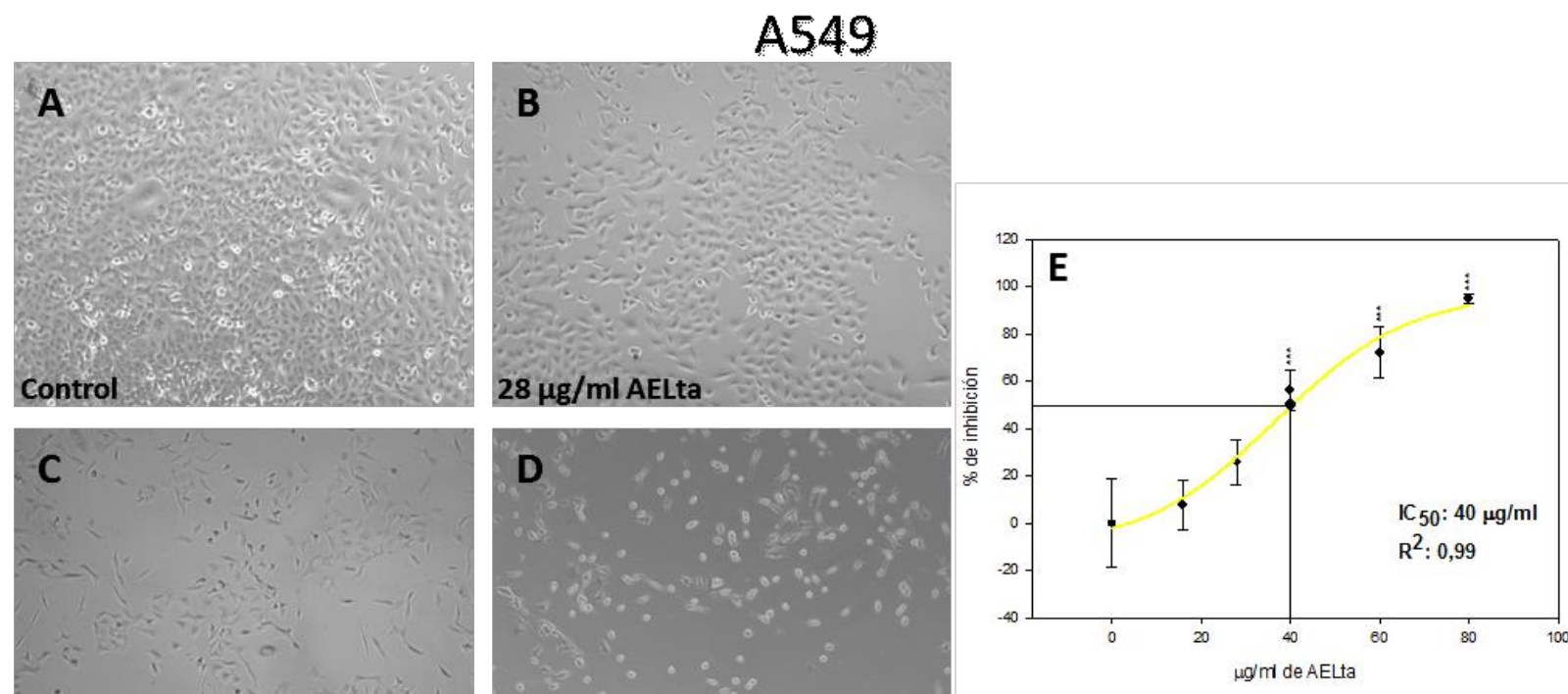

\section{$50 \mu \mathrm{g} / \mathrm{mlAELTa}$}

$60 \mu \mathrm{g} / \mathrm{ml}$ AELta

Figura 4.4. Inhibición de la proliferación de células A549 determinada por recuento celular. Las células creciendo exponencialmente fueron tratadas con concentraciones crecientes de AELta durante 48 horas. Paneles A-D: Imágenes representativas de células tratadas con concentraciones en aumento de AELta de tres experimentos independientes con resultados similares. Panel E: El número de células, determinado por conteo en cámara de Neubauer, se expresó como porcentaje respecto al control generándose una curva de inhibición de proliferación. Los datos representan el promedio $\pm \mathrm{DS}$ $(n=3) ;{ }^{*} p<0,05 ;{ }^{* *} p<0,01 ;{ }^{* * *} p<0,001$.

En la Figura 4.3 Panel A se observa el crecimiento trabecular y la morfología epitelial normal de las células HepG2. El tratamiento con AELta a $16 \mu \mathrm{g} / \mathrm{ml}$ (Fig. 4.3, Panel B) causó vacuolización y la pérdida de la organización trabecular, aumentando la presencia de células aisladas y con morfología redondeada. En células tratadas con concentraciones mayores del aceite el fenómeno descrito anteriormente se incrementó y aumentó a su vez la presencia de células con marcada condensación de cromatina, la aparición de membranas encrespadas y con formación de vesículas (Fig.4.3, Paneles C y D), cambios que se asocian a muerte celular por apoptosis.

En la Figura 4.4 Panel A se muestra la morfología epitelial normal de las células A549. El tratamiento con AELta $28 \mu \mathrm{g} / \mathrm{ml}$ causó la contracción del volumen celular y la adquisición de una morfología fibroblástica (Fig. 4.4, Panel B). A una concentración mayor ( $40 \mu \mathrm{g} / \mathrm{ml}$ ) se observó vacuolización citoplasmática y condensación de la cromatina, cambios reminiscentes de muerte celular por apoptosis (Fig. 4.4, Panel C), similares a los que fueron observados en células HepG2. En cultivos tratados con la concentración del aceite que inhibe la proliferación celular más del $70 \%(60 \mu \mathrm{g} / \mathrm{ml})$, las células mostraron los cambios 
morfológicos descritos anteriormente y además se observaron células redondeadas, con algunas de ellas desprendidas de la matriz de cultivo (Fig. 4.4, Panel D)

\section{C. Mecanismos involucrados en la actividad antiproliferativa de AELta}

Teniendo en cuenta que los valores de $\mathrm{IC}_{50}$ correspondientes al AELta obtenidos por los distintos métodos son próximos entre sí, se utilizaron como referencia para los posteriores experimentos de esta tesis doctoral los valores $I_{50}$ calculados a partir de resultados obtenidos en los ensayos de MTT.

\section{C.1. Efectos sobre el ciclo celular}

Las células en proliferación requieren de la progresión del ciclo celular desde una fase inicial postmitótica $\mathrm{G} 1$, a través de $S$ y $\mathrm{G} 2$, hasta la fase $M$ donde tendrá lugar la subsiguiente mitosis.

Con el objeto de determinar si la actividad antiproliferativa del AELta está asociada a un arresto del ciclo celular (efecto citostático) que se refleja en cambios en la distribución de la población celular en las distintas fases del ciclo, células HepG2 y A549 sembradas en placas de 6 pocillos fueron tratadas durante 24 horas con concentraciones de AELta correspondientes al IC $50\left(1,0 x I C_{50}\right)$ y la mitad de este $\left(0,5 x I C_{50}\right)$. Posteriormente, las células teñidas con IP se analizaron en un citómetro de flujo, según se describió en el ítem 3.B.6.

En células HepG2 (Fig. 4.5, Panel A), luego de $24 \mathrm{~h}$ de tratamiento con AELta, el porcentaje de células en fase G1 se incrementó significativamente desde 46,1 \pm 1,8 (control) a $61,6 \pm 5,1\left(0,5 \times I C_{50}\right)$ y $68,5 \pm 2,4\left(1,0 \times I C_{50}\right)$; cambios que representan un aumento de hasta el 50 \% del número de células que se encuentran en esta fase. Contrariamente, el porcentaje de células en la fase $S$ disminuyó de $43,2 \pm 3,8$ (control) a $34,8 \pm 1,6\left(0,5 x \mathrm{IC}_{50}\right)$ y $24,0 \pm 2,8$ $\left(1,0 x \mid C_{50}\right)$. Por este motivo, la relación $\mathrm{G} 1 / \mathrm{S}$ aumentó muy significativamente desde $1,1 \pm 0,1$ (control) hasta $1,8 \pm 0,2$ (para $\left.0,5 \times I C_{50}, P<0,001\right)$ y $2.9 \pm 0.4$ (para $1,0 \times I C_{50}, P<0,001$ ) indicando un arresto del ciclo celular en la fase G0/G1 en ambas condiciones evaluadas. El porcentaje de células que se encuentran en G2/M no presenta cambios significativos.

El AELta tuvo un efecto diferente sobre la distribución de la población de células A549 en el ciclo celular (Fig. 4.5, Panel B). Luego de 24 h de incubación con 0,5x IC 50 de 
AELta, el porcentaje de células en fases G1 y $S$ y la resultante relación G1/S no cambió significativamente; mientras que la exposición a 1,0x IC $C_{50}$ de $A E L t a$ ocasionó una disminución del porcentaje de células en la fase S y un moderado incremento del mismo en fase G1 que se traduce en un aumento significativo $(P<0,05)$ en la relación $G 1 / S$ desde $1,8 \pm 0,2$ (control) a 2,3 $\pm 0,1\left(1,0 \times \quad I C_{50}\right)$, indicando un arresto en fase G0/G1. Concomitantemente, el porcentaje de células en fase $G 2$ se incrementó desde 5,0 \pm 0,5 (control) a 9,2 $\pm 1,0(0,5 x$ $\left.I C_{50}, P<0,001\right)$ y $7,7 \pm 0,1 \%\left(1,0 \times I C_{50}, P<0,001\right)$, lo cual sugiere un arresto en fase $G 2$ mediado por AELta en esta línea celular en ambas condiciones evaluadas.
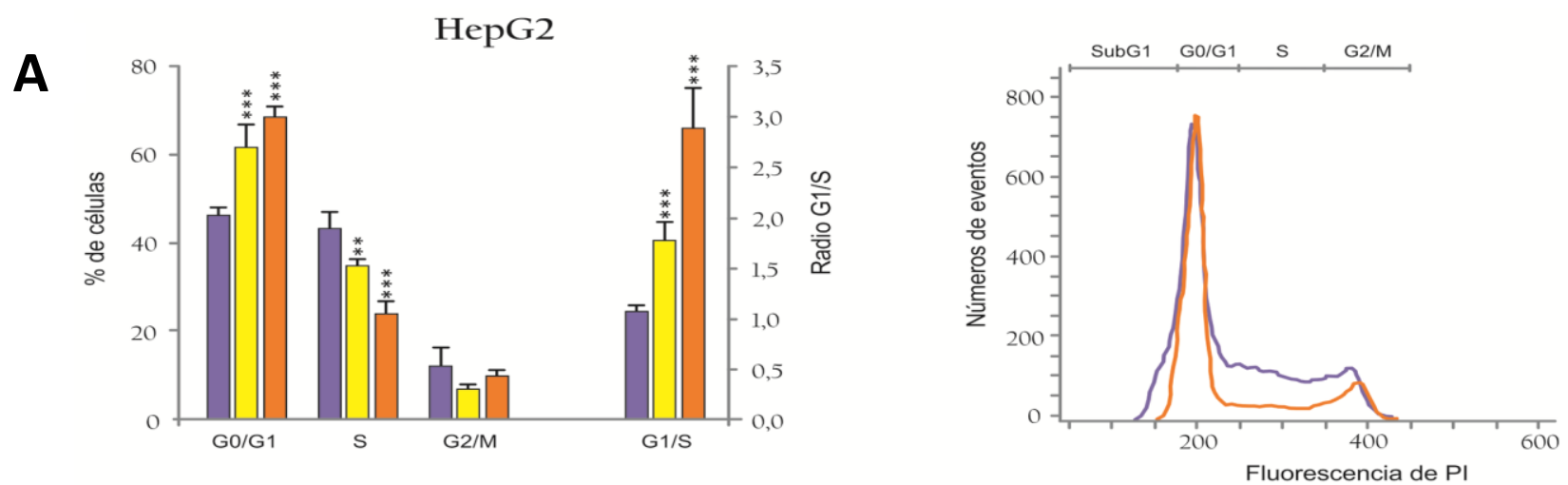

B
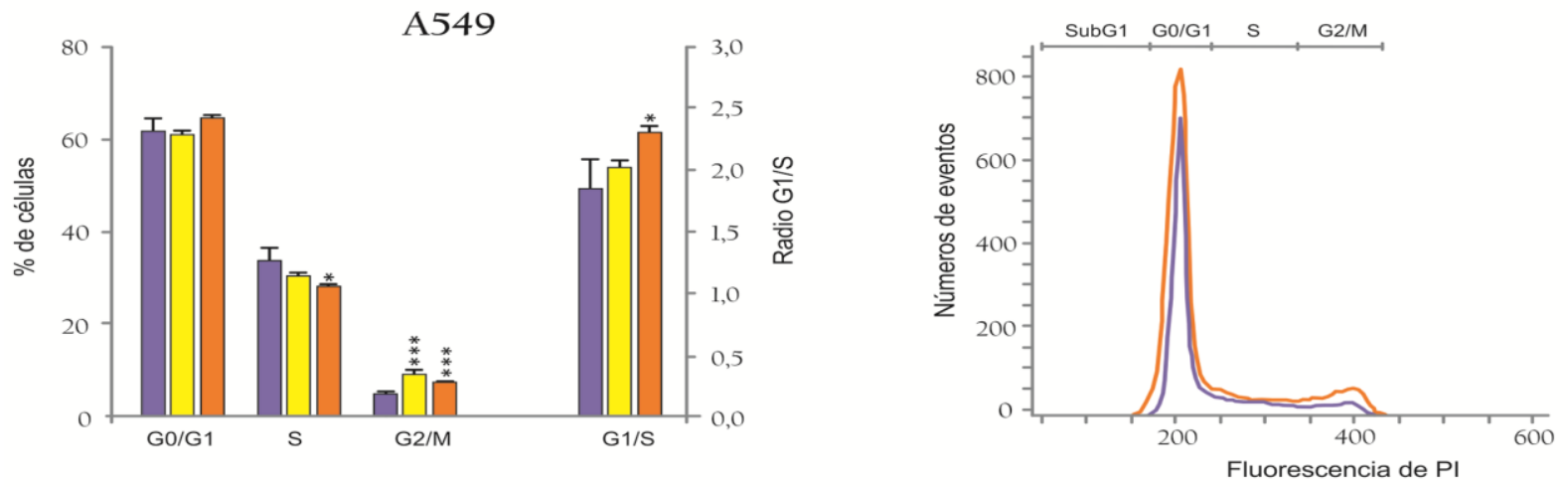

$\square$ Control $\square 0,5 \times \mathrm{IC}_{50}$ AELta $\square 1 \times 1 \mathrm{C}_{50}$ AELta

Figura 4.5. Análisis del ciclo celular de células HepG2 (Panel A) y A549 (Panel B) luego del tratamiento con AELta. La distribución de células en las distintas fases del ciclo celular fue analizada por citometría de flujo de células teñidas con IP. Los resultados se expresan como porcentaje de células de la población en cada fase del ciclo celular. Las figuras muestran el promedio $\pm D S(n=3) ;\left({ }^{*}\right) p<0,05 ;\left(^{* *}\right) p$ $<0,01 ;\left({ }^{* *}\right)$ p $<0,001$. A la derecha de cada una de las gráficas se muestran los histogramas representativos del control comparado con el IC $\mathrm{C}_{50}$ de $\mathrm{AEIta.}$ 


\section{C.2. Detección de células apoptóticas}

Habiendo observado, en las células tratadas con concentraciones de AELta que inhiben la proliferación celular, cambios morfológicos compatibles con los que presentan células que están transitando por un proceso de muerte celular programada (Figura 4.3 y 4.4), se investigó si la inducción de apoptosis está implicada en actividad antiproliferativa del AELta en estas líneas de células malignas. La cuantificación de apoptosis se realizó por distintos métodos.

\section{C.2.1. Ensayo de TUNEL}

Con el propósito de evaluar la existencia de un efecto pro-apoptótico del AELta se analizó la fragmentación de ADN nuclear por medio del ensayo de TUNEL. Para esto, células HepG2 y A549 creciendo sobre cubreobjetos de $24 \times 24 \mathrm{~mm}$ se trataron con una concentración correspondiente al $\mathrm{IC}_{50}$ del AELta durante 48 horas. Posteriormente fueron lavadas, fijadas, permeabilizadas y tratadas con el kit de detección de muerte celular in situ (TUNEL) de Roche ${ }^{\circledR}$ según lo detallado en la sección 3.B.7.1

En la Figura 4.6 se presentan imágenes representativas, obtenidas por microscopía de fluorescencia, correspondientes a los tratamientos en las líneas celulares HepG2 y A549. Allí puede observarse que el tratamiento con una concentración de AELta que inhibe un 50 \% la viabilidad ocasionó un incremento moderado del número de células TUNEL positivo. Los resultados de la cuantificación de las imágenes obtenidas se muestran en la Tabla 4.3 donde puede observarse que, pese a encontrarse una diferencia significativa con respecto al control, el porcentaje de células en apoptosis es relativamente bajo. 


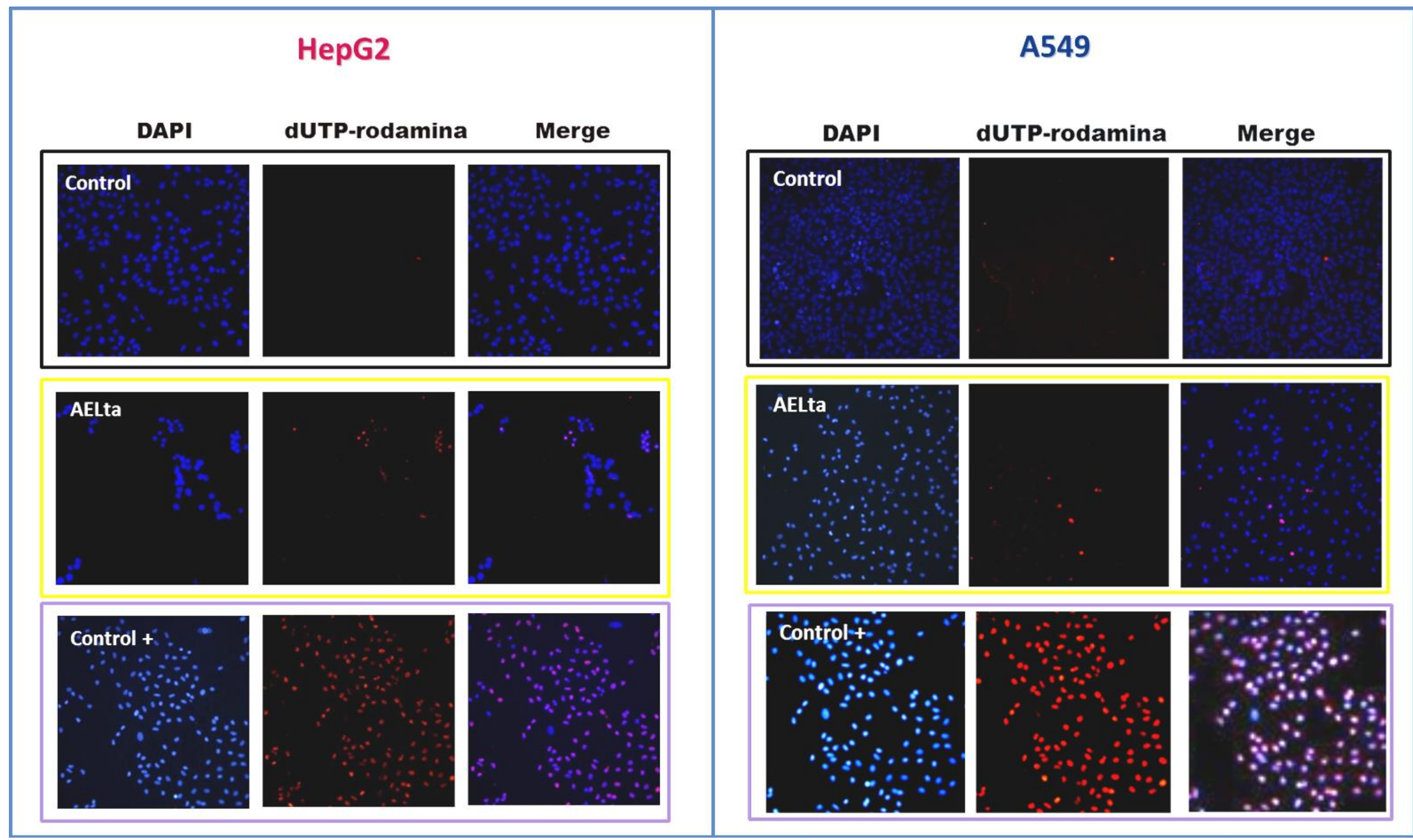

Figura 4.6. Apoptosis determinada por ensayo de TUNEL en células HepG2 (panel rosa) y A549 (panel celeste). Imágenes de microscopía de fluorescencia (400X) de células tratadas con DMSO 0,2 \% (Control) y el IC ${ }_{50}$ de AELta: $32 \mu \mathrm{g} / \mathrm{ml}$ durante 48 horas. Se observa el núcleo teñido con DAPI, las células apoptóticas que incorporaron d-UTP-rodamina y la imagen combinada. Un grupo de células control fijadas y tratadas durante 30 minutos con DNasa fue utilizado como control positivo (Control +). 
Tabla 4.3. Inducción de apoptosis en células HepG2 y A549 tratadas con AELta determinada por el ensayo TUNEL.

\begin{tabular}{clc}
\hline & \multicolumn{2}{l}{ Porcentaje células apoptóticas } \\
\hline HepG2 & A549 \\
Control & $0,57 \pm 0,14$ & $1,67 \pm 0,57$ \\
$\mathbf{1 , 0 \times ~ I C} 50$ & $9,38 \pm 1,35^{* * *}$ & $6,32 \pm 3,34 * *$ \\
\hline
\end{tabular}

El porcentaje de células TUNEL positivas se determinó del conteo de 10 campos ópticos con 300 células/campo para cada condición experimental. Se expresan los valores como el promedio $\pm \mathrm{DS},(\mathrm{n}=3) ;{ }^{* *} \mathrm{p}<0.01 ;{ }^{* *} \mathrm{p}<0.001$

\section{C.2.2. Análisis de la morfología nuclear por microscopía de fluorescencia en células teñidas con Hoechst 33258/IP}

Con el propósito de corroborar el aumento de apoptosis y analizar la presencia de necrosis se analizaron por microscopía de fluorescencia los cambios morfológicos de los núcleos de células HepG2 tratadas con AELta y sometidas a doble tinción con los colorantes fluorescentes Hoechst e IP.

Al igual que para el ensayo de TUNEL, células creciendo en cubreobjetos fueron tratadas con una concentración correspondiente a 1,0x IC 50 de AELta durante 48 horas. Luego fueron teñidas con Hoechst y posteriormente con IP para ser visualizadas por medio de microscopia de fluorescencia según se describió en Materiales y Métodos.

El colorante fluorescente azul Hoechst 33258 se utilizó para identificar los núcleos apoptóticos o necróticos. Los núcleos de células no apoptóticas pueden diferenciarse morfológicamente de los apoptóticos y necróticos según la intensidad de la tinción y la presencia de la fragmentación de ADN. Así pues, un núcleo se considera apoptótico cuando presenta mayor intensidad de tinción y/o la aparición de cuerpos apoptóticos, esto debido a la condensación del ADN y/o el compromiso de la permeabilidad de la membrana celular. En el caso de las necróticas también se observa mayor intensidad de tinción pero con la morfología y el tamaño del núcleo conservado. En contraposición, un núcleo normal (no apoptótico ni necrótico) presenta una tinción más difusa y punteada correspondiendo a la tinción de los nucléolos. El colorante fluorescente rojo IP, que sólo pueden ingresar al núcleo y unirse al ADN en células que presentan un compromiso en la permeabilidad o disrupción de la membrana, se utilizó para identificar células muertas. 
Como puede observarse en la Figura 4.7, la mayoría de las células control mostraron núcleos intactos de forma ovoide teñidos con fluorescencia azul moderadamente brillante (debida al colorante Hoechst 33258), componentes nucleares distribuidos uniformemente, ADN genómico aparentemente intacto y ausencia de fluorescencia roja (debido a la falta de penetración del colorante IP), que marca el patrón de las células normales intactas. En las células tratadas con AELta a la dosis de $\mathrm{IC}_{50}$ se observa un aumento del número de células que tienen mayor intensidad de fluorescencia con Hoechst 33258 y/o con los cambios morfológicos asociados a fenómenos de muerte celular. Numerosas células exhibieron núcleos con características típicas de apoptosis, con una cromatina altamente condensada o fragmentada que resultó intensamente fluorescente con Hoechst 33258. Una pequeña proporción de estas células están en un estadio temprano de la apoptosis donde la permeabilidad de la membrana todavía se conserva y la fluorescencia roja, por lo tanto, está ausente; mientras que la mayoría se encuentran en apoptosis tardía y emiten fluorescencia de color rojo debido a que la permeabilidad de la membrana se encuentra comprometida y el PI ingresa en las células (Figura 4.7, Panel A, subcampos 1 y 2). También se observó un aumento de células necróticas que emiten fluorescencia roja con núcleos intactos y cromatina organizada (células muertas con núcleos normales) (Fig. 4.7, Panel A, subcampo 2).

En la Figura 4.8 se muestran los porcentajes de células apoptóticas y necróticas calculados como se describió en Materiales y Métodos. El tratamiento de células HepG2 con $1,0 \times I_{50}$ de AELta incrementó el porcentaje de células apoptóticas por más de 5 veces mientras que el de necróticas sólo fue duplicado. 


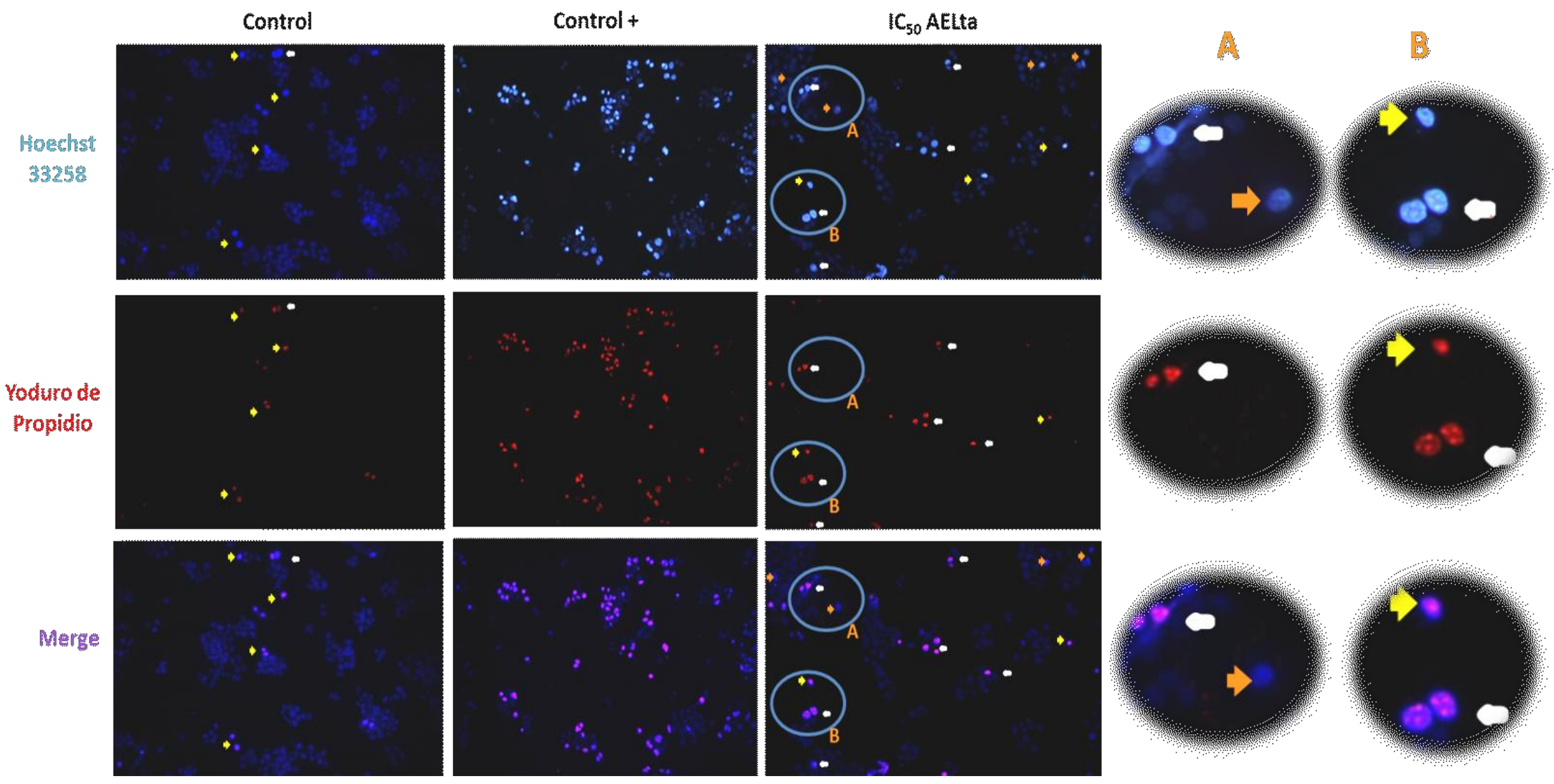

Figura 4.7. Apoptosis en células HepG2 determinada por observación de cambios morfológicos en el núcleo. Imágenes de microscopía de fluorescencia (400X) de células tratadas con DMSO 0,2 \% (Control), DMSO $3 \%$ (Control +) y el IC fol $_{\text {del }}$ AELta durante 48 horas. Se observa células apoptóticas tempranas (flechas naranja) que tienen indicadores morfológicos de apoptosis, mayor intensidad en Hoechst pero no incorporan IP. Células en apoptosis tardía (flechas blancas) que presentan los cambios anteriores e incorporan el colorante IP. Células necróticas (flechas amarillas) con mayor intensidad en Hoechst, incorporan IP pero no presentan cambios morfológicos. Los subcampos (A) y (B) son imágenes ampliadas de las regiones indicadas como $A$ y $B$ en el panel correspondiente a las células tratadas con AELta. 


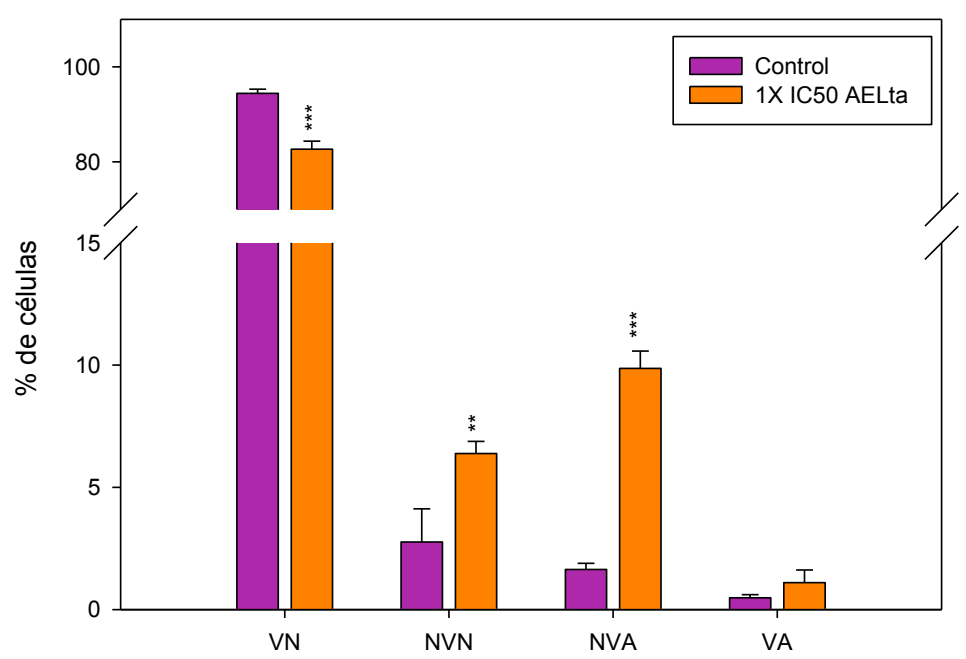

Figura 4.8. Porcentaje de células HepG2 apoptóticas y necróticas determinadas mediante ensayo morfológico por tinción de Hoechst e IP. El porcentaje de células viables $(V N)$, células necróticas (NVN), células en apoptosis tardía (NVA) y apoptosis temprana (VA) fue cuantificado como previamente descrito y los valores muestran el promedio \pm DS $(n=3) ; * p$ $<0,05 ;{ }^{* *} p<0,01 ;{ }^{* * *} p<0,001$.

\section{C.3. Efectos sobre la vía del mevalonato}

Una de las hipótesis planteadas acerca del mecanismo a través del cual algunos isoprenoides presentes en los AEs ejercen su actividad antiproliferativa, está relacionada con los múltiples efectos inhibitorios sobre la VM, que daría por resultado un desabastecimiento de productos de la misma vinculados al crecimiento y proliferación celular.

\section{C.3.1. Efecto sobre la síntesis de productos de la vía}

Con el propósito de analizar si la supresión del crecimiento mediada por AELta puede ser atribuida a una inhibición en la VM, se evaluó la extensión en la cual el ${ }^{14} \mathrm{C}$-acetato fue metabolizado a colesterol y otros lípidos insaponificables de VM (lanosterol, escualeno, dolicol y ubiquinona), por medio de la cuantificación de la incorporación de radioactividad en células tratadas con AELta por 48 horas a una concentración del 1,0x IC $\mathrm{C}_{50}$. Como control positivo de un inhibidor de la VM a nivel de la HMGCR se utilizó Sv.

En células HepG2 (Figura 4.9, Panel A) fue cuantificable la incorporación de acetato en escualeno, lanosterol (intermediarios de VM específicamente relacionados con la síntesis de colesterol) y en ubiquinona (otro producto final de la VM además del colesterol). En células tratadas con AELta se inhibió la colesterogénesis por un $90 \%$ y disminuyó la incorporación de radiactividad en lanosterol y escualeno en un $70 \%$ y $80 \%$ respectivamente. La incorporación en ubiquinona se cuadruplicó con respecto al control.

En células A549 (Figura 4.9, Panel B), la incorporación de acetato solo se pudo cuantificar en colesterol, lanosterol y ubiquinona; escualeno y otros intermediarios de la VM fueron indetectables bajo las condiciones tratadas. AELta disminuyó la incorporación de 
radiactividad en colesterol y lanosterol en alrededor de un $90 \%$, mientras que la marca radiactiva en ubiquinona se incrementó grandemente (alrededor de 25 veces).

A

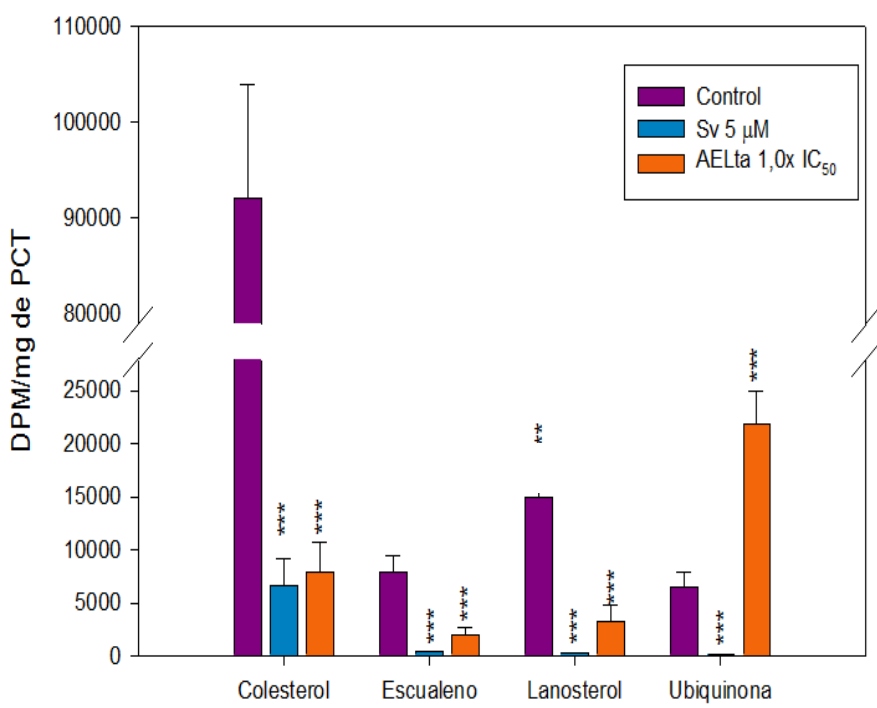

B

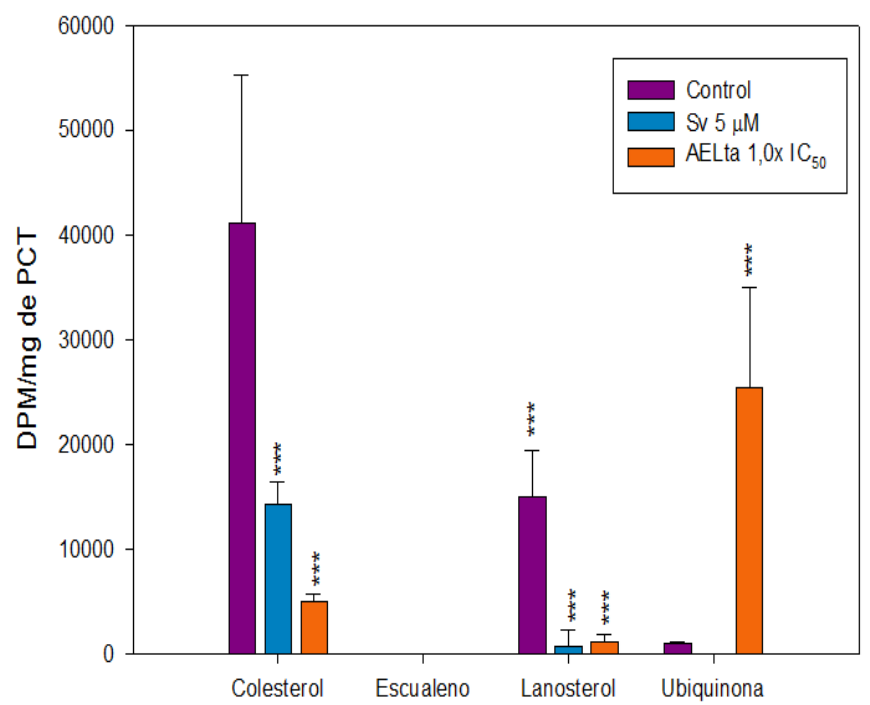

Figura 4.9. Incorporación de ${ }^{14} \mathrm{C}$-acetato en colesterol y otros lípidos insaponificables de la vía del mevalonato en células HepG2 y A549. Células en crecimiento exponencial fueron tratadas por 48 horas con $1,0 \times \mathrm{IC}_{50}$ de AELta o Sv $5 \mu \mathrm{M}$ y marcadas con $1 \mu \mathrm{Ci} / \mathrm{ml}$ de ${ }^{14} \mathrm{C}$-acetato durante las últimas 3 horas de tratamiento. La incorporación de radiactividad en colesterol, lanosterol, escualeno y ubiquinona en células HepG2 (Panel A) y en colesterol, lanosterol y ubiquinona en células A549 (Panel B) fue localizada por autorradiografía y cuantificada por densitometría. Los datos se expresan como el promedio \pm DS $(n=4) ;{ }^{*} p<0.05,{ }^{*} p<0.01, * * * p<0.001$. DPM: destellos por minuto; PCT: proteína celular total.

A pesar de la profunda inhibición de la colesterogénesis, el contenido de colesterol en las dos líneas celulares se mantuvo sin cambios (Tabla 4.4).

Tabla 4.4. Contenido de colesterol en células HepG2 y A549 tratadas con 1,0x IC 50 de AELta.

\begin{tabular}{lcccc}
\hline & \multicolumn{2}{c}{ HepG2 } & \multicolumn{2}{c}{ A549 } \\
\hline $\boldsymbol{\mu g} / \mathrm{mg}$ de PCT & Control & $\mathbf{1 , 0 \times}$ IC 50 & Control & $\mathbf{1 , 0 \times}$ IC 50 \\
Colesterol Libre & $14,55 \pm 2,73$ & $16,23 \pm 1,90$ & $10,12 \pm 0,92$ & $10,70 \pm 2,41$ \\
Ester de Colesterol & $4,30 \pm 0,41$ & $4,46 \pm 1,26$ & $3,51 \pm 0,97$ & $3,71 \pm 0,78$ \\
Colesterol total & $18,85 \pm 2,65$ & $20,69 \pm 0,98$ & $13,62 \pm 3,79$ & $14,06 \pm 1,70$ \\
\hline
\end{tabular}

Células en crecimiento exponencial fueron tratadas con el 1,0x IC 50 de AELta por 48 horas. Se extrajeron los lípidos totales de células, se separaron por TLC y se cuantificó el colesterol y éster de colesterol por densitometría. Se expresan los valores como el promedio $\pm D S(n=4)$. 


\section{C.3.2. Efecto sobre HMG-CoA reductasa.}

Para determinar si los efectos antiproliferativos se asocian a una disminución de la cantidad de HMGCR, se trataron células HepG2 con el aceite por 48 horas y luego por Western Blotting se determinaron los niveles de esta proteína en las células. Tanto para el 0,5x IC 50 como para el 1,0x IC 5 se registró una disminución de la cantidad de HMGCR en las células de una manera dosis dependiente (Figura 4.10). Se utilizó Sv $5 \mu \mathrm{M}$ como control positivo del incremento de los niveles de HMGCR.

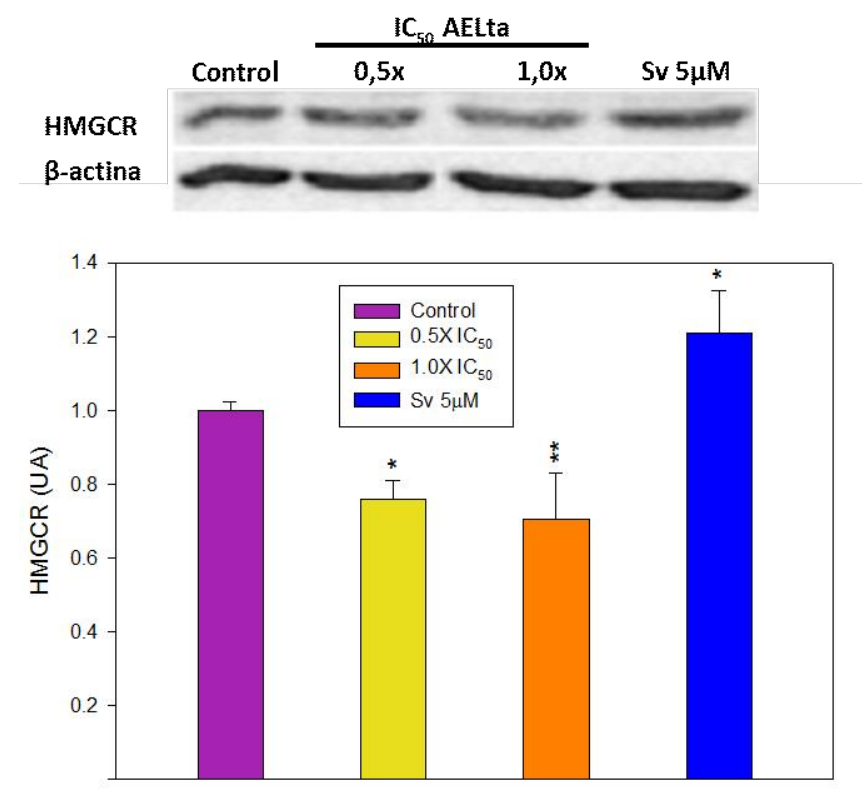

Figura 4.10. Efecto del AELta sobre los niveles de HMGCR en células HepG2. Células en fase exponencial de crecimiento fueron tratadas con AELta a $0,5 \times I_{50}$ y $1,0 \times I C_{50}$ de proliferación celular. Se utilizó simvastatina (Sv) $5 \mu \mathrm{M}$ como control positivo del aumento en los niveles de HMGCR. Las bandas inmunoreactivas fueron cuantificadas por densitometría y normalizadas con $\beta$-actina. Los resultados se expresan relativos al control, como el promedio \pm DS $(n=3) ;{ }^{*} p$ $<0,05 ; \quad * * p \quad<0,01 ; \quad * * * p \quad<0,001 . \quad \cup A=$ unidades arbitrarias. 


\section{C.3.3. Efecto de la adición de mevalonato sobre la inhibición de la viabilidad celular por AELta}

Con el fin de determinar si la inhibición de HMGCR era la causa o el resultado de la citotoxicidad inducida por AELta, se trataron células HepG2 y células A549 con concentraciones crecientes de AELta $\left(0,5 x, 1,0 x, 1,75 x\right.$ del $\left.I C_{50}\right) \circ$ con Sv, en presencia o ausencia de mevalonato ( $\mathrm{Mv} ; 0,5 \mathrm{mM}$ ) durante $48 \mathrm{~h}$, y luego se midió la viabilidad celular mediante el ensayo de MTT. Las células tratadas con concentraciones de Sv que inhiben significativamente su viabilidad (seleccionadas a partir de las curvas dosis-respuesta presentadas en el Apéndice I.3) fueron utilizadas como control positivo de una inhibición de crecimiento celular que puede ser restaurado por la adición de Mv.

En ningún caso la adición de Mv al medio de cultivo fue capaz de revertir la acción inhibitoria de la proliferación promovida por el aceite. Sin embargo, como era esperado, la adición de Mv exógeno, restableció significativamente la viabilidad de las células tratadas con Sv (Tabla 4.5).

Tabla 4.5. Viabilidad de células HepG2 y A549 tratadas con AELta en ausencia (-Mv) y presencia de (+Mv) de mevalonato exógeno.

\begin{tabular}{|c|c|c|c|c|}
\hline & \multicolumn{2}{|c|}{ HepG2 } & \multicolumn{2}{|c|}{ A549 } \\
\hline & $-M v$ & $+M v$ & $-M v$ & $+M v$ \\
\hline Control & $100,00 \pm 2,93$ & $109,00 \pm 10,84$ & $100,00 \pm 3,16$ & $110,00 \pm 6,18$ \\
\hline $0,5 \times I C_{50}$ & $78,64 \pm 7,22$ & $78,59 \pm 7,58$ & $82,91 \pm 0,59$ & $74,89 \pm 5,49$ \\
\hline $1,0 \times I C_{50}$ & $41,64 \pm 6,29$ & $38,85 \pm 1,46$ & $54,93 \pm 2,96$ & $61,52 \pm 3,37$ \\
\hline $1,75 \times I C_{50}$ & $15,39 \pm 4,94$ & $14,09 \pm 0,97$ & $30,59 \pm 1,27$ & $36,15 \pm 2,72$ \\
\hline Sv $10 \mu \mathrm{M}$ & $77,78 \pm 3,05$ & $123,16 \pm 2,70 * * *$ & nd & nd \\
\hline Sv $20 \mu \mathrm{M}$ & nd & nd & $60,13 \pm 1,61$ & $98,68 \pm 4,92 * * *$ \\
\hline
\end{tabular}

Células HepG2 y $A 549$ en crecimiento exponencial en placas de 24 pocillos fueron tratadas con concentraciones crecientes de AELta, o simvastatina (Sv) con o $\sin 0,5 \mathrm{mM}$ de mevalonato (Mv) por 48 h. La viabilidad celular se determinó por el ensayo de MTT y los resultados se expresan como el porcentaje con respecto al control. Los valores son los promedios \pm DS $(n=4)$. nd, no determinado; * $p$ $<0.05, * * p<0.01, * * * p<0.001$ vs. el mismo tratamiento $\sin \mathrm{Mv}$. 


\section{D. Efecto de la combinación de los AEs con simvastatina sobre la viabilidad celular.}

Partiendo de la hipótesis de que la interferencia de la VM es uno de los mecanismos a través de los cuales tanto los isoprenoides (componentes mayoritarios de los AEs) como las estatinas ejercen su efecto antiproliferativo y teniendo en cuenta que dicha interferencia se produciría a distintos niveles de la vía y/o por mecanismos diferentes, se consideró importante estudiar el potencial efecto sinérgico de los AEs en combinación con Sv.

La selección de la concentración de Sv utilizada en los ensayos combinados se realizó a través de curvas dosis-respuesta construidas a partir de los resultados obtenidos tras incubar células de ambas líneas con concentraciones crecientes de la estatina y cuantificar la viabilidad por ensayo de MTT (Ver Apéndice I.3). Los valores de $\mathrm{IC}_{50}$ de Sv determinados para nuestras condiciones experimentales fueron: 17,5 $\mu \mathrm{M}$ en HepG2 y 26,6 $\mu \mathrm{M}$ en $\mathrm{A} 549$.

Para evaluar el efecto sinérgico, células en fase exponencial de crecimiento se trataron con los compuestos adicionados individualmente o combinados de a pares. Se utilizaron concentraciones sub-óptimas de cada una de las sustancias a evaluar, las cuales no inhiben significativamente la viabilidad celular cuando son adicionadas individualmente: $0,5 \mathrm{x}$ $I_{50}$ de los aceites, Sv $5 \mu \mathrm{M}$ (HepG2) o $10 \mu \mathrm{M}$ (A549). Además se evaluaron concentraciones de los $\mathrm{AE}$ correspondientes al $\mathrm{IC}_{25}$, donde la inhibición es leve. La viabilidad celular se determinó mediante los ensayos de MTT y RN. Se calcularon los valores del índice de sinergismo (R) según se detalló en la sección 3.B.12. Como se mencionó anteriormente, todo valor de $R>1$ indica un efecto sinérgico en la combinación de ambos compuestos mientras que un $\mathrm{R} \leq 1$ responde a la ausencia de sinergismo.

En todos los ensayos realizados con HepG2 el tratamiento individual con dosis subóptimas de los compuestos no produjo inhibición significativa de la viabilidad celular. Mientras que al combinarlos de a pares se observó una inhibición significativa de la viabilidad, con índices $\mathrm{R}$ superiores a 1,19 que indican la existencia de efecto sinérgico entre ambos. Al combinar simvastatina con dosis levemente inhibitorias de los AEs también se registró un efecto sinérgico que en la mayoría de los casos resultó más marcado (Figura 4.11).

En células A549, el tratamiento combinado ocasionó una inhibición significativa de la viabilidad celular en todos los casos. Se registró un efecto sinérgico para la mayoría de las combinaciones de Sv con concentraciones de AEL subóptimas o levemente inhibitorias, siendo éstos más leves que los encontrados en células HepG2 (Figura 4.12). 


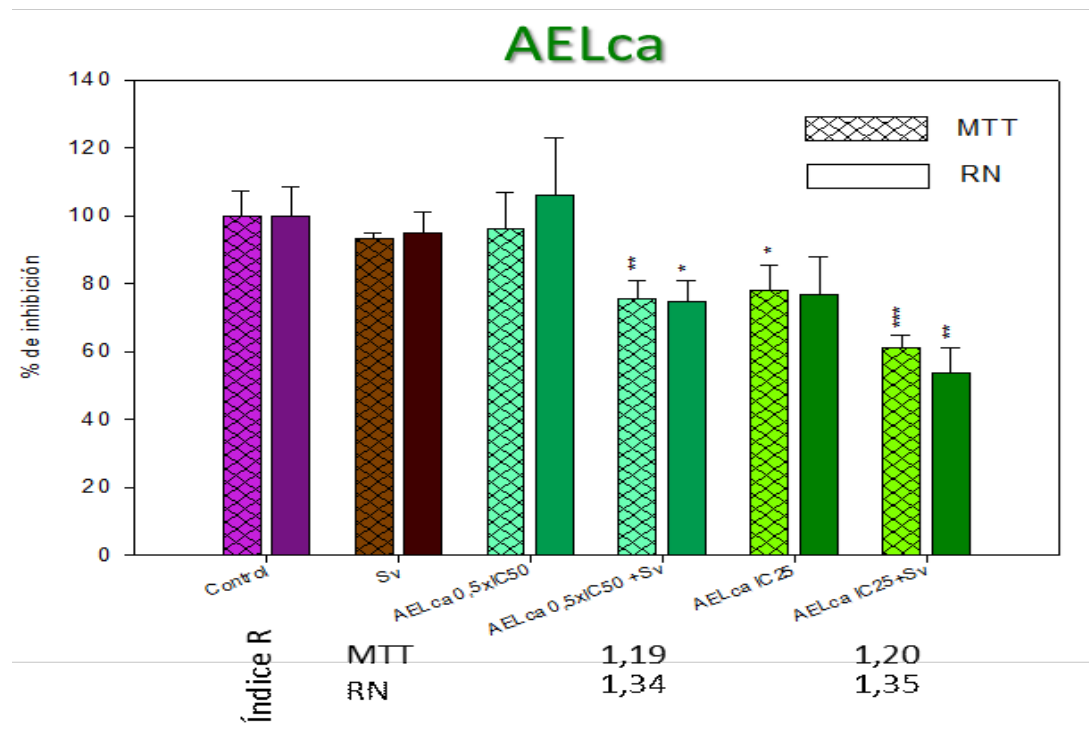

HepG2
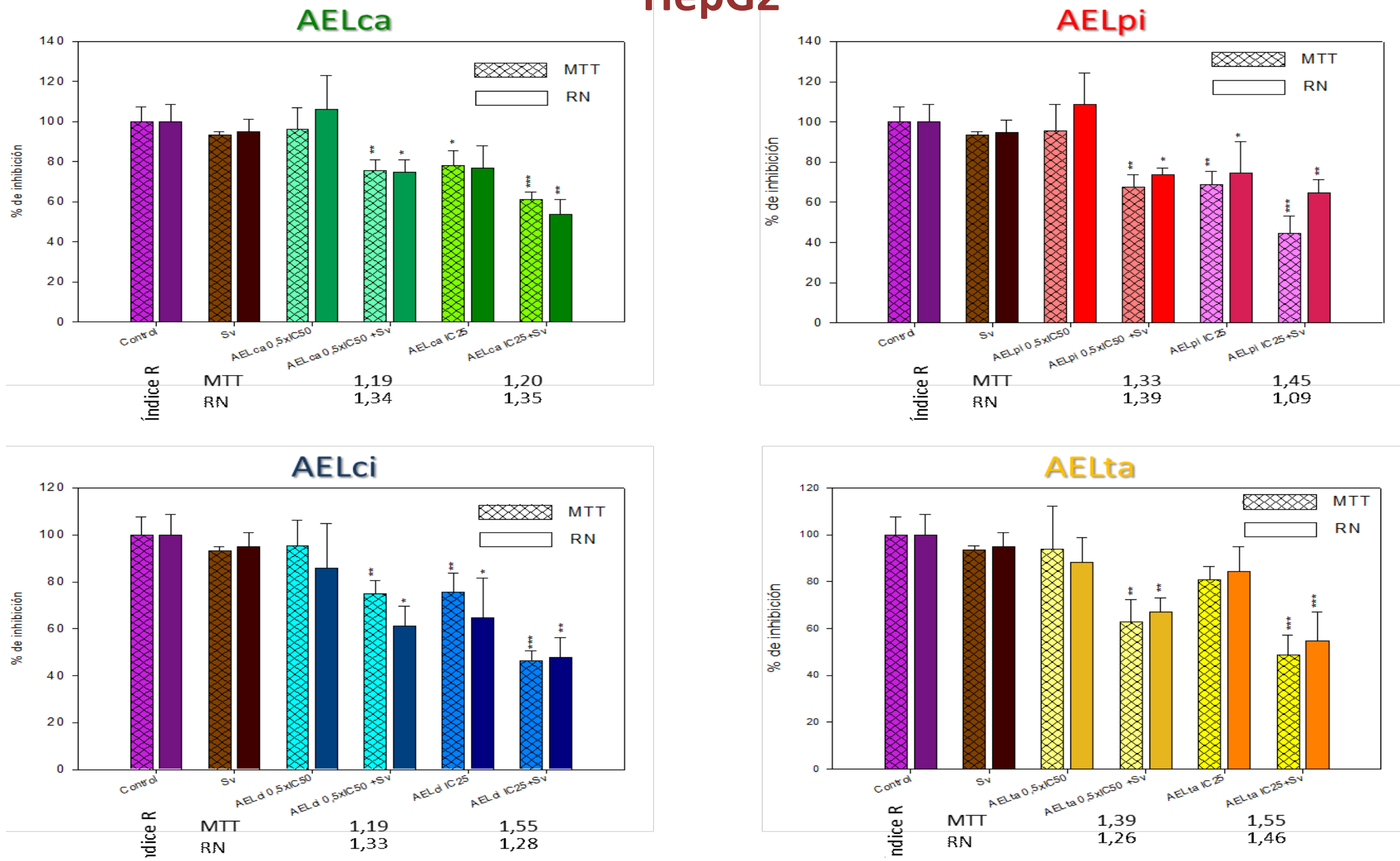

Figura 4.11. Efecto de la combinación de los AEs y simvastatina sobre la proliferación de células HepG2. Las células en fase exponencial de crecimiento fueron tratadas con la combinación de cada aceite en una dosis subóptima, 0,5xIC $\mathrm{C}_{50}$, o levemente inhibitoria, $\mathrm{IC}_{25}$, con simvastatina en una dosis subóptima, $5 \mu \mathrm{M}$, durante 48 horas. La proliferación fue determinada mediante los ensayos de MTT y RN. El efecto sinérgico fue evaluado calculando el índice $R$ como se describió anteriormente. Un $R>1$ indica sinergismo, mientras que un $R=1$ (efecto aditivo) o inferior implica ausencia de sinergismo. Los resultados están expresados como el promedio $\pm D S(n=3) ;{ }^{*} p<0,05 ;{ }^{* *} p<0,01 ; * * * p<0,01$. 

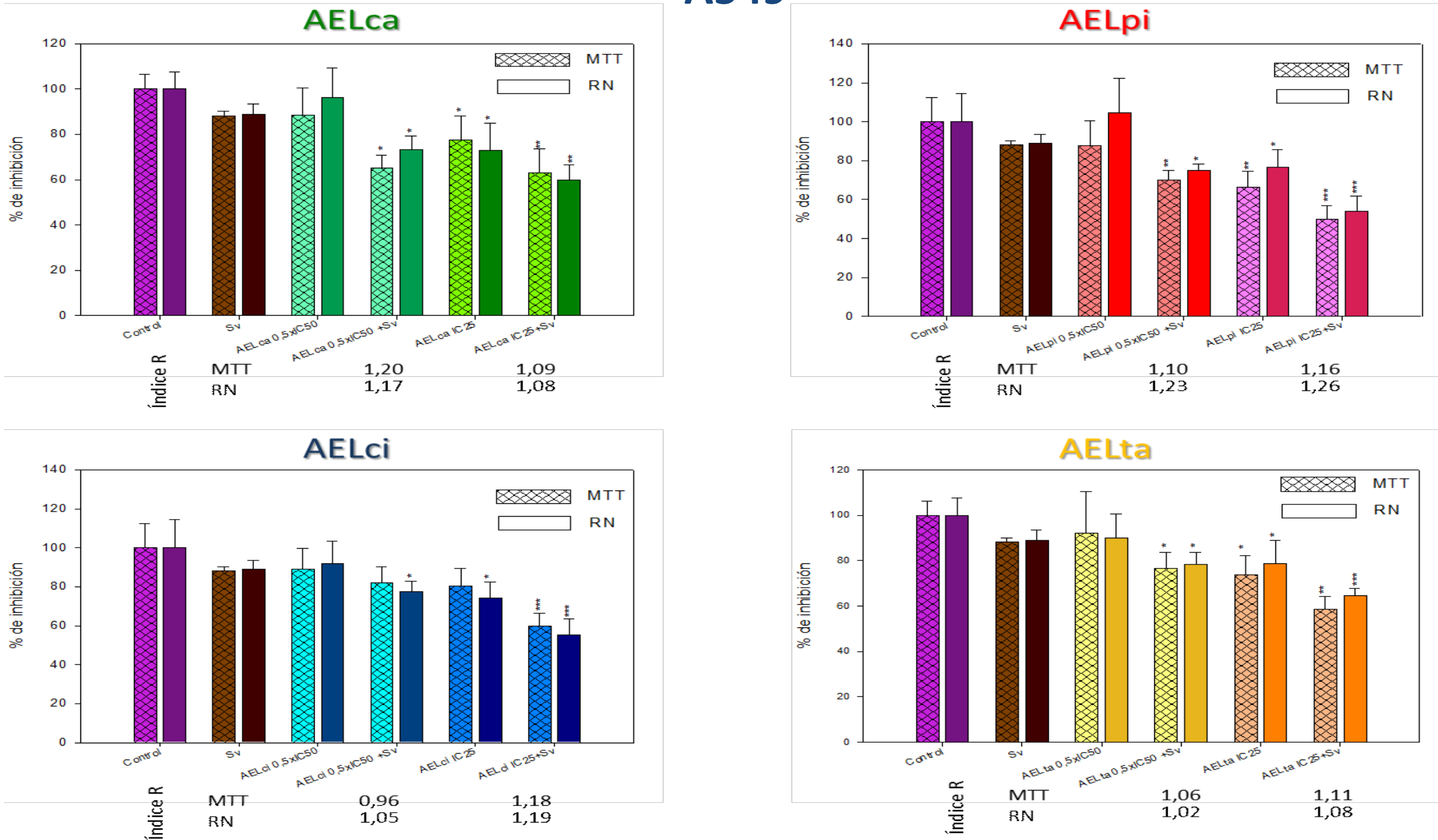

Figura 4.12. Efecto de la combinación de los AEs y simvastatina sobre la proliferación de células A549. Las células en fase exponencial de crecimiento fueron tratadas con la combinación de cada aceite en una dosis subóptima, 0,5x IC $C_{50}$, o levemente inhibitoria, $\mathrm{IC}_{25}$, con simvastatina en una dosis subóptima, $10 \mu \mathrm{M}$, durante 48 horas. La proliferación celular fue determinada mediante los ensayos de MTT y RN. El efecto sinérgico fue evaluado calculando el índice $\mathrm{R}$ como se describió anteriormente. Un $\mathrm{R}>1$ indica sinergismo, mientras que un $\mathrm{R}=1$ (efecto aditivo) o inferior implica ausencia de sinergismo. Los resultados están expresados como el promedio \pm DS $(n=3) ;{ }^{*} p<0,05 ;{ }^{* *} p<0,01 ;{ }^{* *} p<0,01$. 


\section{E. Discusión}

El cáncer es una enfermedad genética compleja que comprende características específicas. Estas incluyen el mantenimiento de la señalización proliferativa, la evasión de supresores del crecimiento, la resistencia a la muerte celular, la inducción de la angiogénesis, la activación de la invasión y la metástasis, la reprogramación del metabolismo energético y la evasión de la respuesta inmunitaria (109). Por este motivo, la quimioterapia aprovecha la facultad de diversas drogas para reducir la capacidad de crecer y dividirse de las células neoplásicas y/o para inducir daño y muerte celular.

El estudio de productos naturales ha sido la estrategia más exitosa para el descubrimiento de nuevos medicamentos utilizados en la terapia contra el cáncer y más de dos tercios de los fármacos utilizados en el tratamiento del cáncer provienen directamente de productos naturales o son desarrollados usando los conocimientos adquiridos al estudiar la actividad de sus componentes $(394,395)$.

En años recientes, diversos estudios realizados utilizando AEs han demostrado que los mismos poseen actividad antitumoral tanto in vivo como in vitro $(332,396)$.

En este trabajo lo primero que se analizó fue la potencial utilidad farmacológica de AEs de cuatro quimiotipos de Lippia alba cultivados en Costa Rica en la terapia del cáncer.

Uno de los parámetros a tener en cuenta en la selección de potenciales fármacos antitumorales es su eficacia para inhibir el crecimiento de células tumorales. En este sentido, con el fin de analizar la actividad citotóxica de los cuatro quimiotipos en estudio, se evaluó en células tumorales el efecto sobre la viabilidad celular.

El Instituto Nacional del Cáncer de EUA (US- $\mathrm{NCl}$ ) establece que un extracto crudo que muestra un valor de $\mathrm{IC}_{50}$ de viabilidad inferior a los $100 \mu \mathrm{g} / \mathrm{ml}$ se considera citotóxicamente activo. Cuando el valor de $\mathrm{IC}_{50}$ es inferior a $30 \mu \mathrm{g} / \mathrm{ml}$, el US- $\mathrm{NCl}$ considera al extracto crudo como prometedor para la purificación y el estudio de su actividad biológica $(397,398)$. En el caso de compuestos puros, se consideran activos cuando los valores de $I_{50}$ son inferiores a $4 \mu \mathrm{g} / \mathrm{ml}(399,400)$.

De acuerdo con los resultados obtenidos de la medida de viabilidad (Tabla 4.1 y 4.2 ) sólo los aceites esenciales de L. alba correspondientes a los quimiotipos tagetenona y citral, que ocasionan un $50 \%$ de inhibición de la viabilidad de células A549 y HepG2 con concentraciones próximas a los $30 \mu \mathrm{g} / \mathrm{ml}$, pueden considerarse citotóxicamente activos en 
estas células neoplásicas. Por el contrario, los valores de $\mathrm{IC}_{50}$ obtenidos en células $\mathrm{A} 549$ y HepG2 tratadas con AEs de los quimiotipos carvona y piperitona, indican que no clasifican como extractos crudos citotóxicos según la US-NCI.

Según los valores de $I_{50}$ obtenidos en células Vero (Tabla 4.1), los AEs de los quimiotipos carvona, piperitona y tagetenona muestran poca o ninguna citotoxicidad $\left(\mathrm{IC}_{50}>\right.$ $100 \mu \mathrm{g} / \mathrm{ml}$ ) y sólo el quimiotipo citral ( $\left(C_{50}\right.$ cercano al $100 \mu \mathrm{g} / \mathrm{ml}$ ) puede considerarse citotóxicamente activo en esta línea celular no tumoral.

Otro parámetro a considerar en la selección de fármacos contra el cáncer es la selectividad del efecto citotóxico sobre las células tumorales en comparación con no tumorales. De acuerdo con los criterios utilizados por Bézivin et al.(392) y Prayong et al.(401) una droga puede considerarse selectiva cuando el IS tiene un valor superior a tres. En nuestro caso sólo AELta resultó ser altamente selectiva para células tumorales con valores de IS próximos a 7 (Tabla 4.1). Concentraciones que tienen un fuerte efecto citotóxico en las líneas celulares de carcinoma (con la inhibición de la viabilidad de más de 95 \%) no afectan significativamente la viabilidad de las células de la línea no cancerosa (Figura 4.1).

Por lo tanto, dado que el AELta manifiesta tanto un efecto citotóxico como una marcada selectividad por las células neoplásicas, éste AE puede ser considerado como un fitocomplejo prometedor para el desarrollo de fármacos anticáncer.

La citotoxicidad y selectividad de diversos AEs del género Lippia han sido analizados por otros autores con resultados variables. La actividad citotóxica de los quimiotipos citral y carvona fue evaluada por Mesa-Arango et al. (304). En este estudio el quimiotipo citral presentó la actividad citotóxica más alta en la línea tumoral HeLa y el quimiotipo carvona la actividad más baja ( $\left(C_{50}: 3.5 \mu \mathrm{g} / \mathrm{ml}\right.$ y $74.5 \mu \mathrm{g} / \mathrm{ml}$, respectivamente), y ninguno de los dos quimiotipos fueron citotóxicos sobre las células no tumorales Vero. Zapata et al. (332) evaluaron la selectividad y la actividad citotóxica de treinta AEs del género Lippia (veinticinco de los cuales corresponden a plantas de $L$. alba) encontrando que ninguno es citotóxico para las células Vero y sólo tres AEs de L. alba del quimiotipo citral mostraron actividad citotóxica sobre células HepG2 (entre $I C_{50} 17,5$ y $24,5 \mu \mathrm{g} / \mathrm{ml}$ ) pero con bajos IS. Ferraz et al. (402) mostraron que el AE de Lippia gracilis tiene actividad citotóxica en tres líneas de células tumorales (HepG2, K562 y B16-F10), así como en los linfocitos normales. A nuestro entender esta es la primera evaluación del AE de L. alba quimiotipo tagetenona. 
Las diferencias en las actividades biológicas de los distintos AEs se atribuyen principalmente a las diferencias en la composición de monoterpenos, los que se describen como principales responsables de la actividad antitumoral de estos (304, 402-405). Recientemente en nuestro laboratorio se describió que 1,8-cineol, uno de los monoterpenos mayoritarios de AELta, inhibe la viabilidad de las células HepG2 y A549 (250). Los valores de $\mathrm{IC}_{50}$ registrados para 1,8-cineol $(6050 \mu \mathrm{M}=933.2 \mu \mathrm{g} / \mathrm{ml}$ y $5030 \mu \mathrm{M}=775.9 \mu \mathrm{g} / \mathrm{ml}$, para HepG2 y A549 respectivamente) son mucho más altos que los obtenidos en esta tesis para el AELta en idénticas condiciones experimentales. Estos resultados, que indican que el AELta es un inhibidor más potente que uno de sus componentes mayoritarios, son consistentes con los reportados por varios autores como Doll-Boscardin y Li $(406,407)$ y por nuestro grupo de trabajo donde el aceite esencial de mandarina presenta actividad antiproliferativa más efectiva que el limoneno (su principal componente) en células HepG2 y A549 (408). La mayor actividad de los AEs respecto a los componentes mayoritarios puros se atribuyen a la interacción de estos últimos entre sí o con componentes minoritarios al presentarse combinados en el AE completo (409-411). Por lo tanto, los estudios realizados con los componentes individuales pueden reportar resultados que no recapitulan el efecto del tratamiento con el fitocomplejo como un todo.

Mientras que la selectividad y citotoxicidad se han documentado para algunos quimiotipos de $L$. alba en ensayos de tamizaje, poco se ha explorado en relación con los mecanismos por los que se generan estos efectos. Se han descrito diferentes mecanismos a través de los cuales los AEs o sus constituyentes pueden ejercer su efecto citotóxico. Estos incluyen la inducción de la muerte celular por apoptosis y/o necrosis, el arresto del ciclo celular, y la pérdida de la función de organelas claves $(238,412)$.

La detención del ciclo celular es una causa común de inhibición del crecimiento celular y uno de los mecanismos mediante los cuales los AEs pueden ejercer sus efectos citotóxicos (412). Al arrestarse el ciclo celular se crea una oportunidad para que las células se sometan, ya sea, a la reparación o a entrar en apoptosis de manera que se mantenga la homeostasis del tejido y se eliminen células neoplásicas mutadas e hiperproliferantes del sistema (413).

Aquí se demostró que el efecto citotóxico de AELta sobre células HepG2 y A549 está vinculado con una inhibición de la proliferación como resultado de la detención del ciclo celular (Figura 4.5). El efecto citostático con arresto tanto en G1 y G2 se ha informado para 
otros aceites esenciales y monoterpenos $(238,402)$. Generalmente el arresto del ciclo en G0/G1 que ocasionan los isoprenoides se asocia a efectos producidos sobre proteínas involucradas en la transición de la fase G1 a S, como ciclina D1, p21, p27 y p53 entre otras $(414,415)$. El arresto en G2/M se ha descrito en la línea celular A549 para monoterpenos, como es el caso del terpinen-4-ol, y para otros compuestos, a los cuales se les atribuye un efecto inhibitorio sobre proteínas de la vías efectoras de Ras (PI3K/Akt) que participan en la transición de G2 a M $(416,417)$.

La inducción de la apoptosis, evento que acompaña al arresto del ciclo celular en la supresión del crecimiento generada por isoprenoides, es otro mecanismo por el que los AEs pueden ejercer sus efectos citotóxicos $(244,247,412)$, y cuyo enfoque es útil en terapias contra el cáncer (418).

Se demostró que los AELs en HepG2 y AELta en A549, son capaces de inducir la fragmentación del ADN (Figura 4.6, Tabla 4.3 y Apéndice 2), evento característico de la inducción de muerte celular a través de apoptosis (419). Con AELta, la presencia de apoptosis fue corroborada al evaluar los cambios en la morfología nuclear por el ensayo de Hoechst e IP (Figura 4.7 y 4.8), es así que se puede implicar a la inducción de apoptosis como uno de los mecanismos por los que los AELs tienen su efecto anticanceroso.

La detención del ciclo celular y los efectos proapoptóticos de los AEs se han atribuido a la interferencia de los monoterpenos, sus principales constituyentes, con varios procesos bioquímicos relacionados con el crecimiento y la proliferación celular (412). Entre ellos, la actividad antiproliferativa de los monoterpenos se ha atribuido a múltiples efectos inhibitorios sobre la VM $(246,249,262,266,270,420,421)$.

Algunos isoprenoides poseen la propiedad de disminuir los niveles de la HMGCR (262, 266). Por ejemplo, Cho et al (422) informaron de una disminución en los niveles de HMGCR en células HepG2 tratadas con linalool, causada por una inhibición a nivel transcripcional y un aumento de la degradación de la enzima. Por otra parte, más recientemente, en nuestro laboratorio se describió que el geraniol inhibe a la HMGCR a nivel postranscriptional (246). Los inhibidores HMGCR, al interrumpir la síntesis de mevalonato, disminuyen la síntesis de productos finales (colesterol, ubiquinona y dolicol) que realizan importantes funciones fisiológicas e inactivan la translocación de Ras y la señalización corriente abajo de MEK/ERK y PI3K/Akt, lo que lleva a la inhibición de la progresión del ciclo celular y la apoptosis de las células cancerosas $(29,44,423)$. 
En este trabajo se demostró que una concentración de AELta que inhibe el $50 \%$ de viabilidad celular conduce a la disminución de los niveles de HMGCR en células HepG2 (Figura 4.10). Sin embargo, bajo estas condiciones, la adición de Mv no logró revertir en ningún caso la inhibición de la proliferación celular ocasionada por AELta; entonces, la inhibición de la reductasa no parece ser la causa de la citotoxicidad ejercida por este AE (Tabla 4.5).

También se observó que condiciones experimentales que ocasionan una disminución moderada de los niveles de HMGCR (como el tratamiento con concentración de AELta correspondiente al IC $\mathrm{C}_{50}$ de viabilidad; Figura 4.10), resultan en una marcada inhibición de la colesterogénesis (90\%) y de la incorporación de acetato en intermediarios de la VM específicamente involucrados en la síntesis de colesterol, pero causan un incremento de la síntesis de otro producto final de la vía como la ubiquinona (Figura 4.9). Entonces, la disminución de la síntesis de colesterol podría ser atribuida a una modesta inhibición de la HMGCR y a un profundo bloqueo de alguna otra etapa de la VM directamente relacionada a la colesterogénesis, presumiblemente la conversión de FPP a escualeno por escualeno sintasa, que ocasionaría una acumulación y redireccionamiento de FPP (metabolito del principal punto de ramificación de la VM) hacia la generación de otros productos finales de la VM tal como ubiquinona. Efectos similares se han reportado para los monoterpenos tales como linalool y 1,8-cineol en HepG2 y células A549 (250) o el geraniol en las células HepG2 (249).

La depleción del contenido de colesterol celular, por disminución de la síntesis de colesterol, no sería la causa de la inhibición de la proliferación registrada, dado que, pese a la profunda inhibición de la colesterogénesis ocasionada por el tratamiento con 1,0x $\mathrm{IC}_{50}$ AELta, el contenido de colesterol celular se halla conservado (Tabla 4.4), lo que estaría indicando que las células satisfacen sus necesidades por incorporación de colesterol exógeno. Sin embargo, un incremento del farnesol endógeno, producido a partir del FPP acumulado por acción de farnesilpirofosfatasa (424) podría ser una de las causas del efecto antiproliferativo del AELta, dado que diversos autores han reportado que este isoprenoide inhibe la proliferación celular e induce apoptosis en un amplio rango de células malignas y que las células tumorales son generalmente más sensibles que las células normales (425).

Ciertos monoterpenos, presentes en los AEs compiten con reacciones de isoprenilación de proteínas disminuyendo o bloqueando la función de las proteínas de 
señalización celular que conducen al crecimiento de células cancerosas $(426,427)$. Muchos componentes de los AEs, como limoneno $(428,429)$ y perillil alcohol $(44)$, inhiben isoprenilación de proteínas de la familia Ras y con ello bloquean el desarrollo del cáncer. En nuestro caso se cree que futuros estudios permitirán elucidar si la inhibición en la prenilación de proteínas está relacionada con el efecto citotóxico mostrado por estos aceites.

Numerosos estudios han demostrado que las estatinas son capaces de inhibir la proliferación de una amplia variedad de células tumorales incluyendo de carcinoma pancreático, gástrico y prostático, adenocarcinoma de colon, de pulmón, glioblastoma, neuroblastoma, melanoma y leucemia mieloide aguda, cáncer hepático y de mama entre tantas otras $(120,430,431)$. Diferentes líneas de evidencia sugieren que estas drogas inhiben la progresión del ciclo celular mediante la inducción de la expresión de las proteínas p21 y p27 y/o la represión de factores proliferativos como las ciclinas y CDKs (120, 432, 433). También se ha visto que promueven la apoptosis atenuando la actividad de Ras y RhoA y sus vías efectoras, principalmente a causa de la depleción del GGPP y en menor medida de FPP $(40,120,434)$. Otros trabajos reportan que las estatinas podrían tener un efecto benéfico en la disminución del riesgo de desarrollar hepatocarcinoma celular (HCC) y cáncer de pulmón entre otros, en el mejoramiento de la supervivencia de pacientes con HCC (en tratamientos asociados a otras drogas terapéuticas) y en la reducción de la recurrencia de ciertos tipos de cáncer (435-438).

En particular, se ha descrito que la Sv inhibe la proliferación de células tumorales en el rango de concentraciones que aquí describimos (439-441). En las condiciones experimentales estudiadas, la Sv inhibe en un 50 \% la proliferación de ambas líneas celulares a concentraciones cercanas a $20 \mu \mathrm{M}$ (Apéndice 1.3), valores muy superiores a las concentraciones alcanzados en plasma con dosis terapéuticas máximas de Sv administradas en los tratamientos de hipercolesterolemia en humanos $(0,04 \mu \mathrm{M})(442)$.

Teniendo en cuenta que las dosis máximas de Sv utilizadas en el tratamiento de hipercolesterolemia han sido asociadas a múltiples efectos tóxicos $(120,443,444)$ y que las estatinas utilizadas como agentes quimioterapéuticos únicos exhiben propiedades anticancerígenas modestas $(40,92)$, se considera su potencial uso en el tratamiento del cáncer principalmente en combinación con otras sustancias quimioterapéuticas $(40,120$, 430). Por tal motivo, se planteó estudiar la combinación de Sv con los aceites esenciales de 
Lippia alba en busca de posibles efectos sinérgicos que permitan aumentar su efectividad y/o disminuir las concentraciones de estatinas empleadas.

En células HepG2 la combinación de la Sv con los aceites esenciales mostró en todos los casos un efecto antiproliferativo sinérgico ( $R>1$ ) (Figura 4.11). En el caso de células A549, a excepción de AELci que parece tener un efecto aditivo, también se observó un efecto sinérgico al combinar Sv con los AEs, aunque más moderado que el registrado en HepG2 (Figura 4.12). Similares resultados fueron obtenidos en nuestro laboratorio al analizar la combinación de Sv con los monoterpenos linalool y 1,8-cineol $(250,445)$. Estos resultados alientan la propuesta de utilizar las estatinas combinadas con otros compuestos capaces de inhibir la proliferación de células malignas, como los aceites esenciales o sus constituyentes mayoritarios. 


\section{Capítulo \\ SOBRE EL METABOLISMO LIPÍDICO CELULAR}

\section{Combinación con simvastatina}


Este capítulo está dedicado inicialmente al estudio de la acción de distintos quimiotipos de AEL sobre la VM evaluando especialmente la actividad anticolesterogénica y el impacto que ella tiene sobre el contenido de lípidos en células hepáticas y extra-hepáticas. Para validar el modelo experimental se utilizó la Simvastatina (Sv) como compuesto testigo de un inhibidor de la colesterogénesis empleado para el tratamiento de hipercolesterolemia en humanos. Los experimentos llevados a cabo para analizar efectos sobre el metabolismo lipídico en general, se realizaron con el quimiotipo más eficaz en la inhibición de la síntesis de colesterol y se desarrollaron fundamentalmente en células HepG2 como modelo de células hepáticas.

\section{A. Vía del mevalonato y colesterogénesis en células HepG2 y A549 tratadas con simvastatina}

Inicialmente, para validar las condiciones experimentales en las que se estudiarían los AEs, se evaluó el efecto sobre la generación de productos de la VM de Sv, un inhibidor competitivo de la HMGCR y droga de primera línea en el tratamiento de hipercolesterolemia en humanos. Para esto, células HepG2 y A549 en fase exponencial de crecimiento fueron tratadas durante 48 horas con concentraciones crecientes de Sv en el rango de 0,01 a $5 \mu \mathrm{M}$, adicionando ${ }^{14} \mathrm{C}$-acetato durante las últimas 3 horas de tratamiento. Los lípidos insaponificables (LI) fueron extraídos, separados por TLC y las especies lipídicas radiactivas presentes fueron reveladas por autorradiografía (Figura 5.1, Paneles A y D). Se identificó el colesterol y otros lípidos de la VM (lanosterol, ubiquinona, dolicol y escualeno) por comparación con una mezcla de estándares resuelta en la misma placa y se cuantificó la radiactividad incorporada en ellos por densitometría, según lo descrito en Materiales y Métodos (Figura 5.1, Paneles B y E). Además, se realizaron curvas de inhibición de la incorporación de ${ }^{14} \mathrm{C}$-acetato en colesterol en función de la concentración y por regresión no lineal se calcularon los valores de $\mathrm{IC}_{50 \mathrm{sc}}$, la cual es la concentración que inhibe en un $50 \%$ la síntesis de colesterol (Figura 5.1, Paneles C y F).

En células HepG2 la Sv inhibió significativamente la síntesis de colesterol a partir de $0,02 \mu \mathrm{M}$ y el IC $\mathrm{I}_{50 \text { sc }}$ para estas células es de 0,06 $\mu \mathrm{M}$. También fue posible cuantificar la radiactividad incorporada en lanosterol, ubiquinona y escualeno observándose, como era esperable, que la incorporación de ${ }^{14} \mathrm{C}$-acetato en estos productos disminuyó drásticamente 
siendo significativa inclusive para la mínima concentración ensayada (Figura 5.1, Paneles A, B y C)

En las células A549 la Sv inhibe significativamente la síntesis de colesterol a partir de $0,5 \mu \mathrm{M}$ y el I $C_{50 \text { sc }}$ es de 1,2 $\mu \mathrm{M}$. En esta línea celular, además de colesterol, sólo se pudo cuantificar radiactividad en lanosterol registrándose una inhibición de la incorporación de

${ }^{14} \mathrm{C}$-acetato más marcada que en el producto final de su metabolismo. (Figura 5.1, Paneles D, E y F).

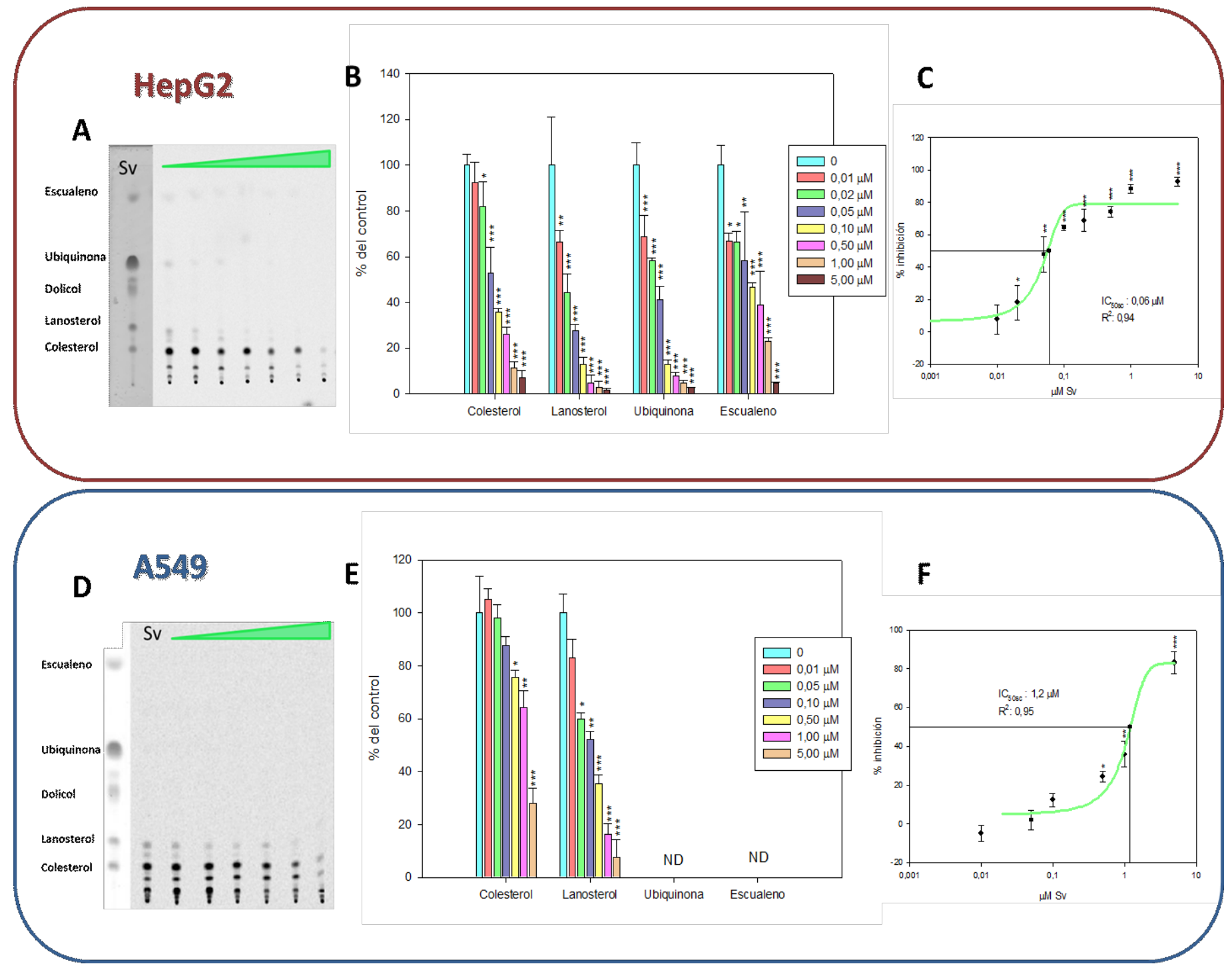

Figura 5.1. Incorporación de ${ }^{14} \mathrm{C}$-acetato en colesterol y otros lípidos insaponificables de la vía del mevalonato en células HepG2 y A549 tratadas con simvastatina. Las células se trataron con concentraciones crecientes de Sv que no inhiben la viabilidad celular durante 48 horas, agregando $1 \mu \mathrm{Ci} / \mathrm{ml}$ de ${ }^{14} \mathrm{C}$-acetato durante las últimas 3 horas. La incorporación de radiactividad en colesterol, lanosterol, ubiquinona y escualeno en HepG2 se reveló por autorradiografía (panel A y D) y cuantificó por densitometría (panel B y E).

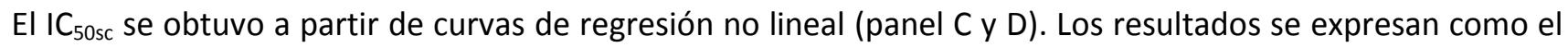
promedio \pm DS $(\mathrm{n}=4) ;{ }^{*} \mathrm{p}<0,05,{ }^{* *} \mathrm{p}<0,01,{ }^{* * *} \mathrm{p}<0,001$ 


\section{B. Efectos de los AEs de $L$. alba sobre la vía del mevalonato y el contenido de lípidos mayoritarios de células HepG2 y $\mathrm{A549}$}

\section{B.1. Vía del mevalonato y la colesterogénesis}

Una vez validado el modelo experimental con Sv, se evaluó la actividad de los 4 quimiotipos del AE de $L$. alba sobre la generación de productos de la VM y especialmente sobre la colesterogénesis, en células hepáticas (HepG2) y extrahepáticas (A549), bajo las mismas condiciones experimentales. Se utilizaron concentraciones crecientes de cada AE y en todos los casos la concentración máxima ensayada fue inferior a la concentración mínima inhibitoria del crecimiento.

\section{B.1.1. Incorporación de ${ }^{14} \mathrm{C}$-acetato en intermediarios y productos finales de la VM}

El tratamiento de ambas líneas celulares con los distintos AEs ocasionó una inhibición de la colesterogénesis dosis dependiente. En células A549 la inhibición de la síntesis de colesterol resultó significativa a partir de: $2 \mu \mathrm{g} / \mathrm{ml}$ para AELta, $4 \mu \mathrm{g} / \mathrm{ml}$ para AELpi, y $8 \mu \mathrm{g} / \mathrm{ml}$ para AELca y AELci (Figura 5.2). Mientras que en HepG2, la inhibición es significativa a concentraciones mayores o iguales a: $2 \mu \mathrm{g} / \mathrm{ml}$ para AELci y AELta, $20 \mu \mathrm{g} / \mathrm{ml}$ para AELca y alrededor de $40 \mu \mathrm{g} / \mathrm{ml}$ para AELpi (Figura 5.3).

Al analizar la incorporación de ${ }^{14} \mathrm{C}$-acetato en otros lípidos insaponificables de la VM, se detectó, identificó y cuantificó la radiactividad incorporada en lanosterol y ubiquinona para células A549 (Figura 5.2), mientras que para células HepG2 se determinó radiactividad en escualeno, lanosterol para todos los AEs y en ubiquinona para AELca, AELci y AELta (Figura 5.3).

La incorporación de ${ }^{14} \mathrm{C}$-acetato en los intermediarios de la VM específicamente involucrados en la colesterogénesis, lanosterol y escualeno, decrece en ambas líneas celulares al ser tratadas con los AEs, y las curvas de porcentaje de inhibición vs concentración son similares a las observadas para el colesterol (Figuras 5.2 y 5.3). Por el contrario, se registró un incremento de la radiactividad incorporada en ubiquinona, otro producto final de la VM (Figuras 5.2 y 5.3). 

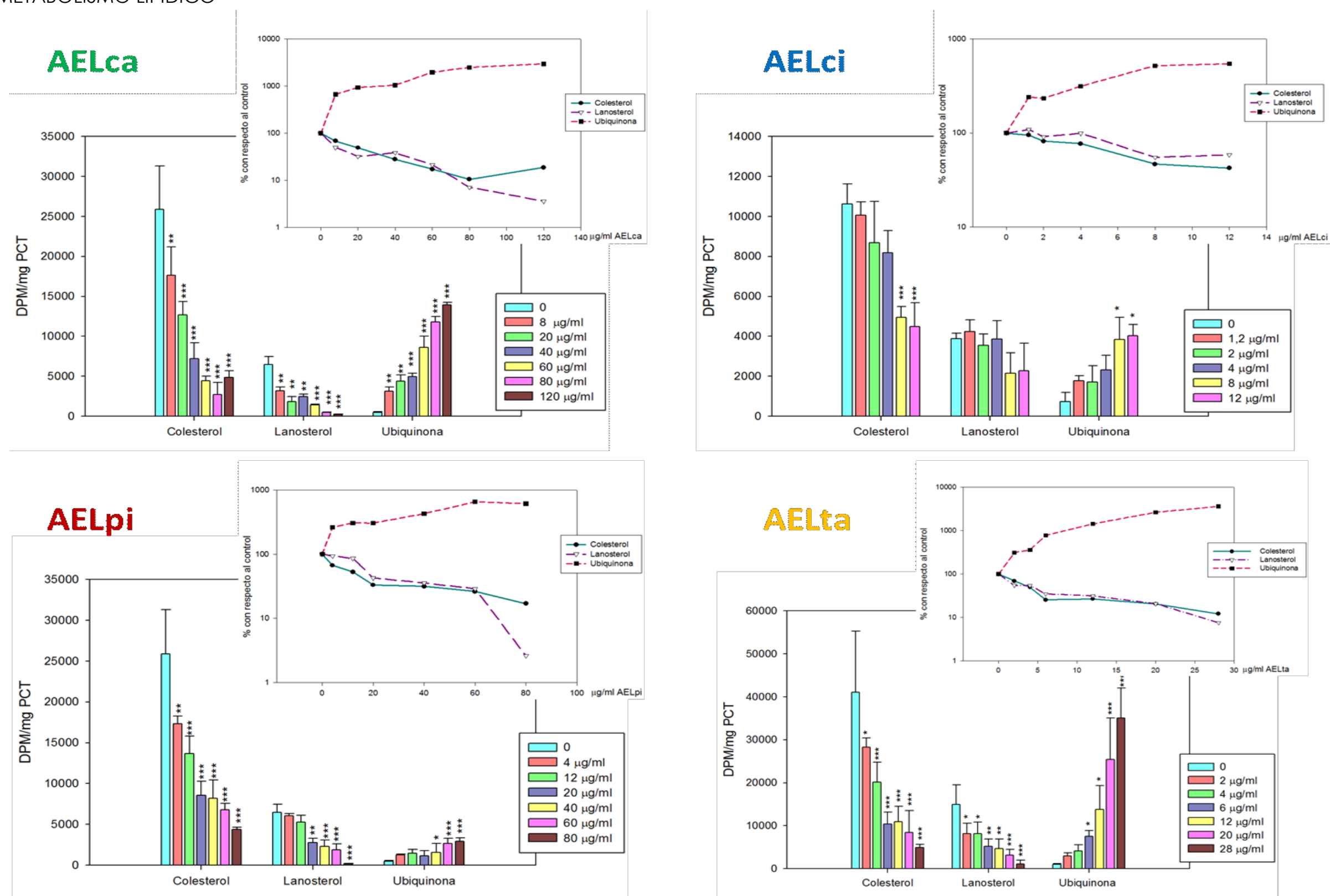

Figura 5.2. Incorporación de ${ }^{14} \mathrm{C}$-acetato en colesterol y otros lípidos insaponificables en células A549 tratadas con los AELs. Las células se trataron con concentraciones crecientes de cada uno de los AE de Lippia alba durante 48 horas, agregando $1 \mu \mathrm{Cl} / \mathrm{ml}$ de ${ }^{14} \mathrm{C}$-acetato durante las últimas 3 horas. La incorporación de radiactividad en colesterol, lanosterol, ubiquinona se reveló por autorradiografía y cuantificó por densitometría. Los resultados se expresan como el promedio \pm DS $(n=4) ;{ }^{*} p<0,05,{ }^{* *} p<0,01,{ }^{* * *} p<0,001$. Insertos: Curvas dosis respuesta de los intermediarios para cada tratamiento. 

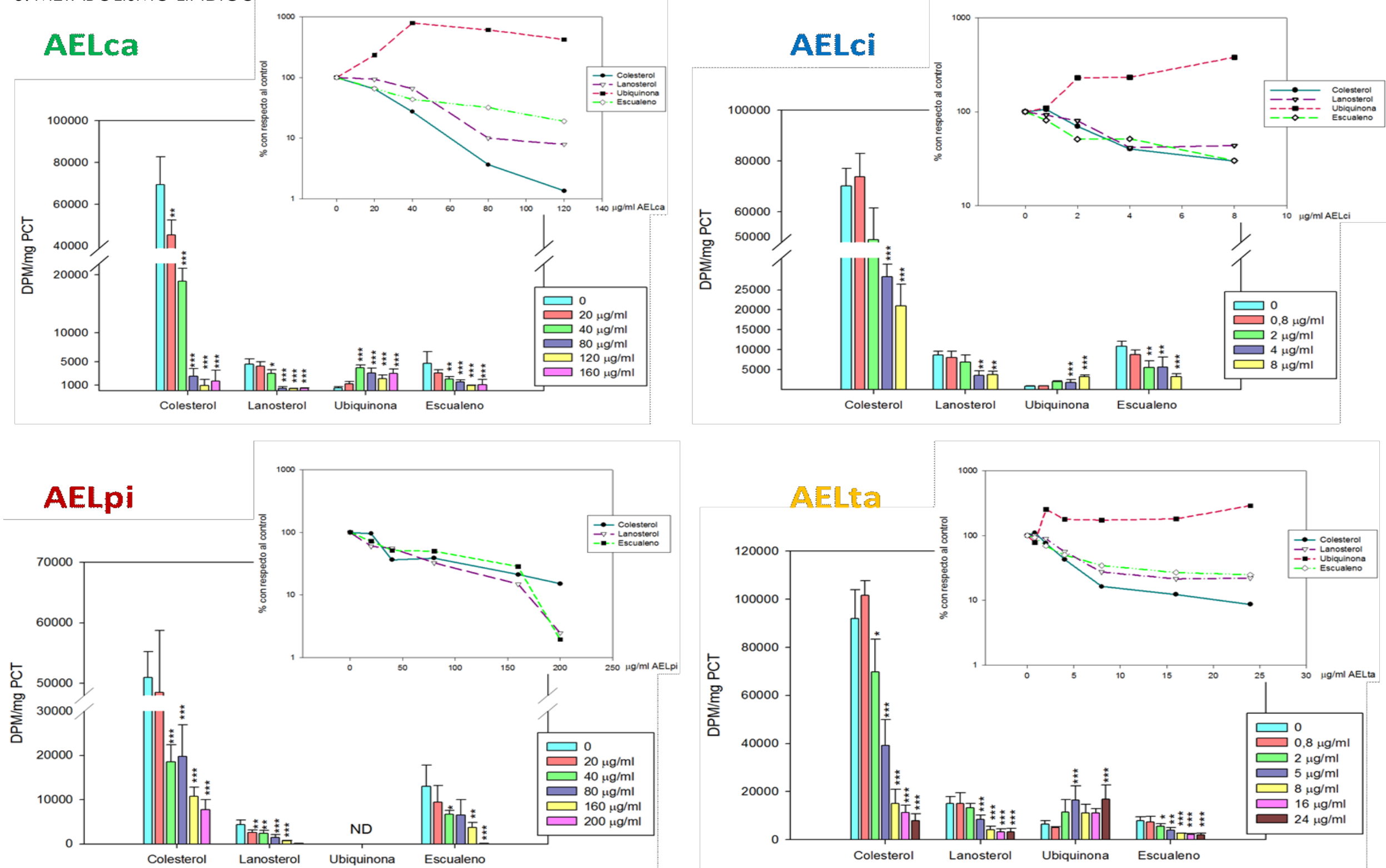

Figura 5.3. Incorporación de ${ }^{14} \mathrm{C}$-acetato en colesterol y otros lípidos insaponificables en células HepG2 tratadas con los AELs. Las células se trataron con concentraciones crecientes de cada uno de los AE de Lippia alba durante 48 horas, agregando $1 \mu \mathrm{Ci} / \mathrm{ml}$ de ${ }^{14} \mathrm{C}$-acetato durante las últimas 3 horas. La incorporación de radiactividad en colesterol, lanosterol, ubiquinona y escualeno se reveló por autorradiografía y cuantificó por densitometría. Los resultados se expresan como el promedio \pm DS $(n=4) ; * p<0,05, * * p<0,01, * * * p<0,001$. Insertos: Curvas dosis respuesta de los intermediarios para cada tratamiento. 
Además de colesterol, lanosterol, ubiquinona y escualeno, se detectó y cuantificó la incorporación de ${ }^{14} \mathrm{C}$-acetato en otros lípidos insaponificables que no pudieron ser fehacientemente identificados por carecer de estándares comerciales. Es probable que estas bandas radiactivas correspondan a intermediarios esteroideos de la VM comprometidos en la síntesis de colesterol o bien a oxiesteroles producidos a partir de reacciones derivadas de la VM. En todos los casos se detectaron al menos 2 y hasta 4 compuestos que se denominaron lípidos $X, Y, Z$ y W, en función de su relación de avance (Rf), para las cuales $R f$ $(X)<\operatorname{Rf}(Y)<\operatorname{Rf}(Z)<\operatorname{Rf}(W)$ (Figura 5.4, Panel A).

En base a distintos trabajos publicados, que emplean técnicas y metodologías comparables a las aquí presentadas (446-451), el compuesto identificado como lípido "Y" podría ser desmosterol y/o 24(S),25-epoxicolesterol (24,25-EC). El primero es un intermediario propio de la vía de Bloch que se convierte en colesterol en una reacción catalizada por la enzima DHCR24. El segundo es un oxiesterol sintetizado de forma paralela al colesterol en una reacción derivada de la VM donde el 2,3;22,23-diepoxiescualeno (DOS) es convertido a 24(S),25-epoxilanosterol a partir de la actividad la enzima 2,3-oxidoesqualeno:lanosterol ciclasa (OSC). Esta enzima también es la encargada de convertir el 2,3monoepoxiescualeno (MOS) en lanosterol. Por otra parte, el lípido "Z" sería latosterol, esterol de 27 carbonos que es convertido a 7-dehidrocolesterol por acción de la enzima latosterol oxidasa. Para el lípido " $X$ " no se encontró suficiente evidencia en función de su Rf que permita asociarlo a algún intermediario en particular y pese a correr muy cercano al estándar de 25-hidroxicolesterol, la banda tiene un Rf menor al que presenta el estándar. En la Figura 5.4, Panel B se representan las vías descritas para la síntesis de colesterol y de 24,25-EC en las que participan los intermediarios y productos mencionados. El lípido "W" puede ser otro intermediario o una variante de ubiquinona. 


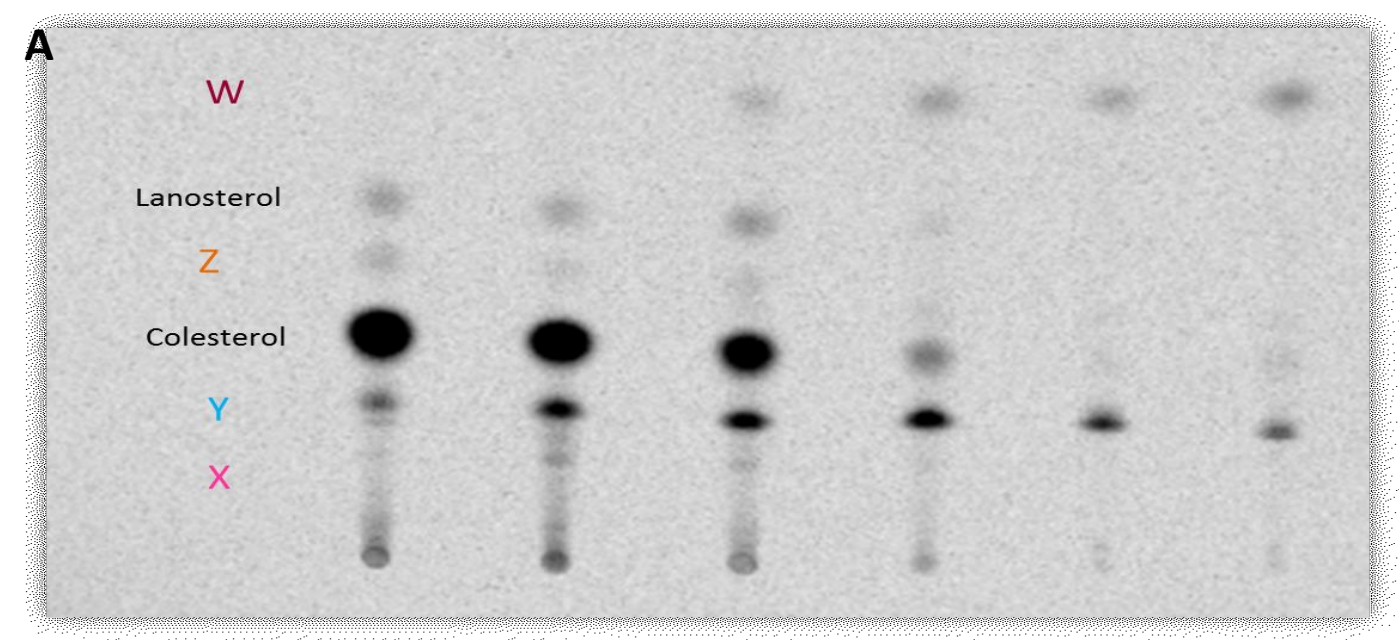

B
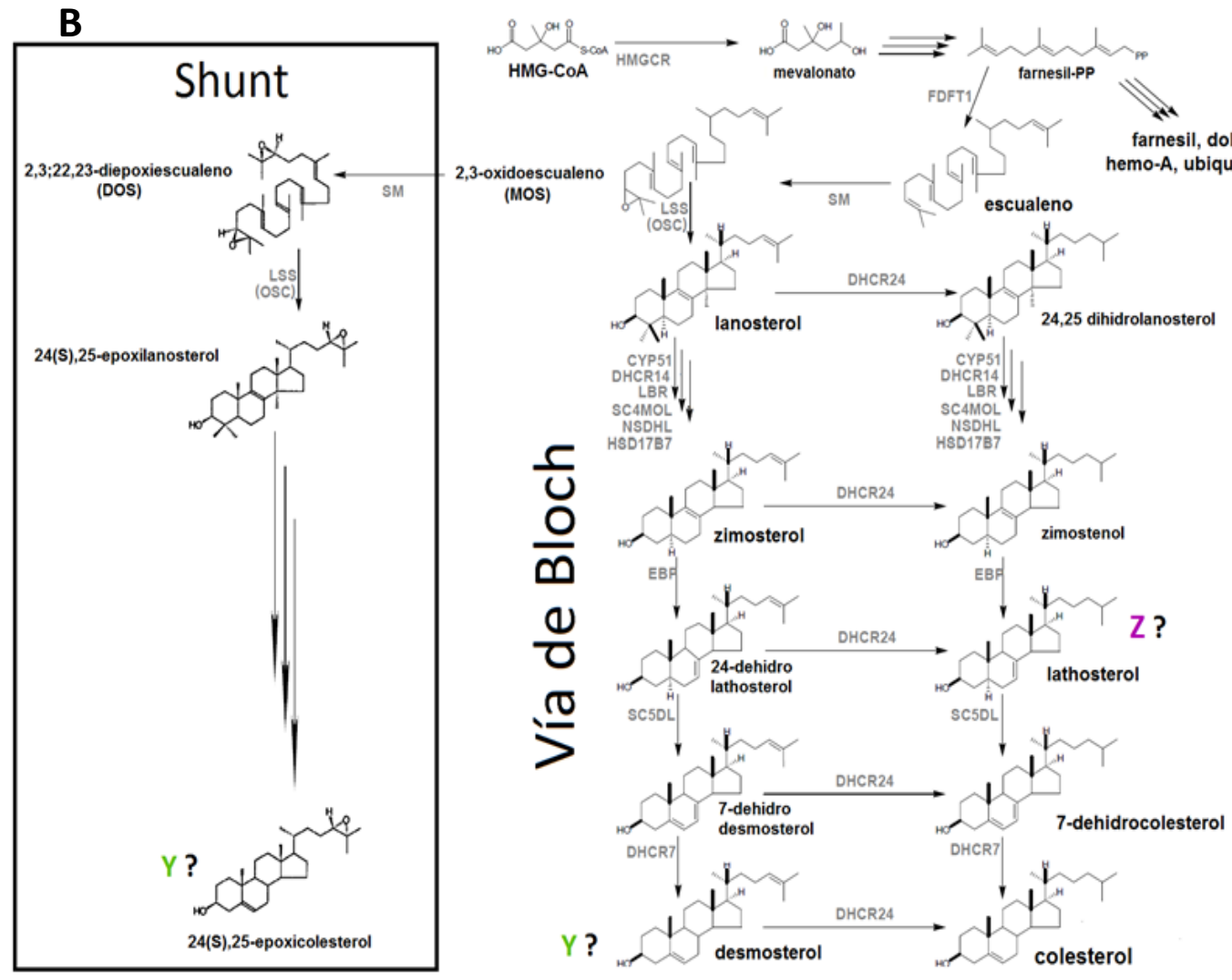

ona $W$

Figura 5.4. Lípidos insaponificables no identificados de la vía del mevalonato en células HepG2 y A549. (A) Ubicación relativa de los lípidos $X, Y, Z$ y $W$ al separar $L I$ radiactivos según lo descrito en la sección 3.B.8.2 (B) Esquema que representa las vías de Bloch y Kandutsch-Russell para la síntesis de colesterol, y la vía derivada (shunt) de síntesis de 24(S),25 epoxicolesterol a partir de 2,3oxidoescualeno, donde se señalan las posibles identidades para los lípidos W, Y y Z. Adaptado de Ačimovič et al. (70). 
En células A549 se observó incorporación de ${ }^{14} \mathrm{C}$-acetato en los lípidos " $\mathrm{Z}$ " e " $\mathrm{Y}$ " con todos los tratamientos (Figura 5.5). La incorporación en "Z" (latosterol) disminuye de manera similar al colesterol. En cambio la incorporación en "Y" (demosterol y/o 24(S),25epoxicolesterol) disminuye sólo con las concentraciones mayores de AEs. El compuesto "W" se detectó sólo en las células tratadas con AELca y presenta un aumento en la incorporación similar al que se presenta para la ubiquinona, con lo que podría tratarse de un intermediario de su síntesis. Por último, sólo en células tratadas con AELta se pudo determinar el lípido " $\mathrm{X}$ " que no presenta diferencias significativas con el control.

En células HepG2 también se pudo observar la aparición de estas bandas radiactivas (Figura 5.6). El compuesto " $X$ " se encontró en células tratadas con los AELs excepto AELci. En todos los casos se muestra una disminución de la incorporación de la radioactividad con el aumento de la concentración de AEs utilizada. El compuesto " $Y$ " también presenta una disminución de la incorporación pero sólo con las mayores concentraciones de aceite utilizadas. Por último se observó la presencia de "W" para las células tratadas con AELca y AELta, que muestran un aumento dosis dependiente de la incorporación de ${ }^{14} \mathrm{C}$-acetato. 

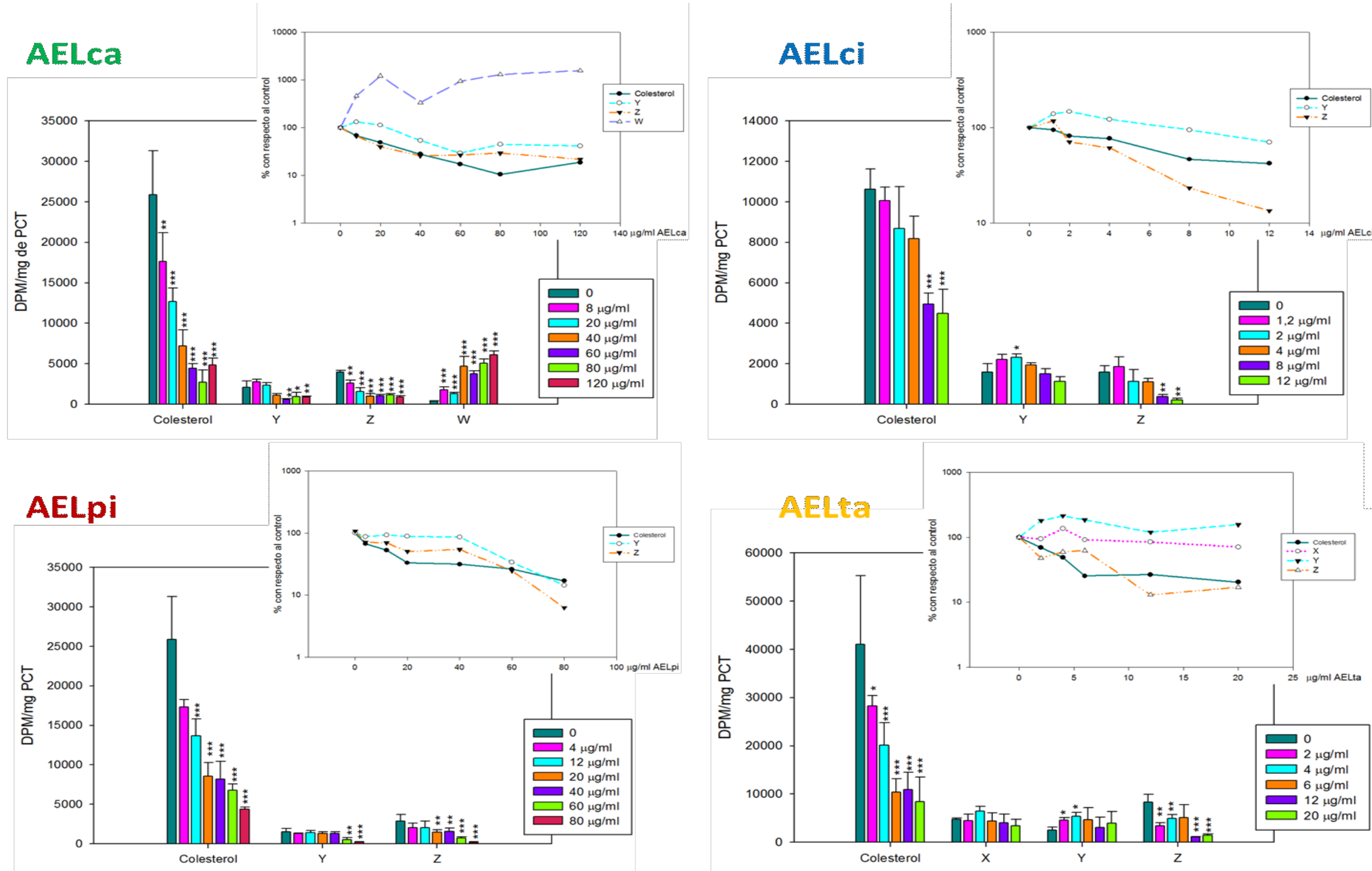

Figura 5.5. Incorporación de ${ }^{14} \mathrm{C}$-acetato en colesterol y otros lípidos insaponificables en células A549 tratadas con los AELs. Las células se trataron con concentraciones crecientes de cada uno de los AE de Lippia alba durante 48 horas, agregando $1 \mu \mathrm{Ci} / \mathrm{ml}$ de ${ }^{14} \mathrm{C}$-acetato durante las últimas 3 horas. La incorporación de radiactividad en colesterol, $X, Y, Z$ y W para los tratamientos se reveló por autorradiografía y cuantificó por densitometría. Los resultados se expresan como el promedio $\pm D S(n=4) ;{ }^{*} p<0,05, * * p<0,01, * * * p<0,001$. Insertos: Curvas dosis respuesta de los intermediarios para cada tratamiento. 

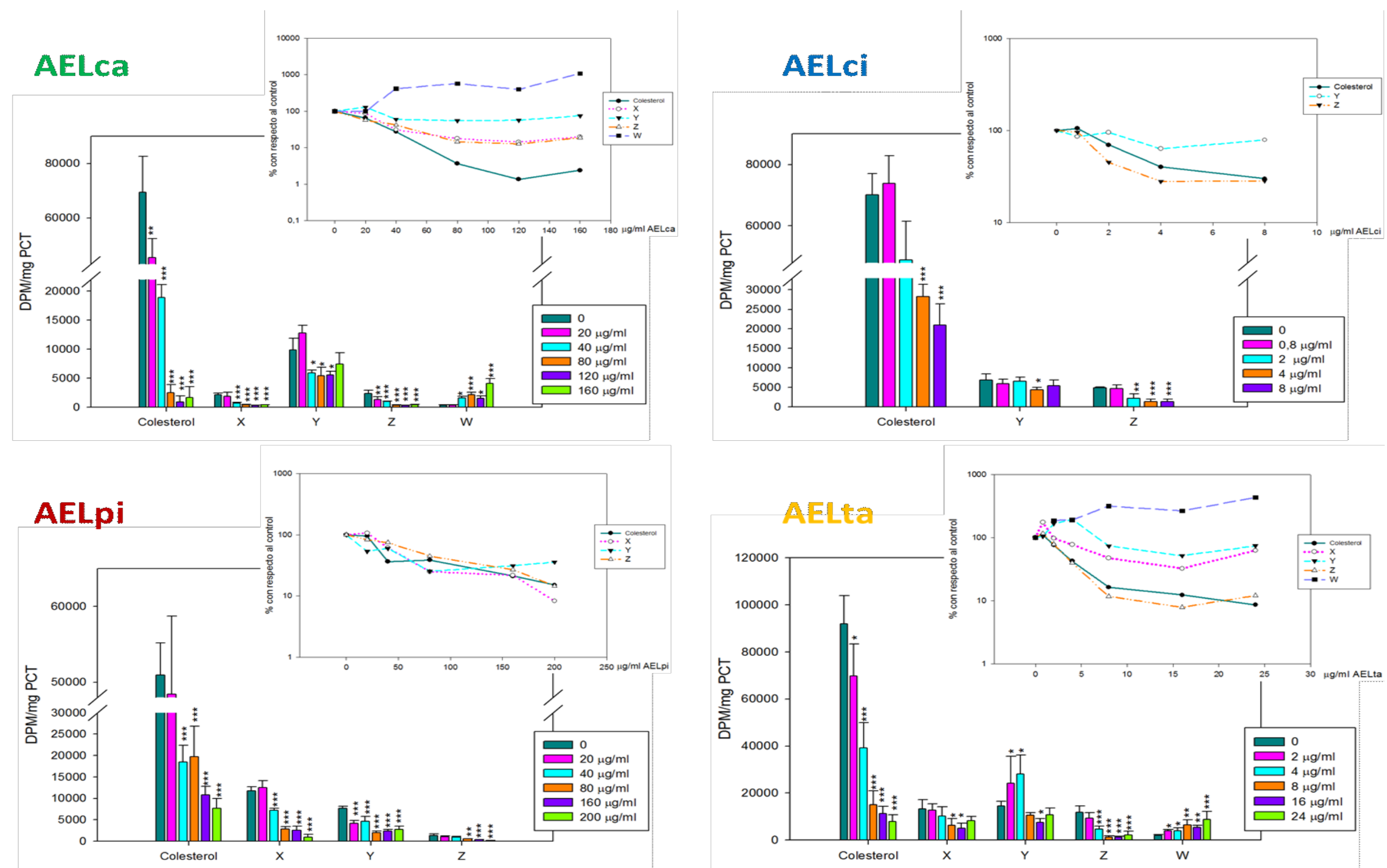

Figura 5.6. Incorporación de ${ }^{14} \mathrm{C}$-acetato en colesterol y otros lípidos insaponificables en células HepG2 tratadas con los AELs. Las células se trataron con concentraciones crecientes de cada uno de los $\mathrm{AE}$ de Lippia alba durante 48 horas, agregando $1 \mu \mathrm{Ci} / \mathrm{ml}$ de ${ }^{14} \mathrm{C}$-acetato durante las últimas 3 horas. La incorporación de radiactividad en colesterol, $X, Y, Z$ y W para los tratamientos se reveló por autorradiografía y cuantificó por densitometría. Los resultados se expresan como el promedio $\pm D S(n=4) ;{ }^{*}<<0,05,{ }^{* *} p<0,01,{ }^{* * *} p<0,001$. Insertos: Curvas dosis respuesta de los intermediarios para cada tratamiento. 


\section{B.1.2. Actividad anticolesterogénica}

Se realizaron curvas de inhibición de la incorporación de acetato en colesterol en función de la concentración y por regresión no lineal se calcularon los valores de $I_{50 s c}$ que se muestran en la Figura 5.7.

Para los quimiotipos con mayor actividad antiproliferativa (AELci y AELta) se observó que la concentración necesaria para inhibir en un $50 \%$ la colesterogénesis es de 5 a 10 veces menor que los $\mathrm{IC}_{50}$ necesarios para inhibir la proliferación celular. En el caso de AELca y AELpi, los cuales son menos efectivos en inhibir la proliferación celular, los IC $\mathrm{C}_{50 \text { sc }}$ son hasta 20 veces menores que el de la proliferación celular.

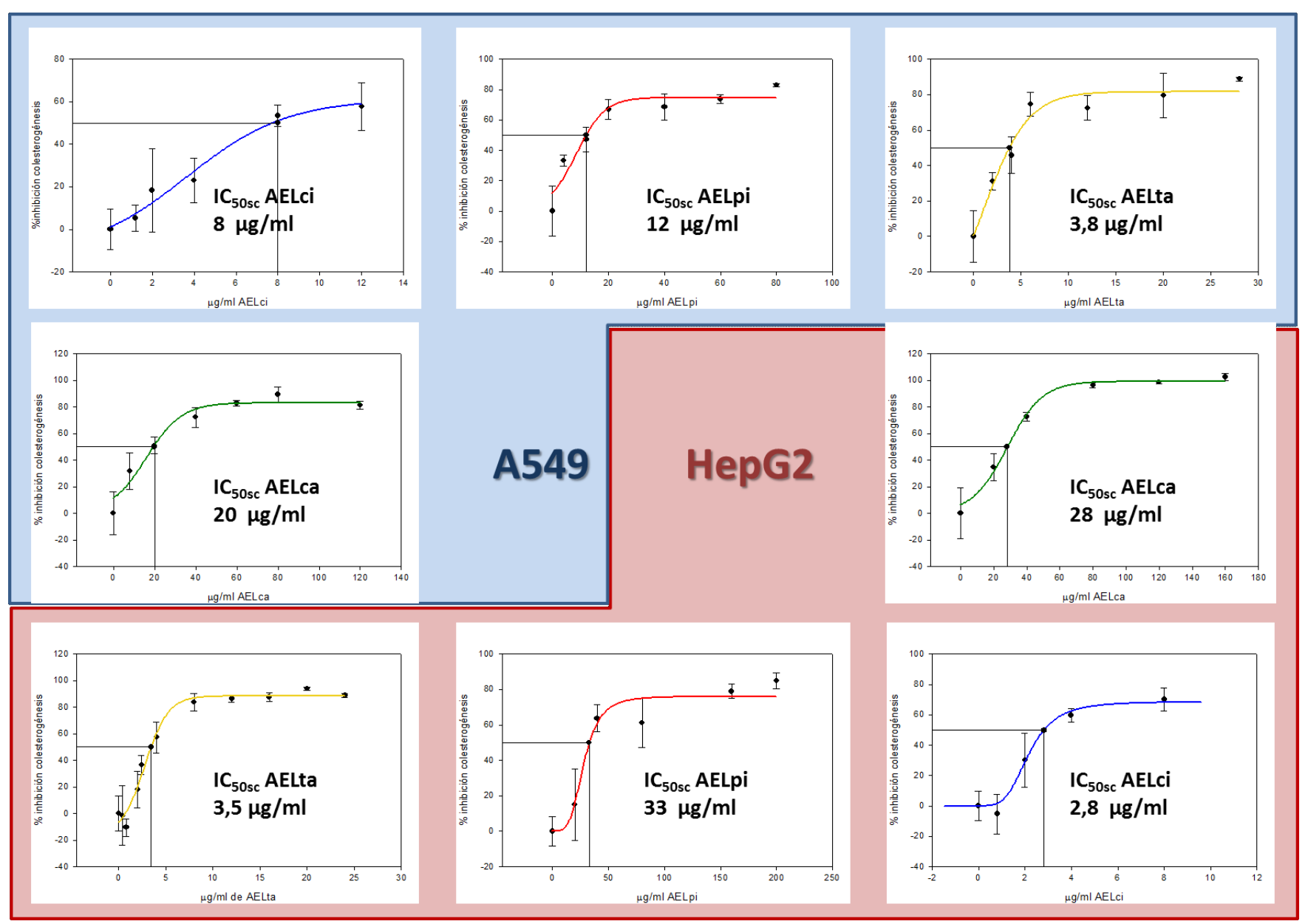

Figura 5.7. Curvas de dosis respuesta para A549 y HepG2 incubadas con los AEs con respecto a colesterogénesis. Los IC50sc se obtuvieron a partir de curvas de regresión no lineal. Cada punto de las curvas está calculado con el promedio \pm DS de 4 determinaciones. 
Al igual que lo registrado en proliferación, citral (ci) y tagetenona (ta) son los quimiotipos con valores de $I_{50 s c}$ más bajos en ambas líneas celulares. No obstante, los porcentajes de inhibición máximos alcanzados con AELci no superan el 70 \% mientras que con AELta se alcanzan valores superiores al $80 \%$. En ambas líneas celulares la curva de inhibición de la síntesis de colesterol en función de la concentración del AELta alcanza una meseta de máxima inhibición a partir de $8 \mu \mathrm{g} / \mathrm{ml}$.

A los efectos de comparar los distintos quimiotipos, se determinó la síntesis de colesterol por medida de incorporación de ${ }^{14} \mathrm{C}$-acetato en células de las dos líneas tratadas con $8 \mu \mathrm{g} / \mathrm{ml}$ de cada uno de los AEs. Los resultados obtenidos se presentan en la Figura 5.8, donde puede observarse claramente la mayor potencia del quimiotipo tagetenona como agente anticolesterogénico tanto en células hepáticas como extrahepáticas.

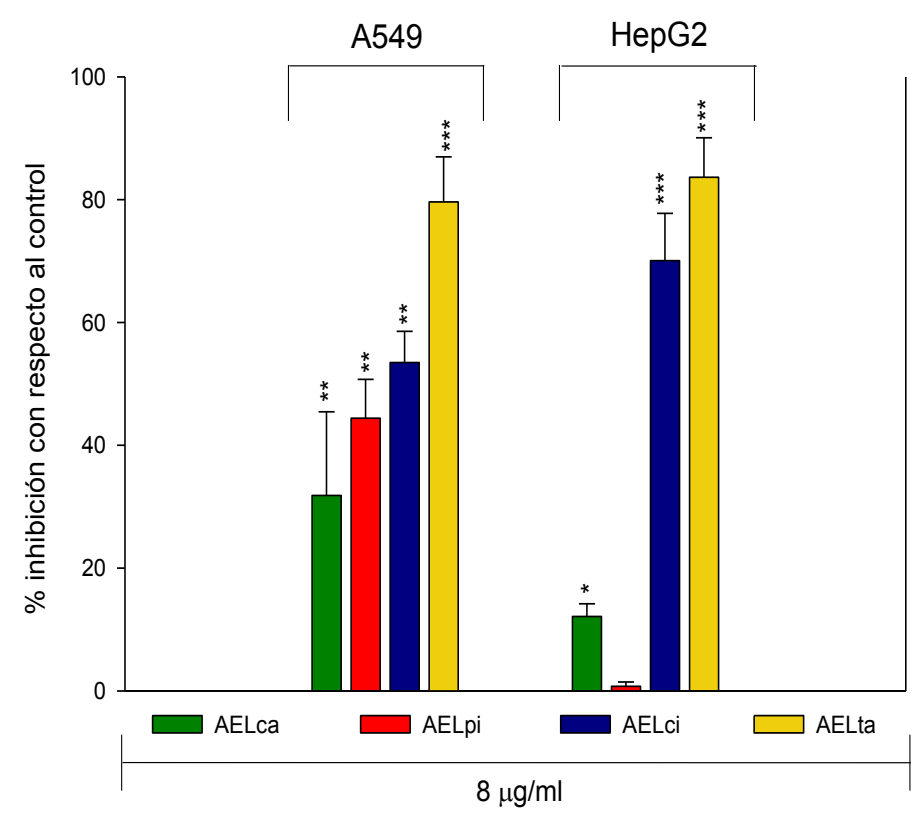

Figura 5.8. Incorporación ${ }^{14} \mathrm{C}$-acetato en colesterol en células A549 y HepG2 tratadas con $8 \mu \mathrm{g} / \mathrm{ml}$ de AELs. Se trató a las células con $8 \mu \mathrm{g} / \mathrm{ml}$ de cada $\mathrm{AE}$ de Lippia alba, durante 48 horas. Los datos son el promedio \pm DS $(n=4) ; * p$ $<0.05, \quad * * p<0.01$ y $* * * p<0.001$ respecto al control.

\section{B.2. Contenido de lípidos celulares mayoritarios.}

Con el objetivo de determinar si la inhibición de la síntesis de colesterol ocasionada por los AEs de L. alba se traduce en cambios en el contenido de colesterol y analizar el impacto que tiene en el contenido de los otros lípidos celulares, células HepG2 y A549 se trataron con los $I_{50 \text { sc }}$ de los aceites esenciales de los cuatro quimiotipos por 48 horas. Se extrajeron los lípidos totales (LT) por el método de Folch, las especies lipídicas fueron separadas por TLC y se determinó el contenido de colesterol libre (CL), colesterol 
esterificado (CE), triacilglicéridos (TAG) y fosfolípidos (FL) como se detalló en la sección 3.B.8.3.

En células A549 se observó una disminución del contenido de colesterol total significativa sólo para AELta y AELci. Es probable que esta disminución sea a expensas del colesterol libre, ya que el contenido de los ésteres de colesterol tiene una tendencia a disminuir aunque en ningún caso llega a ser significativa (Tabla 5.1). El contenido de triglicéridos mostró una tendencia a disminuir luego del tratamiento con los AEs, excepto con el AELci para el cual se observó un aumento significativo de estos lípidos. En general no se observaron cambios en el contenido de fosfolípidos presentes en las células al ser tratados con los aceites con excepción de AELpi quien ocasionó un aumento significativo (Tabla 5.1).

Tabla 5.1. Composición lipídica de células A549 tratadas con AEs de 4 quimiotipos de Lippia alba.

\begin{tabular}{lccccc} 
& \multicolumn{1}{c}{$\mathrm{CL}$} & \multicolumn{2}{c}{ CE } & TT & FL \\
\cline { 2 - 5 } & \multicolumn{4}{c}{$(\mu \mathrm{g} / \mathrm{mg}$ PCT $)$} & (nmol/mg PCT) \\
\hline Control & $10,51 \pm 0,86$ & $2,77 \pm 0,41$ & $13,28 \pm 0,78$ & $8,97 \pm 1,17$ & $78,52 \pm 5,5$ \\
AELta & $8,25 \pm 0,66^{*}$ & $2,13 \pm 0,54$ & $10,38 \pm 0,38^{*}$ & $8,05 \pm 1,39$ & $65,61 \pm 9,23$ \\
AELca & $10,10 \pm 0,99$ & $2,30 \pm 0,53$ & $12,40 \pm 1,44$ & $4,82 \pm 1,17^{*}$ & $82,09 \pm 3,55$ \\
AELci & $8,68 \pm 0,13$ & $1,96 \pm 0,40$ & $10,64 \pm 0,47^{*}$ & $14,85 \pm 2,89^{* *}$ & $76,17 \pm 6,65$ \\
AELpi & $10,56 \pm 1,82$ & $2,24 \pm 0,34$ & $12,80 \pm 2,10$ & $6,96 \pm 0,72$ & $98,52 \pm 7,63^{*}$ \\
\hline
\end{tabular}

Las células fueron tratadas con concentraciones correspondientes a 1.0x $\mathrm{IC}_{50 \mathrm{sc}}$ de cada quimiotipo durante 48 horas. Los LT fueron separados por TLC. El CL y CE se revelaron aplicando una solución ácida de cloruro férrico en forma de espray sobre la placa y posterior carbonización a $180^{\circ} \mathrm{C}$, y se cuantificaron por densitometría. Los TAG se rasparon de la placa y se determinaron por medio de un kit comercial. Las regiones correspondientes a $\mathrm{FL}$ se removieron de la placa, se mineralizaron con ácido perclórico y se cuantificó el fósforo inorgánico ( $\mathrm{Pi}$ ) por el método de Chen. Los resultados se expresan como el promedio \pm DS $(n=4) ; *<<0,05, * * p<0,01$.

En células HepG2 tratadas con AELca, AELpi y AELci no se observa cambios en la composición lipídica (Tabla 5.2). En células tratadas con AELta se observó una disminución significativa tanto de los lípidos de almacenamiento (ésteres de colesterol y triglicéridos) como de los fosfolípidos. El tratamiento con los otros quimiotipos también mostró una tendencia a la disminución de fosfolípidos (Tabla 5.2). 
Tabla 5.2. Composición lipídica de células HepG2 tratadas con AEs de 4 quimiotipos de Lippia alba.

\begin{tabular}{lccccc} 
& CL & CE & CT & TAG & FL \\
\cline { 2 - 5 } & \multicolumn{4}{c}{$(\mu \mathrm{g} / \mathrm{mg} \mathrm{PCT})$} & $(\mathrm{nmol} / \mathrm{mg}$ PCT $)$ \\
\hline Control & $14,55 \pm 2.73$ & $4,30 \pm 0,41$ & $18,85 \pm 2,65$ & $41,05 \pm 7,84$ & $64,81 \pm 4,38$ \\
\hline AELta & $13,62 \pm 2,88$ & $3,51 \pm 0,59 *$ & $17,38 \pm 3,30$ & $31,62 \pm 6,01^{*}$ & $48,54 \pm 7,16^{* * *}$ \\
\hline AELca & $15,97 \pm 2,22$ & $4,34 \pm 0,84$ & $20,31 \pm 3,06$ & $33,52 \pm 11,53$ & $59,80 \pm 6,62$ \\
\hline AELci & $15,22 \pm 1,59$ & $4,75 \pm 0,73$ & $19,97 \pm 2,08$ & $44,25 \pm 6,26$ & $57,52 \pm 4,6$ \\
\hline AELpi & $15,15 \pm 3,36$ & $5,32 \pm 1,61$ & $20,47 \pm 4,69$ & $40,68 \pm 10,12$ & $53,55 \pm 4,91$ \\
\hline
\end{tabular}

Las células fueron tratadas con concentraciones correspondientes a $1 \times \mathrm{IC}_{50 \mathrm{sc}}$ de cada quimiotipo durante 48 horas. Los LT fueron separados por TLC. EI CL y CE se revelaron aplicando una solución ácida de cloruro férrico en forma de espray sobre la placa y posterior carbonización a $180^{\circ} \mathrm{C}$, y se cuantificaron por densitometría. Los TAG se rasparon de la placa y se determinaron por medio de un kit comercial. Las regiones correspondientes a $\mathrm{FL}$ se removieron de la placa, se mineralizaron con ácido perclórico y se cuantificó el fósforo inorgánico ( $\mathrm{Pi}$ ) por el método de Chen. Los resultados se expresan como el promedio \pm DS $(n=4) ; *<<0,05, * * p<0,01 y^{* * *} p<0.001$.

\section{C. Efectos del AELta sobre el metabolismo lipídico en células HepG2.}

Tomando en cuenta que AELta resultó ser el más efectivo en la inhibición de la colesterogénesis, los siguientes ensayos presentados en este capítulo se realizaron con el $A E$ de este quimiotipo. Los experimentos llevados a cabo se desarrollaron en células HepG2 como modelo de células hepáticas, por ser éstas últimas de fundamental importancia en la regulación del metabolismo lipídico en mamíferos y el principal blanco de las terapias hipolipemiantes con estatinas.

Las células HepG2 fueron tratadas durante 48 horas con tres concentraciones del AE: $2 \mu \mathrm{g} / \mathrm{ml}\left(0,5 \mathrm{x} \mathrm{IC}_{50 \mathrm{sc}}\right) ; 4 \mu \mathrm{g} / \mathrm{ml}\left(1,0 \mathrm{xIC}_{50 \mathrm{sc}}\right)$ y $16 \mu \mathrm{g} / \mathrm{ml}$ (4,0x IC 50 sc; máxima concentración que no presenta actividad antiproliferativa). 


\section{C.1. Incorporación de ${ }^{14} \mathrm{C}$-acetato en lípidos neutros y polares.}

Durante las últimas 3 horas de tratamiento se adicionó ${ }^{14} \mathrm{C}$-acetato al medio de cultivo, se extrajeron los lípidos totales y se cuantificó la radiactividad por centelleo líquido. Las distintas fracciones lipídicas fueron separadas y se cuantificó la radiactividad incorporada en cada una de ellas según se describió en Materiales y Métodos.

\section{C.1.1. Ácidos grasos y lípidos insaponificables.}

Una alícuota de LT fue saponificada, se extrajeron lípidos insaponificables y ácidos grasos y se cuantificó la radiactividad presente en ellos por centelleo líquido. Los resultados obtenidos se presentan en la Figura 5.9.

El tratamiento con AELta ocasionó una disminución dosis dependiente de la radiactividad incorporada en lípidos insaponificables, así como una disminución en la incorporación de acetato en ácidos grasos la cual no es dosis dependiente.

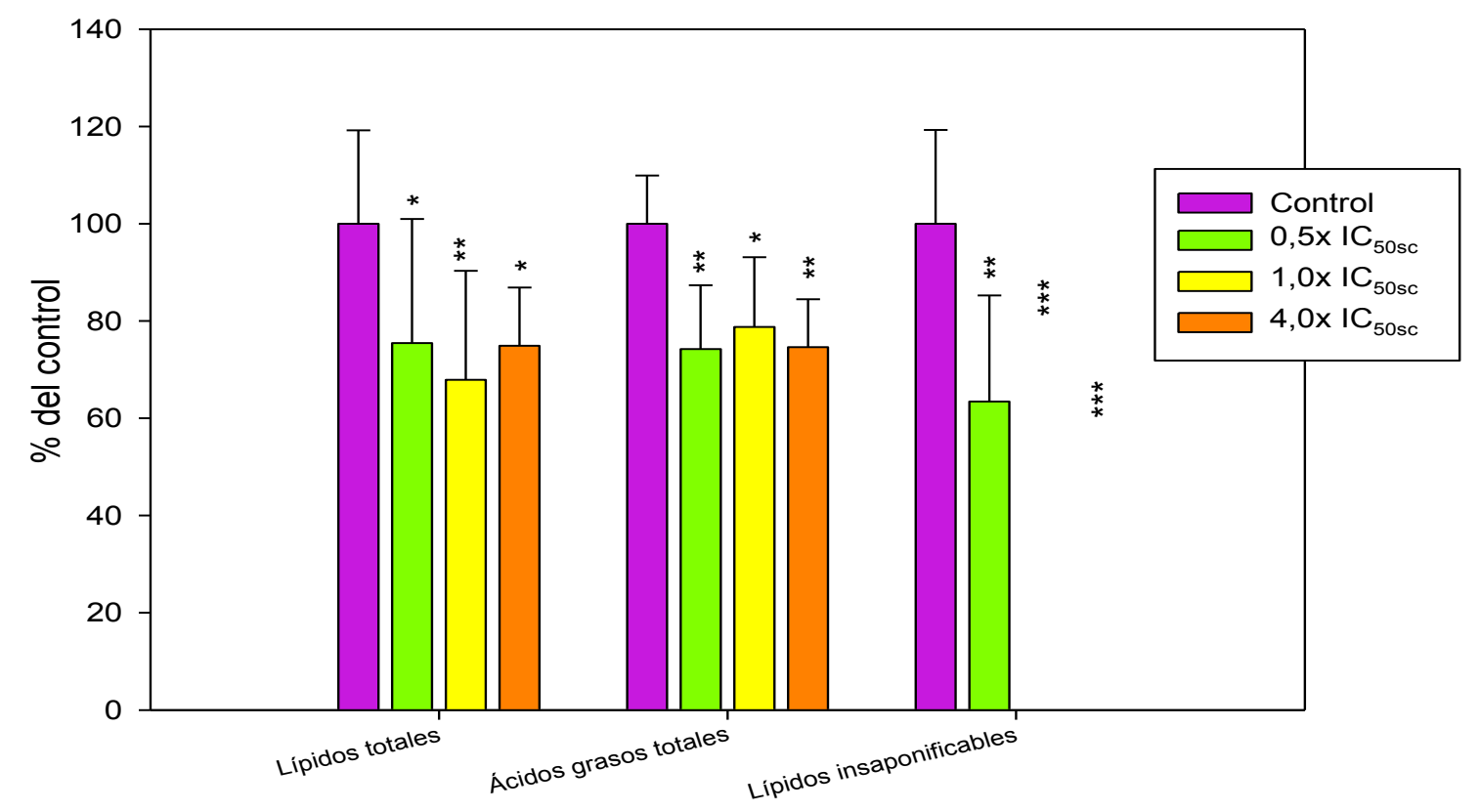

Figura 5.9. Incorporación de ${ }^{14} \mathrm{C}$-acetato en ácidos grasos y lípidos insaponificables de células HepG2. Las células fueron tratadas con las tres concentraciones de AELta por 48 horas y se adicionó ${ }^{14} \mathrm{C}$-acetato en las últimas 3 horas de incubación. Las distintas fracciones fueron cuantificadas por centelleo líquido en un contador Wallac 1214 Rack Beta. Los datos son el promedio \pm DS de tres experimentos independientes realizados por cuadruplicado. ${ }^{*} p<0.05,{ }^{* *} p$ $<0.01, * * * p<0.001$. 
A los efectos de evaluar el impacto del AELta sobre las desaturasas, ácidos grasos extraídos de LT de células HepG2 tratadas con concentraciones crecientes del AE fueron esterificados y separados por TLC; la radiactividad presente en ellos se detectó por autorradiografía y se cuantificó por densitometría como se describe en la Sección 3.B.9.3. Se observó un aumento del porcentaje de radiactividad incorporada en ácidos grasos saturados que se hace significativo con dosis que presentaron inhibición de la proliferación (Figura $5.10)$.

A

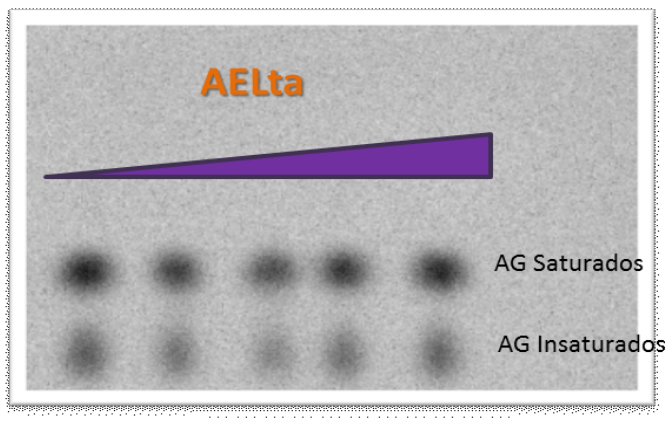

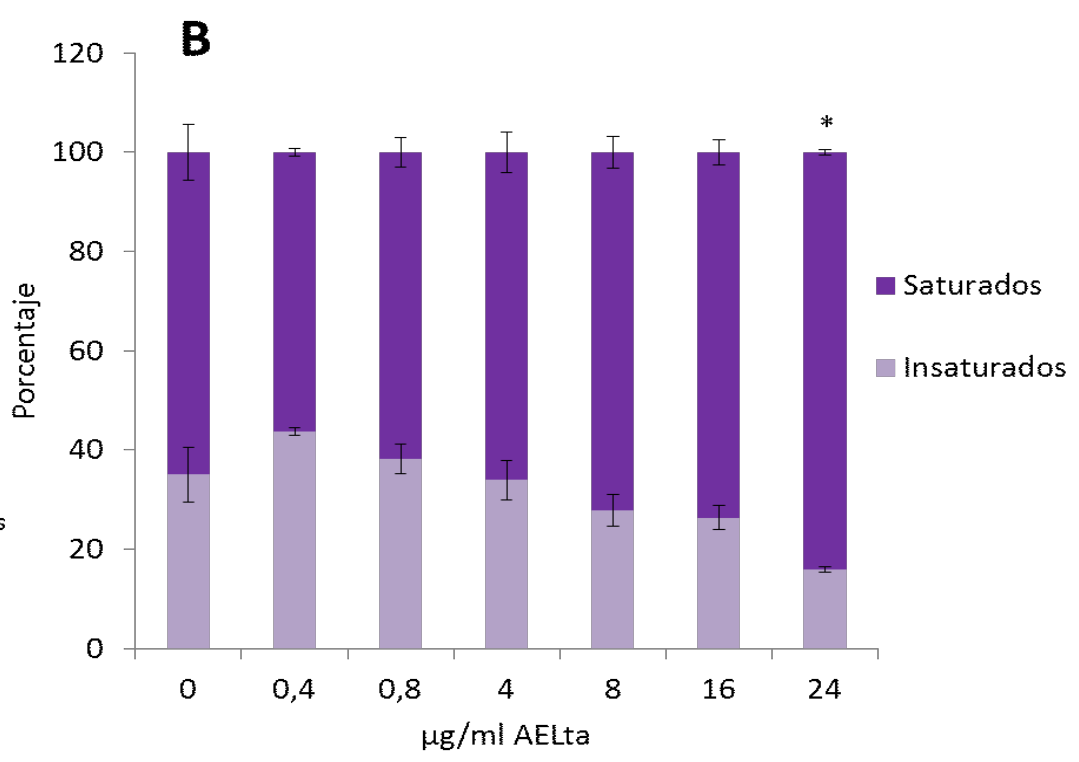

Figura 5.10. Distribución radiactividad incorporada en ácidos grasos saturados e insaturados de células HepG2. Las células fueron tratadas con concentraciones crecientes de AELta por 48 horas y se adicionó ${ }^{14} \mathrm{C}$-acetato en las últimas 3 horas de incubación. Los ácidos grasos fueron extraídos, esterificados y separados por TLC utilizando placas impregnadas con nitrato de plata (panel A). La radiactividad presente en ellos se detectó por autorradiografía y se cuantificó por densitometría como se describe en la Sección 3.B.9.3. Los datos son el promedio $\pm D S(n=4) ;{ }^{*} p<0.05,{ }^{* *} p<0.01$, $* * * p<0.001$.

\section{C.1.2. Lípidos neutros}

Los lípidos neutros presentes en una alícuota de LT extraídos de células HepG2 tratadas con AELta fueron separados por TLC y la radiactividad presente en cada uno de ellos fue identificada por autorradiografía y cuantificada por densitometría según se describe en Materiales y Métodos. 
Se observó una disminución de la incorporación de ${ }^{14} \mathrm{C}$-acetato en todas las especies detectadas y cuantificadas: diacilglicéridos (DAG), CL, TAG y CE. En CL y CE la inhibición de la radiactividad incorporada es dosis dependiente; mientras que en DAG y TAG la disminución de incorporación no mostró ser dosis dependiente (Figura 5.11).
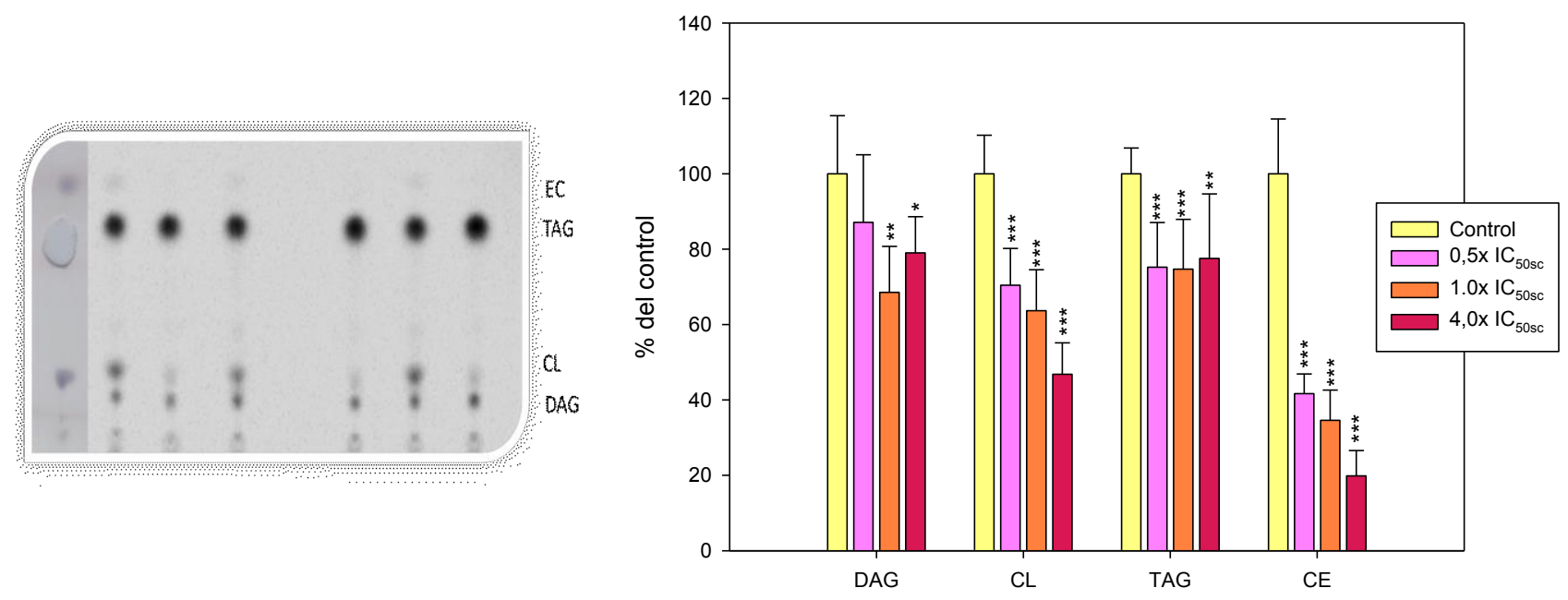

Figura 5.11. Incorporación de ${ }^{14} \mathrm{C}$-acetato en lipidos neutros en células HepG2 tratadas con AELta. Las células fueron tratadas con concentraciones crecientes de AELta que no inhiben la viabilidad celular durante 48 horas, agregando $1 \mu \mathrm{Ci} / \mathrm{ml}$ de ${ }^{14} \mathrm{C}$-acetato en las últimas 3 horas. La incorporación de radiactividad en lípidos neutros separados por TLC fue revelada por autorradiografía y cuantificada por densitometría. Los resultados muestran el promedio \pm DS de tres experimentos independientes por cuadruplicado; ${ }^{*} p<0,05 ;{ }^{* *} p<0,01 ; * * p<0,001$.

\section{C.1.3. Fosfolípidos}

Las distintas clases de fosfolípidos presentes en una alícuota de LT extraídos de células HepG2 tratadas con AELta fueron separados por TLC y la radiactividad presente en cada uno de ellos fue identificada por autorradiografía y cuantificada por densitometría según se describe en Materiales y Métodos.

En células tratadas con AELta se observó una disminución de la radiactividad incorporada en fosfolípidos totales (FLT) a expensas de 3 de las 4 especies fosfolipídicas separadas e identificadas (Figura 5.12). 

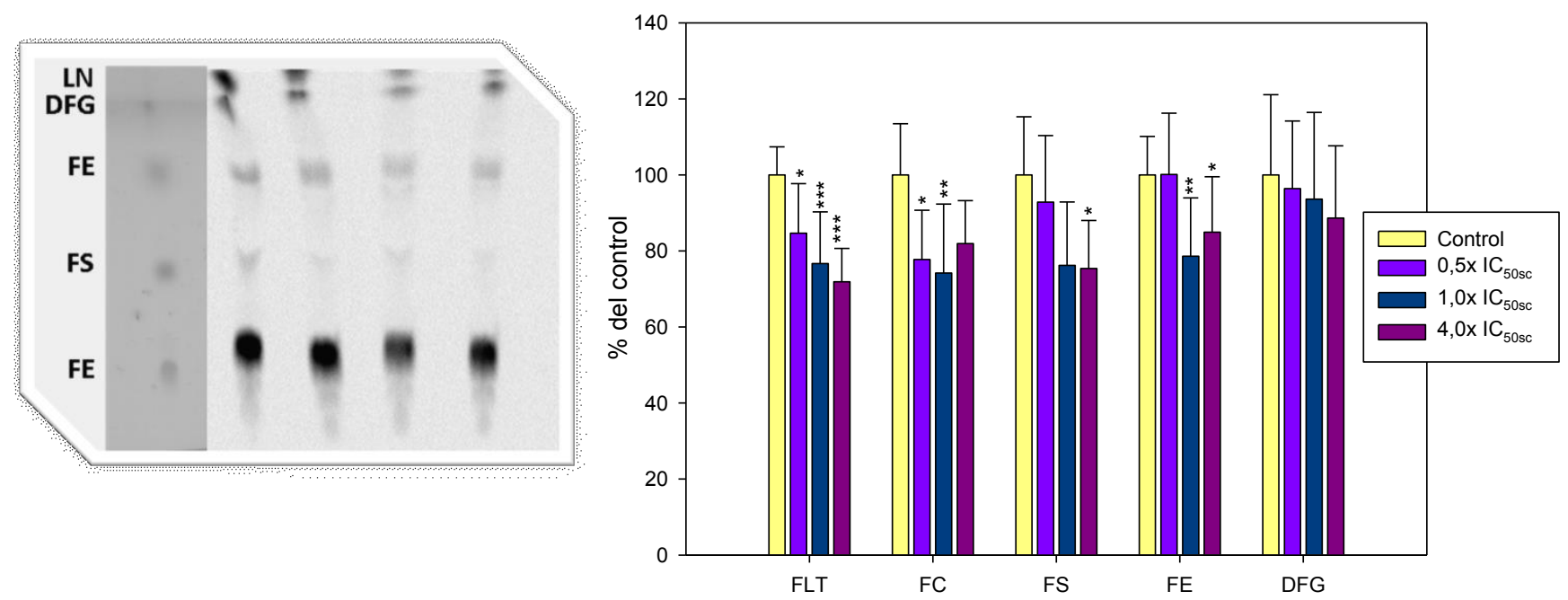

Figura 5.12. Incorporación de ${ }^{14} \mathrm{C}$-acetato en fosfolípidos en células HepG2 tratadas con AELta. Las células fueron tratadas con tres concentraciones crecientes que no inhiben la viabilidad celular significativamente durante 48 horas, agregando $1 \mu \mathrm{Ci} / \mathrm{ml}$ de ${ }^{14} \mathrm{C}$-acetato las últimas 3 horas. La incorporación de radiactividad en distintos tipos de fosfolípidos separados por TLC fue revelada por autorradiografía y cuantificada por densitometría. DFG: difosfatidilglicerol, FE: fosfatidiletanolamina, FS: fosfatidilserina, FC: fosfatidilcolina. Los resultados muestran el promedio \pm DS de tres experimentos independientes por cuadruplicado; ${ }^{*} p<0,05 ;{ }^{* *} p<0,01 ; * * *<<0,001$

\section{C.2. Impacto sobre la composición lipídica}

Para determinar si los cambios ocasionados por el AELta en la incorporación de acetato en los distintos lípidos celulares se traducen en cambios en el contenido de los mismos, se extrajeron los LT de células HepG2 luego del tratamiento con AELta y las distintas fracciones lipídicas fueron separadas y cuantificadas según se describió en el capítulo 3.

\section{C.2.1. Contenido de lípidos neutros y fosfolípidos}

Los distintos tipos de lípidos neutros y los fosfolípidos presentes en una alícuota de LT extraídos de células HepG2 tratadas con AELta fueron separados por TLC y cuantificados según se describió en Materiales y Métodos.

Los resultados obtenidos se muestran en la Figura 5.13. Con excepción del colesterol libre que no sufrió modificaciones, se observó una disminución del contenido de todas las especies lipídicas estudiadas que se hace significativa a la concentración más baja de AELta estudiada $\left(0,5 \times I_{50 s c}\right)$ y se mantiene para las concentraciones mayores. 


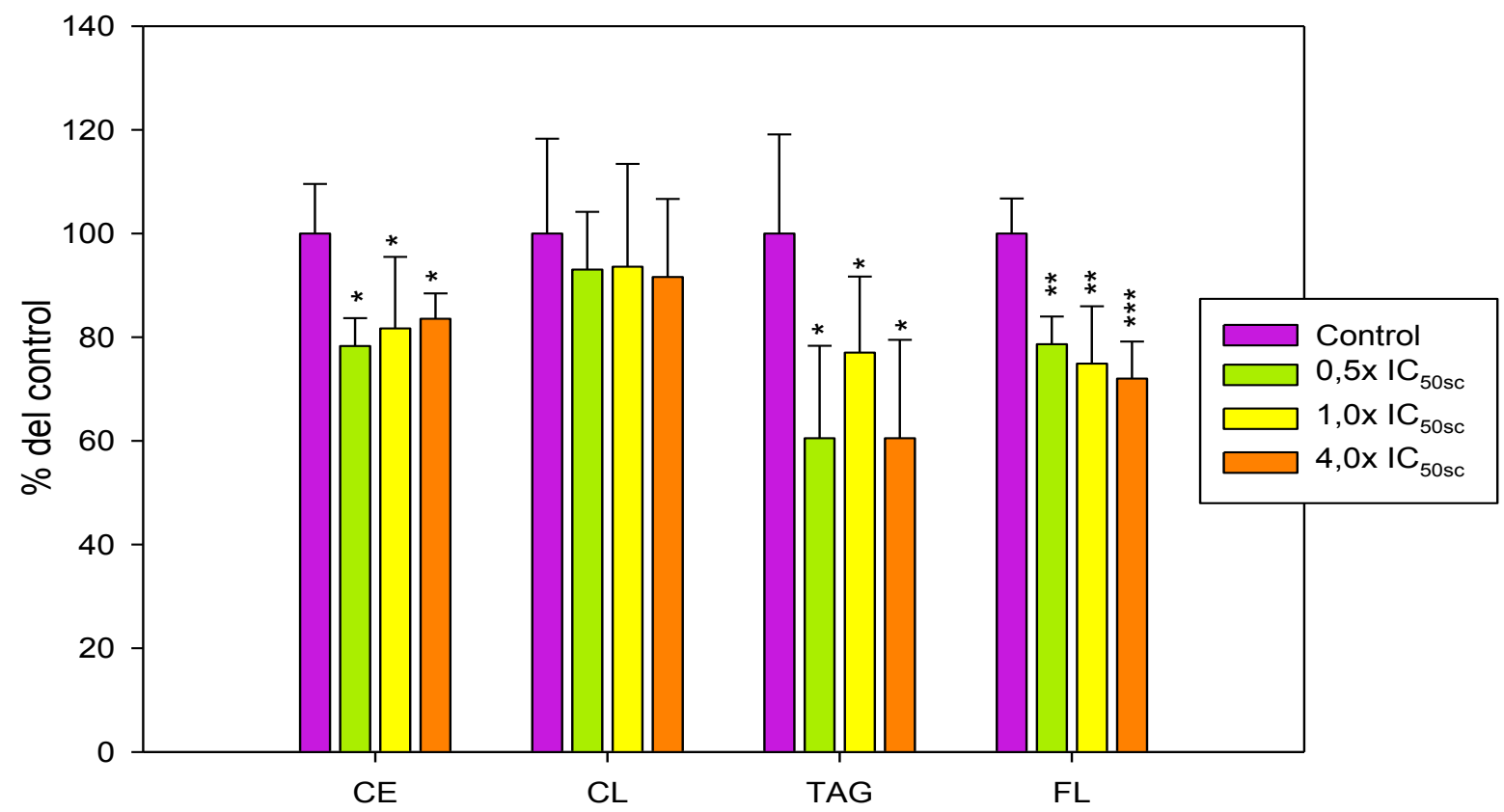

Figura 5.13. Determinación del contenido lipídico de células HepG2 tratadas con AELta. Células en fase exponencial de crecimiento fueron tratadas durante 48 horas con concentraciones de AELta que no inhiben proliferación. Se extrajeron LT y se separaron lípidos neutros por TLC. Se raspó la sílica de las zonas correspondientes a TAG, se los extrajo con cloroformo y se cuantificaron colorimétricamente utilizando kit enzimático TG color. La sílica de las regiones correspondientes a FL se removió de la placa, se mineralizó con ácido perclórico y se cuantificó el fósforo inorgánico ( $\mathrm{Pi}$ ) por el método de Chen. La presencia de CL y CE se reveló aplicando una solución ácida de cloruro férrico en forma de espray sobre la placa con posterior carbonización a $180{ }^{\circ} \mathrm{C}$ y se cuantificó por densitometría. Los resultados muestran el promedio $\pm \mathrm{DS}$ de tres experimentos independientes por cuadruplicado; ${ }^{*} p<0,05 ;{ }^{* *} p<0,01 ;{ }^{* * *} p<0,001$.

\section{C.2.2. Composición de ácidos grasos}

Los ácidos grasos presentes en LT de células HepG2 tratadas con AELta fueron extraídos y se determinó la composición porcentual por GLC según lo descrito en la sección 3.B.8.4.1.

En células control se observó la presencia de cuatro ácidos grasos mayoritarios: palmítico $(16: 0)$, oleico $(18: 1, \omega 9)$, ácido vaccénico $(18: 1, \omega 7)$ y esteárico $(18: 0)$; los dos primeros representan el 55.4 \% del total de ácidos grasos mientras que los dos últimos equivalen al 27,6 \% del total. Adicionalmente se detectó la presencia de una serie de componentes minoritarios que van de los 16 a 22 carbonos (Tabla 5.3). Este patrón se mantuvo esencialmente sin cambios en células tratadas con AELta. 
Tabla 5.3. Composición de ácidos grasos de células HepG2 tratadas con AELta

\begin{tabular}{|c|c|c|c|c|}
\hline \multirow[b]{2}{*}{ Ácido Graso } & \multicolumn{4}{|c|}{ Distribución Porcentual } \\
\hline & Control & $0,5 \times I C_{50 s c}$ & $1,0 \times I_{50 s c}$ & $4,0 \times I C_{50 s c}$ \\
\hline 16:0 & $30,7 \pm 5,7$ & $27,7 \pm 2,9$ & $29,3 \pm 5,1$ & $29,3 \pm 2,6$ \\
\hline 16:1 & $8,7 \pm 3,5$ & $9,1 \pm 2,3$ & $8,0 \pm 0,1$ & $8,8 \pm 0,7$ \\
\hline 18:0 & $13,2 \pm 1,3$ & $12,5 \pm 1,1$ & $15,8 \pm 2,9$ & $17,5 \pm 0,9$ \\
\hline $18: 1(n-9)$ & $24,7 \pm 0,1$ & $27,9 \pm 5,1$ & $25,2 \pm 3,8$ & $23,5 \pm 0,8$ \\
\hline $18: 1(n-7)$ & $14,4 \pm 0,1$ & $12,0 \pm 0,2$ & $12,7 \pm 2,4$ & $13,7 \pm 0,8$ \\
\hline $18: 2(n-6)$ & $3,0 \pm 1,2$ & $5,7 \pm 1,3$ & $4,0 \pm 0,6$ & $3,1 \pm 0,6$ \\
\hline 20:4 & $4,9 \pm 2,3$ & $4,7 \pm 0,7$ & $4,8 \pm 1,3$ & $3,9 \pm 1,0$ \\
\hline 22:6 & $5,6 \pm 3,7$ & $3,3 \pm 0,6$ & $2,7 \pm 1,2$ & $4,6 \pm 2,1$ \\
\hline
\end{tabular}

Las células fueron tratadas durante 48 horas con las concentraciones de AELta indicadas. Los ácidos grasos totales fueron extraídos y esterificados según se describió en la sección 3.B.8.4.1., y luego se separaron y analizaron por GLC. Los resultados se expresan como el promedio \pm DS $(n=4) ;{ }^{*} p<0,05$, $* * p<0,01$ y*** $p<0.001$.

\section{D. Análisis de los parámetros morfológicos de gotas lipídicas de células HepG2 tratadas con AELta.}

Dado que el tratamiento de células HepG2 con AELta modifica el contenido celular de TAG y CE, se estudió el efecto de éste aceite esencial sobre las gotas lipídicas (GL) citoplasmáticas, principales estructuras de almacenamiento de estos lípidos en las células. Para ello, células -sembradas en cubreobjetos- en fase exponencial de crecimiento fueron tratadas con $1,0 \times I_{50 s c}(4 \mu \mathrm{g} / \mathrm{ml})$ y $4,0 \times I_{50 s c}(16 \mu \mathrm{g} / \mathrm{ml})$ de AELta durante 48 horas y luego fijadas y teñidas con DAPI y BODIPY 493/503 según lo descrito en la sección 3.B.10 (Figura 5.14). 
Campo Claro
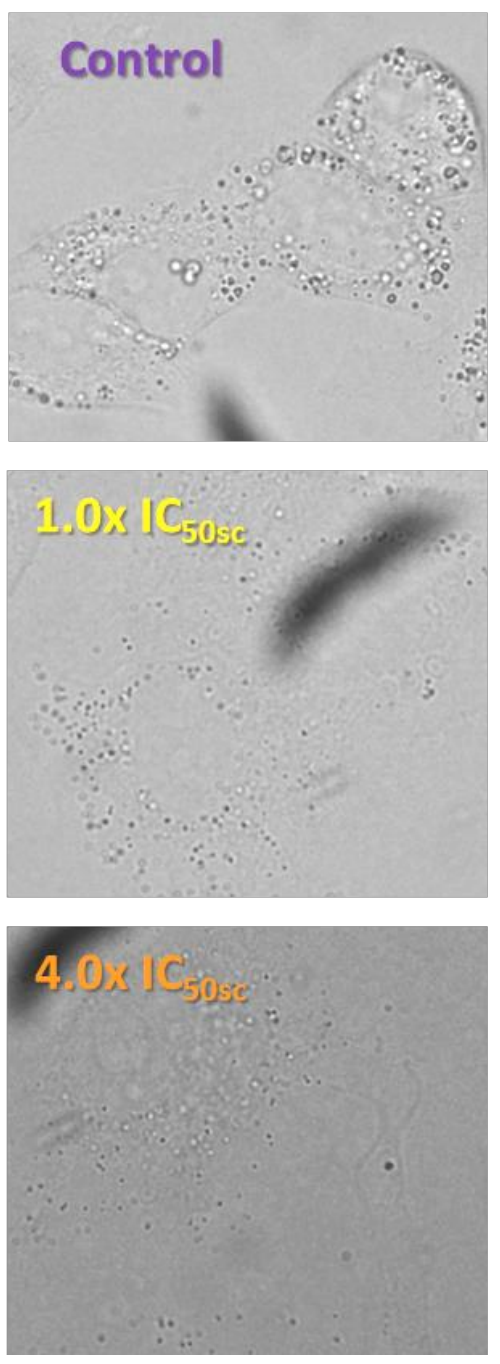

\section{Fluorescencia}
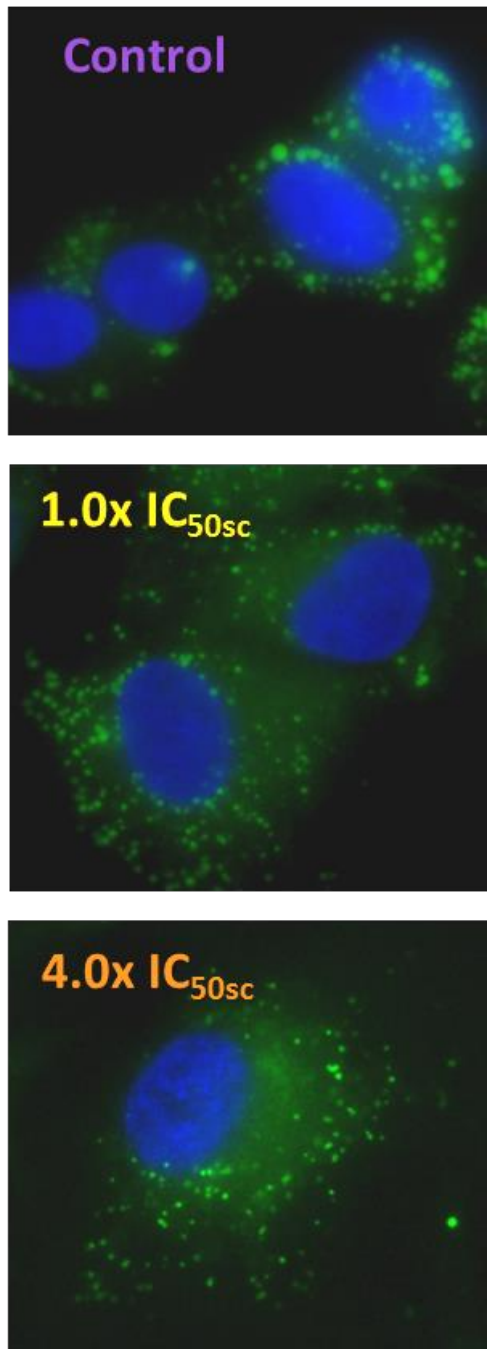

Figura 5.14. Gotas lipídicas en células HepG2 incubadas con AELta. Células en fase exponencial de crecimiento tratadas con AELta durante 48 horas fueron fijadas, teñidas $y$ visualizadas bajo microscopía de campo claro y de fluorescencia. Se muestran fotografías demostrativas de algunos de los campos examinados donde se observan los núcleos teñidos con DAPI (azul) y las gotas lipídicas con BODIPY 493/503 (verde). Magnificación 1000X.

A partir de las imágenes obtenidas por microscopía de fluorescencia, se cuantificó el diámetro de las GL citoplasmáticas. Para el análisis estadístico se utilizaron pruebas no paramétricas dado que la prueba de Kolmogorov-Smirnov con corrección de Lilliefors demostró que éste parámetro morfológico no presenta una distribución normal.

El diámetro de las GL citoplasmáticas presentes en células tratadas con el aceite resultó menor que el de las células control. Además se encontraron diferencias significativas entre tratamientos, siendo las GL de las células tratadas con 4,0x IC $\mathrm{I}_{50 \text { sc }}$ de AELta las de menor tamaño (Figura 5.15). 


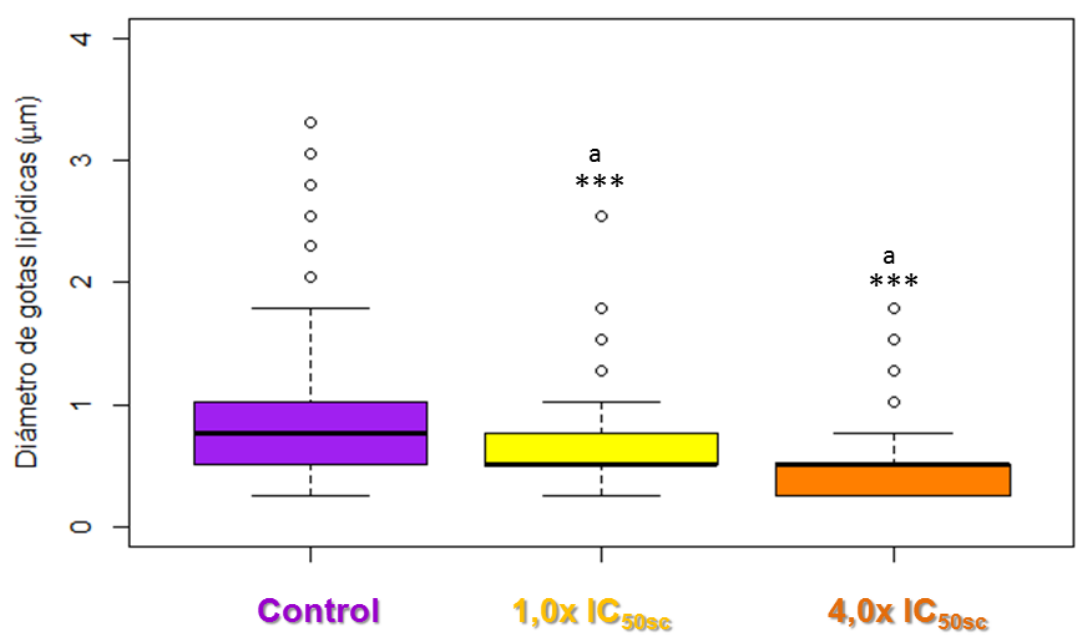

Figura 5.15. Diámetros de GL de células HepG2 tratadas con AELta. Se muestran los diagramas de caja que representan límites de tres cuartiles de los datos para cada condición, con el rango de datos indicado por los corchetes arriba y debajo de las cajas. La mediana está representada por la línea negra horizontal dentro de la caja. Los datos se toman de alrededor de $2000 \mathrm{GL}$ medidas para cada condición experimental. Para el análisis estadístico de los datos se utilizó el test de Kruskal-Wallis, seguido del test poshoc de Bonferroni. ${ }^{*} p<0,05 ;{ }^{* *} p<0,01 ;{ }^{* * *} p<0,001$; a: diferencia entre tratamientos.

Basado en los cuartiles calculados para las GL de las células control, se generaron tres grupos de GL de acuerdo al tamaño: pequeñas $(\leq 0,51 \mu \mathrm{m})$, medianas (entre 0,51 $\mu \mathrm{m}$ y 1,02 $\mu \mathrm{m})$, y grandes $(>1,02 \mu \mathrm{m})$. Al analizar las proporciones de estos tres grupos, utilizando la prueba de chi cuadrado y posterior corrección de Bonferroni, se encontraron diferencias significativas entre el control y los tratamientos. Las células tratadas con AELta presentaron una mayor proporción de GL pequeñas que el control. Éste incremento se da a expensas de una disminución de GL grandes y medianas cuando la concentración ensayada fue de 4,0x $I_{50 s c}$ y sólo de GL grandes cuando se utilizó $1,0 x I_{50 s c}$ de AELta (Figura 5.16).
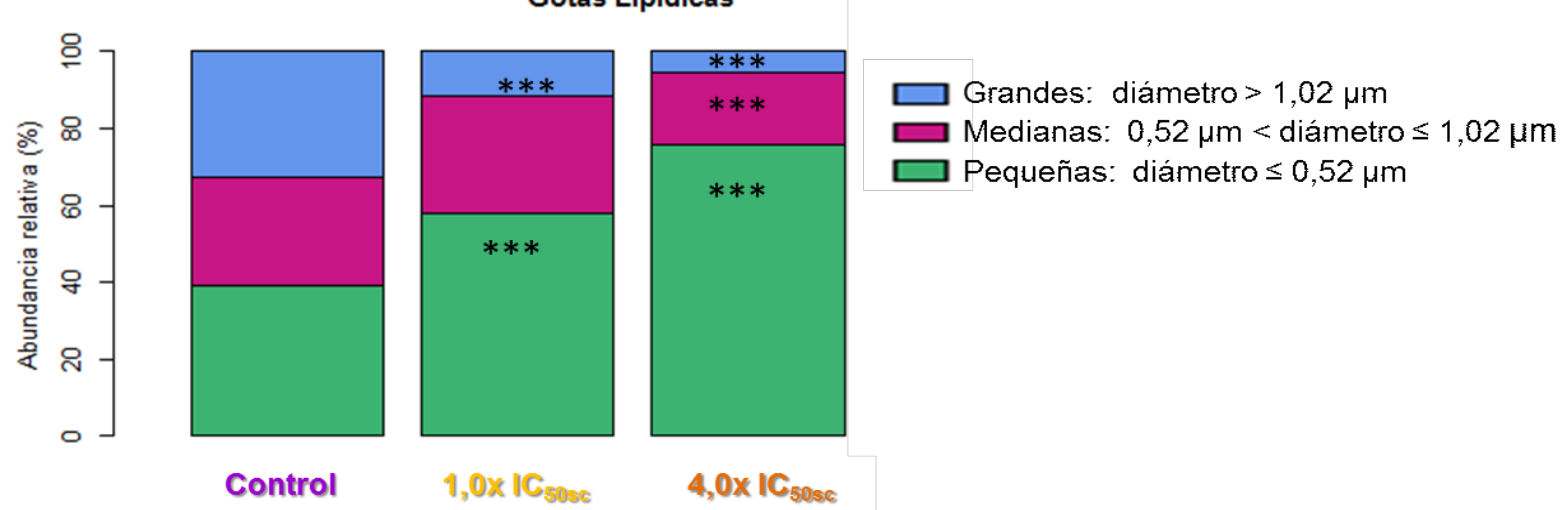

Figura 5.16. Distribución en porcentaje de GL clasificadas en pequeñas, medianas, y grandes. A partir de los cuartiles del control se dividieron a las GL en tres grupos. Cada categoría de GL para cada tratamiento fue comparada con la correspondiente del control a través de la prueba de Chi cuadrado. ${ }^{* * *} \mathrm{p}<0.001$. 
Se calculó también el número y volumen total de las GL por célula (considerándolas como esferas). Respecto al número de GL por célula, no se observaron diferencias significativas con ninguna de las concentraciones de AELta utilizadas (Figura 5.17, Panel A). Mientras que en el caso del volumen total, la mediana obtenida para las células tratadas $\left[9,39 \mu \mathrm{m}^{3}(6,42 ; 8,75)\right.$ para IC $50 \mathrm{sc}$ y $4,87 \mu \mathrm{m}^{3}(4,50 ; 8,75)$ para $\left.4,0 x \mathrm{IC}_{50 \mathrm{sc}}\right]$ fue menor que para las células control $\left[28,58 \mu^{3}(21,58 ; 39,24)\right]$ siendo la diferencia estadísticamente significativa para la concentración correspondiente a 4,0x IC $\mathrm{C}_{50 \mathrm{sc}}$ (Figura 5.17, Panel B).

A Número de GL por célula

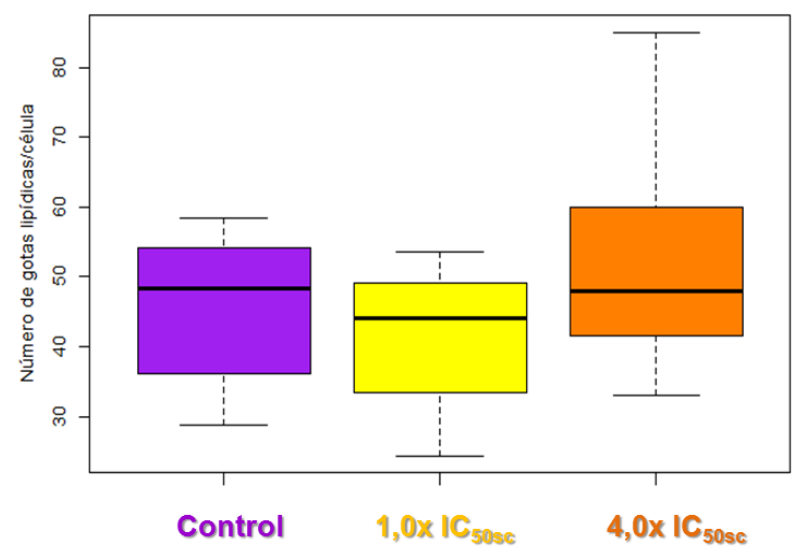

B Volumen total por célula

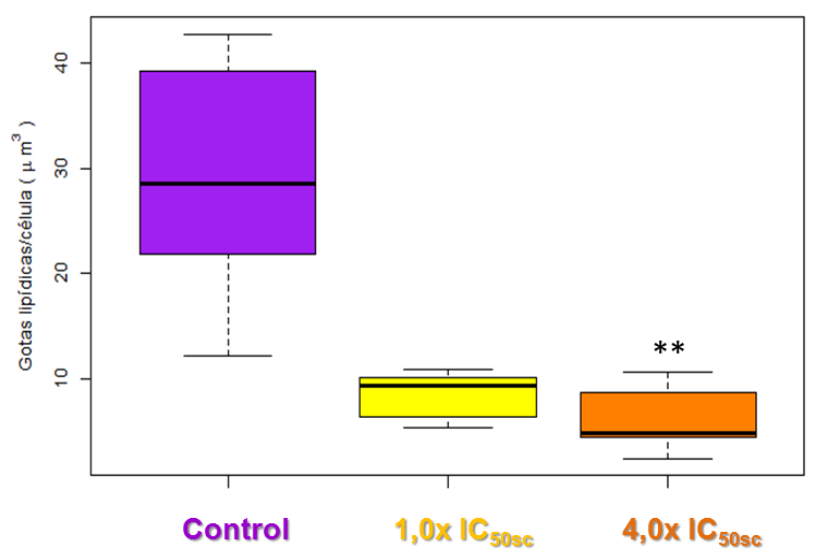

Figura 5.17. Cuantificación del número y volumen total de GL por célula. Se analizaron imágenes de microscopía y se calculó el promedio de gotas lipídicas que se presentaban por célula (Panel A) así como el volumen total medio por célula (Panel B) que se presentaba para cada campo evaluado. Para el análisis estadístico de los datos se utilizó el test de Kruskal-Wallis, seguido del test poshoc de Bonferroni. $(\mathrm{n}=7) * * \mathrm{p}<0.01$. 


\section{E. Efectos de la combinación de AELta y simvastatina}

Teniendo en cuenta que, según los resultados presentados en las secciones 5.A y 5.B.1.1, los AELs disminuirían la colesterogénesis inhibiendo una etapa de la VM diferente a la afectada por las estatinas, surge la hipótesis de la existencia de un probable efecto anticolesterogénico sinérgico entre ambos tipos de inhibidores. Esto permitiría la utilización de menores dosis de estatinas para lograr un tratamiento efectivo de las hipercolesterolemias y disminuir la incidencia de efectos secundarios indeseables producidos por las estatinas, que están frecuentemente asociados a la inhibición de la síntesis de productos de la VM distintos del colesterol.

Para validar parte de esta hipótesis se estudió el efecto de la combinación de Sv con AELta (el quimiotipo de AE de L. alba que presenta mayor efecto anticolesterogénico) sobre la síntesis de productos finales de la VM, la distribución de lípidos neutros, la composición lipídica celular y los niveles de HMGCR.

Se seleccionaron concentraciones mínimas inhibitorias de Sv para realizar el tratamiento combinado de Sv con AELta. Se utilizó Sv: $0,02 \mu \mathrm{M}$ y 0,1 $\mu \mathrm{M}$ para HepG2 y A549, respectivamente y dos concentraciones de AELta $1,0 \times \mathrm{IC}_{50 \mathrm{sc}}(4 \mu \mathrm{g} / \mathrm{ml})$ y $0,5 \times \mathrm{IC}_{50 \mathrm{sc}}(2 \mu \mathrm{g} / \mathrm{ml}$, inhibe aproximadamente $20 \%$ la colesterogénesis).

\section{E.1. Vía del mevalonato y colesterogénesis. Incorporación de ${ }^{14} \mathrm{C}$-acetato en lípidos de la vía del mevalonato}

Ambas líneas celulares fueron tratadas con el AELta y Sv (adicionados solos y combinados de a par) y se analizó el efecto sobre la síntesis de colesterol y otros productos de la VM por incorporación de ${ }^{14} \mathrm{C}$-acetato según se describió previamente.

Los resultados correspondientes a la radiactividad incorporada en los productos finales de la VM (colesterol y ubiquinona) detectados en células HepG2 y A549 se presentan en las Figuras 5.18 y 5.19, respectivamente.

En ambas líneas celulares, el tratamiento combinado de Sv con cada una de las dos concentraciones de AELta presentó un efecto anticolesterogénico sinérgico, con valores de índice $R>1$ que indican una inhibición por encima de lo esperado para una interacción aditiva (Figura 5.18, Panel B y Figura 5.19). Además, ambas combinaciones presentaron una diferencia significativa en la inhibición de la colesterogénesis con respecto a Sv individual y 


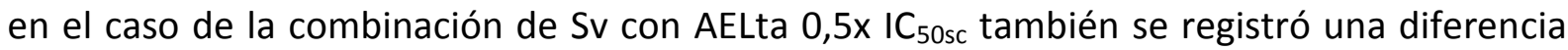
significativa con respecto al de AELta solo. Es importante destacar que en los tratamientos combinados Sv-AELta los niveles de ${ }^{14} \mathrm{C}$-ubiquinona mostraron un incremento muy similar al registrado en el tratamiento con AELta solo, y en el caso de células HepG2 se revierte la inhibición de la síntesis de este lípido ocasionada por el tratamiento con Sv.
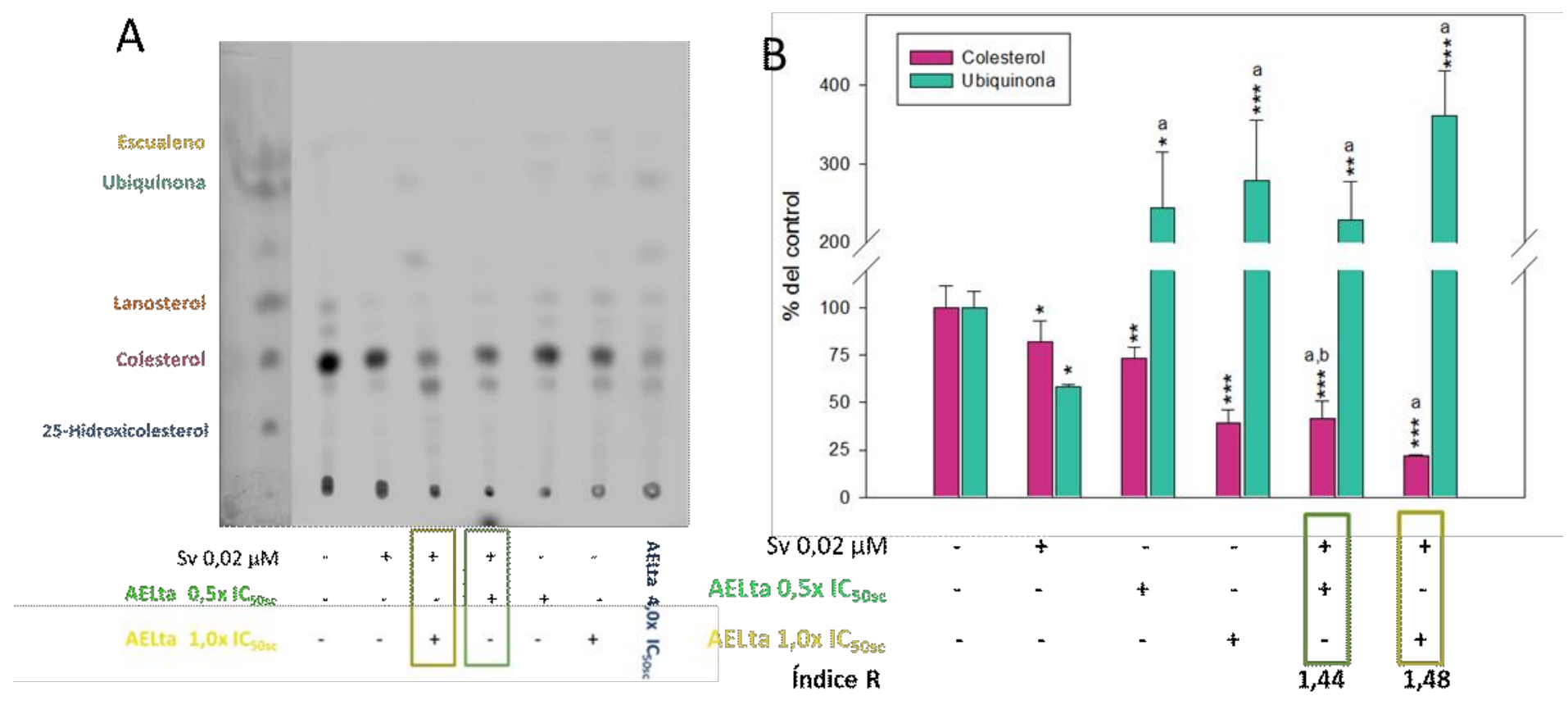

Figura 5.18. Efecto de la combinación entre AELta y simvastatina sobre la síntesis de colesterol en células HepG2. Las células fueron tratadas con AELta o Sv individualmente o combinados de a pares durante 48 horas, agregando $1 \mu \mathrm{Ci} / \mathrm{ml}$ de ${ }^{14} \mathrm{C}$-acetato durante las últimas 3 horas. La fracción de lípidos insaponificables fue separada por TLC. (Panel A). La incorporación de radiactividad en colesterol y ubiquinona fue revelada por autorradiografía, cuantificada por densitometría, normalizada al contenido de PCT (DPM/mg PCT) y expresada como porcentaje del control (Panel B). El efecto sinérgico sobre la inhibición de la síntesis de colesterol fue evaluado a partir del índice R. Los resultados se expresan como el promedio \pm DS $(n=4) ;{ }^{*} p$ $<0,05, * * p<0,01, * * * p<0,00$, a: diferencia significativa con el tratamiento individual de Sv, b: diferencia significativa con la misma dosis de AELta individual. 


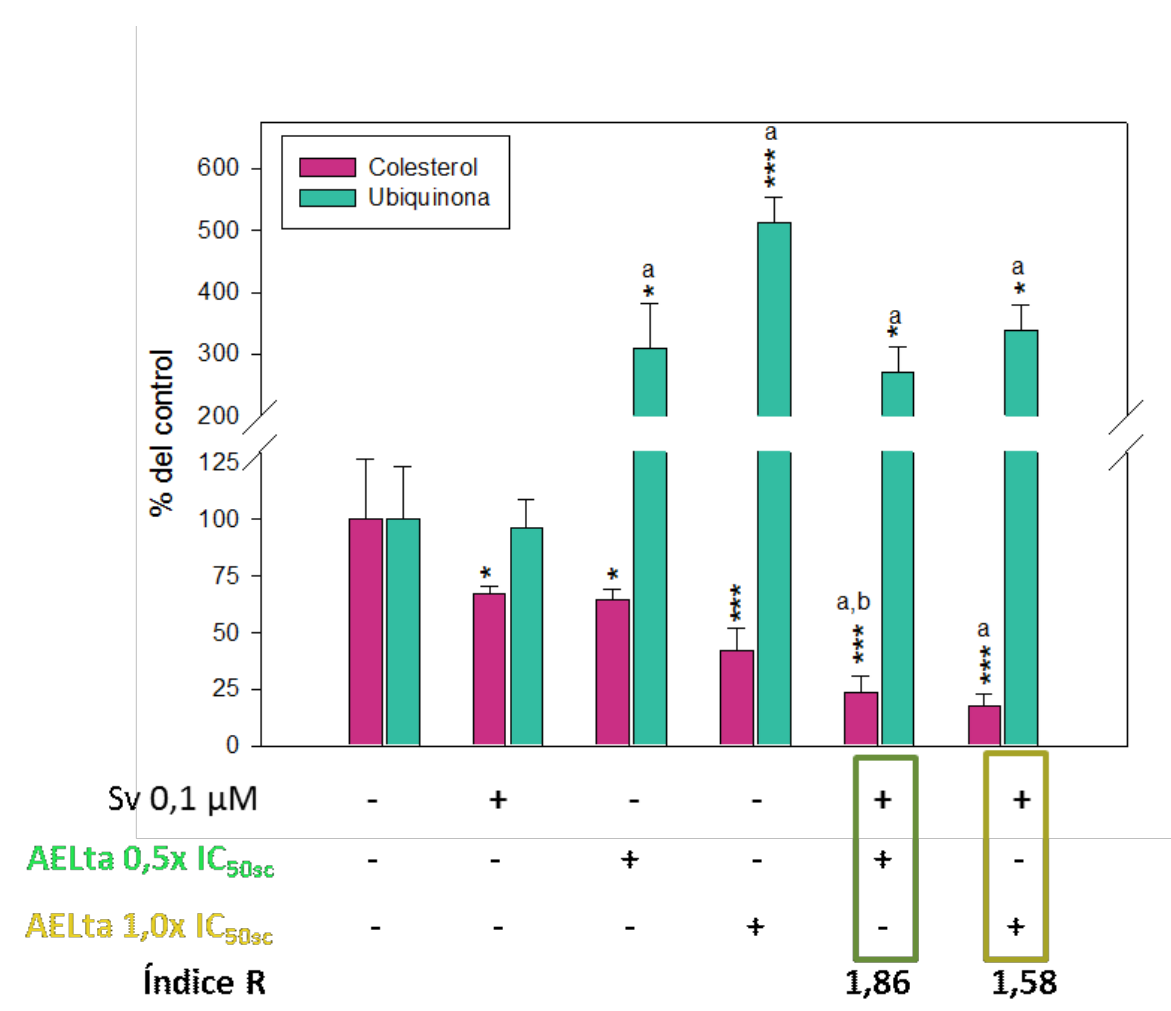

Figura 5.19. Efecto de la combinación entre AELta y simvastatina sobre la síntesis de productos finales de la vía del mevalonato en células A549. Las células fueron tratadas con AELta o Sv individualmente $\mathrm{o}$ combinados de a par durante 48 horas, agregando $1 \mu \mathrm{Ci} / \mathrm{ml}$ de ${ }^{14} \mathrm{C}$-acetato durante las últimas 3 horas. La incorporación de radiactividad en colesterol y ubiquinona fue revelada por autorradiografía, cuantificada por densitometría, normalizada al contenido de PCT (DPM/mg PCT) y expresada como porcentaje del control. El efecto sinérgico sobre la inhibición de la síntesis de colesterol fue evaluado a partir del índice R. Los resultados se expresan como el promedio \pm DS $(n=4) ; * p<0,05, * * p<0,01, * * * p<0,00$, a: diferencia significativa con respecto al

\section{E.2. Incorporación de ${ }^{14} \mathrm{C}$-acetato en lípidos neutros y polares}

Durante las últimas 3 horas de tratamiento se adicionó ${ }^{14} \mathrm{C}$-acetato al medio de cultivo, se extrajeron los lípidos totales y se cuantificó la radiactividad por centelleo líquido. Las distintas fracciones lipídicas fueron separadas y se cuantificó la radiactividad incorporada en cada una de ellas según se describió en Materiales y Métodos.

\section{E.2.1. Ácidos grasos y lípidos insaponificables}

Una alícuota de LT fue saponificada, se extrajeron lípidos insaponificables y ácidos grasos y se cuantificó la radiactividad presente en ellos por centelleo líquido. Los resultados obtenidos se presentan en la Figura 5.20.

Se observó un aumento de la incorporación de radiactividad en lípidos totales para Sv, el cual es a expensas de un aumento equivalente en la incorporación de acetato en 
ácidos grasos. En las combinaciones AELta-Sv, es revertida la disminución de la incorporación de acetato en ácidos grasos que se observó en células tratadas con AELta individualmente.

En lípidos insaponificables se evidencia que los tratamientos individuales de Sv o AELta generaron una previsible disminución de la radiactividad incorporada. Se observa un efecto sinérgico de esta disminución para los tratamientos combinados con un índice $R$ en ambos casos de 1,18.

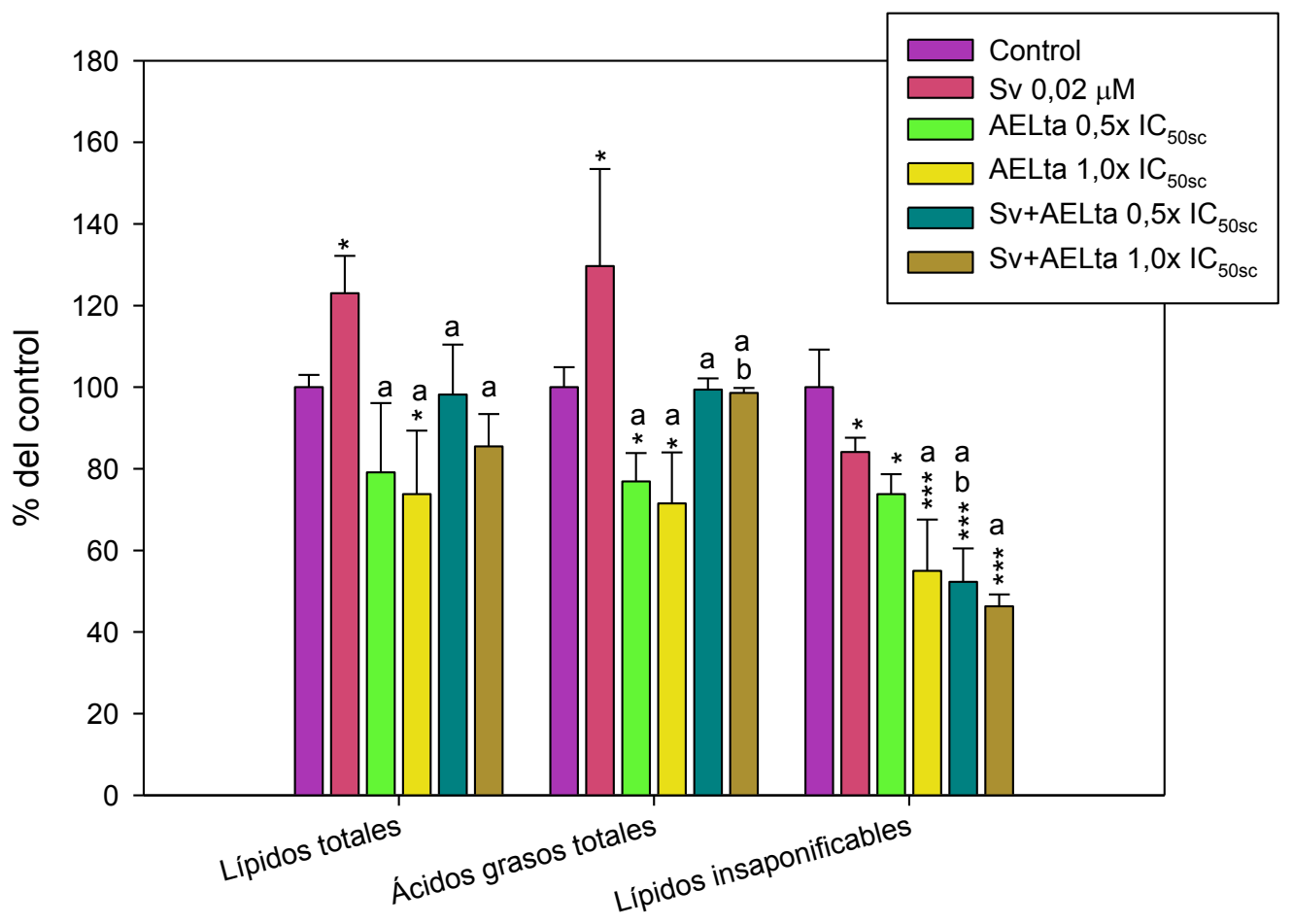

Figura 5.20. Incorporación de ${ }^{14} \mathrm{C}$-acetato en ácidos grasos y lípidos insaponificables de células HepG2. Las células fueron tratadas con dos concentraciones de AELta y Sv 0,02 $\mu \mathrm{M}$ (solo o combinado entre si) por 48 horas y se adicionó ${ }^{14} \mathrm{C}$-acetato en las últimas 3 horas de incubación. Las distintas fracciones fueron cuantificadas por centelleo líquido en un contador Wallac 1214 Rack Beta. Los datos son el promedio \pm DS $(n=4) * p<0.05,{ }^{* *} p<0.01, * * * p<0.001$; a: diferencia significativa con respecto al tratamiento individual de Sv, b: diferencia significativa con respecto al tratamiento con AELta.

\section{E.2.2. Lípidos neutros}

Los lípidos neutros presentes en una alícuota de LT extraídos de células HepG2 tratadas con AELta y Sv (individualmente o combinado) fueron separados por TLC y la radiactividad presente en cada uno de ellos fue identificada por autorradiografía y cuantificada por densitometría según se describe en Materiales y Métodos. 
En la incorporación de radiactividad, para tanto colesterol libre como esterificado, se observó una disminución significativa en todos los tratamientos. La combinación Sv-AELta tanto para CL como CE presenta un efecto sinérgico en la baja de estas especies.

En el caso de la incorporación de acetato en triglicéridos, se observa un aumento en las células tratadas con Sv, mientras que en los tratamientos con AELta, como se había observado en la sección anterior, esta disminuye. Los tratamientos Sv-AELta no presentan cambios significativos con respecto al control, pero sí presentan una diferencia con respecto al tratamiento individual de Sv (Figura 5.21).

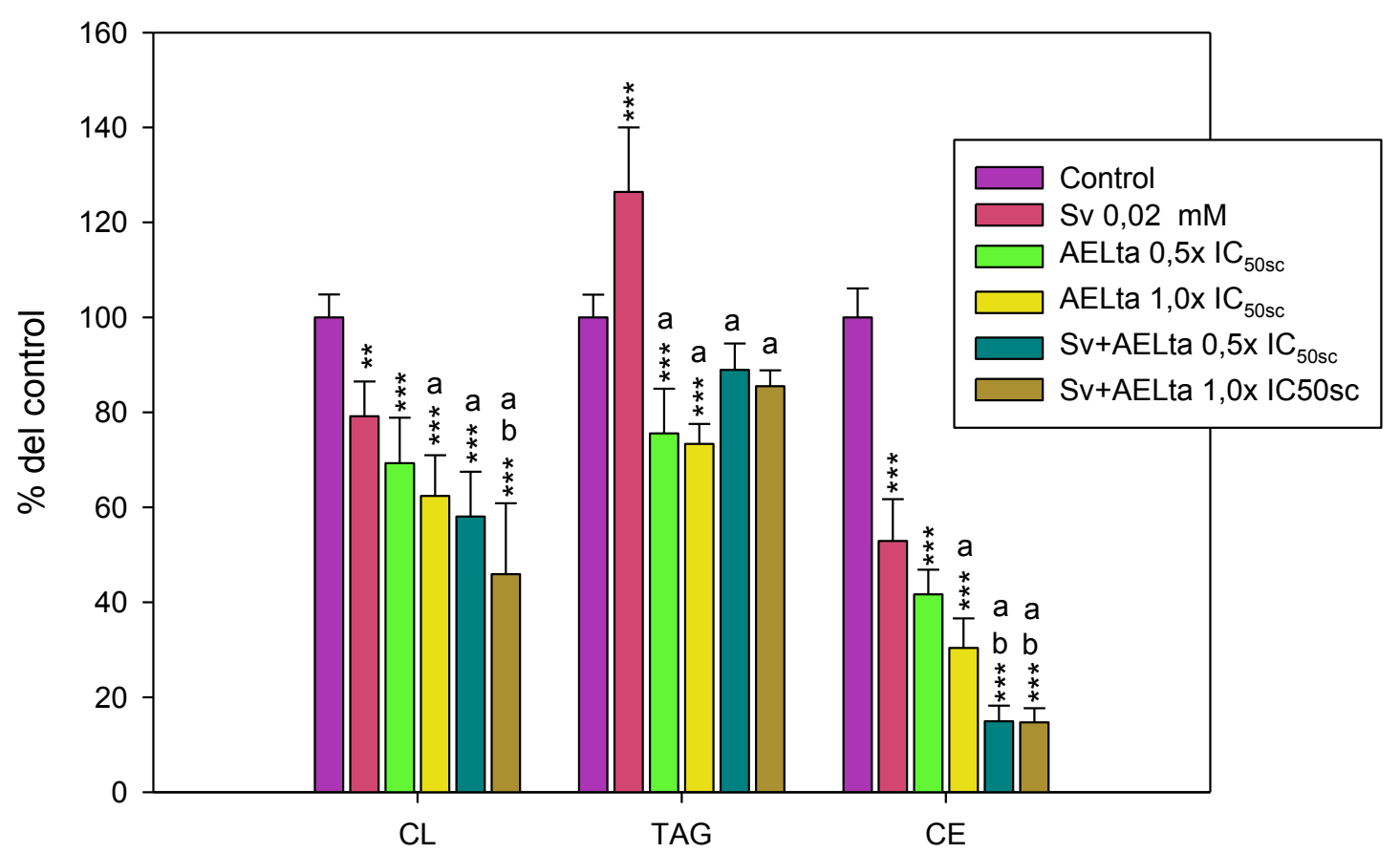

Figura 5.21. Incorporación de ${ }^{14} \mathrm{C}$-acetato en lípidos neutros. Las células fueron tratadas con dos concentraciones de AELta y Sv $0,02 \mu \mathrm{M}$ (solo o combinado) por 48 horas y se adicionó ${ }^{14} \mathrm{C}$-acetato en las últimas 3 horas de incubación. La incorporación de radiactividad en lípidos neutros separados por TLC fue revelada por autorradiografía y cuantificada por densitometría. Los resultados muestran el promedio \pm DS $(n=4) ;{ }^{*} p<0,05 ;{ }^{*} p<0,01 ;{ }^{* *} p<0,001$; a: diferencia significativa con respecto al tratamiento individual de Sv, b: diferencia significativa con respecto al tratamiento con AELta. CL: colesterol libre; TAG: triacilglicéridos; CE: colesterol esterificado. 


\section{E.3. Contenido de lípidos neutros.}

Con la intención de evidenciar si la inhibición sinérgica de la colesterogénesis se traduce en una disminución de los niveles de colesterol, células HepG2 en fase de crecimiento exponencial fueron tratadas con el AELta y Sv (adicionados solos y combinados de a pares) y se determinó el contenido de CL, TAG y CE según lo descrito previamente.

Los tratamiento con Sv y AELta, solos o combinados, no ocasionaron cambios significativos en el contenido de colesterol libre (Figura 5.22). Mientras que, tanto para TAG como para EC se observó un efecto aditivo en la disminución del contenido de estas especies lipídicas al combinar Sv y AELta.

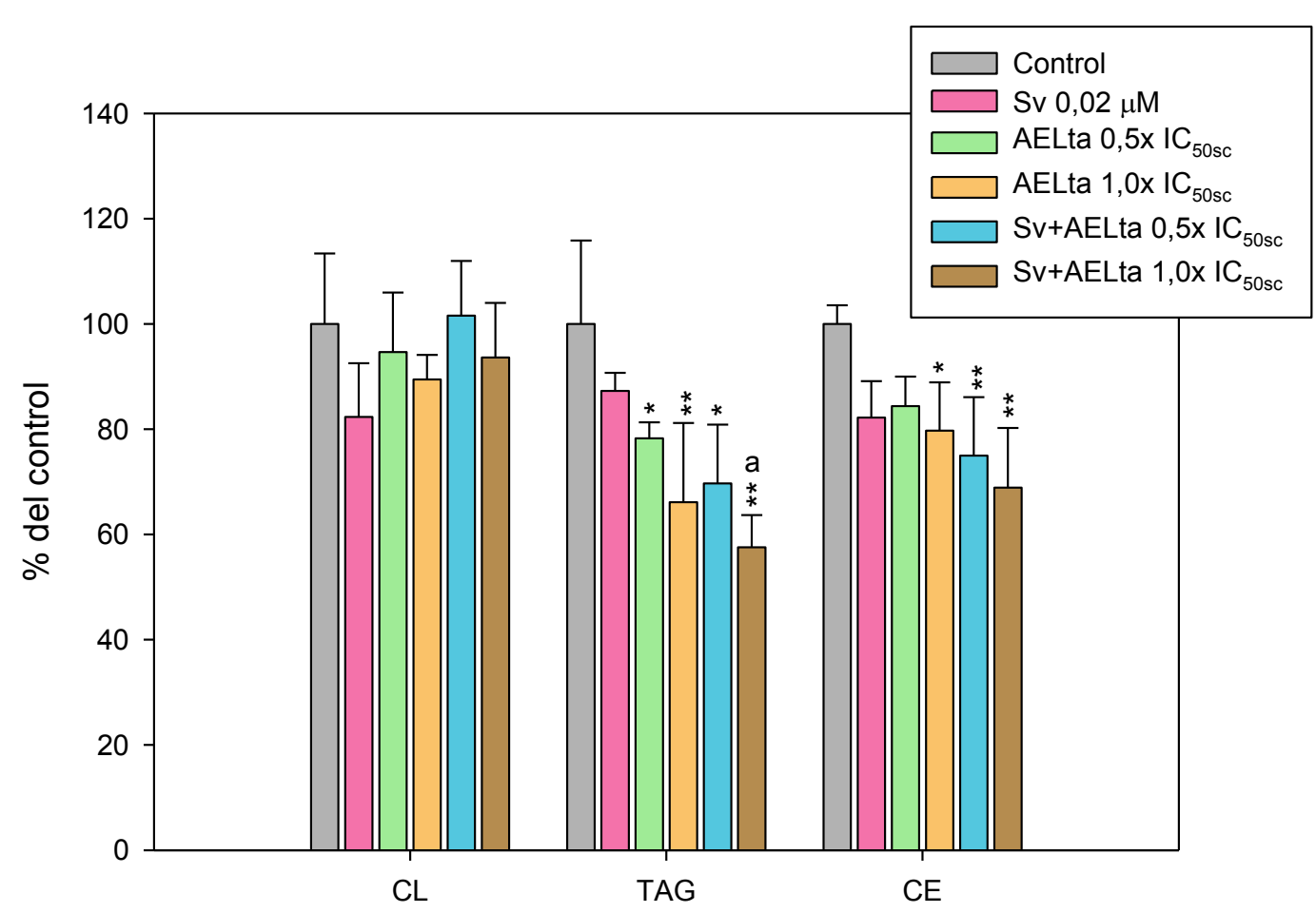

Figura 5.22. Efecto combinado de AELta y simvastatina sobre el contenido de colesterol y TAG en células HepG2. Las células fueron tratadas con AELta, Sv $0,02 \mu \mathrm{M}$ y sus combinaciones de a pares durante 48 horas. Se extrajeron LT y se separaron lípidos neutros por TLC. Se raspó la sílica de las zonas correspondientes a TAG, se los extrajo con cloroformo y se cuantificaron colorimétricamente utilizando kit enzimático TG color. La presencia de CL y CE se reveló aplicando una solución ácida de cloruro férrico en forma de espray sobre la placa con posterior carbonización a $180^{\circ} \mathrm{C}$ y se cuantificó por densitometría. Los resultados se expresan como el promedio \pm DS $(n=4) ;{ }^{*} p<0,05,{ }^{* *} p<0,01$, $* * * p<0,00$, a: diferencia significativa con el tratamiento individual de Sv. CL: colesterol libre; TAG: triacilglicéridos; CE: colesterol esterificado. 


\section{E.4. Niveles de HMGCR}

Se analizó el efecto del AELta y su combinación con dosis baja Sv, sobre los niveles de HMGCR en células HepG2. Para ello, las células fueron tratadas con el IC $\mathrm{ISsc}_{\text {sc }}$ de $A E L t a$ y 0,02 $\mu \mathrm{M}$ de Sv (individualmente o combinados entre sí) y se determinaron los niveles de la enzima mediante Western Blotting según se describe en Materiales y Métodos.

Se observó que el tratamiento con una concentración de AELta que inhibe la colesterogénesis un 50 \% no ocasionó cambios en los niveles de la enzima con respecto al control. Por otra parte, se encontró un aumento característico de la cantidad de HMGCR en células tratadas con Sv que no fue contrarrestado en células tratadas con la combinación de AELta-Sv (Figura 5.23).

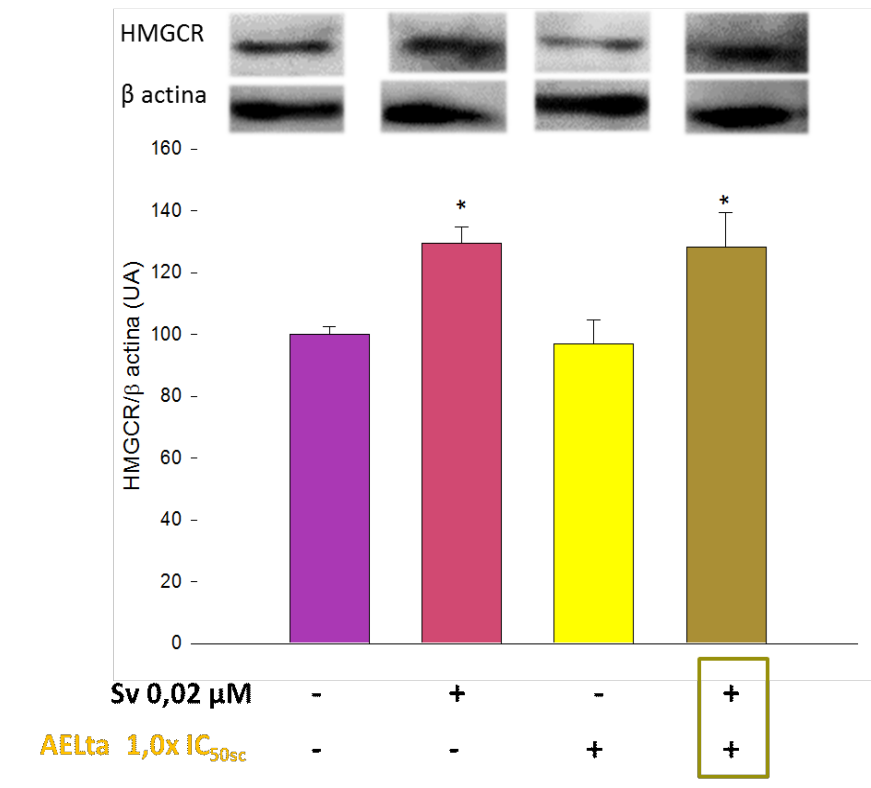

Figura 5.23. Efecto sobre los niveles de HMGCR en células HepG2 tratadas con AELta, simvastatina y su combinación. Las bandas inmunodetectadas fueron cuantificadas por densitometría y normalizadas con $\beta$-actina. Los resultados se expresan relativos al control como el promedio \pm DS $(n=4) ;{ }^{*} p$ $<0,05$. $\cup A=$ unidades arbitrarias. 


\section{F. Discusión}

Las enfermedades cardiovasculares (ECV) son la principal causa de mortalidad en el mundo y la elevación del colesterol asociado a las lipoproteínas de baja densidad (LDLcolesterol) es un factor de riesgo importante para el desarrollo de las mismas $(100,452)$. Las estatinas, inhibidores competitivos de la HMGCR, son la clase de medicamentos anticolesterogénicos más ampliamente utilizada. Varios ensayos clínicos han demostrado la eficacia de la terapia con estatinas en la disminución de LDL-colesterol y la reducción de la morbilidad y mortalidad por $\operatorname{ECV}(453,454)$. Sin embargo, ciertas poblaciones tienen un alto riesgo residual de ECV a pesar de recibir terapia con estatinas $(455,456)$ y en ciertos individuos el uso de estas drogas es limitada debido a la aparición de reacciones adversas, como las miopatías (457). Además, las estatinas resultan poco efectivas para disminuir niveles elevados de TAG en plasma, un factor de riesgo de ECV comúnmente asociado con el síndrome metabólico $(458,459)$. Por lo tanto, se necesitan agentes alternativos que permitan disminuir los niveles de LDL-colesterol con escasos efectos secundarios y mejorar el perfil lipídico general en dislipidemias.

Los aceites esenciales de hierbas aromáticas contienen una gran variedad de compuestos volátiles que pueden tener propiedades medicinales incluyendo efectos hipolipidémicos $(460,461)$. En función de esto, el consumo de distintos productos obtenidos de L. alba es popularmente promovido en la actualidad como un medio eficaz de eliminar los problemas causados por la hipercolesterolemia $(295,296)$. Sin embargo, son muy escasos los reportes científicos que han demostrado los efectos de esta planta o sus extractos sobre el metabolismo lipídico o que sugieran un potencial efecto terapéutico en dislipidemias. De hecho, hasta el momento solo Olivero Verdel et al. (333) han reportado efectos de L. alba quimiotipo citral en la expresión de ciertos genes relacionados con el metabolismo lipídico. Esto nos llevó a examinar el efecto sobre el metabolismo lipídico de distintos quimiotipos de AEL en busca de actividades que puedan ser útiles en el tratamiento de dislipidemias y la prevención de ECV. En este sentido, en esta tesis se evaluó inicialmente la potencial utilidad de AEL como agentes anticolesterogénicos en células humanas hepáticas (HepG2) y extrahepáticas (A549) en cultivo. Se utilizó la simvastatina como compuesto testigo que inhibe efectivamente la colesterogénesis y que es empleada como droga de primera línea para el tratamiento de la hipercolesterolemia en humanos. 
En las condiciones experimentales empleadas en esta tesis la simvastatina presentó efecto anticolesterogénico en ambas líneas celulares. En células HepG2 se consiguió una inhibición del $50 \%$ de la colesterogénesis con 0,06 $\mu \mathrm{M}$ de simvastatina (Figura 5.1, Panel C), concentración similar a la reportadas en otros trabajos (377) y a la alcanzada en plasma durante los tratamientos de hipercolesterolemia (443). Mientras que en A549 la concentración de simvastatina requerida para producir el mismo efecto fue aproximadamente 20 veces mayor (Figura 5.1, Panel F), lo que puede ser atribuido a la menor actividad colesterogénica de las células extra-hepáticas o algún tipo de hepatoselectividad para la simvastatina. Dado que las estatinas inhiben la VM en una etapa temprana, la inhibición de colesterogénesis correlaciona con la disminución de incorporación de acetato en todos los intermediarios de la VM detectados y de síntesis de ubiquinona (Figura 5.1, Paneles B y E). La deficiencia de esta última se asocia al debilitamiento muscular y rabdomiolisis producida por los tratamientos con estatinas (462-465).

El tratamiento de células HepG2 con una concentración de simvastatina que inhibe efectivamente la colesterogénesis no ocasionó modificación del contenido de colesterol (Figura 5.22) y se registró un incremento de los niveles de HMGCR (Figura 5.23), lo que indica que se han disparado mecanismos compensatorios para el mantenimiento de la homeostasis del colesterol en estas células. Como es sabido, en respuesta a una disminución en los niveles de colesterol se produce el clivaje del precursor de SREBP-2. En su forma activa, el factor de transcripción induce la expresión de los genes de HMGCR y LDLR entre otros, con el fin de compensar la depleción de este lípido esteroideo $(50,466)$.

Adicionalmente, la simvastatina ha tenido un impacto sobre el metabolismo de otros lípidos analizados en HepG2. Cuando las células fueron tratadas con concentraciones de Sv que inhiben la colesterogénesis se registró un importante aumento de la incorporación de acetato en LT y AGs (Figura 5.20) y TAG (Figura 5.21). El resultado obtenido en AGs puede atribuirse a una disminución de la $\beta$-oxidación y/o a un incremento de la síntesis de los mismos. Recientemente se han identificado nuevas regiones genómicas bajo la regulación de SREBP-2, entre las que se encuentra una que codifica para un microARN altamente conservado denominado miR-33. Una de las funciones de miR-33 es inhibir la $\beta$-oxidación de AGs a través de la supresión de varias enzimas (467). Cuando los niveles de colesterol son bajos y se produce la activación de SREBP-2, estos mecanismos permiten retener el colesterol intracelular e incrementar la disponibilidad de AGs de cadena larga necesarios 
para formar ésteres de colesterol, que son la forma predilecta y más "segura" de almacenarlo (Figura 5.19) $(467,468)$. Asimismo, aunque existe cierta preferencia de SREBP-2 por activar genes involucrados en la síntesis de colesterol, se ha sugerido que también es capaz de activar la mayoría de aquellos relacionados con la síntesis de ácidos grasos, sobre todo cuando se expresa por encima de los niveles fisiológicos (50). La elevada síntesis de TAG podría ser simplemente consecuencia de la inducción de los genes lipogénicos en general, aunque también podría tratarse de un mecanismo protector para secuestrar el exceso de AGs de manera no tóxica. Esto se debe a que los AGs, junto con otras especies como acil-CoA, DAG y ceramidas, promueven la disfunción y muerte celular en un proceso denominado "lipotoxicidad" (469-471).

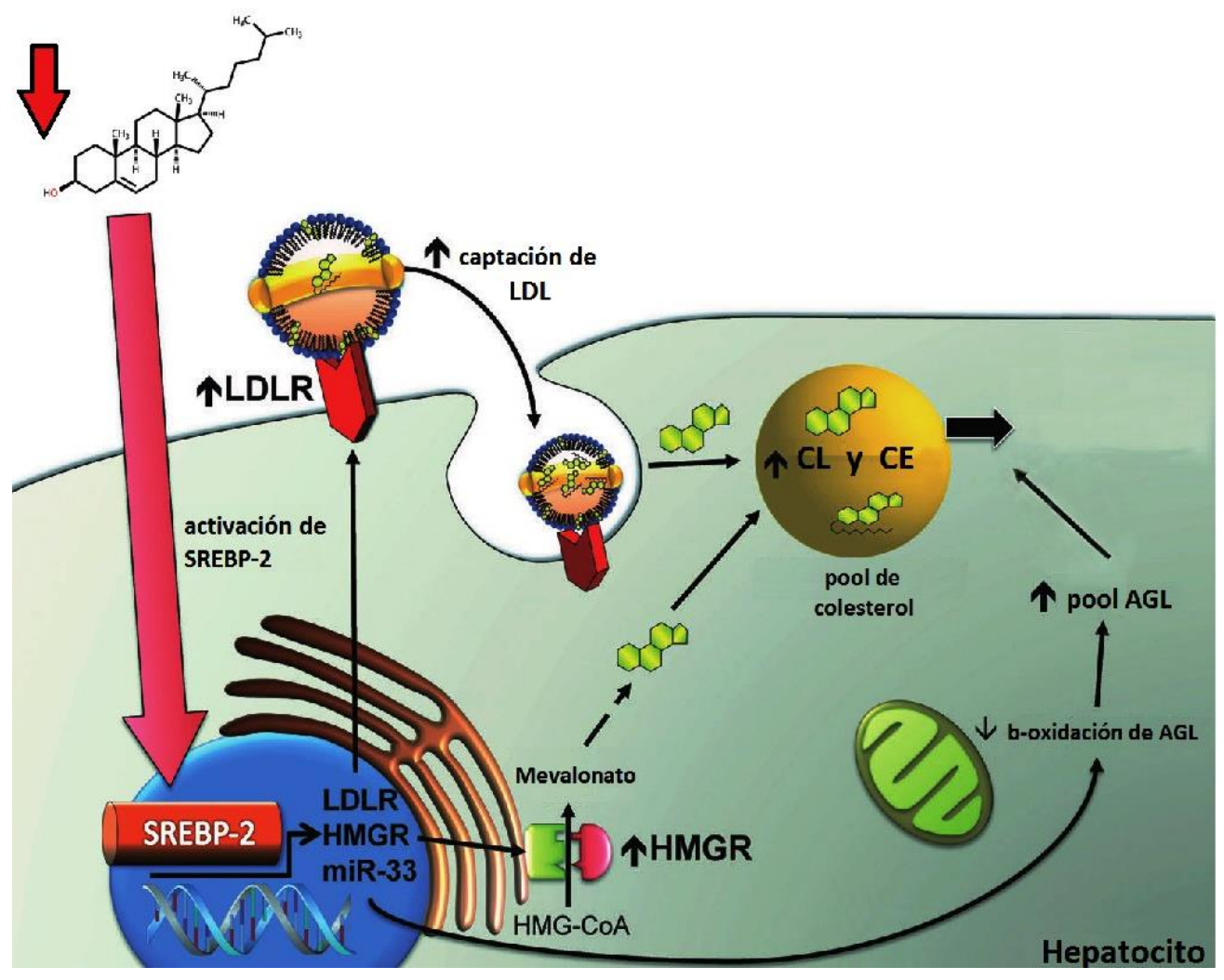

Figura 5.24. Activación de la expresión de genes regulados por SREBP-2 en respuesta a niveles bajos de colesterol intracelular. Niveles bajos de colesterol promueven la activación proteolítica de SREBP-2. El factor maduro trasloca al núcleo y activa la transcripción de genes involucrados en la síntesis (HMGCR) y captación extracelular de colesterol (LDLR) y de genes que incrementan la disponibilidad del pool de AGs libres (miR-33). La acción conjunta de estos 3 mecanismos compensatorios incrementa los niveles intracelulares de colesterol y su almacenamiento en forma de CE. Adaptado de Van Rooven et al. (467). 
Bajo las mismas condiciones experimentales utilizadas para simvastatina, todos los aceites evaluados mostraron efecto anticolesterogénico en ambas líneas celulares. Los valores de $\mathrm{IC}_{50 \text { sc }}$ calculados para cada quimiotipo en HepG2 y A549 son del mismo orden de magnitud lo cual indica que ninguno de ellos presenta hepatoselectividad (Figura 5.7).

El quimiotipo más efectivo como anticolesterogénico fue AELta con valores de $I_{50 s c}$ del orden de los $3,5 \mu \mathrm{g} / \mathrm{ml}$ y una inhibición de la síntesis de colesterol superior al $80 \%$ cuando las concentraciones ensayadas fueron $\geq 8 \mu \mathrm{g} / \mathrm{ml}$ (Figura 5.7). La efectividad del AELta es sustancialmente mayor a la del 1,8-cineole (uno de sus monoterpenos mayoritarios), para quien se han reportado valores de $\mathrm{IC}_{50 \mathrm{sc}}$ de $86 \mu \mathrm{g} / \mathrm{ml}$ y $53 \mu \mathrm{g} / \mathrm{ml}$ en HepG2 y A549, respectivamente (250).

En todos los casos, la inhibición de la síntesis de colesterol fue acompañada con disminución de incorporación de acetato en intermediarios de la VM específicamente involucrados en colesterogénesis -escualeno y lanosterol- y un incremento de la síntesis de ubiquinona, excepto para AELpi en HepG2 (Figuras 5.2, 5.3, 5.5 y 5.6). Efectos similares han sido reportados en células HepG2 tratadas con los monoterpenos geraniol (249) y 1,8cineole (250). Estos resultados estarían indicando una inhibición de escualeno sintasa, un acúmulo de FPP y el redireccionamiento del mismo hacia otros destinos finales como ubiquinona. Los inhibidores de escualeno sintasa (SSIs)- como escualestatin 1 y lapaquistatbloquean la primera etapa de la VM comprometida específicamente en la síntesis de colesterol (472) y, a diferencia de inhibidores de HMGCR, preservan la síntesis de isoprenoides no esteroles que son utilizados en modificaciones postraduccionales de proteínas, síntesis de glicoproteínas y para la generación de componentes del metabolismo aeróbico $(81,98,473,474)$.

El tratamiento con concentraciones de los AEs que inhiben un $50 \%$ la colesterogénesis no ocasionó una disminución del contenido de colesterol celular, excepto para AELta en la que se registra una moderada disminución del mismo (Tabla 5.1). Esto estaría indicando que se han disparado en ambas líneas celulares los mecanismos compensatorios para el mantenimiento de la homeostasis del colesterol celular mediados por SREBP-2, tal como fue descrito previamente para tratamiento con Sv. Sin embargo, a diferencia de lo observado con la estatina, el tratamiento de células HepG2 con $1 \times I_{50 s c}$ de AELta no ocasiona un incremento de los niveles de HMGCR (Figura 5.23). Esto podría deberse a un incremento de la degradación de la enzima inducida por el acúmulo de FPP. En 
este sentido, diversos autores han reportado que el farnesol, producido a partir de FPP por acción de farnesil pirofosfatasa (424), acelera la degradación proteosomal de la HMGCR (475-478) por incremento de la ubiquitinación de la enzima $(479,480)$. En la Figura 5.25 se describe el modelo propuesto para explicar efectos de AELta sobre la síntesis de colesterol y los niveles de HMGCR en células hepáticas.

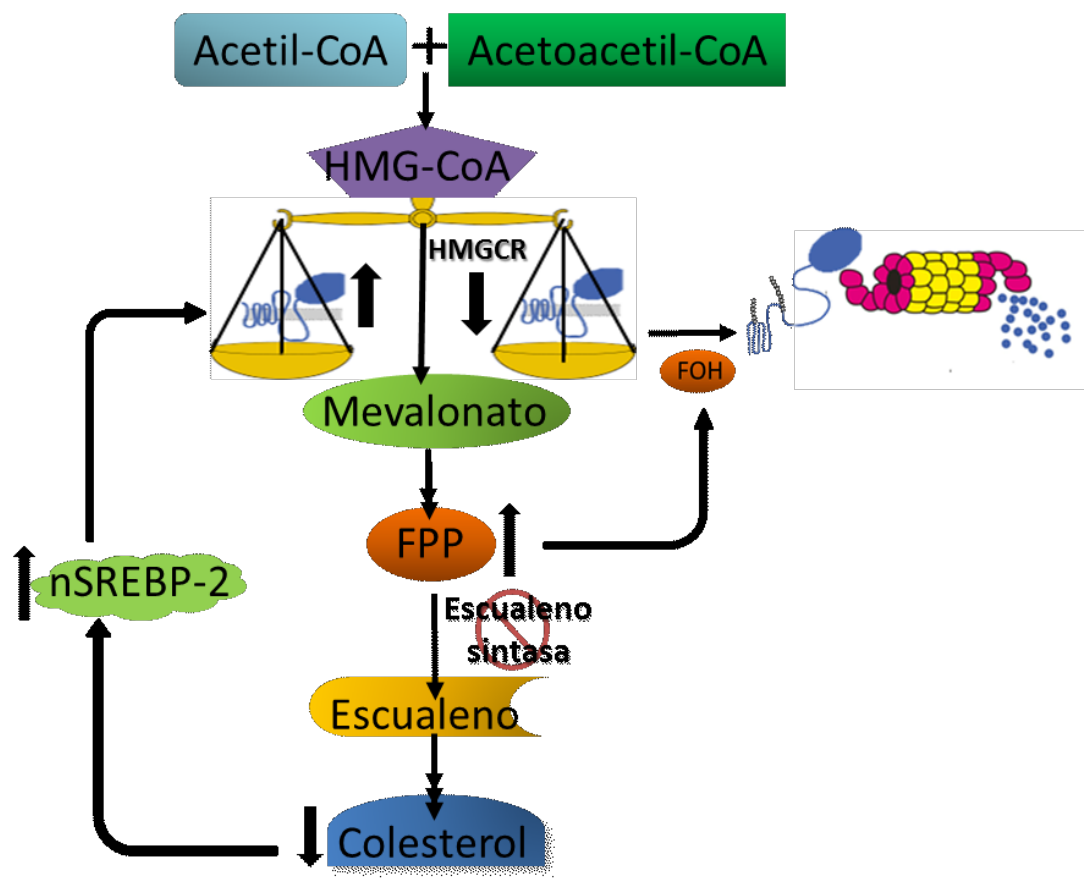

Figura 5.25. Modelo propuesto para describir el efecto de AELta sobre la VM en células HepG2 y su impacto sobre síntesis y degradación de HMGCR.

Además del efecto promovido por la acumulación de intermediarios, otros mecanismos podrían estar afectando la expresión de la HMGCR. Por ejemplo, isoprenoides presentes en el $A E$ podrían inhibir la síntesis de esta enzima a nivel post-transcripcional, como se ha postulado para isoprenoides no esteroideos de la VM no identificados $(51,99)$ y para isoprenoides vegetales como limoneno y perillil alcohol (245) y geraniol (259). No obstante se necesita información suplementaria, como ensayos de expresión del ARNm y de actividad de la enzima, para profundizar el entendimiento de los mecanismos por los cuales el AELta modula la expresión de HMGCR.

Al analizar el impacto del AELta sobre el metabolismo lipídico general en células hepáticas se observó que el tratamiento con el aceite esencial, además de inhibir la colesterogénesis, también ocasionó modificaciones en el metabolismo de otros lípidos en células HepG2 registrándose una disminución de la incorporación de ${ }^{14} \mathrm{C}$-acetato en $\mathrm{AGs}$ totales (Figura 5.9), DAG, TAG y CE (Figura 5.11) y FL (Figura 5.12). Los resultados obtenidos 
en AGs totales pueden deberse a una disminución de síntesis y/o un aumento de la degradación de los mismos y serían en parte la causa de la disminución de la radiactividad registrada en los lípidos saponificables. Similares resultados a los aquí presentados fueron reportados por otros autores en células HepG2 tratadas con 1,8-cineole (uno de los monoterpenos mayoritarios del AELta) (250) y en hepatocitos de rata tratados con el monoterpeno farnesol y con SSIs (481).

Estos resultados, opuestos a los encontrados con Sv en idénticas condiciones experimentales, indican que el efecto sobre el metabolismo de los lípidos saponificables es independiente de la disminución de la síntesis de colesterol que ellos ocasionan. La actividad hipolipogénica general del AELta en células HepG2 puede estar mediada por el intermediario FPP acumulado, por algún componente específico del AE o por ambos.

El FPP puede ser desfosforilado a farnesol y luego metabolizado para producir ácido farnesoico y ácidos dicarboxílicos de cadena corta $(482,483)$. Se ha demostrado que todos estos compuestos son efectivos en la inhibición de la síntesis tanto de colesterol como de TAG en hepatocitos de rata y son los responsables de la disminución de la síntesis hepática y del contenido plasmático de TAG (a través de un mecanismo independiente de LDLR) en tratamientos con SSIs (481).

Los efectos del farnesol y sus derivados sobre el metabolismo de los AGs y TAG pueden ser atribuidos a que varios de estos compuestos isoprenoides funcionan como moléculas señal (agonistas) que pueden modular la actividad de receptores nucleares como FXR y PPARs, los cuales juegan un rol importante en el metabolismo lipídico (484-488). La activación de FXR induce la expresión del receptor nuclear SHP (small heterodimer partner) quien disminuye la expresión de SREBP-1c (489), un factor de transcripción que juega un rol crítico en la estimulación de la síntesis de ácidos grasos y lipogénesis por inducción de la expresión de enzimas claves como ácido graso sintasa (FAS), acetil-CoA carboxilasa (ACC), estearoil-CoA desaturasa (SCD) y glicerol-3-fosfato aciltransferasa (GPAT) (50). Adicionalmente, los agonistas de FXR pueden inducir la expresión de PPAR y promover la oxidación de AGs a través de la inducción de la piruvato deshidrogenasa quinasa-4, su gen blanco $(490,491)$. De modo que, la activación de FXR ocasiona una reducción de los niveles hepáticos de TAG y de la secreción de VLDL como consecuencia de la reducción de SREBP-1c y la inducción de PPARa. 
En nuestro modelo experimental, la disminución de la lipogénesis en células HepG2 tratadas con AELta se tradujo en una reducción del contenido celular de los principales lípidos saponificables (Figura 5.13) y en una disminución del tamaño de las principales estructuras responsables del almacenamiento de lípidos de reserva, las gotas lipídicas citoplasmáticas (Figuras 5.14 a 5.17). Resultados similares fueron obtenidos por Jun et al. en células HepG2 tratadas con aceite esencial de Melissa Officinalis, en las que se detectó una reducción significativa de la síntesis de ácidos grasos debida a la disminución de la expresión de SREBP-1c y de sus genes blanco responsables de la síntesis de AGs (492). Se necesitan estudios adicionales, como medida de activación de receptores nucleares y expresión de genes lipogénicos vinculados a ellos, que permitan confirmar o refutar los mecanismos propuestos a través de los cuales el AELta afecta la síntesis y el contenido de lípidos hepáticos.

Además de la reducción de la lipogénesis de novo, la activación de FXR puede incrementar el aclaramiento de TAG plasmáticos por inducción de genes claves como el del receptor de VLDL (VLDLR), el de sindecan-1 (un proteoglucano heparán sulfato responsable del aclaramiento de partículas remanentes) y el de Apo-ClI, un activador de la lipoproteína lipasa (LPL) responsable de la hidrólisis de TAG de las VLDL $(493,494)$. Además, la activación de FXR reprime la expresión de Apo-C-III y ANGPTL3, dos inhibidores de $\operatorname{LPL}(489,495)$.

En un trabajo reciente desarrollado en nuestro laboratorio, la activación de FXR ha sido propuesta para explicar el efecto hipolipogénico a nivel hepático e hipolipemiante (disminución de colesterolemia y trigliceridemia) del monoterpeno geraniol en ratones (259).

De modo que, los resultados obtenidos en células hepáticas en cultivo tratadas con AELta y presentados en esta tesis resultan alentadores respecto a una posible capacidad hipolipemiante in vivo de este aceite. En este sentido, trabajos realizados en modelos de animales hiperlipidémicos tratados con aceites esenciales describen que son efectivos en la prevención de la oxidación de lipoproteínas, la disminución de los niveles de colesterol y TAG séricos y el mejoramiento del perfil lipídico en general (496-498).

En la Figura 5.26 se presenta un esquema del mecanismo molecular propuesto para explicar el efecto antilipogénico observado y del hipotetizado para predecir una posible capacidad hipolipemiante. 


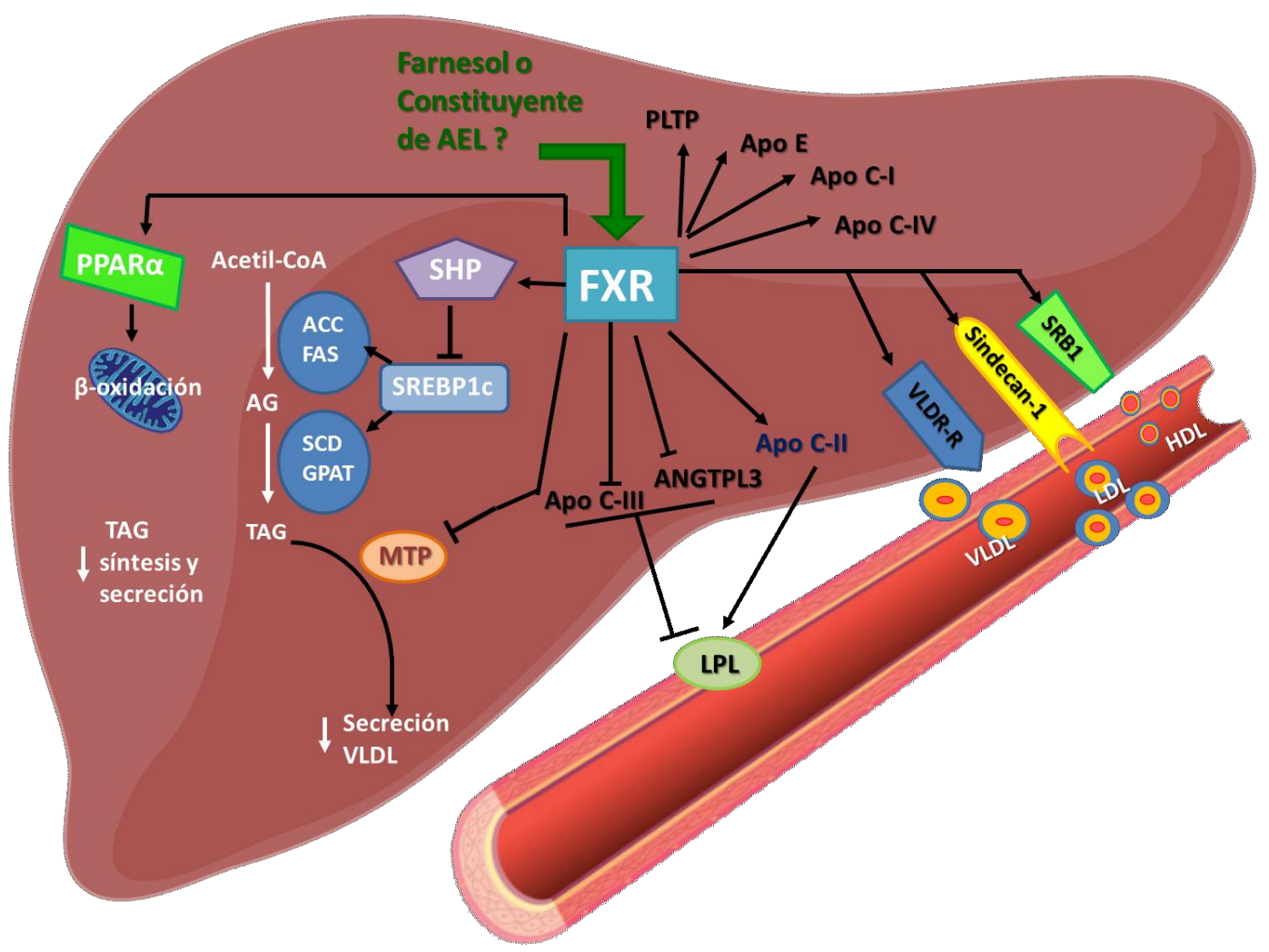

Figura 5.26. Modelo propuesto para explicar el efecto hipolipogénico del AELta en células hepáticas. Farnesol -generado a partir de FPP acumulado por inhibición de SS y/o algún isoprenoide presente en el AELta actúa como agonista de FXR. La activación de FXR conduce a la represión de la lipogénesis hepática por reducción de la expresión de SREBP-1c a través de SHP. SREBP-1c induce la expresión de genes claves para la síntesis de ácidos grasos y la lipogénesis como ACC, FAS, SCD y GPAT. Por incremento de la expresión de PPAR $\alpha$, FXR también promueve el catabolismo de AGs libres vía $\beta$-oxidación. Por represión de MTP (enzima que controla el ensamblaje de VLDL) FXR reduce la producción de VLDL. La activación de FXR incrementa el aclaramiento de TAG por aumento de la actividad de LPL (vía inducción del activador Apo C-II y disminución de los inhibidores Apo C-III y ANGPTL3) e incremento de la expresión de VLDLR y sindican-1 para la captación hepática de LDL e IDL (remanentes). La activación de FXR también ocasiona un incremento de la expresión de PLTP (transfiere fosfolípidos y apolipoproteínas desde LDL a HDL), SRB1 (responsable de la captación de HDL) y Apo E, Apo C-I y Apo C-IV.

Al combinar AELta con una concentración de Sv que inhibe moderadamente la colesterogénesis, cuando es administrada sola (aprox. $20 \%$ ), se obtiene un efecto anticolesterogénico sinérgico, que supera en más de un 44 \% la inhibición que se obtendría por un simple efecto aditivo, persistiendo el incremento de la síntesis de ubiquinona (Figuras 5.18 y 5.19). Esto último indicaría que la inhibición de la escualeno sintasa ocasionada por el aceite es lo suficientemente profunda como para redireccionar el FPP, cuya síntesis se halla disminuida como consecuencia de la inhibición de la HMGCR ocasionada por la estatina, 
hacia la generación de otros productos finales. Este resultado es interesante dado que, el tratamiento combinado permitiría disminuir las concentraciones anticolesterogénicas efectivas de las estatinas y los riesgos de efectos secundarios vinculados al descenso de los niveles de ubiquinona. De hecho, una estrategia propuesta para evitar el agotamiento de isoprenoides no-esteroles asociada con el tratamiento con estatinas es el co-tratamiento con inhibidores de escualeno sintasa (499).

Por el contrario, en el tratamiento combinado la presencia del aceite no permitió evitar el incremento de los niveles de HMGCR que resultan del tratamiento con Sv (Figura 5.23), probablemente porque la disminución del acumulo de FPP no permite alcanzar concentraciones de farnesol críticas que incrementen la degradación de la enzima a nivel proteosomal. Esto reforzaría la hipótesis de la degradación mediada por acúmulo del intermediario.

Con respecto a la síntesis de ácidos grasos y de lípidos saponificables, la presencia de Sv atenuó el efecto antilipogénico del aceite (Figuras 5.20 y 5.21) persistiendo la disminución del contenido de lípidos de reserva en las células hepáticas sometidas al tratamiento combinado (Figura 5.22). Estos resultados estarían indicando que la concentración de farnesol aún es suficiente para activar FXR o bien que el efecto inhibitorio sobre la síntesis de estos lípidos es mediado por alguno de los componentes del aceite. De modo que, el tratamiento combinado con AELta podría potencialmente mejorar la escasa capacidad de la Sv para disminuir niveles elevados de trigliceridemia.

Además, cabe destacar que aunque el inhibidor de la escualeno sintasa (SSI) lapaquistat (TAK-475) mostró efectos prometedores en los perfiles de lípidos en suero en los primates (500), su desarrollo se dio por terminado durante la fase III de ensayos clínicos fundamentalmente debido a hepatotoxicidad asociada a su administración y la falta de viabilidad comercial en dosis más bajas (165). Sin embargo, recientemente se ha propuesto que, si una acumulación de farnesol es el factor causal de la hepatotoxicidad de los SSIs, la coadministración con las estatinas podría aliviar la toxicidad en el hígado mediante la reducción de la síntesis de FPP y resultar una estrategia novedosa para el tratamiento de dislipidemias y la prevención de aterosclerosis (501).

Nuestros datos indican que el AELta puede ser un potencial nutracéutico con efectos hipolipidémicos y que un tratamiento combinado con estatinas permitiría disminuir la dosis efectiva y los efectos secundarios indeseables de los tratamientos individuales. 


\section{Capítulo}

Conclusiones Finales 
En esta tesis, a partir de experimentos diseñados para cumplir con los objetivos propuestos que intentan reforzar o refutar las hipótesis planteadas, hemos evaluado los efectos sobre el metabolismo lípidos y la proliferación celular de 4 quimiotipos de aceites esenciales de L. alba (administrados solos o combinados cada uno con simvastatina) en células tumorales humanas HepG2 (modelo de célula hepática) y A549 (modelo de célula extra-hepática), analizando algunos mecanismos de acción. Los resultados obtenidos permiten confirmar las hipótesis planteadas y concluir que:

\section{A. Respecto a la proliferación celular}

\section{Los AEs de L. alba}

- Inhiben la viabilidad celular en ambas líneas tumorales y en la no tumoral. Los quimiotipos citral y tagetenona son los más potentes. La efectividad de cada uno de los quimiotipos es similar en ambas líneas celulares tumorales y en todos los casos las células no neoplásicas resultan menos sensibles.

- Para inhibir la viabilidad celular en ambas líneas tumorales se requieren concentraciones muy superiores a las necesarias para que actúen como agentes anticolesterogénicos. Para inhibir un $50 \%$ la viabilidad se requieren concentraciones entre 5-20 veces mayores al $\mathrm{IC}_{50 \mathrm{sc}}$.

- Los quimiotipos tagetenona y citral pueden considerarse citotóxicamente activos en estas células neoplásicas. Con valores de $\mathrm{IC}_{50}$ del orden de los $30 \mu \mathrm{g} / \mathrm{ml}$ para estas líneas celulares neoplásicas clasifican como extractos crudos citotóxicos según USCNI.

- Los quimiotipos tagetenona, carvona y piperitona presentan escasa o nula citotoxicidad en células no tumorales. Con valores de $\mid C_{50} \gg 100 \mu \mathrm{g} / \mathrm{ml}$.

- El quimiotipo tagetenona puede ser considerado como un fitocomplejo prometedor para el desarrollo de fármacos anticáncer. Es el único de los quimiotipos que manifiesta tanto un efecto citotóxico como una marcada selectividad por las células neoplásicas. 
2. El AE de $L$. alba correspondiente al quimiotipo tagetenona.

- Inhibe la proliferación de ambas líneas tumorales. Con valores de $\mathrm{IC}_{50}$ similares a los registrados para viabilidad.

- El arresto del ciclo celular y la inducción de apoptosis son dos de los mecanismos por los cuales ejerce su efecto antiproliferativo. En condiciones en las cuales la proliferación se halla inhibida un 50 \% se registra un arresto del ciclo celular y un incremento de la presencia de marcadores apoptóticos en ambos modelos tumorales. El arresto sólo ocurre en G0/G1 en células hepáticas mientras que en A549 se observa adicionalmente en G2/M.

- Inhibe la VM a nivel de HMGCR y de alguna etapa específicamente vinculada a la síntesis de colesterol (posiblemente escualeno sintasa). En concentraciones antiproliferativas disminuye profundamente la colesterogénesis (> $90 \%$ ) por descenso moderado de los niveles de HMGCR y marcada inhibición de alguna etapa específicamente vinculada a la síntesis de colesterol (posiblemente escualeno sintasa).

- La profunda inhibición de la colesterogénesis no es la causa del efecto antiproliferativo. En condiciones en las cuales la colesterogénesis se halla profundamente disminuida el contenido de colesterol está conservado de modo que, las células pueden satisfacer sus necesidades por captación de colesterol exógeno.

- La inhibición de la HMGCR mediada por el aceite no es, por sí sola, responsable del efecto antiproliferativo. La adición de mevalonato exógeno no revierte la inhibición de la proliferación mediada por el aceite.

- Un incremento de farnesol generado como consecuencia de la acumulación de FPP podría ser una de las causas de la inhibición de la proliferación.

\section{La simvastatina}

- Inhibe la proliferación de ambas líneas celulares a concentraciones muy superiores a las alcanzadas en plasma con dosis terapéuticas máximas administradas en los tratamientos de hipercolesterolemia en humanos. Las concentraciones requeridas 
para inhibir la proliferación un $50 \%$ son unas 500 veces superiores a las alcanzadas en tratamientos de hipercolesterolemia (20 $\mu \mathrm{M}$ versus $0,04 \mu \mathrm{M})$.

4. La combinación de los AEs de L. alba con simvastatina

- Presentan un efecto antiproliferativo sinérgico permitiendo reducir las concentraciones efectivas de la estatina. Esto permitiría disminuir los efectos secundarios asociados al empleo de estatinas en el tratamiento del cáncer y fortalece el uso promisorio de las mismas como agentes quimioterapéuticos asociados a otros fármacos.

\section{B. Respecto al metabolismo lipídico:}

1. Los AEs de L. alba

- Ejercen un efecto anticolesterogénico no hepatoselectivo a concentraciones que no afectan la proliferación celular. Cada quimiotipo presenta valores de $\mathrm{IC}_{50 \mathrm{sc}}$ del mismo orden de magnitud en ambas líneas celulares, de modo que ninguno de ellos presenta hepatoselectividad.

- El quimiotipo tagetenona es el más efectivo como anticolesterogénico con valores de IC50sc del orden de los 3,5 $\mathrm{mg} / \mathrm{ml}$ y una inhibición de la síntesis de colesterol superior al $80 \%$ cuando las concentraciones son $\geq 8 \mu \mathrm{g} / \mathrm{ml}$.

- Excepto para AELpi, la actividad anticolesterogénica de los quimiotipos estaría relacionada con una inhibición de la escualeno sintasa. La inhibición de síntesis de colesterol es acompañada con disminución de incorporación de acetato en intermediarios de la VM específicamente involucrados en colesterogénesis y un redireccionamiento del intermediario FPP (principal punto de la ramificación de la VM) hacia la síntesis de ubiquinona.

- Son potenciales agentes hipocolesterolemiantes. La inhibición de la síntesis de colesterol está asociada a mecanismos compensatorios mediados por SREBP-2 que favorecen la internalización de colesterol extracelular, generalmente de LDL-C vía LDLR. Esto promueve una reducción de los niveles de colesterol plasmático, lo que constituye el mecanismo de acción tradicional de algunos fármacos 
hipocolesterolemiantes. Si bien no se ha estudiado el efecto de estos AELs sobre la expresión del LDLR y/o sobre la captación de colesterol por esta vía, el hecho de que los tratamientos no afecten significativamente el contenido de colesterol es un indicio de la presencia de mecanismos que favorecerían la actividad hipolipemiante de estos aceites.

\section{El AE de L. alba correspondiente al quimiotipo tagetenona.}

- Inhibe la síntesis de colesterol sin ocasionar un incremento de los niveles de HMGCR en células HepG2, a diferencia de las estatinas. Como parte de los efectos compensatorios de la inhibición de la síntesis de colesterol mediados por SERBP-2 se produce un incremento de la síntesis de HMGCR, sin embargo el tratamiento con concentraciones de AELta que inhiben 50 \% la colesterogénesis no modifica la cantidad de HMGCR en células HepG2. Esto podría ser el resultado de una efecto directo de algunos de los isoprenoides constituyentes del aceite sobre la síntesis y/o degradación de la enzima o bien un efecto indirecto provocado por la acumulación de intermediarios como FPP que facilitan la degradación proteosomal de la reductasa.

- A concentraciones anticolesterogénicas disminuye la síntesis de ácidos grasos, el contenido de lípidos saponificables mayoritarios y el tamaño de las gotas lipídicas citoplasmáticas de células hepáticas. Efecto que puede estar mediado por el intermediario FPP acumulado, por algún componente específico del AE o por ambos, quienes podrían actuar como agonistas del receptor nuclear FXR e inducir a PPAR $\alpha$ (aumentando $\beta$-oxidación de AGs) y reprimir a SREBP-1c (disminuyendo síntesis de AGs y $T A G)$.

- Es un potencial agente hipolipemiante. La disminución de la síntesis y contenido de TAG en hígado podría ocasionar una disminución de la exportación hepática de VLDL. Además, una probable activación de FXR podría resultar en un aumento de receptores hepáticos con incremento de la captación de lipoproteínas ricas en TAG. Estos eventos darían por resultado una disminución de la colesterolemia y trigliceridemia. 


\section{La simvastatina}

- Inhibe la síntesis de colesterol a concentraciones que no afectan la proliferación celular siendo su eficiencia mayor en las células hepáticas. El valor de $\mathrm{IC}_{50 \mathrm{sc}}$ en las células HepG2 (del mismo orden de magnitud que las concentraciones alcanzadas en plasma durante los tratamientos de hipercolesterolemia) es unas 20 veces menor que en células A549, lo que indicaría una hepatoselectividad de la simvastatina.

- Inhibe la VM en una etapa temprana e incrementa los niveles de HMGCR en células HepG2 confirmando lo observado en otros modelos. Este compuesto, al inhibir competitivamente a la HMGCR, provoca una disminución de la síntesis de colesterol, de intermediarios (escualeno, lanosterol) y de otros productos finales de la vía (ubiquinona). Además, ocasiona un incremento de los niveles de HMGCR, esperable por la activación de la transcripción del gen correspondiente mediada por mSREBP-2.

- A concentraciones anticolesterogénicas incrementa la síntesis de ácidos grasos. Que podría atribuirse a una disminución de $\beta$-oxidación mediada por miR-33 y/o a una activación de genes involucrados en síntesis de AGs mediada por mSREBP-2.

\section{La combinación de AELta con simvastatina.}

- Inhibe sinérgicamente la colesterogénesis permitiendo incrementar la efectividad de sus dosis. Este efecto podría deberse a que los compuestos inhiben a la VM en distintas etapas y a la HMGCR por diferentes mecanismos. Los tratamientos combinados provocan un efecto inhibitorio equivalente al que se obtiene con concentraciones 5 y 20 veces mayores de simvastatina utilizada como agente único en células HepG2 y A549, respectivamente.

- No evita el aumento de los niveles de HMGCR ocasionados por el tratamiento con simvastatina. Refuerza la hipótesis de que la acumulación de FPP sería responsable de incremento de degradación de HMGCR.

- Revierte la inhibición de la síntesis de ubiquinona provocada por simvastatina en células HepG2, lo cual disminuiría uno de los efectos secundarios indeseables de las estatinas. Pese a la disminución de la síntesis de FPP ocasionada por la inhibición de la HMGCR por la simvastatina, la inhibición de la escualeno sintasa por el AELta sería 
suficiente como para redireccionar este intermediario e incrementar la síntesis de ubiquinona.

- Podría potencialmente mejorar la escasa capacidad de la Sv para disminuir niveles elevados de trigliceridemia. Se atenúa el efecto antilipogénico del AE persistiendo disminución de contenido de lípidos de reserva de modo que la concentración de farnesol sería aún suficiente para activar FXR o bien que el efecto inhibitorio sobre la síntesis de estos lípidos estaría mediado por alguno de los componentes del aceite.

En función de los resultados obtenidos a lo largo de esta tesis, se propone un modelo del mecanismo a través del cual el AELta inhibe la vía de mevalonato y a través de ello modula el metabolismo lipídico y la proliferación en células HepG2. El mismo se presenta en la Figura 6.1.

Los resultados presentados a lo largo de este trabajo contribuyen a un mejor entendimiento de la acción de los aceites esenciales de L. alba y su combinación con estatinas sobre una vía metabólica tan compleja como lo es la vía del mevalonato. Además sugieren que el uso individual de aceites esenciales, y su combinación con estatinas, pueden aportar alternativas que resulten beneficiosas para la salud en el tratamiento del cáncer y/o enfermedades cardiovasculares. 


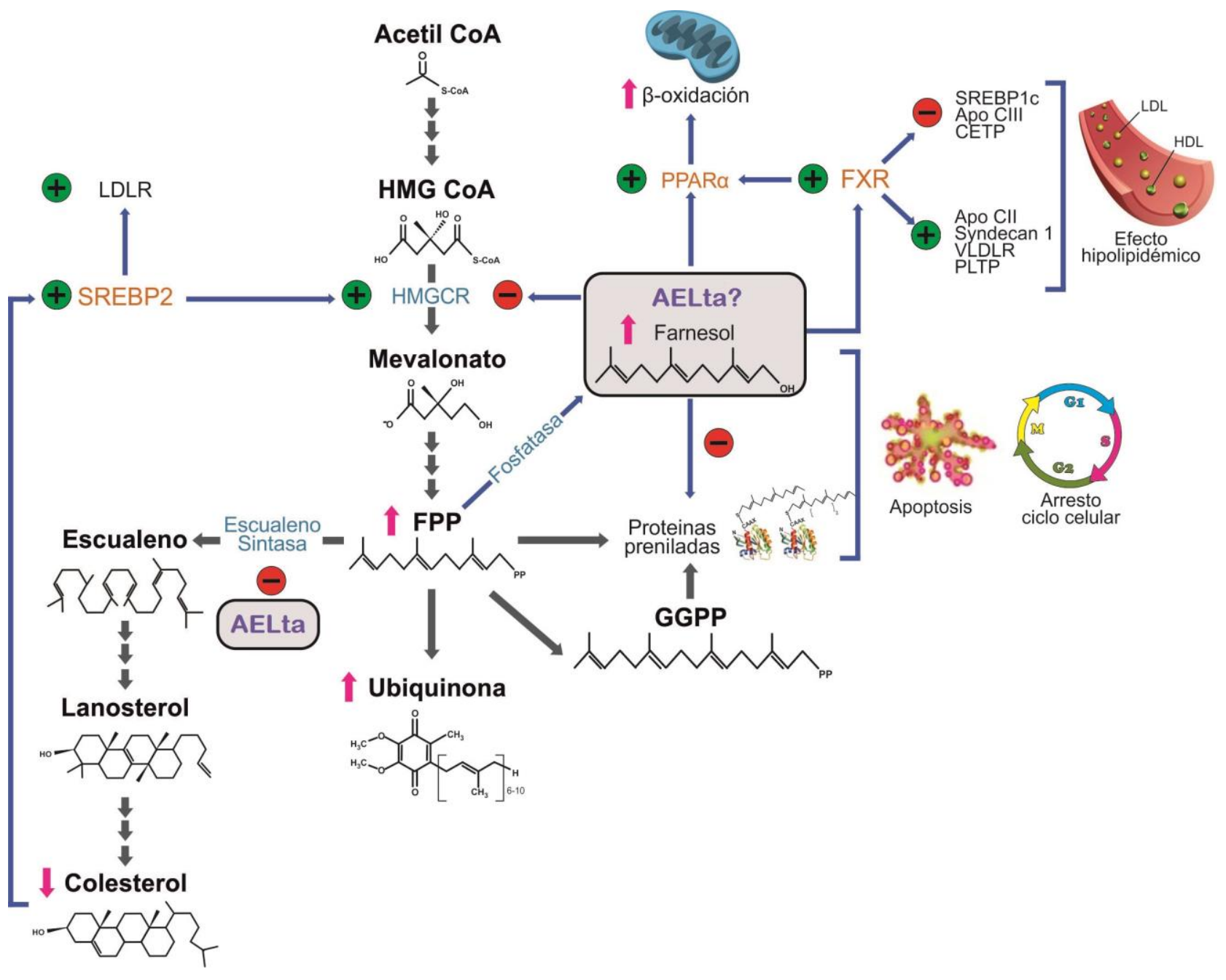

Figura 6.1. Modelo propuesto de la acción de AELta en la vía del mevalonato y sus efectos sobre la proliferación celular y metabolismo de lípidos en células HepG2. A dosis bajas (no antiproliferativas) AELta inhibe la colesterogénesis, probablemente a nivel de la escualeno sintasa (SS). Las células al detectar una disminución de colesterol, activan los mecanismos compensatorios por medio de la activación de SREBP-2, lo que lleva al aumento de HMGCR y de receptores para LDL. Por otra parte, la inhibición de la SS genera la acumulación de FPP el cual es desfosforilado a farnesol y otros farnesoides. El aumento de farnesol o algún componente del AEL, estimula la degradación de HMGCR y a su vez la activación de receptores nucleares que generarían un aumento de la $\beta$-oxidación y la inducción de respuestas con un potencial efecto hipolipemiante. A dosis antiproliferativas de AELta, los efectos de los monoterpenos del aceite y/o una mayor concentración de farnesol, genera arresto del ciclo celular y la inducción de apoptosis en estas células posiblemente al inhibir mecanismos necesarios para la prenilación de proteínas. 


$$
\text { Referencias }
$$


1. Rivera-Andrade A, Luna MA. Trends and heterogeneity of cardiovascular disease and risk factors across Latin American and Caribbean countries. Progress in cardiovascular diseases. 2014;57(3):276-85.

2. Lanas F, Avezum A, Bautista LE, Diaz R, Luna M, Islam S, et al. Risk Factors for Acute Myocardial Infarction in Latin America The INTERHEART Latin American Study. Circulation. 2007;115(9):106774.

3. Organización Panamericana de la Salud. Indicadores Básicos 2016. Situación de la Salud en las Américas Washington, D.C: Organización Panamericana de la Salud; 2016 [cited 2016 2016-1021T14:56:14Z]. 1era [Dataset/ statistical data]. Available from: http://iris.paho.org/xmlui/handle/123456789/31288.

4. Rached FH, Chapman MJ, Kontush A. An overview of the new frontiers in the treatment of atherogenic dyslipidemias. Clinical Pharmacology \& Therapeutics. 2014;96(1):57-63.

5. Lanas F, Serón P, Lanas A. Coronary heart disease and risk factors in Latin America. Global heart. 2013;8(4):341-8.

6. Miranda JJ, Herrera VM, Chirinos JA, Gómez LF, Perel P, Pichardo R, et al. Major cardiovascular risk factors in Latin America: a comparison with the United States. The Latin American consortium of studies in obesity (LASO). PloS one. 2013;8(1):e54056.

7. Pramparo P, Montano CM, Barceló A, Avezum A, Wilks R. Cardiovascular diseases in Latin America and the Caribbean: The present situation. Prevention and Control. 2006;2(3):149-57.

8. Goldstein LB, Adams R, Alberts MJ, Appel L, Brass LM, Bushnell CD, et al. Primary Prevention of Ischemic Stroke A Guideline From the American Heart Association/American Stroke Association Stroke Council: Cosponsored by the Atherosclerotic Peripheral Vascular Disease Interdisciplinary Working Group; Cardiovascular Nursing Council; Clinical Cardiology Council; Nutrition, Physical Activity, and Metabolism Council; and the Quality of Care and Outcomes Research Interdisciplinary Working Group: The American Academy of Neurology affirms the value of this guideline. Stroke. 2006;37(6):1583-633.

9. Wadhera RK, Steen DL, Khan I, Giugliano RP, Foody JM. A review of low-density lipoprotein cholesterol, treatment strategies, and its impact on cardiovascular disease morbidity and mortality. Journal of clinical lipidology. 2016;10(3):472-89.

10. Vinueza R, Boissonnet CP, Acevedo M, Uriza F, Benitez FJ, Silva $H$, et al. Dyslipidemia in seven Latin American cities: CARMELA study. Preventive medicine. 2010;50(3):106-11.

11. Bahmani M, Mirhoseini M, Shirzad H, Sedighi M, Shahinfard N, Rafieian-Kopaei M. A review on promising natural agents effective on hyperlipidemia. Journal of evidence-based complementary \& alternative medicine. 2015;20(3):228-38.

12. Tabatabaei-Malazy O, Larijani B, Abdollahi M. Targeting metabolic disorders by natural products. Journal of Diabetes \& Metabolic Disorders. 2015;14(1):1.

13. Cicero AF, Colletti A. Combinations of phytomedicines with different lipid lowering activity for dyslipidemia management: the available clinical data. Phytomedicine. 2015.

14. Cicero AF, Parini A, Rosticci M. Nutraceuticals and cholesterol-lowering action. IJC Metabolic \& Endocrine. 2015;6:1-4.

15. Braun S, Bitton-Worms K, LeRoith D. The link between the metabolic syndrome and cancer. Int J Biol Sci. 2011;7(7):1003-15.

16. Sinagra D, Amato C, Scarpitta A, Brigandi M, Amato M, Saura G, et al. Metabolic syndrome and breast cancer risk. European review for medical and pharmacological sciences. 2002;6:55-9.

17. Agnoli C, Grioni S, Sieri S, Sacerdote C, Vineis P, Tumino R, et al. Colorectal cancer risk and dyslipidemia: a case-cohort study nested in an Italian multicentre cohort. Cancer epidemiology. 2014;38(2):144-51.

18. Gutierrez-Pajares JL, Hassen CB, Chevalier S, Frank PG. SR-BI: Linking Cholesterol and Lipoprotein Metabolism with Breast and Prostate Cancer. Frontiers in Pharmacology. 2016;7.

19. Zadra G, Photopoulos C, Loda M. The fat side of prostate cancer. Biochimica et Biophysica Acta (BBA)-Molecular and Cell Biology of Lipids. 2013;1831(10):1518-32.

20. Munoz-Pinedo C, El Mjiyad N, Ricci J. Cancer metabolism: current perspectives and future directions. Cell death \& disease. 2012;3(1):e248. 
21. Baenke F, Peck B, Miess H, Schulze A. Hooked on fat: the role of lipid synthesis in cancer metabolism and tumour development. Disease Models and Mechanisms. 2013;6(6):1353-63.

22. Zhang F, Du G. Dysregulated lipid metabolism in cancer. World journal of biological chemistry. 2012;3(8):167-74.

23. Mullen PJ, Yu R, Longo J, Archer MC, Penn LZ. The interplay between cell signalling and the mevalonate pathway in cancer. Nature Reviews Cancer. 2016;16(10):718-31.

24. Santos CR, Schulze A. Lipid metabolism in cancer. Febs Journal. 2012;279(15):2610-23.

25. Silvente-Poirot S, Poirot M. Cholesterol metabolism and cancer: the good, the bad and the ugly. Current opinion in pharmacology. 2012;12(6):673-6.

26. Kuzu OF, Noory MA, Robertson GP. The Role of Cholesterol in Cancer. Cancer research. 2016;76(8):2063-70.

27. Jiang $P$, Mukthavaram R, Chao $Y$, Nomura N, Bharati IS, Fogal V, et al. In vitro and in vivo anticancer effects of mevalonate pathway modulation on human cancer cells. British journal of cancer. 2014;111(8):1562-71.

28. Thurnher M, Gruenbacher G, Nussbaumer O. Regulation of mevalonate metabolism in cancer and immune cells. Biochimica et Biophysica Acta (BBA)-Molecular and Cell Biology of Lipids. 2013;1831(6):1009-15.

29. Swanson KM, Hohl RJ. Anti-cancer therapy: targeting the mevalonate pathway. Current cancer drug targets. 2006;6(1):15-37.

30. Künzl M, Wasinger $C$, Hohenegger M. Statins role in cancer prevention and development-recent meta-analyses. World J Pharmacol. 2013; 2(4):100-6.

31. Kubatka P, Kruzliak P, Rotrekl V, Jelinkova S, Mladosievicova B. Statins in oncological research: from experimental studies to clinical practice. Critical reviews in oncology/hematology. 2014;92(3):296-311.

32. Altwairgi AK. Statins are potential anticancerous agents (Review). Oncology reports. 2015;33(3):1019-39.

33. Cruz PM, Mo H, McConathy W, Sabnis NA, Lacko AG. The role of cholesterol metabolism and cholesterol transport in carcinogenesis: a review of scientific findings, relevant to future cancer therapeutics. Frontiers in pharmacology. 2013;4:119.

34. Stryjkowska-Góra A, Karczmarek-Borowska B, Góra T, Krawczak K. Statins and cancers. Contemp Oncol (Pozn). 2015;19(3):167-75.

35. Likus W, Siemianowicz K, Bieńk K, Pakuła M, Pathak H, Dutta C, et al. Could drugs inhibiting the mevalonate pathway also target cancer stem cells? Drug Resistance Updates. 2016;25:13-25.

36. Thurnher M, Nussbaumer O, Gruenbacher G. Novel aspects of mevalonate pathway inhibitors as antitumor agents. Clinical Cancer Research. 2012;18(13):3524-31.

37. Sylvester PW. Synergistic anticancer effects of combined gamma-tocotrienol with statin or receptor tyrosine kinase inhibitor treatment. Genes \& nutrition. 2012;7(1):63-74.

38. McAnally JA, Gupta J, Sodhani S, Bravo L, Mo H. Tocotrienols potentiate lovastatin-mediated growth suppression in vitro and in vivo. Exp Biol Med (Maywood). 2007;232(4):523-31.

39. Staedler D, Chapuis-Bernasconi C, Dehmlow H, Fischer H, Juillerat-Jeanneret L, Aebi JD. Cytotoxic effects of combination of oxidosqualene cyclase inhibitors with atorvastatin in human cancer cells. Journal of medicinal chemistry. 2012;55(11):4990-5002.

40. Osmak M. Statins and cancer: current and future prospects. Cancer letters. 2012;324(1):1-12.

41. Hardcastle IR, Rowlands MG, Barber AM, Grimshaw RM, Mohan MK, Nutley BP, et al. Inhibition of protein prenylation by metabolites of limonene. Biochemical pharmacology. 1999;57(7):801-9.

42. Crowell PL, Chang RR, Ren Z, Elson CE, Gould MN. Selective inhibition of isoprenylation of 21-26$\mathrm{kDa}$ proteins by the anticarcinogen $\mathrm{d}$-limonene and its metabolites. Journal of Biological Chemistry. 1991;266(26):17679-85.

43. Ren Z, Elson CE, Gould MN. Inhibition of type I and type II geranylgeranyl-protein transferases by the monoterpene perillyl alcohol in NIH3T3 cells. Biochemical pharmacology. 1997;54(1):113-20.

44. Afshordel S, Kern B, Clasohm J, König H, Priester M, Weissenberger J, et al. Lovastatin and perillyl alcohol inhibit glioma cell invasion, migration, and proliferation-Impact of Ras-/Rho-prenylation. Pharmacological research. 2015;91:69-77. 
45. Eberlé $D$, Hegarty $B$, Bossard P, Ferré $P$, Foufelle F. SREBP transcription factors: master regulators of lipid homeostasis. Biochimie. 2004;86(11):839-48.

46. Metallo CM, Gameiro PA, Bell EL, Mattaini KR, Yang J, Hiller K, et al. Reductive glutamine metabolism by IDH1 mediates lipogenesis under hypoxia. Nature. 2012;481(7381):380-4.

47. Zaidi N, Swinnen JV, Smans K. ATP-citrate lyase: a key player in cancer metabolism. Cancer research. 2012;72(15):3709-14.

48. Morad SA, Cabot MC. Ceramide-orchestrated signalling in cancer cells. Nature Reviews Cancer. 2013;13(1):51-65.

49. Wymann MP, Schneiter R. Lipid signalling in disease. Nature Reviews Molecular Cell Biology. 2008;9(2):162-76.

50. Horton JD, Goldstein JL, Brown MS. SREBPs: activators of the complete program of cholesterol and fatty acid synthesis in the liver. The Journal of clinical investigation. 2002;109(9):1125-31.

51. Goldstein JL, DeBose-Boyd RA, Brown MS. Protein sensors for membrane sterols. Cell. 2006;124(1):35-46.

52. Raghow R, Yellaturu C, Deng X, Park EA, Elam MB. SREBPs: the crossroads of physiological and pathological lipid homeostasis. Trends in Endocrinology \& Metabolism. 2008;19(2):65-73.

53. Sakakura Y, Shimano H, Sone H, Takahashi A, Inoue K, Toyoshima H, et al. Sterol regulatory element-binding proteins induce an entire pathway of cholesterol synthesis. Biochemical and biophysical research communications. 2001;286(1):176-83.

54. Ferre P, Foufelle F. SREBP-1c transcription factor and lipid homeostasis: clinical perspective. Hormone Research in Paediatrics. 2007;68(2):72-82.

55. Sato R. SREBPs: protein interaction and SREBPs. FEBS journal. 2009;276(3):622-7.

56. Sun L-P, Seemann J, Goldstein JL, Brown MS. Sterol-regulated transport of SREBPs from endoplasmic reticulum to Golgi: Insig renders sorting signal in Scap inaccessible to COPII proteins. Proceedings of the National Academy of Sciences. 2007;104(16):6519-26.

57. Ikonen E. Cellular cholesterol trafficking and compartmentalization. Nature reviews Molecular cell biology. 2008;9(2):125-38.

58. Xiao X, Song B-L. SREBP: a novel therapeutic target. Acta biochimica et biophysica Sinica. 2013;45(1):2-10.

59. Wang Y, Viscarra J, Kim S-J, Sul HS. Transcriptional regulation of hepatic lipogenesis. Nature Reviews Molecular Cell Biology. 2015;16(11):678-89.

60. Beaven SW, Tontonoz P. Nuclear receptors in lipid metabolism: targeting the heart of dyslipidemia. Annu Rev Med. 2006;57:313-29.

61. Mello T. Nuclear Receptors in the Regulation of Lipid Metabolism. Current Cardiovascular Risk Reports. 2010;4(2):142-9.

62. Goto T, Kim YI, Takahashi N, Kawada T. Natural compounds regulate energy metabolism by the modulating the activity of lipid-sensing nuclear receptors. Molecular nutrition \& food research. 2013;57(1):20-33.

63. Desvergne B, Michalik L, Wahli W. Transcriptional regulation of metabolism. Physiological reviews. 2006;86(2):465-514.

64. Ma Z, Deng C, Hu W, Zhou J, Fan C, Di S, et al. Liver X Receptors and their Agonists: Targeting for Cholesterol Homeostasis and Cardiovascular Diseases. Current issues in molecular biology. 2016;22:41.

65. Serviddio G, Bellanti F, Vendemiale G. Free radical biology for medicine: learning from nonalcoholic fatty liver disease. Free Radical Biology and Medicine. 2013;65:952-68.

66. Alaynick WA. Nuclear receptors, mitochondria and lipid metabolism. Mitochondrion. 2008;8(4):329-37.

67. Teodoro JS, Rolo AP, Palmeira CM. Hepatic FXR: key regulator of whole-body energy metabolism. Trends in Endocrinology \& Metabolism. 2011;22(11):458-66.

68. Waterham HR. Defects of cholesterol biosynthesis. FEBS letters. 2006;580(23):5442-9.

69. Guijarro C, Egido J. Modulación de la vía de mevalonato: posibles mecanismos de protección vascular por medio de inhibidores de la HMG-CoA reductasa independientes de la reducción de colesterol. Cardiovascular Risk Factors. 1998;7:48-55. 
70. Ačimovič J, Rozman D. Steroidal triterpenes of cholesterol synthesis. Molecules. 2013;18(4):400217.

71. Goldstein JL, Brown MS. Regulation of the mevalonate pathway. Nature. 1990;343(6257):425.

72. Hinson D, Chambliss K, Toth M, Tanaka R, Gibson K. Post-translational regulation of mevalonate kinase by intermediates of the cholesterol and nonsterol isoprene biosynthetic pathways. Journal of lipid research. 1997;38(11):2216-23.

73. Chan KK, Oza AM, Siu LL. The statins as anticancer agents. Clinical cancer research. 2003;9(1):109.

74. Holstein SA, Hohl RJ. Isoprenoids: remarkable diversity of form and function. Lipids. 2004;39(4):293-309.

75. Buhaescu I, Izzedine H. Mevalonate pathway: a review of clinical and therapeutical implications. Clinical biochemistry. 2007;40(9):575-84.

76. Gruenbacher G, Thurnher M. Mevalonate metabolism in cancer. Cancer letters. 2015;356(2):1926.

77. Mazein A, Watterson S, Hsieh W-Y, Griffiths WJ, Ghazal P. A comprehensive machine-readable view of the mammalian cholesterol biosynthesis pathway. Biochemical pharmacology. 2013;86(1):56-66.

78. Gough DP, Hemming F. The characterization and stereochemistry of biosynthesis of dolichols in rat liver. Biochemical Journal. 1970;118(1):163-6.

79. Carroll K, Guthrie N, Ravi K. Dolichol: function, metabolism, and accumulation in human tissues. Biochemistry and Cell Biology. 1992;70(6):382-4.

80. Rip JW, Rupar CA, Ravi K, Carroll KK. Distribution, metabolism and function of dolichol and polyprenols. Progress in lipid research. 1985;24(4):269-309.

81. Dallner G, Sindelar PJ. Regulation of ubiquinone metabolism. Free Radical Biology and Medicine. 2000;29(3):285-94.

82. Bentinger M, Tekle M, Dallner G. Coenzyme Q-biosynthesis and functions. Biochemical and biophysical research communications. 2010;396(1):74-9.

83. Papucci L, Schiavone N, Witort E, Donnini M, Lapucci A, Tempestini A, et al. Coenzyme q10 prevents apoptosis by inhibiting mitochondrial depolarization independently of its free radical scavenging property. Journal of Biological Chemistry. 2003;278(30):28220-8.

84. Thomas SR, Neužil J, Stocker R. Cosupplementation with coenzyme Q prevents the prooxidant effect of $\alpha$-tocopherol and increases the resistance of LDL to transition metal-dependent oxidation initiation. Arteriosclerosis, thrombosis, and vascular biology. 1996;16(5):687-96.

85. Döring F, Schmelzer C, Lindner I, Vock C, Fujii K. Functional connections and pathways of coenzyme Q10-inducible genes: An in-silico study. IUBMB life. 2007;59(10):628-33.

86. Hederstedt L. Heme A biosynthesis. Biochimica et Biophysica Acta (BBA)-Bioenergetics. 2012;1817(6):920-7.

87. Andela VB, Pirri M, Schwarz EM, Puzas EJ, O'Keefe RJ, Rosenblatt JD, et al. The mevalonate synthesis pathway as a therapeutic target in cancer. Clinical orthopaedics and related research. 2003;415:S59-S66.

88. Xu N, Shen N, Wang X, Jiang S, Xue B, Li C. Protein prenylation and human diseases: a balance of protein farnesylation and geranylgeranylation. Science China Life Sciences. 2015;58(4):328.

89. Park J, Matralis AN, Berghuis AM, Tsantrizos YS. Human isoprenoid synthase enzymes as therapeutic targets. Frontiers in chemistry. 2014;2:50.

90. Gysin S, Salt M, Young A, McCormick F. Therapeutic strategies for targeting ras proteins. Genes \& cancer. 2011;2(3):359-72.

91. Resh MD. Targeting protein lipidation in disease. Trends in molecular medicine. 2012;18(4):20614.

92. Konstantinopoulos PA, Karamouzis MV, Papavassiliou AG. Post-translational modifications and regulation of the RAS superfamily of GTPases as anticancer targets. Nature reviews Drug discovery. 2007;6(7):541-55.

93. Chang $\mathrm{T}-\mathrm{Y}$, Chang CC, Ohgami N, Yamauchi Y. Cholesterol sensing, trafficking, and esterification. Annu Rev Cell Dev Biol. 2006;22:129-57. 
94. Cortes VA, Busso D, Mardones P, Maiz A, Arteaga A, Nervi F, et al. Retracted: Advances in the physiological and pathological implications of cholesterol. Biological Reviews. 2013;88(4):825-43.

95. Westover E, Covey D. The enantiomer of cholesterol. The Journal of membrane biology. 2004;202(2):61-72.

96. Goedeke L, Fernández-Hernando C. Regulation of cholesterol homeostasis. Cellular and Molecular Life Sciences. 2012;69(6):915-30.

97. van der Wulp MY, Verkade HJ, Groen AK. Regulation of cholesterol homeostasis. Molecular and cellular endocrinology. 2013;368(1-2):1-16.

98. Edwards PA, Ericsson J. Sterols and isoprenoids: signaling molecules derived from the cholesterol biosynthetic pathway. Annual review of biochemistry. 1999;68(1):157-85.

99. Burg JS, Espenshade PJ. Regulation of HMG-CoA reductase in mammals and yeast. Progress in lipid research. 2011;50(4):403-10.

100. Goldstein JL, Brown MS. A century of cholesterol and coronaries: from plaques to genes to statins. Cell. 2015;161(1):161-72.

101. Mohamed A, Smith K, de Chaves EP. The Mevalonate Pathway in Alzheimer's DiseaseCholesterol and Non-Sterol Isoprenoids. 2015. In: Alzheimer's Disease - Challenges for the Future [Internet]. InTech. Available from:

http://www.intechopen.com/books/export/citation/EndNote/alzheimer-s-disease-challenges-forthe-future/the-mevalonate-pathway-in-alzheimer-s-disease-cholesterol-and-non-sterolisoprenoids.

102. Sharpe L, Brown AJ. Controlling cholesterol synthesis beyond 3-hydroxy-3-methylglutaryl-CoA reductase (HMGCR). Journal of Biological Chemistry. 2013;288(26):18707-15.

103. Friesen JA, Rodwell VW. The 3-hydroxy-3-methylglutaryl coenzyme-A (HMG-CoA) reductases. Genome biology. 2004;5(11):1.

104. Hardie DG, Hawley SA, Scott JW. AMP-activated protein kinase-development of the energy sensor concept. The Journal of physiology. 2006;574(1):7-15.

105. Motoshima H, Goldstein BJ, Igata M, Araki E. AMPK and cell proliferation-AMPK as a therapeutic target for atherosclerosis and cancer. The Journal of physiology. 2006;574(1):63-71.

106. DeBose-Boyd RA. Feedback regulation of cholesterol synthesis: sterol-accelerated ubiquitination and degradation of HMG CoA reductase. Cell research. 2008;18(6):609-21.

107. Sever N, Song B-L, Yabe D, Goldstein JL, Brown MS, DeBose-Boyd RA. Insig-dependent ubiquitination and degradation of mammalian 3-hydroxy-3-methylglutaryl-CoA reductase stimulated by sterols and geranylgeraniol. Journal of Biological Chemistry. 2003;278(52):5247990.

108. Jo Y, DeBose-Boyd RA. Control of cholesterol synthesis through regulated ER-associated degradation of HMG CoA reductase. Critical reviews in biochemistry and molecular biology. 2010;45(3):185-98.

109. Hanahan D, Weinberg RA. Hallmarks of cancer: the next generation. Cell. 2011;144(5):646-74.

110. Huang C, Freter C. Lipid metabolism, apoptosis and cancer therapy. International journal of molecular sciences. 2015;16(1):924-49.

111. Larsson O. HMG-CoA reductase inhibitors: role in normal and malignant cells. Critical reviews in oncology/hematology. 1996;22(3):197-212.

112. Duncan RE, Lau D, El-Sohemy A, Archer MC. Geraniol and $\beta$-ionone inhibit proliferation, cell cycle progression, and cyclin-dependent kinase 2 activity in MCF-7 breast cancer cells independent of effects on HMG-CoA reductase activity. Biochemical pharmacology. 2004;68(9):1739-47.

113. Mo H, Elson CE. Studies of the isoprenoid-mediated inhibition of mevalonate synthesis applied to cancer chemotherapy and chemoprevention. Experimental Biology and Medicine. 2004;229(7):567-85.

114. Kumar AS, Benz CC, Shim V, Minami CA, Moore DH, Esserman L. Estrogen Receptor-Negative Breast Cancer Is Less Likely to Arise among Lipophilic Statin Users. Cancer Epidemiology Biomarkers \& Prevention. 2008;17(5):1028-33.

115. Kwan ML, Habel LA, Flick ED, Quesenberry CP, Caan B. Post-diagnosis statin use and breast cancer recurrence in a prospective cohort study of early stage breast cancer survivors. Breast cancer research and treatment. 2008;109(3):573-9. 
116. Clendening JW, Pandyra A, Boutros PC, El Ghamrasni S, Khosravi F, Trentin GA, et al.

Dysregulation of the mevalonate pathway promotes transformation. Proceedings of the National Academy of Sciences. 2010;107(34):15051-6.

117. Downward J. Targeting RAS signalling pathways in cancer therapy. Nature Reviews Cancer. 2003;3(1):11-22.

118. Santarpia L, Lippman SM, El-Naggar AK. Targeting the MAPK-RAS-RAF signaling pathway in cancer therapy. Expert opinion on therapeutic targets. 2012;16(1):103-19.

119. Wilson KF, Erickson JW, Antonyak MA, Cerione RA. Rho GTPases and their roles in cancer metabolism. Trends in molecular medicine. 2013;19(2):74-82.

120. Pisanti S, Picardi P, Ciaglia E, D'Alessandro A, Bifulco M. Novel prospects of statins as therapeutic agents in cancer. Pharmacological research. 2014;88:84-98.

121. Kato K, Cox AD, Hisaka MM, Graham SM, Buss JE, Der CJ. Isoprenoid addition to Ras protein is the critical modification for its membrane association and transforming activity. Proceedings of the National Academy of Sciences. 1992;89(14):6403-7.

122. Walker K, Olson MF. Targeting Ras and Rho GTPases as opportunities for cancer therapeutics. Current opinion in genetics \& development. 2005;15(1):62-8.

123. Pylayeva-Gupta Y, Grabocka E, Bar-Sagi D. RAS oncogenes: weaving a tumorigenic web. Nature Reviews Cancer. 2011;11(11):761-74.

124. Sandoval Usme M. Mecanismos Moleculares De Las Estatinas Sobre El Cáncer. Bogotá, Colombia: Universidad Nacional de Colombia 2012.

125. Lasunción MA, Martín-Sánchez C, Canfrán-Duque A, Busto R. Post-lanosterol biosynthesis of cholesterol and cancer. Current opinion in pharmacology. 2012;12(6):717-23.

126. Sahai E, Marshall CJ. RHO-GTPases and cancer. Nature Reviews Cancer. 2002;2(2):133-42.

127. Etienne-Manneville S, Hall A. Rho GTPases in cell biology. Nature. 2002;420(6916):629-35.

128. Roberts PJ, Mitin N, Keller PJ, Chenette EJ, Madigan JP, Currin RO, et al. Rho Family GTPase modification and dependence on CAAX motif-signaled posttranslational modification. Journal of Biological Chemistry. 2008;283(37):25150-63.

129. Bryan B, d'Amore P. What tangled webs they weave: Rho-GTPase control of angiogenesis. Cellular and Molecular Life Sciences. 2007;64(16):2053-65.

130. Mantha AJ, Hanson JE, Goss G, Lagarde AE, Lorimer IA, Dimitroulakos J. Targeting the mevalonate pathway inhibits the function of the epidermal growth factor receptor. Clinical Cancer Research. 2005;11(6):2398-407.

131. Graaf MR, Richel DJ, van Noorden CJ, Guchelaar H-J. Effects of statins and farnesyltransferase inhibitors on the development and progression of cancer. Cancer treatment reviews. 2004;30(7):609-41.

132. Kakimi K, Matsushita H, Murakawa T, Nakajima J. $\gamma \delta$ T cell therapy for the treatment of non-small cell lung cancer. Translational lung cancer research. 2013;3(1):23-33.

133. Riganti C, Massaia M. Inhibition of the mevalonate pathway to override chemoresistance and promote the immunogenic demise of cancer cells: Killing two birds with one stone.

Oncoimmunology. 2013;2(9):e25770.

134. Murai T. Cholesterol lowering: role in cancer prevention and treatment. Biological chemistry. 2015;396(1):1-11.

135. Brusselmans K, Timmermans L, Van de Sande T, Van Veldhoven PP, Guan G, Shechter I, et al. Squalene synthase, a determinant of Raft-associated cholesterol and modulator of cancer cell proliferation. Journal of Biological Chemistry. 2007;282(26):18777-85.

136. Yeganeh B, Wiechec E, Ande SR, Sharma P, Moghadam AR, Post M, et al. Targeting the mevalonate cascade as a new therapeutic approach in heart disease, cancer and pulmonary disease. Pharmacology \& therapeutics. 2014;143(1):87-110.

137. Li YC, Park MJ, Ye S-K, Kim C-W, Kim Y-N. Elevated levels of cholesterol-rich lipid rafts in cancer cells are correlated with apoptosis sensitivity induced by cholesterol-depleting agents. The American journal of pathology. 2006;168(4):1107-18.

138. Istvan ES, Deisenhofer J. Structural mechanism for statin inhibition of HMG-CoA reductase. Science. 2001;292(5519):1160-4. 
139. Gaw A. HDL-C and triglyceride levels: relationship to coronary heart disease and treatment with statins. Cardiovascular drugs and therapy. 2003;17(1):53-62.

140. Wierzbicki AS, Poston R, Ferro A. The lipid and non-lipid effects of statins. Pharmacology \& therapeutics. 2003;99(1):95-112.

141. Rosenson RS. Current overview of statin-induced myopathy. The American journal of medicine. 2004;116(6):408-16.

142. Gazzerro P, Proto MC, Gangemi G, Malfitano AM, Ciaglia E, Pisanti S, et al. Pharmacological actions of statins: a critical appraisal in the management of cancer. Pharmacological reviews. 2012;64(1):102-46.

143. Gluba-Brzozka A, Franczyk B, Toth PP, Rysz J, Banach M. Molecular mechanisms of statin intolerance. Archives of medical science: AMS. 2016;12(3):645-58.

144. Kong W, Zhu Y. The pleiotropic effects of statins in the prevention of atherosclerosis. Cardiovascular drugs and therapy. 2012;26(1):5-7.

145. Zhou Q, Liao JK. Pleiotropic effects of statins: basic research and clinical perspectives. Circulation journal: official journal of the Japanese Circulation Society. 2010;74(5):818.

146. Taylor F, Huffman MD, Macedo AF, Moore TH, Burke M, Davey Smith G, et al. Statins for the primary prevention of cardiovascular disease. The Cochrane Library. 2013.

147. Cuello M, Kato S, Díaz D, Owen G. Efectos de las estatinas en cáncer:¿ potencial rol en terapéutica y prevención? Revista médica de Chile. 2013;141(2):227-36.

148. Davies JT, Delfino SF, Feinberg CE, Johnson MF, Nappi VL, Olinger JT, et al. Current and Emerging Uses of Statins in Clinical Therapeutics: A Review. Lipid insights. 2016;9:13.

149. Bardou M, Barkun A, Martel M. Effect of statin therapy on colorectal cancer. Gut. 2010;59(11):1572-85.

150. Jakobisiak M, Golab J. Statins can modulate effectiveness of antitumor therapeutic modalities. Medicinal research reviews. 2010;30(1):102-35.

151. Shimoyama S. Statins are logical candidates for overcoming limitations of targeting therapies on malignancy: their potential application to gastrointestinal cancers. Cancer chemotherapy and pharmacology. 2011;67(4):729-39.

152. Chae YK, Yousaf M, Malecek M-K, Carneiro B, Chandra S, Kaplan J, et al. Statins as anti-cancer therapy; Can we translate preclinical and epidemiologic data into clinical benefit? Discovery medicine. 2015;20(112):413-27.

153. Navarro V, Zabala A, Gómez S, Portillo M. Metabolismo del colesterol: bases actualizadas. Rev Esp Obes. 2009;7(6):360-84.

154. Rogers MJ, Crockett JC, Coxon FP, Mönkkönen J. Biochemical and molecular mechanisms of action of bisphosphonates. Bone. 2011;49(1):34-41.

155. Dunford J. Molecular targets of the nitrogen containing bisphosphonates: the molecular pharmacology of prenyl synthase inhibition. Current pharmaceutical design. 2010;16(27):2961-9.

156. Van Acker HH, Anguille S, Willemen Y, Smits EL, Van Tendeloo VF. Bisphosphonates for cancer treatment: mechanisms of action and lessons from clinical trials. Pharmacology \& therapeutics. 2016;158:24-40.

157. Mansueto P, Vitale G, Seidita A, Guarneri FP, Pepe I, Rinollo C, et al. Mevalonate pathway: role of bisphosphonates and statins. Acta Med Mediterr. 2011;27(2):85-95.

158. Kennel KA, Drake MT. Adverse effects of bisphosphonates: implications for osteoporosis management. Mayo Clinic Proceedings. 2009;84(7):632-8.

159. Holstein SA, Hohl RJ. Is there a future for prenyltransferase inhibitors in cancer therapy? Current opinion in pharmacology. 2012;12(6):704-9.

160. Berndt N, Hamilton AD, Sebti SM. Targeting protein prenylation for cancer therapy. Nature Reviews Cancer. 2011;11(11):775-91.

161. Nishimoto T, Ishikawa E, Anayama H, Hamajyo H, Nagai H, Hirakata M, et al. Protective effects of a squalene synthase inhibitor, lapaquistat acetate (TAK-475), on statin-induced myotoxicity in guinea pigs. Toxicology and applied pharmacology. 2007;223(1):39-45.

162. Trapani L, Segatto M, Ascenzi P, Pallottini V. Potential role of nonstatin cholesterol lowering agents. IUBMB life. 2011;63(11):964-71. 
163. Kourounakis A, Katselou M, Matralis A, Ladopoulou E, Bavavea E. Squalene synthase inhibitors: An update on the search for new antihyperlipidemic and antiatherosclerotic agents. Current medicinal chemistry. 2011;18(29):4418-39.

164. Elsayed RK, Evans JD. Emerging lipid-lowering drugs: squalene synthase inhibitors. Expert opinion on emerging drugs. 2008;13(2):309-22.

165. Stein EA, Bays H, O'Brien D, Pedicano J, Piper E, Spezzi A. Lapaquistat acetate development of a squalene synthase inhibitor for the treatment of hypercholesterolemia. Circulation. 2011;123(18):1974-85.

166. Ladopoulou EM, Matralis AN, Nikitakis A, Kourounakis AP. Antihyperlipidemic morpholine derivatives with antioxidant activity: An investigation of the aromatic substitution. Bioorganic \& medicinal chemistry. 2015;23(21):7015-23.

167. Ichikawa M, Ohtsuka M, Ohki H, Ota M, Haginoya N, Itoh M, et al. Discovery of DF-461, a potent squalene synthase inhibitor. ACS medicinal chemistry letters. 2013;4(10):932-6.

168. Matralis AN, Kourounakis AP. Design of Novel Potent Antihyperlipidemic Agents with Antioxidant/Anti-inflammatory Properties: Exploiting Phenothiazine's Strong Antioxidant Activity. Journal of medicinal chemistry. 2014;57(6):2568-81.

169. Saito K, Shirasago Y, Suzuki T, Aizaki H, Hanada K, Wakita T, et al. Targeting cellular squalene synthase, an enzyme essential for cholesterol biosynthesis, is a potential antiviral strategy against hepatitis C virus. Journal of virology. 2015;89(4):2220-32.

170. Ros E. Inhibición de la absorción intestinal del colesterol: nueva diana terapéutica en la reducción de la colesterolemia. Clínica e investigación en arteriosclerosis. 2003;15(6):261-75.

171. Ikonen E. Mechanisms for cellular cholesterol transport: defects and human disease. Physiological reviews. 2006;86(4):1237-61.

172. Maldonado Saavedra O, Ramírez Sánchez I, García Sánchez JR, Ceballos Reyes GM, Méndez Bolaina E. Colesterol: Función biológica e implicaciones médicas. Revista mexicana de ciencias farmacéuticas. 2012;43(2):7-22.

173. Charlton-Menys V, Durrington P. Human cholesterol metabolism and therapeutic molecules. Experimental physiology. 2008;93(1):27-42.

174. van der Velde AE, Vrins CL, van den Oever K, Kunne C, Oude Elferink RP, Kuipers F, et al. Direct intestinal cholesterol secretion contributes significantly to total fecal neutral sterol excretion in mice. Gastroenterology. 2007;133(3):967-75.

175. van der Velde AE, Brufau G, Groen AK. Transintestinal cholesterol efflux. Curr Opin Lipidol. 2010;21(3):167-71.

176. Pujol MC. Mecanismos básicos. Absorción y excreción de colesterol y otros esteroles. Clínica e Investigación en Arteriosclerosis. 2014;26(1):41-7.

177. Fisher EA, Feig JE, Hewing B, Hazen SL, Smith JD. High-density lipoprotein function, dysfunction, and reverse cholesterol transport. Arteriosclerosis, thrombosis, and vascular biology. 2012;32(12):2813-20.

178. Zhao C, Dahlman-Wright K. Liver X receptor in cholesterol metabolism. Journal of Endocrinology. 2010;204(3):233-40.

179. Portincasa P, Moschetta A, Palasciano G. Cholesterol gallstone disease. The Lancet. 2006;368(9531):230-9.

180. Gau GT, Wright RS. Pathophysiology, diagnosis, and management of dyslipidemia. Current problems in cardiology. 2006;31(7):445-86.

181. Dean BB, Borenstein JE, Henning JM, Knight K, Merz CNB. Can change in high-density lipoprotein cholesterol levels reduce cardiovascular risk? American heart journal. 2004;147(6):966-76.

182. Gotto AM. Evolving concepts of dyslipidemia, atherosclerosis, and cardiovascular disease: the Louis F. Bishop Lecture. Journal of the American College of Cardiology. 2005;46(7):1219-24.

183. Arsenault BJ, Rana JS, Stroes ES, Després J-P, Shah PK, Kastelein JJ, et al. Beyond low-density lipoprotein cholesterol: respective contributions of non-high-density lipoprotein cholesterol levels, triglycerides, and the total cholesterol/high-density lipoprotein cholesterol ratio to coronary heart disease risk in apparently healthy men and women. Journal of the American College of Cardiology. 2009;55(1):35-41. 
184. Steinberg D, Witztum JL. Is the oxidative modification hypothesis relevant to human atherosclerosis? Circulation. 2002;105(17):2107-11.

185. Glass CK, Witztum JL. Atherosclerosis: the road ahead. Cell. 2001;104(4):503-16.

186. Helkin A, Stein JJ, Lin S, Siddiqui S, Maier KG, Gahtan V. Dyslipidemia Part 1-Review of Lipid Metabolism and Vascular Cell Physiology. Vascular and endovascular surgery. 2016;50(2):107-18.

187. Singh RB, Mengi SA, Xu Y-J, Arneja AS, Dhalla NS. Pathogenesis of atherosclerosis: A multifactorial process. Experimental \& Clinical Cardiology. 2002;7(1):40.

188. Hansson GK, Libby P. The immune response in atherosclerosis: a double-edged sword. Nature Reviews Immunology. 2006;6(7):508-19.

189. Lewis SJ. Lipid-lowering therapy: who can benefit. Vasc Health Risk Manag. 2011;7(1):525-34.

190. Harchaoui K, Visser M, Kastelein J, Stroes E, Dallinga-Thie G. Triglycerides and cardiovascular risk. Current cardiology reviews. 2009;5(3):216-22.

191. Ginsberg HN. New perspectives on atherogenesis. Circulation. 2002;106(16):2137-42.

192. Kawakami A, Yoshida M. Remnant lipoproteins and atherogenesis. Journal of atherosclerosis and thrombosis. 2005;12(2):73-6.

193. Carmena R, Duriez P, Fruchart J-C. Atherogenic lipoprotein particles in atherosclerosis. Circulation. 2004;109(23 suppl 1):III-2-III-7.

194. Rosenson RS. Lipoprotein classification, metabolism, and role in atherosclerosis UptoDate: Wolters Kluwer; 2015 [updated Jun 09, 2015; cited 2016 Octubre]. Available from: https://www.uptodate.com/contents/lipoprotein-classification-metabolism-and-role-inatherosclerosis.

195. Tuteja S, Rader DJ. High-Density Lipoproteins in the Prevention of Cardiovascular Disease: Changing the Paradigm. Clinical Pharmacology \& Therapeutics. 2014;96(1):48-56.

196. Boekholdt SM, Arsenault BJ, Hovingh GK, Mora S, Pedersen TR, LaRosa JC, et al. Levels and changes of $\mathrm{HDL}$ cholesterol and apolipoprotein $\mathrm{Al}$ in relation to risk of cardiovascular events among statin-treated patients: a meta-analysis. Circulation. 2013:1504-12.

197. Barter P, Gotto AM, LaRosa JC, Maroni J, Szarek M, Grundy SM, et al. HDL cholesterol, very low levels of LDL cholesterol, and cardiovascular events. New England Journal of Medicine. 2007;357(13):1301-10.

198. Libby P, Ridker PM, Hansson GK. Progress and challenges in translating the biology of atherosclerosis. Nature. 2011;473(7347):317-25.

199. Rohatgi A, Khera A, Berry JD, Givens EG, Ayers CR, Wedin KE, et al. HDL cholesterol efflux capacity and incident cardiovascular events. New England Journal of Medicine. 2014;371(25):2383-93.

200. Vallejo-Vaz AJ, Ray KK. Cholesterol Efflux Capacity as a Novel Biomarker for Incident Cardiovascular Events. Circulation research. 2015;116(10):1646-8.

201. Eckel RH, Jakicic JM, Ard JD, Hubbard VS, de Jesus JM, Lee I-M, et al. 2013 AHA/ACC guideline on lifestyle management to reduce cardiovascular risk. Circulation. 2013;129(25):s76-s99.

202. Stone NJ, Robinson JG, Lichtenstein AH, Merz CNB, Blum CB, Eckel RH, et al. 2013 ACC/AHA guideline on the treatment of blood cholesterol to reduce atherosclerotic cardiovascular risk in adults. Circulation. 2014;129(25 suppl 2):S1-S45.

203. Canalizo-Miranda E, Favela-Pérez EA, Salas-Anaya JA, Gómez-Díaz R, Jara-Espino R, del Pilar Torres-Arreola L, et al. Diagnóstico y tratamiento de las dislipidemias. Rev Med Inst Mex Seguro Soc. 2013;51(6):700-9.

204. Gonzalez L, Helkin A, Gahtan V. Dyslipidemia Part 2: Review of Dyslipidemia Treatment in Patients With Noncoronary Vascular Disease. Vascular and endovascular surgery. 2016;50(2):119-35.

205. Bays H, Stein EA. Pharmacotherapy for dyslipidaemia-current therapies and future agents. Expert opinion on pharmacotherapy. 2003;4(11):1901-38.

206. Shiuan D, Chen Y-H, Lin H-K, Huang K-J, Tai D-F, Chang D-K. Discovering Peptide Inhibitors of Human Squalene Synthase Through Screening the Phage-Displayed Cyclic Peptide c7c Library. Applied biochemistry and biotechnology. 2016;179(4):597-609.

207. Colletti A, Derosa G, Cicero AF. Retargeting the management of hypercholesterolemia-focus on evolocumab. Therapeutics and Clinical Risk Management. 2016;12:1365.

208. Sando KR, Knight M. Nonstatin therapies for management of dyslipidemia: a review. Clinical therapeutics. 2015;37(10):2153-79. 
209. Chen Z-Y, Ma KY, Liang Y, Peng C, Zuo Y. Role and classification of cholesterol-lowering functional foods. Journal of Functional Foods. 2011;3(2):61-9.

210. Chen G, Wang H, Zhang X, Yang S-T. Nutraceuticals and functional foods in the management of hyperlipidemia. Critical reviews in food science and nutrition. 2014;54(9):1180-201.

211. Barbagallo $C M$, Cefalù $A B$, Noto $D$, Averna MR. Role of nutraceuticals in hypolipidemic therapy. Frontiers in Cardiovascular Medicine [Internet]. 2015; 2. Available from: https://doi.org/10.3389/fcvm.2015.00022.

212. Sahebkar A, Serban M-C, Gluba-Brzózka A, Mikhailidis DP, Cicero AF, Rysz J, et al. Lipid-Modifying Effects of Nutraceuticals: An Evidence-Based Approach. Nutrition. 2016.

213. Al-zuhair H, El-Fattah AaA, El Latif HaA. Efficacy of simvastatin and pumpkin-seed oil in the management of dietary-induced hypercholesterolemia. Pharmacological research. 1997;35(5):403-8.

214. Rouhi-Boroujeni H, Rouhi-Boroujeni H, Heidarian E, Mohammadizadeh F, Rafieian-Kopaei M. Herbs with anti-lipid effects and their interactions with statins as a chemical anti-hyperlipidemia group drugs: A systematic review. ARYA atherosclerosis. 2015;11(4):244.

215. Hamed Ahmad Alobaidi A. Effect of Nigella sativa and Allium sativum coadminstered with simvastatin in dyslipidemia patients: a prospective, randomized, double-blind trial. AntiInflammatory \& Anti-Allergy Agents in Medicinal Chemistry (Formerly Current Medicinal Chemistry-Anti-Inflammatory and Anti-Allergy Agents). 2014;13(1):68-74.

216. Gliozzi M, Walker R, Muscoli S, Vitale C, Gratteri S, Carresi C, et al. Bergamot polyphenolic fraction enhances rosuvastatin-induced effect on LDL-cholesterol, LOX-1 expression and protein kinase B phosphorylation in patients with hyperlipidemia. International journal of cardiology. 2013;170(2):140-5.

217. Bandoni A. Los recursos vegetales aromáticos en Latinoamérica, su aprovechamiento industrial para la producción de aromas y sabores Ed. I Editorial de la Universidad Nacional de la Plata. 1 ed. CYTED Cl, editor. Argentina: Ed. U.N.L.P. ; 2000.410 p.

218. Cordell GA, Colvard MD. Some thoughts on the future of ethnopharmacology. Journal of ethnopharmacology. 2005;100(1):5-14.

219. Mishra BB, Tiwari VK. Natural products: an evolving role in future drug discovery. European journal of medicinal chemistry. 2011;46(10):4769-807.

220. Newman DJ, Cragg GM, Holbeck S, Sausville EA. Natural products and derivatives as leads to cell cycle pathway targets in cancer chemotherapy. Current cancer drug targets. 2002;2(4):279-308.

221. Koehn FE, Carter GT. The evolving role of natural products in drug discovery. Nature reviews Drug discovery. 2005;4(3):206-20.

222. Clardy J, Walsh C. Lessons from natural molecules. Nature. 2004;432(7019):829-37.

223. Simoes CM, Spitzer V. Óleos Voláteis. In: Simoes C, Schenkel E, Gosmann G, Mello J, Mentz L, Petrovick P, editors. Farmacognosia: Da Planta ao Medicamento. 5 ed. Porto Alegre: Editora da UFRGS; 2003. p. 467-95.

224. Bioactive Essential Oils and Cancer. 1 ed. João Pessoa, Paraíba, Brazil: Springer International Publishing; 2015. 19-61, 111-24,75-200,31-36 p.

225. Buchbauer $G$. The detailed analysis of essential oils leads to the understanding of their properties. Perfumer \& flavorist. 2000;25(2):64-7.

226. Dellacassa E, Rossini C, Menendez P, Moyna P, Verzera A, Trozzi A, et al. Citrus essential oils of Uruguay. Part I. Composition of oils of some varieties of mandarin. Journal of Essential Oil Research. 1992;4(3):265-72.

227. Burt S. Essential oils: their antibacterial properties and potential applications in foods-a review. International journal of food microbiology. 2004;94(3):223-53.

228. Wagner K-H, Elmadfa I. Biological relevance of terpenoids. Annals of Nutrition and metabolism. 2003;47(3-4):95-106.

229. Panizzi L, Flamini G, Cioni P, Morelli I. Composition and antimicrobial properties of essential oils of four Mediterranean Lamiaceae. Journal of ethnopharmacology. 1993;39(3):167-70.

230. Lahlou M, Berrada R. Composition and niticidal activity of essential oils of three chemotypes of Rosmarinus officinalis L. acclimatized in Morocco. Flavour and fragrance journal. 2003;18(2):1247. 
231. Cano C, Bonilla P, Roque M, Ruiz J. Actividad antimicótica in vitro y metabolitos del aceite esencial de las hojas de Minthostachys mollis (muña). Revista peruana de medicina experimental y salud pública. 2008;25(3):298-301.

232. Martínez J, de Ferrer BS, de Rodríguez GO, Ferrer A, Nava R. Actividad antibacteriana del aceite esencial de mandarina. Revista de la Facultad de Agronomía. 2003;20(4).

233. Edris AE. Pharmaceutical and therapeutic potentials of essential oils and their individual volatile constituents: a review. Phytotherapy research. 2007;21(4):308-23.

234. Ricci E, Padín S, Kahan A, Ré S. Efecto repelente de los aceites esenciales de laurel y lomongrass sobre Brevicoryne brassicae L.(Homoptera: Aphididae) en repollo. Boletín de Sanidad Vegetal Plagas. 2002;28(2):207-12.

235. Bakkali F, Averbeck S, Averbeck D, Idaomar M. Biological effects of essential oils-a review. Food and chemical toxicology. 2008;46(2):446-75.

236. Grassmann J. Terpenoids as plant antioxidants. Vitamins \& Hormones. 2005;72:505-35.

237. Mahmoud GI. Biological effects, antioxidant and anticancer activities of marigold and basil essential oils. Journal of Medicinal Plants Research. 2013;7(10):561-72.

238. Gautam N, Mantha AK, Mittal S. Essential oils and their constituents as anticancer agents: a mechanistic view. BioMed research international. 2014;2014.

239. Bhalla Y, Gupta VK, Jaitak V. Anticancer activity of essential oils: a review. Journal of the Science of Food and Agriculture. 2013;93(15):3643-53.

240. Ramak P, Osaloo SK, Sharifi M, Ebrahimzadeh H, Behmanesh M. Biosynthesis, regulation and properties of plant monoterpenoids. Journal of Medicinal Plants Research. 2014;8(29):983-91.

241. Rodríguez-Concepción M. Plant isoprenoids: a general overview. Plant Isoprenoids: Methods and Protocols. 2014:1-5.

242. Paduch R, Kandefer-Szerszeń M, Trytek M, Fiedurek J. Terpenes: substances useful in human healthcare. Archivum immunologiae et therapiae experimentalis. 2007;55(5):315-27.

243. Koziol A, Stryjewska A, Librowski T, Salat K, Gawel M, Moniczewski A, et al. An overview of the pharmacological properties and potential applications of natural monoterpenes. Mini reviews in medicinal chemistry. 2014;14(14):1156-68.

244. Mo H, Elson CE. Apoptosis and cell-cycle arrest in human and murine tumor cells are initiated by isoprenoids. The Journal of nutrition. 1999;129(4):804-13.

245. Peffley DM, Gayen AK. Plant-derived monoterpenes suppress hamster kidney cell 3-hydroxy-3methylglutaryl coenzyme a reductase synthesis at the post-transcriptional level. The Journal of nutrition. 2003;133(1):38-44.

246. Crespo R, Montero Villegas S, Abba MC, de Bravo MG, Polo MP. Transcriptional and posttranscriptional inhibition of HMGCR and PC biosynthesis by geraniol in 2 Hep-G2 cell proliferation linked pathways. Biochemistry and Cell Biology. 2013;91(3):131-9.

247. Jones S, Fernandes NV, Yeganehjoo H, Katuru R, Qu H, Yu Z, et al. $\beta$-Ionone induces cell cycle arrest and apoptosis in human prostate tumor cells. Nutrition and cancer. 2013;65(4):600-10.

248. Ren Z, Gould MN. Inhibition of ubiquinone and cholesterol synthesis by the monoterpene perillyl alcohol. Cancer letters. 1994;76(2-3):185-90.

249. Polo MP, de Bravo MG. Effect of geraniol on fatty-acid and mevalonate metabolism in the human hepatoma cell line Hep G2. Biochemistry and cell biology = Biochimie et biologie cellulaire. 2006;84(1):102-11.

250. Kladniew BR, Polo M, Villegas SM, Galle M, Crespo R, de Bravo MG. Synergistic antiproliferative and anticholesterogenic effects of linalool, 1, 8-cineole, and simvastatin on human cell lines. Chemico-biological interactions. 2014;214:57-68.

251. Hohl RJ, Lewis K. Differential effects of monoterpenes and lovastatin on RAS processing. Journal of Biological Chemistry. 1995;270(29):17508-12.

252. Zeytinoglu $\mathrm{H}$, Incesu Z, Baser $\mathrm{K}$. Inhibition of DNA synthesis by carvacrol in mouse myoblast cells bearing a human N-RAS oncogene. Phytomedicine. 2003;10(4):292-9.

253. Holstein SA, Wohlford-Lenane CL, Wiemer DF, Hohl RJ. Isoprenoid pyrophosphate analogues regulate expression of Ras-related proteins. Biochemistry. 2003;42(15):4384-91. 
254. Kimura K, Yamaoka M, Kamisaka Y. Inhibition of lipid accumulation and lipid body formation in oleaginous yeast by effective components in spices, carvacrol, eugenol, thymol, and piperine. Journal of agricultural and food chemistry. 2006;54(10):3528-34.

255. Cho K-H. 1, 8-cineole protected human lipoproteins from modification by oxidation and glycation and exhibited serum lipid-lowering and anti-inflammatory activity in zebrafish. BMB Rep. 2012;45(10):565-70.

256. Saravanan S, Pari L. Role of thymol on hyperglycemia and hyperlipidemia in high fat diet-induced type 2 diabetic C57BL/6J mice. European journal of pharmacology. 2015;761:279-87.

257. Jayachandran $M$, Chandrasekaran B, Namasivayam N. Effect of geraniol, a plant derived monoterpene on lipids and lipid metabolizing enzymes in experimental hyperlipidemic hamsters. Molecular and cellular biochemistry. 2015;398(1-2):39-53.

258. Vallianou I, Peroulis N, Pantazis P, Hadzopoulou-Cladaras M. Camphene, a plant-derived monoterpene, reduces plasma cholesterol and triglycerides in hyperlipidemic rats independently of HMG-CoA reductase activity. PloS one. 2011;6(11):e20516.

259. Galle M, Kladniew BR, Castro MA, Villegas SM, Lacunza E, Polo M, et al. Modulation by geraniol of gene expression involved in lipid metabolism leading to a reduction of serum-cholesterol and triglyceride levels. Phytomedicine. 2015;22(7):696-704.

260. Kim S-H, Park E-J, Lee CR, Chun JN, Cho N-H, Kim I-G, et al. Geraniol induces cooperative interaction of apoptosis and autophagy to elicit cell death in PC-3 prostate cancer cells. International journal of oncology. 2012;40(5):1683.

261. Palozza P, Colangelo M, Simone R, Catalano A, Boninsegna A, Lanza P, et al. Lycopene induces cell growth inhibition by altering mevalonate pathway and Ras signaling in cancer cell lines. Carcinogenesis. 2010;31(10):1813-21.

262. Elson C, Yu S. The chemoprevention of cancer by mevalonate-derived constituents of fruits and vegetables. J Nutr 1994;124(5):607-14.

263. Yu SG, Hildebrandt LA, Elson CE. Geraniol, an inhibitor of mevalonate biosynthesis, suppresses the growth of hepatomas and melanomas transplanted to rats and mice. The Journal of nutrition. 1995;125(11):2763.

264. He L, Mo H, Hadisusilo S, Qureshi AA, Elson CE. Isoprenoids suppress the growth of murine B16 melanomas in vitro and in vivo. The Journal of nutrition. 1997;127(5):668-74.

265. Raphael T, Kuttan G. Effect of naturally occurring monoterpenes carvone, limonene and perillic acid in the inhibition of experimental lung metastasis induced by B16F-10 melanoma cells. Journal of experimental \& clinical cancer research: CR. 2003;22(3):419-24.

266. Ong TP, Heidor R, de Conti A, Dagli MLZ, Moreno FS. Farnesol and geraniol chemopreventive activities during the initial phases of hepatocarcinogenesis involve similar actions on cell proliferation and DNA damage, but distinct actions on apoptosis, plasma cholesterol and HMGCoA reductase. Carcinogenesis. 2006;27(6):1194-203.

267. Chaudhary SC, Siddiqui MS, Athar M, Alam MS. Geraniol inhibits murine skin tumorigenesis by modulating COX-2 expression, Ras-ERK1/2 signaling pathway and apoptosis. Journal of Applied Toxicology. 2013;33(8):828-37.

268. Galle M, Crespo R, Rodenak Kladniew B, Montero Villegas S, Polo M, de Bravo MG. Suppression by geraniol of the growth of A549 human lung adenocarcinoma cells and inhibition of the mevalonate pathway in culture and in vivo: potential use in cancer chemotherapy. Nutrition and cancer. 2014;66(5):888-95.

269. Yuri T, Danbara N, Tsujita-Kyutoku M, Kiyozuka Y, Senzaki H, Shikata N, et al. Perillyl alcohol inhibits human breast cancer cell growth in vitro and in vivo. Breast cancer research and treatment. 2004;84(3):251-60.

270. Cardozo MT, de Conti A, Ong TP, Scolastici C, Purgatto E, Horst MA, et al. Chemopreventive effects of $\beta$-ionone and geraniol during rat hepatocarcinogenesis promotion: distinct actions on cell proliferation, apoptosis, HMGCoA reductase, and RhoA. The Journal of nutritional biochemistry. 2011;22(2):130-5.

271. Murata S, Shiragami R, Kosugi C, Tezuka T, Yamazaki M, Hirano A, et al. Antitumor effect of 1, 8cineole against colon cancer. Oncology reports. 2013;30(6):2647-52. 
272. Jana S, Patra K, Sarkar S, Jana J, Mukherjee G, Bhattacharjee S, et al. Antitumorigenic potential of linalool is accompanied by modulation of oxidative stress: an in vivo study in sarcoma-180 solid tumor model. Nutrition and cancer. 2014;66(5):835-48.

273. Wattenberg LW, Sparnins VL, Barany G. Inhibition of N-nitrosodiethylamine carcinogenesis in mice by naturally occurring organosulfur compounds and monoterpenes. Cancer research. 1989;49(10):2689-92.

274. Gupta SK, Khanuja S, Kumar S. In vitro micropropagation of Lippia alba. Current ScienceBangalore-. 2001;81(2):206-9.

275. Cicció JF, Ocampo RA. Variación anual de la composición química del aceite esencial de Lippia alba (Verbenaceae) cultivada en Costa Rica. Lankesteriana. 2006;6(3):149-54.

276. Pascual M, Slowing K, Carretero E, Mata DS, Villar A. Lippia: traditional uses, chemistry and pharmacology: a review. Journal of ethnopharmacology. 2001;76(3):201-14.

277. Viccini L, Pierre P, Praça M, da Costa DS, da Costa Romanel E, de Sousa S, et al. Chromosome numbers in the genus Lippia (Verbenaceae). Plant Systematics and Evolution. 2005;256(1-4):1718.

278. Normalización de productos naturales obtenidos de especies de la flora aromática latinoamericana: proyecto CYTED IV. 20 / Eduardo Dellacasa (organizador). Porto Alegre: EdiPUCRS; 2010. Available from: <http://www.pucrs.br/edipucrs .

279. Rao G, Singh M, Singh P, Singh S, Catalan C, Kapoor I, et al. Studies on chemical constituents and antifungal activity of leaf essential oil of Lippia alba (Mill). Indian Journal of Chemical Technology. 2000;7:332-5.

280. Ara N, Nur M, Amran M, Wahid M, Ahmed M. In vitro antimicrobial and cytotoxic activities of leaves and flowers extracts from Lippia alba. Pakistan journal of biological sciences: PJBS. 2009;12(1):87-90.

281. Day M, McAndrew T. The biology and host range of Falconia intermedia (Hemiptera: Miridae), a potential biological control agent for Lantana camara (Verbenaceae) in Australia. Biocontrol Science and Technology. 2003;13(1):13-22.

282. Hennebelle T, Sahpaz S, Joseph H, Bailleul F. Ethnopharmacology of Lippia alba. Journal of Ethnopharmacology. 2008;116(2):211-22.

283. Muñoz A, Cabrera FAV, Sánchez MS. Morfología y anatomía de las flores y semillas de pronto alivio. Acta Agronómica. 2007;56(1):7.

284. TRAMIL. TRAMILoteca 2010. Available from: http://www.tramil.net/fototeca/imageDisplay.php?id elem=211\&famil=VERBENACEAE.

285. UNCTAD. Market Brief in the European Union for selected natural ingredients derived from native species. Lippia alba; Prontoalivio, Erva cidreira, juanilama, Melissa: The United Nations Conference on Trade and Development (UNCTAD) BioTrade Initiative / BioTrade Facilitation Programme (BTFP); 2005. 39 p.

286. Fajardo SV, Lizcano PT. Estudio exploratorio de mercado para Lippia alba como alternativa de producción sostenible en la cuenca media y baja del Rio Las Ceibas, Neiva Colombia. Ingeniería y Región. 2015;13(1):125-37.

287. Hennebelle T, Sahpaz S, Dermont C, Joseph H, Bailleul F. The essential oil of Lippia alba: analysis of samples from French overseas departments and review of previous works. Chemistry \& biodiversity. 2006;3(10):1116-25.

288. Ricciardi G, Ciccio JF, Ocampo R, Lorenzo D, Ricciardi A, Bandoni A, et al. Chemical variability of essential oils of Lippia alba (Miller) N. E. Brown growing in Costa Rica and Argentina. Natural product communications. 2009;4(6):853-8.

289. Stashenko EE, Jaramillo BE, Martínez JR. Comparación de la composición química y de la actividad antioxidante in vitro de los metabolitos secundarios volátiles de plantas de la familia Verbenaceae. Rev Acad Colomb Cienc. 2003;27(105):579-97.

290. Ricciardi G, Veglia J, Ricciardi A, Bandoni A. Examen Comparado de la Composición de los Aceites Esenciales de Especies Autóctonas de Lippia alba (Mill.) NE Br. Comunicaciones científicas y tecnológicas. 1999:103-6. 
291. Tavares E, Julião L, Lopes D, Bizzo H, Lage C, Leitão S. Análise do óleo essencial de folhas de três quimiotipos de Lippia alba (Mill.) NE Br.(Verbenaceae) cultivados em condições semelhantes. Revista Brasileira de Farmacognosia. 2005;15(1):1-5.

292. Costa M, Aguiar J, Nascimento S. Atividade citotóxica de extratos brutos de Lippia alba (Mill.) NE Brown (Verbenaceae). Acta Farm Bonaerense. 2004;23(3):349-52.

293. Mamum-or-Rashid A, Sen M, Jamal M, Nasrin S. A comprehensive ethno-pharmacological review on Lippia alba M. International Journal of Biomedical Materials Research. 2013;1(1):14-20.

294. Blanco MA, Colareda GA, van Baren C, Bandoni AL, Ringuelet J, Consolini AE. Antispasmodic effects and composition of the essential oils from two South American chemotypes of Lippia alba. Journal of ethnopharmacology. 2013;149(3):803-9.

295. Linde G, Colauto N, Albertó E, Gazim Z. Quimiotipos, Extracción, Composición y Aplicaciones del Aceite Esencial de Lippia alba. Revista Brasileira de Plantas Medicinais. 2016;18(1):191-200.

296. de Santana BF, Voeks RA, Funch LS. Ethnomedicinal Survey of a Maroon Community in Brazil's Atlantic Tropical Forest. Journal of Ethnopharmacology. 2016;181:37-49.

297. Pino Alea JA, Ortega Luis AG, Rosado Pérez A, Rodríguez Jorge M, Baluja R. Composición y propiedades antibacterianas del aceite esencial de Lippia alba (Mill.) NE Brown. Rev Cubana Farm. 1997;30(1):1.

298. Nogueira MA, Diaz G, Sakumo L, Tagami PM. Antibacterial Activity of Lippia alba (Lemon Herb). Latin American Journal of Pharmacy. 2007;26(3):404.

299. Alviano D, Alviano C. Plant extracts: search for new alternatives to treat microbial diseases. Current Pharmaceutical Biotechnology. 2009;10(1):106-21.

300. Sena Filho JG, Melo JG, Saraiva AM, Gonçalves AM, Psiottano MNC, Xavier HS. Antimicrobial activity and phytochemical profile from the roots of Lippia alba (Mill.) NE Brown. Revista Brasileira de Farmacognosia. 2006;16(4):506-9.

301. Ruffa MJ, Wagner ML, Suriano M, Vicente C, Nadinic J, Pampuro S, et al. Inhibitory effect of medicinal herbs against RNA and DNA viruses. Antiviral Chemistry and Chemotherapy. 2004;15(3):153-9.

302. Meneses R, Ocazionez RE, Martinez JR, Stashenko EE. Inhibitory effect of essential oils obtained from plants grown in Colombia on yellow fever virus replication in vitro. Ann Clin Microbiol Antimicrob. 2009;8:8.

303. Andrighetti-Fröhner C, Sincero T, Da Silva A, Savi L, Gaido C, Bettega J, et al. Antiviral evaluation of plants from Brazilian atlantic tropical forest. Fitoterapia. 2005;76(3):374-8.

304. Mesa-Arango AC, Montiel-Ramos J, Zapata B, Durán C, Betancur-Galvis L, Stashenko E. Citral and carvone chemotypes from the essential oils of Colombian Lippia alba (Mill.) NE Brown: composition, cytotoxicity and antifungal activity. Memórias do Instituto Oswaldo Cruz. 2009;104(6):878-84.

305. Duarte MCT, Figueira GM, Sartoratto A, Rehder VLG, Delarmelina C. Anti-Candida activity of Brazilian medicinal plants. Journal of ethnopharmacology. 2005;97(2):305-11.

306. Souza ELd, Lima EdO, Freire KRdL, Sousa CPd. Inhibitory action of some essential oils and phytochemicals on the growth of various moulds isolated from foods. Brazilian archives of Biology and Technology. 2005;48(2):245-50.

307. Celis CN, Rivero PE, Isaza JH, Stashenko EE, Martínez JR. Estudio comparativo de la composición y actividad biológica de los aceites esenciales extraídos de Lippia alba, Lippia origanoides y Phyla dulcis, especies de la familia Verbenaceae. Scientia et Technica. 2007;1(33).

308. Escobar P, Milena Leal S, Herrera LV, Martinez JR, Stashenko E. Chemical composition and antiprotozoal activities of Colombian Lippia spp essential oils and their major components. Memórias do Instituto Oswaldo Cruz. 2010;105(2):184-90.

309. de Amorim Santos IG, Scher R, Rott MB, Menezes LR, Costa EV, de Holanda Cavalcanti SC, et al. Amebicidal activity of the essential oils of Lippia spp.(Verbenaceae) against Acanthamoeba polyphaga trophozoites. Parasitology research. 2016;115(2):535-40.

310. Tempone AG, Sartorelli P, Teixeira D, Prado FO, Calixto IA, Lorenzi H, et al. Brazilian flora extracts as source of novel antileishmanial and antifungal compounds. Memórias do Instituto Oswaldo Cruz. 2008;103(5):443-9. 
311. Haldar S, Kar B, Dolai N, Kumar RS, Behera B, Haldar PK. In vivo anti-nociceptive and antiinflammatory activities of Lippia alba. Asian Pacific Journal of Tropical Disease. 2012;2:S667-S70.

312. Badilla B, Cambronero J, Cicció J, Cordero T, Mora G. Determination of topical anti-inflammatory activity of the essential oil and extracts of Lippia alba (Mill.) NE Brown (Verbenaceae), using the model of mouse ear edema induced by TPA and AA. Pharmacognosy Magazine. 2007;3(11):139.

313. Viana G, do Vale T, V.S.N R, Matos FJA. Analgesic and Antiinflammatory Effects of Two Chemotypes of Lippia alba: a Comparative Study. Pharmaceutical Biology. 1998;36(5):347-51.

314. Conde R, Corrêa VS, Carmona F, Contini SH, Pereira AM. Chemical composition and therapeutic effects of Lippia alba (Mill.) NE Brown leaves hydro-alcoholic extract in patients with migraine. Phytomedicine. 2011;18(14):1197-201.

315. Viana GS, do Vale TG, Silva CM, Matos FJ. Anticonvulsant activity of essential oils and active principles from chemotypes of Lippia alba (Mill.) N.E. Brown. Biological \& pharmaceutical bulletin. 2000;23(11):1314-7.

316. Nóbrega de Almeida R, Agra MdF, Negromonte Souto Maior F, De Sousa DP. Essential oils and their constituents: anticonvulsant activity. Molecules. 2011;16(3):2726-42.

317. Hatano V, Torricelli A, Giassi A, Coslope L, Viana M. Anxiolytic effects of repeated treatment with an essential oil from Lippia alba and (R)-(-)-carvone in the elevated T-maze. Brazilian Journal of Medical and Biological Research. 2012;45(3):238-43.

318. Zétola M, De Lima T, Sonaglio D, González-Ortega G, Limberger R, Petrovick P, et al. CNS activities of liquid and spray-dried extracts from Lippia alba-Verbenaceae (Brazilian false melissa). Journal of Ethnopharmacology. 2002;82(2):207-15.

319. Hennebelle T, Sahpaz S, Gressier B, Joseph H, Bailleul F. Antioxidant and neurosedative properties of polyphenols and iridoids from Lippia alba. Phytotherapy Research. 2008;22(2):256-8.

320. Vale T, Matos F, De Lima T, Viana G. Behavioral effects of essential oils from Lippia alba (Mill.) NE Brown chemotypes. Journal of Ethnopharmacology. 1999;67(2):127-33.

321. Pascual ME, Slowing K, Carretero ME, Villar A. Antiulcerogenic activity of Lippia alba (Mill.) N. E. Brown (Verbenaceae). Farmaco. 2001;56(5-7):501-4.

322. Henao R, Sandra C, Martínez M, David J, Pacheco G, Natalia L, et al. Antibacterial activity of aqueous extracts of Lippia alba (Mill.) NE Brown against Helicobacter pylori. Revista Colombiana de Gastroenterologia. 2011;26(2):82-7.

323. Maynard LG, Santos KC, Cunha PS, Barreto AS, Peixoto MG, Arrigoni-Blank F, et al. Chemical composition and vasorelaxant effect induced by the essential oil of Lippia alba (Mill.) NE Brown.(Verbenaceae) in rat mesenteric artery. Indian journal of pharmacology. 2011;43(6):694.

324. Guerrero MF, Puebla P, Carron R, Martin ML, Arteaga L, Roman LS. Assessment of the antihypertensive and vasodilator effects of ethanolic extracts of some Colombian medicinal plants. J Ethnopharmacol. 2002;80(1):37-42.

325. Gazola R, Machado D, Ruggiero C, Singi G, Alexandre MM. Lippia alba, Melissa officinalis and Cymbopogon citratus: effects of the aqueous extracts on the isolated hearts of rats. Pharmacological Research. 2004;50(5):477-80.

326. Stashenko EE, Jaramillo BE, Martínez JR. Comparison of different extraction methods for the analysis of volatile secondary metabolites of Lippia alba (Mill.) NE Brown, grown in Colombia, and evaluation of its in vitro antioxidant activity. Journal of Chromatography A. 2004;1025(1):93-103.

327. Olivero-Verbel J, González-Cervera T, Güette-Fernandez J, Jaramillo-Colorado B, Stashenko E. Chemical composition and antioxidant activity of essential oils isolated from Colombian plants. Revista Brasileira de Farmacognosia. 2010;20(4):568-74.

328. Chies CE, Branco CS, Scola G, Agostini F, Gower AE, Salvador M. Antioxidant Effect of Lippia alba (Miller) N. E. Brown. Antioxidants (Basel). 2013;2(4):194-205.

329. Azambuja CR, Mattiazzi J, Riffel APK, Finamor IA, de Oliveira Garcia L, Heldwein CG, et al. Effect of the essential oil of Lippia alba on oxidative stress parameters in silver catfish (Rhamdia quelen) subjected to transport. Aquaculture. 2011;319(1):156-61.

330. Veeck APL, Klein B, Ferreira LF, Becker AG, Heldwein CG, Heinzmann BM, et al. Lipid stability during the frozen storage of fillets from silver catfish exposed in vivo to the essential oil of Lippia alba (Mill.) NE Brown. Journal of the Science of Food and Agriculture. 2013;93(4):955-60. 
331. López MA, Stashenko EE, Fuentes JL. Chemical composition and antigenotoxic properties of Lippia alba essential oils. Genetics and molecular biology. 2011;34(3):479-88.

332. Zapata B, Betancur-Galvis L, Duran C, Stashenko E. Cytotoxic activity of Asteraceae and Verbenaceae family essential oils. Journal of Essential Oil Research. 2014;26(1):50-7.

333. Olivero-Verbel J, Guerrero-Castilla A, Stashenko E. Toxicity of the essential oil of the citral chemotype of Lippia alba (Mill.) N. E. Brown. Acta Toxicol Argent 2010; 18 (1):21-7.

334. Gomide MdS, Lemos FdO, Lopes MT, Alves TMdA, Viccini LF, Coelho CM. The effect of the essential oils from five different Lippia species on the viability of tumor cell lines. Revista Brasileira de Farmacognosia. 2013;23(6):895-902.

335. de Albuquerque PU. Re-examining hypotheses concerning the use and knowledge of medicinal plants: a study in the Caatinga vegetation of NE Brazil. Journal of Ethnobiology and Ethnomedicine. 2006;2(1):1.

336. de Albuquerque UP, de Medeiros PM, de Almeida ALS, Monteiro JM, Neto EMdFL, de Melo JG, et al. Medicinal plants of the caatinga (semi-arid) vegetation of NE Brazil: a quantitative approach. Journal of ethnopharmacology. 2007;114(3):325-54.

337. Di Stasi L, Oliveira G, Carvalhaes M, Queiroz-Junior M, Tien O, Kakinami S, et al. Medicinal plants popularly used in the Brazilian Tropical Atlantic Forest. Fitoterapia. 2002;73(1):69-91.

338. Scarpa G. Plantas empleadas contra trastornos digestivos en la medicina tradicional criolla del Chaco noroccidental. Dominguezia. 2002;18(1):36-50.

339. Knowles BB, Howe CC, Aden DP. Human hepatocellular carcinoma cell lines secrete the major plasma proteins and hepatitis B surface antigen. Science. 1980;209(4455):497-9.

340. Sassa S, Sugita O, Galbraith RA, Kappas A. Drug metabolism by the human hepatoma cell, Hep G2. Biochem Biophys Res Commun. 1987;143(1):52-7.

341. Cohen LH, Griffioen M, Havekes L, Schouten D, van Hinsbergh V, Kempen HJ. Effects of compactin, mevalonate and low-density lipoprotein on 3-hydroxy-3-methylglutaryl-coenzyme A reductase activity and low-density-lipoprotein-receptor activity in the human hepatoma cell line Hep G2. The Biochemical journal. 1984;222(1):35-9.

342. Vock C, Doring F, Nitz I. Transcriptional regulation of HMG-CoA synthase and HMG-CoA reductase genes by human ACBP. Cellular physiology and biochemistry : international journal of experimental cellular physiology, biochemistry, and pharmacology. 2008;22(5-6):515-24.

343. Gerets HH, Hanon E, Cornet M, Dhalluin S, Depelchin O, Canning M, et al. Selection of cytotoxicity markers for the screening of new chemical entities in a pharmaceutical context: a preliminary study using a multiplexing approach. Toxicology in vitro : an international journal published in association with BIBRA. 2009;23(2):319-32.

344. Notas G, Nifli AP, Kampa M, Vercauteren J, Kouroumalis E, Castanas E. Resveratrol exerts its antiproliferative effect on HepG2 hepatocellular carcinoma cells, by inducing cell cycle arrest, and NOS activation. Biochimica et biophysica acta. 2006;1760(11):1657-66.

345. Moscato S, Ronca F, Campani D, Danti S. Poly(vinyl alcohol)/gelatin Hydrogels Cultured with HepG2 Cells as a 3D Model of Hepatocellular Carcinoma: A Morphological Study. Journal of functional biomaterials. 2015;6(1):16-32.

346. Giard DJ, Aaronson SA, Todaro GJ, Arnstein P, Kersey JH, Dosik H, et al. In vitro cultivation of human tumors: establishment of cell lines derived from a series of solid tumors. Journal of the National Cancer Institute. 1973;51(5):1417-23.

347. Chou JY, Lai SY, Pan SL, Jow GM, Chern JW, Guh JH. Investigation of anticancer mechanism of thiadiazole-based compound in human non-small cell lung cancer A549 cells. Biochem Pharmacol. 2003;66(1):115-24.

348. Hsu YL, Kuo PL, Lin CC. Proliferative inhibition, cell-cycle dysregulation, and induction of apoptosis by ursolic acid in human non-small cell lung cancer A549 cells. Life sciences. 2004;75(19):2303-16.

349. Bennis F, Favre G, Le Gaillard F, Soula G. Importance of mevalonate-derived products in the control of HMG-CoA reductase activity and growth of human lung adenocarcinoma cell line a549. International Journal of Cancer. 1993;55(4):640-5.

350. Foster KA, Oster CG, Mayer MM, Avery ML, Audus KL. Characterization of the A549 cell line as a type II pulmonary epithelial cell model for drug metabolism. Experimental cell research. 1998;243(2):359-66. 
351. Berrington D, Lall N. Anticancer Activity of Certain Herbs and Spices on the Cervical Epithelial Carcinoma (HeLa) Cell Line. Evidence-based complementary and alternative medicine : eCAM. 2012;2012:564927.

352. Flórez J, J F. Fármacos Hipolipoproteinemiantes. Control de la obesidad. . In: J F, editor. Farmacología Humana 5ta Ed. ed. Barcelona: Elsevier Masson; 2008. p. 1073-91.

353. Schachter M. Chemical, pharmacokinetic and pharmacodynamic properties of statins: an update. Fundamental \& Clinical Pharmacology. 2005;19(1):117-25.

354. van del Dool H, Kratz P. A generalization of the retention index system including linear temperature programmed gas-liquid partition chromatography. Journal of Chromatography. 1963;11:463-71.

355. Adams R. Identification of Essential Oil Components by Gas Chromatography / Mass Spectrometry. 4ta ed. Illinois, EE.UU.2007.

356. Jakobisiak M, Bruno S, Skierski JS, Darzynkiewicz Z. Cell cycle-specific effects of lovastatin. Proceedings of the National Academy of Sciences of the United States of America. 1991;88(9):3628-32.

357. Freshney R. Basic Principles of Cell Culture. In: Vunjak-Novakovic G, Freshney R, editors. Culture of Cells for Tissue Engineering. 2005.

358. McAteer J, Douglas W. Monolayer Culture Techniques In: Jakoby WP, IH, editor. Methods in enzymology; Cell Culture Vol. LVIII. New York, EE. UU.: Academic Press; 1979. p. 132-40.

359. Denizot F, Lang R. Rapid colorimetric assay for cell growth and survival. Modifications to the tetrazolium dye procedure giving improved sensitivity and reliability. Journal of immunological methods. 1986;89(2):271-7.

360. Mosmann T. Rapid colorimetric assay for cellular growth and survival: application to proliferation and cytotoxicity assays. Journal of immunological methods. 1983;65(1-2):55-63.

361. Repetto G, del Peso A, Zurita JL. Neutral red uptake assay for the estimation of cell viability/cytotoxicity. Nature protocols. 2008;3(7):1125-31.

362. Papadopoulos NG, Dedoussis GV, Spanakos G, Gritzapis AD, Baxevanis CN, Papamichail M. An improved fluorescence assay for the determination of lymphocyte-mediated cytotoxicity using flow cytometry. Journal of immunological methods. 1994;177(1-2):101-11.

363. Kaneshiro E, Wyder M, Wu Y, Cushion M. Reliability of calcein acetoxy methyl ester and ethidium homodimer or propidium iodide for viability assessment of microbes. Journal of Microbiological Methods. 1993;17:1-16.

364. Astiz M, Acaz-Fonseca E, Garcia-Segura LM. Sex differences and effects of estrogenic compounds on the expression of inflammatory molecules by astrocytes exposed to the insecticide dimethoate. Neurotoxicity research. 2014;25(3):271-85.

365. Cook JA, Mitchell JB. Viability measurements in mammalian cell systems. Analytical biochemistry. $1989 ; 179(1): 1-7$.

366. Strober W. Trypan blue exclusion test of cell viability. Current protocols in immunology / edited by John E Coligan [et al]. 2001;Appendix 3:Appendix 3B.

367. Pozarowski P, Darzynkiewicz Z. Analysis of Cell Cycle by Flow Cytometry. In: Schönthal A, editor. Checkpoint Controls and Cancer, Volume 2: Activation and Regulation Protocols. Methods in Molecular Biology. Totowa, NJ: Humana Press 2004. p. 301-11.

368. Gorczyca W, Gong J, Darzynkiewicz Z. Detection of DNA strand breaks in individual apoptotic cells by the in situ terminal deoxynucleotidyl transferase and nick translation assays. Cancer Res. 1993;53(8):1945-51.

369. Loo DT. TUNEL Assay. In: Didenko VV, editor. In Situ Detection of DNA Damage Methods and Protocols. Methods in Molecular Biology. 203. 1 ed. Totowa, NJ: Humana Press; 2002. p. 21-30.

370. Syed Abdul Rahman SN, Abdul Wahab N, Abd Malek SN. In Vitro Morphological Assessment of Apoptosis Induced by Antiproliferative Constituents from the Rhizomes of Curcuma zedoaria. Evidence-Based Complementary and Alternative Medicine. 2013;2013:14.

371. Muppidi J, Porter M, Siegel R. Relatd Isolation procedures and functional assays. Measurement of apoptosis and other forms of cell death. In: Cojco R, editor. Current Protocols in Inmunology. Supplement 59: John Wiley and Sons 2004. p. 3.17.1-3..36. 
372. Folch J, Lees M, Sloane Stanley GH. A simple method for the isolation and purification of total lipides from animal tissues. The Journal of biological chemistry. 1957;226(1):497-509.

373. Christie WW, Han X. Chromatographic analysis of lipids: general principles. In: Han X, Christie WW, editors. Lipid Analysis Isolation, Separation, Identification and Lipidomic Analysis. Fourth edition ed. Bridgwater, England: Oily Press; 2010. p. 21-52.

374. Chen PS, Toribara TY, Warner H. Microdetermination of Phosphorus. Analytical Chemistry. 1956;28(11):1756-8.

375. Lowry RR. Ferric chloride spray detector for cholesterol and cholesteryl esters on thin-layer chromatograms. J Lipid Res. 1968;9(3):397.

376. Morrison WR, Smith LM. Preparation of Fatty Acid Methyl Esters and Dimethylacetals from Lipids with Boron Fluoride--Methanol. J Lipid Res. 1964;5:600-8.

377. Scharnagl H, Schinker R, Gierens H, Nauck M, Wieland H, Marz W. Effect of atorvastatin, simvastatin, and lovastatin on the metabolism of cholesterol and triacylglycerides in HepG2 cells. Biochem Pharmacol. 2001;62(11):1545-55.

378. Holub BJ, Skeaff CM. Nutritional regulation of cellular phosphatidylinositol. Methods in enzymology. 1987;141:234-44.

379. Wilson R, Sargent J. High-resolution separation of polyunsaturated fatty acids by argentation thinlayer chromatography. Journal of Chromatography A. 1992;623(2):403-7.

380. Dudley RA, Anderson RE. Separation of polyunsaturated fatty acids by argentation thin layer chromatography. Lipids. 1975;10(2):113-5.

381. Lowry OH, Rosebrough NJ, Farr AL, Randall RJ. Protein measurement with the folin phenol reagent. The Journal of Biological Chemistry. 1951;193(1):265-75.

382. Bradford MM. A rapid and sensitive method for the quantitation of microgram quantities of protein utilizing the principle of protein-dye binding. Analytical biochemistry. 1976;72:248-54.

383. Kruger NJ. The Bradford Method For Protein Quantitation. In: Walker JM, editor. The Protein Protocols Handbook. 2 ed. Totowa, New Jersey: Humana Press 2002. p. 17-24.

384. Laemmli UK. Cleavage of structural proteins during the assembly of the head of bacteriophage T4. Nature. 1970;227(5259):680-5.

385. Lauriere M. A semidry electroblotting system efficiently transfers both high- and low-molecularweight proteins separated by SDS-PAGE. Analytical biochemistry. 1993;212(1):206-11.

386. Mruk DD, Cheng CY. Enhanced chemiluminescence (ECL) for routine immunoblotting: An inexpensive alternative to commercially available kits. Spermatogenesis. 2011;1(2):121-2.

387. Zoli W, Ricotti L, Tesei A, Barzanti F, Amadori D. In vitro preclinical models for a rational design of chemotherapy combinations in human tumors. Crit Rev Oncol Hematol. 2001;37(1):69-82.

388. Kern DH, Morgan CR, Hildebrand-Zanki SU. In vitro pharmacodynamics of 1-beta-Darabinofuranosylcytosine: synergy of antitumor activity with cis-diamminedichloroplatinum(II). Cancer Res. 1988;48(1):117-21.

389. Romanelli S, Perego P, Pratesi G, Carenini N, Tortoreto M, Zunino F. In vitro and in vivo interaction between cisplatin and topotecan in ovarian carcinoma systems. Cancer chemotherapy and pharmacology. 1998;41(5):385-90.

390. Ferri N, Granata A, Pirola C, Torti F, Pfister PJ, Dorent R, et al. Fluvastatin synergistically improves the antiproliferative effect of everolimus on rat smooth muscle cells by altering p27Kip1/cyclin $E$ expression. Molecular pharmacology. 2008;74(1):144-53.

391. Fabbri F, Brigliadori G, Carloni S, Ulivi P, Vannini I, Tesei A, et al. Zoledronic acid increases docetaxel cytotoxicity through pMEK and Mcl-1 inhibition in a hormone-sensitive prostate carcinoma cell line. Journal of translational medicine. 2008;6:43.

392. Bézivin C, Tomasi S, Lohezic-Le Devehat F, Boustie J. Cytotoxic activity of some lichen extracts on murine and human cancer cell lines. Phytomedicine. 2003;10(6):499-503.

393. de Oliveira PF, Alves JM, Damasceno JL, Oliveira RA, Dias HJ, Crotti AE, et al. Cytotoxicity screening of essential oils in cancer cell lines. Revista Brasileira de Farmacognosia. 2015;25(2):183-8.

394. Pita JCLR, Xavier AL, Sousa TKGd, Mangueira VM, Tavares JF, Júnior RJdO, et al. In vitro and in vivo antitumor effect of trachylobane-360, a diterpene from Xylopia langsdorffiana. Molecules. 2012;17(8):9573-89. 
395. Efferth T. Cancer therapy with natural products and medicinal plants. Planta medica. 2010;76(11):1035-6.

396. Rasoanaivo P, Fortuné Randriana R, Maggi F, Nicoletti M, Quassinti L, Bramucci M, et al. Chemical composition and biological activities of the essential oil of Athanasia brownii Hochr.(Asteraceae) endemic to Madagascar. Chemistry \& biodiversity. 2013;10(10):1876-86.

397. Tan W, Lu J, Huang M, Li Y, Chen M, Wu G, et al. Anti-cancer natural products isolated from chinese medicinal herbs. Chinese medicine. 2011;6(1):1.

398. Suffness M, Pezzuto JM. Assays related to cancer drug discovery. Methods in plant biochemistry: assays for bioactivity. 1990;6:71-133.

399. Shabana MM, Salama MM, Ezzat SM, Ismail LR. In Vitro and In Vivo anticancer activity of the fruit peels of Solanum melongena L. against hepatocellular carcinoma. Journal of Carcinogenesis \& Mutagenesis. 2013;2013.

400. Boik J. Natural Compounds in Cancer Therapy. Minnesota, USA: Oregon Medical Press; 2001. 25p.

401. Prayong P, Barusrux S, Weerapreeyakul N. Cytotoxic activity screening of some indigenous Thai plants. Fitoterapia. 2008;79(7):598-601.

402. Ferraz RP, Bomfim DS, Carvalho NC, Soares MB, da Silva TB, Machado WJ, et al. Cytotoxic effect of leaf essential oil of Lippia gracilis Schauer (Verbenaceae). Phytomedicine. 2013;20(7):615-21.

403. Sobral MV, Xavier AL, Lima TC, de Sousa DP. Antitumor activity of monoterpenes found in essential oils. The Scientific World Journal. 2014;2014.

404. Piaru SP, Mahmud A, Majid S, Ismail S, Man CN. Chemical composition, antioxidant and cytotoxicity activities of the essential oils of Myristica fragrans and Morinda citrifolia. Journal of the Science of Food and Agriculture. 2012;92:593-7.

405. Maggi F, Fortuné Randriana R, Rasoanaivo P, Nicoletti M, Quassinti L, Bramucci M, et al. Chemical composition and in vitro biological activities of the essential oil of Vepris macrophylla (Baker) I. Verd. endemic to Madagascar. Chemistry \& biodiversity. 2013;10(3):356-66.

406. Doll-Boscardin PM, Sartoratto A, Sales Maia BH, Padilha de Paula J, Nakashima T, Farago PV, et al. In Vitro Cytotoxic Potential of Essential Oils of Eucalyptus benthamii and Its Related Terpenes on Tumor Cell Lines. Evidence-based complementary and alternative medicine : eCAM. 2012;2012:342652.

407. Li Y, Yeung CM, Chiu L, Cen YZ, Ooi VE. Chemical composition and antiproliferative activity of essential oil from the leaves of a medicinal herb, Schefflera heptaphylla. Phytotherapy Research,. 2009;23(1):140-2.

408. Manassero CA, Girotti JR, Mijailovsky S, Garcia de Bravo M, Polo M. In vitro comparative analysis of antiproliferative activity of essential oil from mandarin peel and its principal component limonene. Natural product research. 2013;27(16):1475-8.

409. Bakkali F, Averbeck S, Averbeck D, Zhiri A, Baudoux D, Idaomar M. Antigenotoxic effects of three essential oils in diploid yeast (Saccharomyces cerevisiae) after treatments with UVC radiation, 8MOP plus UVA and MMS. Mutation Research/Genetic Toxicology and Environmental Mutagenesis. 2006;606(1):27-38.

410. Russo R, Corasaniti MT, Bagetta G, Morrone LA. Exploitation of cytotoxicity of some essential oils for translation in cancer therapy. Evidence-Based Complementary and Alternative Medicine. 2015;2015.

411. Russo R, Ciociaro A, Berliocchi L, Cassiano MGV, Rombolà L, Ragusa S, et al. Implication of limonene and linalyl acetate in cytotoxicity induced by bergamot essential oil in human neuroblastoma cells. Fitoterapia. 2013;89:48-57.

412. Lesgards JF, Baldovini N, Vidal N, Pietri S. Anticancer activities of essential oils constituents and synergy with conventional therapies: a review. Phytotherapy Research. 2014;28(10):1423-46.

413. Pucci B, Kasten M, Giordano A. Cell cycle and apoptosis. Neoplasia. 2000;2(4):291-9.

414. Bardon S, Foussard V, Fournel S, Loubat A. Monoterpenes inhibit proliferation of human colon cancer cells by modulating cell cycle-related protein expression. Cancer letters. 2002;181(2):18794.

415. Wiseman DA, Werner SR, Crowell PL. Cell cycle arrest by the isoprenoids perillyl alcohol, geraniol, and farnesol is mediated by p21Cip1 and p27Kip1 in human pancreatic adenocarcinoma cells. Journal of Pharmacology and Experimental Therapeutics. 2007;320(3):1163-70. 
416. Wu C-S, Chen Y-J, Chen JJ, Shieh J-J, Huang C-H, Lin P-S, et al. Terpinen-4-ol induces apoptosis in human nonsmall cell lung cancer in vitro and in vivo. Evidence-Based Complementary and Alternative Medicine. 2011;2012.

417. Xu X, Zhang Y, Qu D, Jiang T, Li S. Osthole induces G2/M arrest and apoptosis in lung cancer A549 cells by modulating PI3K/Akt pathway. Journal of Experimental \& Clinical Cancer Research. 2011;30(1):1.

418. Dixon SC, Soriano BJ, Lush RM, Borner MM, Figg WD. Apoptosis: its role in the development of malignancies and its potential as a novel therapeutic target. Annals of Pharmacotherapy. 1997;31(1):76-82.

419. Walsh CM, Edinger AL. The complex interplay between autophagy, apoptosis, and necrotic signals promotes T-cell homeostasis. Immunological reviews. 2010;236(1):95-109.

420. Crowell PL. Prevention and therapy of cancer by dietary monoterpenes. The Journal of nutrition. 1999;129(3):775S-8S.

421. Pattanayak M, Seth P, Smita S, Gupta SK. Geraniol and limonene interaction with 3-hydroxy-3methylglutaryl-CoA (HMG-CoA) reductase for their role as cancer chemo-preventive agents. Journal of Proteomics \& Bioinformatics. 2011;2009.

422. Cho S-Y, Jun H-j, Lee JH, Jia Y, Kim KH, Lee S-J. Linalool reduces the expression of 3-hydroxy-3-methylglutaryl CoA reductase via sterol regulatory element binding protein-2-and ubiquitin-dependent mechanisms. FEBS letters. 2011;585(20):3289-96.

423. Chen C-C, Wu M-L, Ho C-T, Huang T-C. Blockade of the Ras/Raf/ERK and Ras/PI3K/Akt pathways by monacolin $\mathrm{K}$ reduces the expression of GLO1 and induces apoptosis in U937 cells. Journal of agricultural and food chemistry. 2015;63(4):1186-95.

424. Bansal VS, Vaidya S. Characterization of 2 Distinct Allyl Pyrophosphatase Activities from Rat-Liver Microsomes. Archives of biochemistry and biophysics. 1994;315(2):393-9.

425. Joo JH, Jetten AM. Molecular mechanisms involved in farnesol-induced apoptosis. Cancer letters. 2010;287(2):123-35.

426. Gould MN. Cancer chemoprevention and therapy by monoterpenes. Environmental Health Perspectives. 1997;105(Suppl 4):977.

427. Tavera-Loza H. Monoterpenes in essential oils; biosynthesis and properties. Chemicals via Higher Plant Bioengineering, Kluwer Academic Publishers, Plenum Press, New York. 1999.

428. Chaudhary S, Siddiqui M, Athar M, Alam MS. D-Limonene modulates inflammation, oxidative stress and Ras-ERK pathway to inhibit murine skin tumorigenesis. Human \& experimental toxicology. 2012;31(8):798-811.

429. Gould MN, Moore CJ, Zhang R, Wang B, Kennan WS, Haag JD. Limonene chemoprevention of mammary carcinoma induction following direct in situ transfer of v-Ha-ras. Cancer research. 1994;54(13):3540-3.

430. Hindler K, Cleeland CS, Rivera E, Collard CD. The role of statins in cancer therapy. The Oncologist. 2006;11(3):306-15.

431. Sassano A, Katsoulidis E, Antico G, Altman JK, Redig AJ, Minucci S, et al. Suppressive effects of statins on acute promyelocytic leukemia cells. Cancer research. 2007;67(9):4524-32.

432. Maksimova E, Yie T-A, Rom WN. In vitro mechanisms of lovastatin on lung cancer cell lines as a potential chemopreventive agent. Lung. 2008;186(1):45-54.

433. Relja B, Meder F, Wilhelm K, Henrich D, Marzi I, Lehnert M. Simvastatin inhibits cell growth and induces apoptosis and G0/G1 cell cycle arrest in hepatic cancer cells. International journal of molecular medicine. 2010;26(5):735.

434. Chen J, Bi H, Hou J, Zhang X, Zhang C, Yue L, et al. Atorvastatin overcomes gefitinib resistance in KRAS mutant human non-small cell lung carcinoma cells. Cell death \& disease. 2013;4(9):e814.

435. Khurana V, Bejjanki HR, Caldito G, Owens MW. Statins reduce the risk of lung cancer in humans: a large case-control study of US veterans. CHEST Journal. 2007;131(5):1282-8.

436. El-Serag HB, Johnson ML, Hachem C, Morgana RO. Statins are associated with a reduced risk of hepatocellular carcinoma in a large cohort of patients with diabetes. Gastroenterology. 2009;136(5):1601-8. 
437. Ahern TP, Pedersen L, Tarp M, Cronin-Fenton DP, Garne JP, Silliman RA, et al. Statin prescriptions and breast cancer recurrence risk: a Danish nationwide prospective cohort study. Journal of the National Cancer Institute. 2011;103(19):1461-8.

438. Singh P, Saxena R, Srinivas G, Pande G, Chattopadhyay A. Cholesterol biosynthesis and homeostasis in regulation of the cell cycle. PloS one. 2013;8(3):e58833.

439. Campbell MJ, Esserman L, Zhou Y, Shoemaker M, Lobo M, Borman E, et al. Breast cancer growth prevention by statins. Cancer research. 2006;66(17):8707-14.

440. Goc A, Kochuparambil ST, Al-Husein B, Al-Azayzih A, Mohammad S, Somanath PR. Simultaneous modulation of the intrinsic and extrinsic pathways by simvastatin in mediating prostate cancer cell apoptosis. BMC cancer. 2012;12(1):1.

441. Kah J, Wüstenberg A, Keller AD, Sirma H, Montalbano R, Ocker M, et al. Selective induction of apoptosis by HMG-CoA reductase inhibitors in hepatoma cells and dependence on p53 expression. Oncology reports. 2012;28(3):1077-83.

442. Keskitalo JE, Pasanen MK, Neuvonen PJ, Niemi M. Different effects of the ABCG2 c. 421C> A SNP on the pharmacokinetics of fluvastatin, pravastatin and simvastatin. Pharmacogenomics. 2009;10(10):1617-24.

443. Bonetti P, Lerman LO, Napoli C, Lerman A. Statin effects beyond lipid lowering-are they clinically relevant? European heart journal. 2003;24(3):225-48.

444. Pastori D, Polimeni L, Baratta F, Pani A, Del Ben M, Angelico F. The efficacy and safety of statins for the treatment of non-alcoholic fatty liver disease. Digestive and Liver Disease. 2015;47(1):411.

445. Rodenak Kladniew B. Mecanismos de acción de isoprenoides naturales y su combinación con estatinas sobre la proliferación y el metabolismo lipídico en distintos modelos celulares. Universidad Nacional de La Plata: Universidad Nacional de La Plata; 2015.

446. Shefer S, Salen G, Batta A, Honda A, Tint G, Irons M, et al. Markedly inhibited 7dehydrocholesterol-delta 7-reductase activity in liver microsomes from Smith-Lemli-Opitz homozygotes. Journal of Clinical Investigation. 1995;96(4):1779.

447. Rowe AH, Argmann CA, Edwards JY, Sawyez CG, Morand OH, Hegele RA, et al. Enhanced Synthesis of the Oxysterol 24 (S), 25-Epoxycholesterol in Macrophages by Inhibitors of 2, 3-Oxidosqualene: Lanosterol Cyclase A Novel Mechanism for the Attenuation of Foam Cell Formation. Circulation research. 2003;93(8):717-25.

448. Wong J, Quinn CM, Brown AJ. Synthesis of the oxysterol, 24 (S), 25-epoxycholesterol, parallels cholesterol production and may protect against cellular accumulation of newly-synthesized cholesterol. Lipids in health and disease. 2007;6(10).

449. Yamauchi Y, Reid PC, Sperry JB, Furukawa K, Takeya M, Chang CC, et al. Plasma membrane rafts complete cholesterol synthesis by participating in retrograde movement of precursor sterols. Journal of Biological Chemistry. 2007;282(48):34994-5004.

450. Marco C, Jiménez-López JM, Ríos-Marco P, Segovia JL, Carrasco MP. Hexadecylphosphocholine alters nonvesicular cholesterol traffic from the plasma membrane to the endoplasmic reticulum and inhibits the synthesis of sphingomyelin in HepG2 cells. The international journal of biochemistry \& cell biology. 2009;41(6):1296-303.

451. Zerenturk EJ, Kristiana I, Gill S, Brown AJ. The endogenous regulator 24 (S), 25-epoxycholesterol inhibits cholesterol synthesis at DHCR24 (Seladin-1). Biochimica et Biophysica Acta (BBA)Molecular and Cell Biology of Lipids. 2012;1821(9):1269-77.

452. Mathers CD, Boerma T, Fat DM. Global and regional causes of death. British medical bulletin. 2009;92(1):1-5.

453. Trialists CT. Efficacy and safety of more intensive lowering of LDL cholesterol: a meta-analysis of data from 170000 participants in 26 randomised trials. The Lancet. 2010;376(9753):1670-81.

454. Fulcher J, O'Connell R, Voysey M, Emberson J, Blackwell L, Mihaylova B, et al. Cholesterol Treatment Trialists'(CTT) Collaboration. Efficacy and safety of LDL-lowering therapy among men and women: meta-analysis of individual data from 174,000 participants in 27 randomised trials. Lancet. 2015;385(9976):1397-405.

455. Campbell CY, Rivera JJ, Blumenthal RS. Residual risk in statin-treated patients: future therapeutic options. Current cardiology reports. 2007;9(6):499-505. 
456. Sampson UK, Fazio S, Linton MF. Residual cardiovascular risk despite optimal LDL cholesterol reduction with statins: the evidence, etiology, and therapeutic challenges. Current atherosclerosis reports. 2012;14(1):1-10.

457. Tomaszewski M, Stepien KM, Tomaszewska J, Czuczwar SJ. Statin-induced myopathies. Pharmacological reports : PR. 2011;63(4):859-66.

458. Eckel RH, Grundy SM, Zimmet PZ. The metabolic syndrome. The Lancet. 2005;365(9468):1415-28.

459. Boullart A, De Graaf J, Stalenhoef A. Serum triglycerides and risk of cardiovascular disease. Biochimica et Biophysica Acta (BBA)-Molecular and Cell Biology of Lipids. 2012;1821(5):867-75.

460. Chung MJ, Kang A-Y, Park S-O, Park K-W, Jun H-J, Lee S-J. The effect of essential oils of dietary wormwood (Artemisia princeps), with and without added vitamin $\mathrm{E}$, on oxidative stress and some genes involved in cholesterol metabolism. Food and chemical toxicology. 2007;45(8):1400-9.

461. Chung MJ, Park KW, Kim KH, Kim C-T, Baek JP, Bang K-H, et al. Asian plantain (Plantago asiatica) essential oils suppress 3-hydroxy-3-methyl-glutaryl-co-enzyme A reductase expression in vitro and in vivo and show hypocholesterolaemic properties in mice. British Journal of Nutrition. 2008;99(01):67-75.

462. Baker SK, Tarnopolsky MA. Statin myopathies: pathophysiologic and clinical perspectives. Clinical and investigative medicine Medecine clinique et experimentale. 2001;24(5):258-72.

463. Antons KA, Williams CD, Baker SK, Phillips PS. Clinical perspectives of statin-induced rhabdomyolysis. The American journal of medicine. 2006;119(5):400-9.

464. Holbrook A, Wright M, Sung M, Ribic C, Baker S. Statin-associated rhabdomyolysis: is there a dose-response relationship? The Canadian journal of cardiology. 2011;27(2):146-51.

465. Tavintharan S, Ong CN, Jeyaseelan K, Sivakumar M, Lim SC, Sum CF. Reduced mitochondrial coenzyme Q10 levels in HepG2 cells treated with high-dose simvastatin: a possible role in statininduced hepatotoxicity? Toxicology and applied pharmacology. 2007;223(2):173-9.

466. Horton J, Goldstein J, Brown M, editors. SREBPs: transcriptional mediators of lipid homeostasis. Cold Spring Harbor Symposia on Quantitative Biology; 2002: Cold Spring Harbor Laboratory Press.

467. Van Rooyen DM, Farrell GC. SREBP-2: a link between insulin resistance, hepatic cholesterol, and inflammation in NASH. Journal of gastroenterology and hepatology. 2011;26(5):789-92.

468. Gerin I, Clerbaux LA, Haumont O, Lanthier N, Das AK, Burant CF, et al. Expression of miR-33 from an SREBP2 intron inhibits cholesterol export and fatty acid oxidation. The Journal of biological chemistry. 2010;285(44):33652-61.

469. Listenberger LL, Han X, Lewis SE, Cases S, Farese RV, Jr., Ory DS, et al. Triglyceride accumulation protects against fatty acid-induced lipotoxicity. Proceedings of the National Academy of Sciences of the United States of America. 2003;100(6):3077-82.

470. Schaffer JE. Lipotoxicity: when tissues overeat. Current opinion in lipidology. 2003;14(3):281-7.

471. Karagianni P, Talianidis I. Transcription factor networks regulating hepatic fatty acid metabolism. Biochimica et biophysica acta. 2015;1851(1):2-8.

472. Do R, Kiss R, Gaudet D, Engert J. Squalene synthase: a critical enzyme in the cholesterol biosynthesis pathway. Clinical genetics. 2009;75(1):19-29.

473. Krag SS. The importance of being dolichol. Biochemical and biophysical research communications. 1998;243(1):1-5.

474. McTaggart SJ. Isoprenylated proteins. Cellular and Molecular Life Sciences CMLS. 2006;63(3):25567.

475. Bradfute D, Simoni RD. Non-sterol compounds that regulate cholesterogenesis. Analogues of farnesyl pyrophosphate reduce 3-hydroxy-3-methylglutaryl-coenzyme A reductase levels. Journal of Biological Chemistry. 1994;269(9):6645-50.

476. Correll CC, Ng L, Edwards PA. Identification of farnesol as the non-sterol derivative of mevalonic acid required for the accelerated degradation of 3-hydroxy-3-methylglutaryl-coenzyme $A$ reductase. Journal of Biological Chemistry. 1994;269(26):17390-3.

477. Meigs TE, Roseman DS, Simoni RD. Regulation of 3-hydroxy-3-methylglutaryl-coenzyme A reductase degradation by the nonsterol mevalonate metabolite farnesol in vivo. Journal of Biological Chemistry. 1996;271(14):7916-22. 
478. Meigs TE, Simoni RD. Farnesol as a regulator of HMG-CoA reductase degradation: characterization and role of farnesyl pyrophosphatase. Archives of biochemistry and biophysics. 1997;345(1):1-9.

479. Hampton RY, Bhakta H. Ubiquitin-mediated regulation of 3-hydroxy-3-methylglutaryl-CoA reductase. Proceedings of the National Academy of Sciences. 1997;94(24):12944-8.

480. Gardner RG, Hampton RY. A highly conserved signal controls degradation of 3-hydroxy-3methylglutaryl-coenzyme A (HMG-CoA) reductase in eukaryotes. Journal of Biological Chemistry. 1999;274(44):31671-8.

481. Hiyoshi H, Yanagimachi M, Ito M, Yasuda N, Okada T, Ikuta H, et al. Squalene synthase inhibitors suppress triglyceride biosynthesis through the farnesol pathway in rat hepatocytes. Journal of lipid research. 2003;44(1):128-35.

482. Bostedor RG, Karkas JD, Arison BH, Bansal VS, Vaidya S, Germershausen JI, et al. Farnesol-derived dicarboxylic acids in the urine of animals treated with zaragozic acid A or with farnesol. Journal of Biological Chemistry. 1997;272(14):9197-203.

483. Vaidya S, Bostedor R, Kurtz MM, Bergstrom JD, Bansal VS. Massive production of farnesol-derived dicarboxylic acids in mice treated with the squalene synthase inhibitor zaragozic acid A. Archives of biochemistry and biophysics. 1998;355(1):84-92.

484. Forman BM, Goode E, Chen J, Oro AE, Bradley DJ, Perlmann T, et al. Identification of a nuclear receptor that is activated by farnesol metabolites. Cell. 1995;81(5):687-93.

485. Hanley K, Kömüves LG, Ng DC, Schoonjans K, He SS, Lau P, et al. Farnesol stimulates differentiation in epidermal keratinocytes via PPAR $\alpha$. Journal of Biological Chemistry. 2000;275(15):11484-91.

486. Takahashi N, Kawada T, Goto T, Yamamoto T, Taimatsu A, Matsui N, et al. Dual action of isoprenols from herbal medicines on both PPAR $\gamma$ and PPAR $\alpha$ in 3T3-L1 adipocytes and HepG2 hepatocytes. FEBS letters. 2002;514(2-3):315-22.

487. Duncan RE, Archer MC. Farnesol decreases serum triglycerides in rats: Identification of mechanisms including up-regulation of PPAR $\alpha$ and down-regulation of fatty acid synthase in hepatocytes. Lipids. 2008;43(7):619-27.

488. Goto T, Kim Y-I, Funakoshi K, Teraminami A, Uemura T, Hirai S, et al. Farnesol, an isoprenoid, improves metabolic abnormalities in mice via both PPAR $\alpha$-dependent and-independent pathways. American Journal of Physiology-Endocrinology and Metabolism. 2011;301(5):E1022E32.

489. Watanabe M, Houten SM, Wang L, Moschetta A, Mangelsdorf DJ, Heyman RA, et al. Bile acids lower triglyceride levels via a pathway involving FXR, SHP, and SREBP-1c. The Journal of clinical investigation. 2004;113(10):1408-18.

490. Pineda Torra I, Claudel T, Duval C, Kosykh V, Fruchart J-C, Staels B. Bile acids induce the expression of the human peroxisome proliferator-activated receptor $\alpha$ gene via activation of the farnesoid X receptor. Molecular Endocrinology. 2003;17(2):259-72.

491. Savkur RS, Thomas JS, Bramlett KS, Gao Y, Michael LF, Burris TP. Ligand-dependent coactivation of the human bile acid receptor FXR by the peroxisome proliferator-activated receptor $\gamma$ coactivator1 $\alpha$. Journal of Pharmacology and Experimental Therapeutics. 2005;312(1):170-8.

492. Jun H-j, Lee JH, Jia Y, Hoang M-H, Byun H, Kim KH, et al. Melissa officinalis Essential Oil Reduces Plasma Triglycerides in Human Apolipoprotein E2 Transgenic Mice by Inhibiting Sterol Regulatory Element-Binding Protein-1c-Dependent Fatty Acid Synthesis. The Journal of nutrition. 2012;142(3):432-40.

493. Kast HR, Nguyen CM, Sinal CJ, Jones SA, Laffitte BA, Reue K, et al. Farnesoid X-activated receptor induces apolipoprotein C-II transcription: a molecular mechanism linking plasma triglyceride levels to bile acids. Molecular Endocrinology. 2001;15(10):1720-8.

494. Anisfeld AM, Kast-Woelbern HR, Meyer ME, Jones SA, Zhang Y, Williams KJ, et al. Syndecan-1 expression is regulated in an isoform-specific manner by the farnesoid-X receptor. Journal of Biological Chemistry. 2003;278(22):20420-8.

495. Claudel T, Inoue Y, Barbier O, Duran-Sandoval D, Kosykh V, Fruchart J, et al. Farnesoid X receptor agonists suppress hepatic apolipoprotein CIII expression. Gastroenterology. 2003;125(2):544-55. 
496. Chithra V, Leelamma S. Hypolipidemic effect of coriander seeds (Coriandrum sativum): mechanism of action. Plant Foods Hum Nutr. 1997;51(2):167-72.

497. Cho KH. 1,8-cineole protected human lipoproteins from modification by oxidation and glycation and exhibited serum lipid-lowering and anti-inflammatory activity in zebrafish. BMB reports. 2012;45(10):565-70.

498. Khan A, Zaman G, Anderson RA. Bay leaves improve glucose and lipid profile of people with type 2 diabetes. Journal of clinical biochemistry and nutrition. 2009;44(1):52-6.

499. Wasko BM, Smits JP, Shull LW, Wiemer DF, Hohl RJ. A novel bisphosphonate inhibitor of squalene synthase combined with a statin or a nitrogenous bisphosphonate in vitro. Journal of lipid research. 2011;52(11):1957-64.

500. Nishimoto T, Amano Y, Tozawa R, Ishikawa E, Imura Y, Yukimasa H, et al. Lipid-lowering properties of TAK-475, a squalene synthase inhibitor, in vivo and in vitro. British journal of pharmacology. 2003;139(5):911-8.

501. Nagashima S, Yagyu H, Tozawa R, Tazoe F, Takahashi M, Kitamine T, et al. Plasma cholesterollowering and transient liver dysfunction in mice lacking squalene synthase in the liver. Journal of lipid research. 2015;56(5):998-1005. 


$$
\text { Apéndices }
$$




\section{Curvas dosis-respuesta de viabilidad celular}

\section{I.1 Ensayo de MTT en células tratadas con AELs}

Los cultivos celulares fueron incubados durante 48 horas en condiciones estándar hasta alcanzar fase exponencial de crecimiento, luego de lo cual el medio de cultivo se reemplazó por MEM fresco suplementado con 10 \% SFB y concentraciones crecientes de AELs. A las 24 horas de tratamiento se reemplazó el medio de cultivo por MEM fresco más los AEs y se incubaron las células durante otras 24 horas (48 horas de tratamiento). La viabilidad celular fue determinada por el ensayo de MTT según lo descrito en Materiales y métodos. A partir de los resultados obtenidos en los ensayos se elaboraron curvas dosisrespuesta utilizando el software SigmaPlot v. 10. Se muestran las curvas en las Figuras A.1, A. 2 y $A .3$
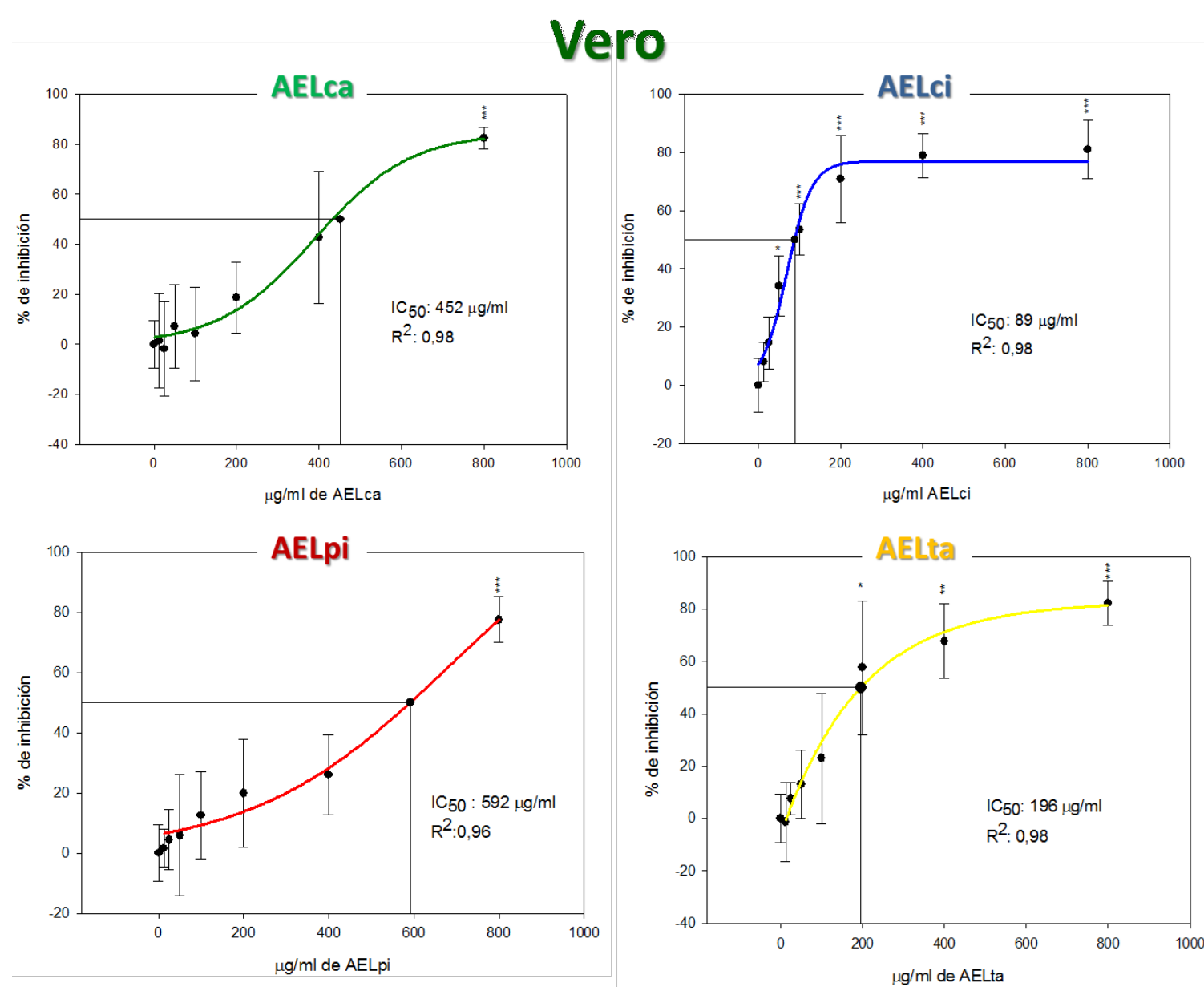

Figura A.1. Efecto de AELs sobre la viabilidad de células Vero determinada por el ensayo de MTT. Las células en fase exponencial de crecimiento fueron tratadas con concentraciones crecientes de cada AE durante 48 horas. La viabilidad celular se determinó por el ensayo de MTT. Los datos se expresan como el promedio \pm DS $(n=4) ;{ }^{*} p<0,05 ;{ }^{* *} p<0,01 ;{ }^{* * *} p<0,001$ 


\section{HepG2}
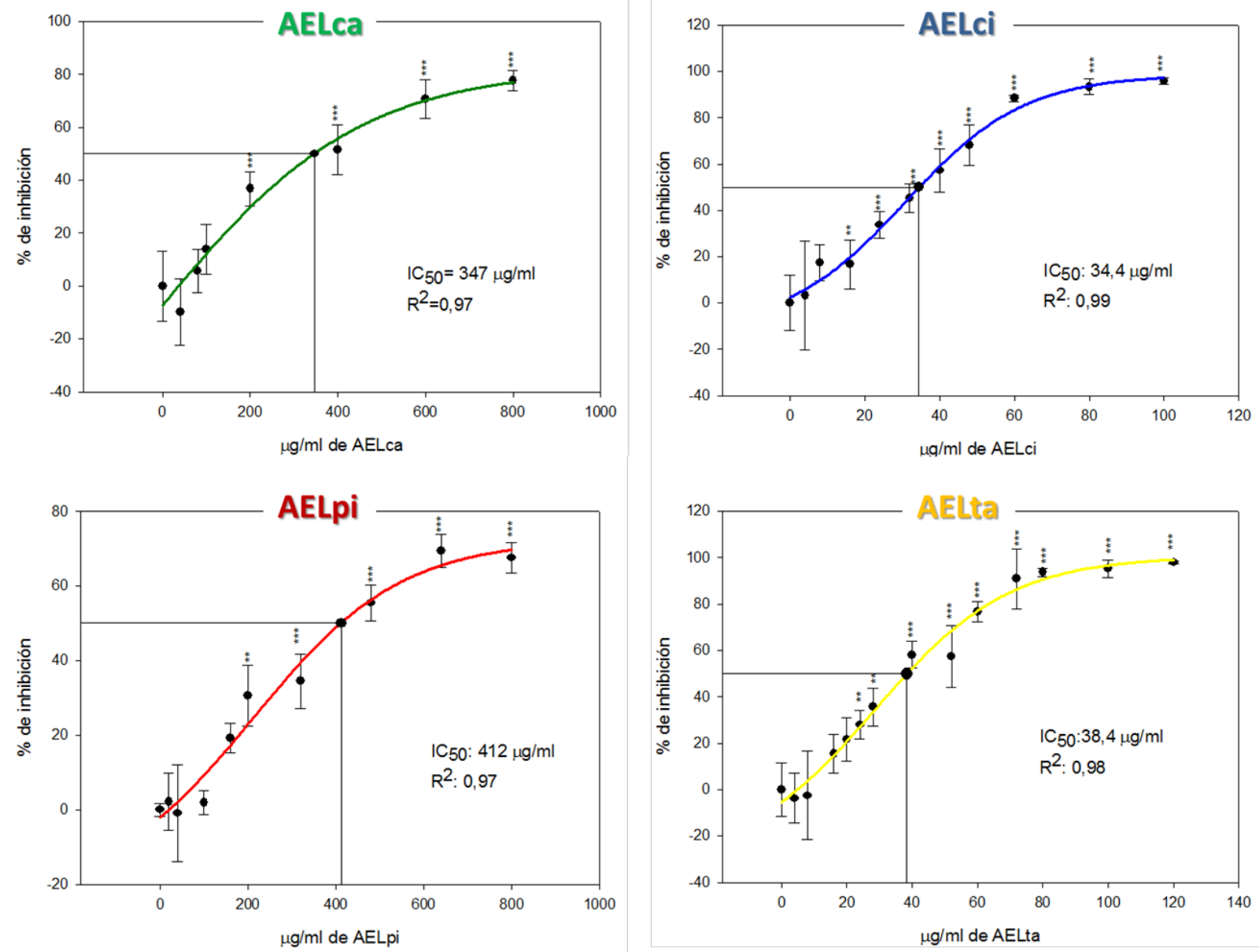

Figura A.2. Efecto de AELs sobre la viabilidad de células HepG2 determinada por el ensayo de MTT. Las células en fase exponencial de crecimiento fueron tratadas con concentraciones crecientes de cada AE durante 48 horas. La viabilidad celular se determinó por el ensayo de MTT. Los datos se expresan como el promedio \pm DS $(n=4) ;{ }^{*} p<0,05 ; * *<0,01 ;{ }^{* * *} p<0,001$ 


\section{A549}
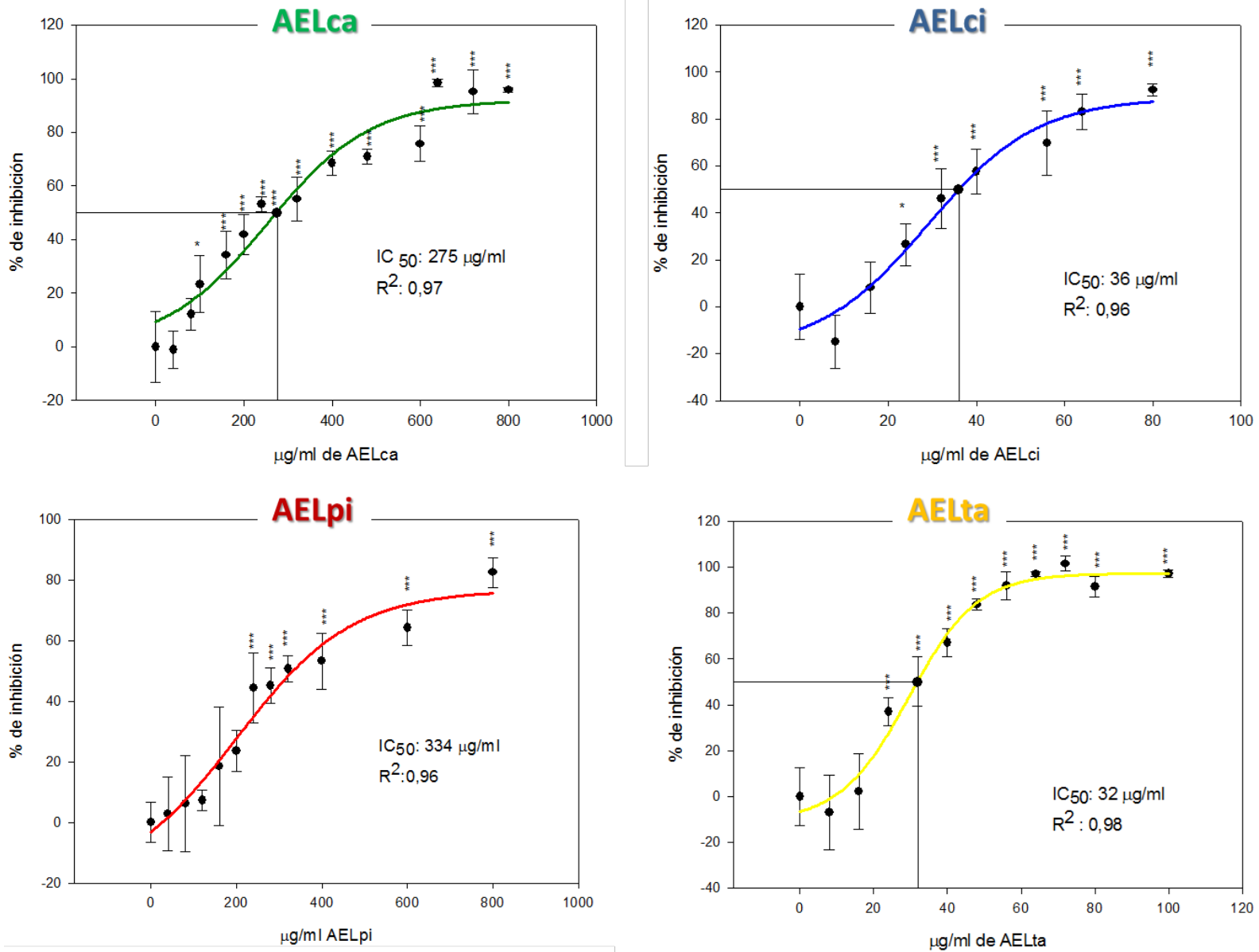

Figura A.3. Efecto de AELs sobre la viabilidad de células A549 determinada por el ensayo de MTT. Las células en fase exponencial de crecimiento fueron tratadas con concentraciones crecientes de cada AE durante 48 horas. La viabilidad celular se determinó por el ensayo de MTT. Los datos se expresan como el promedio \pm DS $(n=4) ;{ }^{*} p<0,05 ;{ }^{* *} p<0,01 ;{ }^{* * *} p<0,001$ 


\section{I.2 Ensayo de rojo neutro en células tratadas con AELs}

Se realizaron tratamientos de la manera anteriormente descrita para el ensayo de MTT. La vialidad celular fue determinada por el ensayo de RN según se describe en la sección 3.B.4.2. A partir de los datos obtenidos se construyó curvas dosis-respuesta utilizando el software SigmaPlot v. 10. Se muestran las curvas en las Figuras A.4 y A.5.
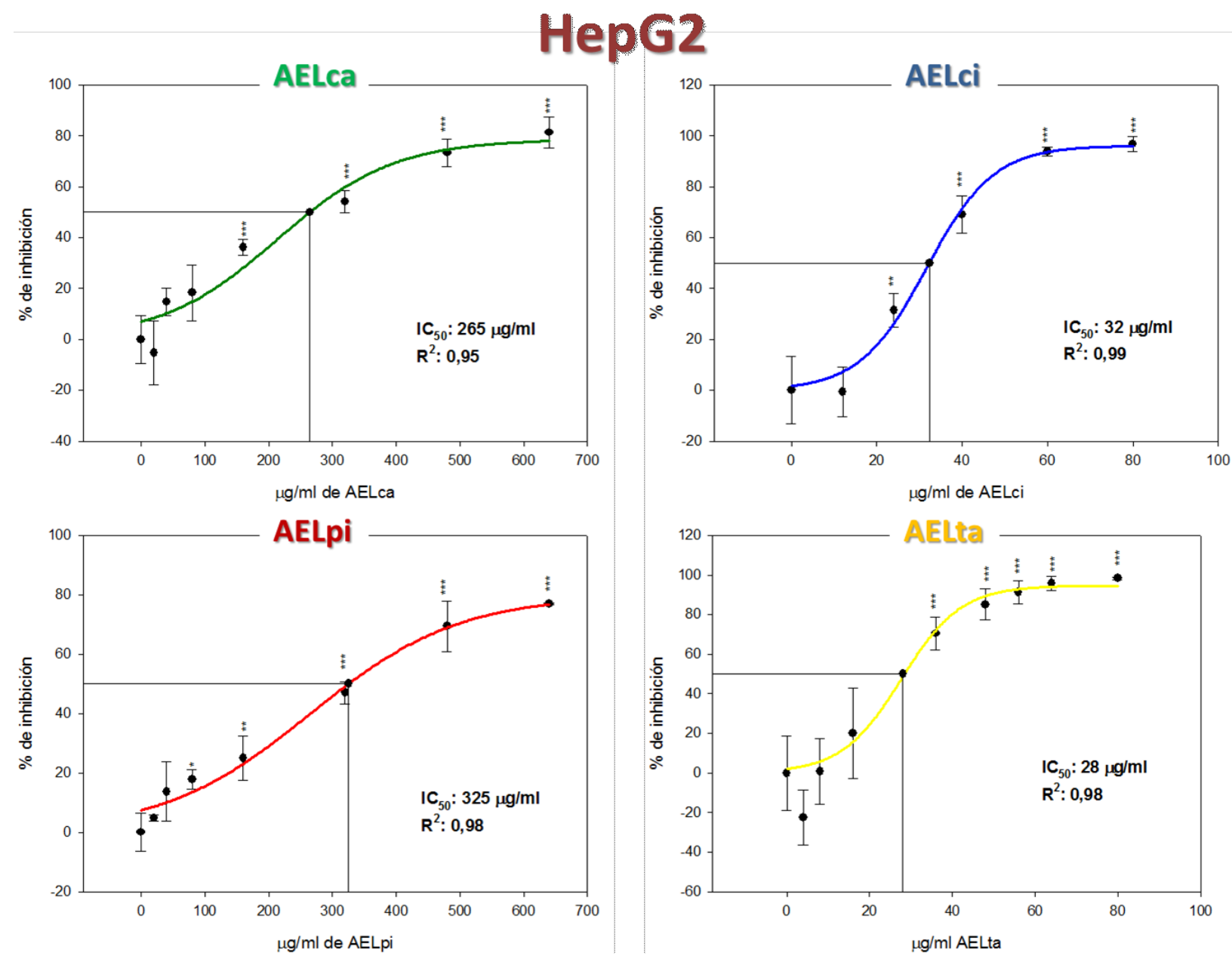

Figura A.4. Inhibición de la viabilidad celular mediada por AELs determinada por el ensayo de RN en células HepG2. Las células en fase exponencial de crecimiento fueron tratadas con concentraciones crecientes de cada AE durante 48 horas. La viabilidad celular se determinó por el ensayo de RN. Los datos se expresan como el promedio \pm DS $(n=4) ;{ }^{*} p<0,05 ;{ }^{* *} p<0,01 ;{ }^{* *} p<0,001$. 

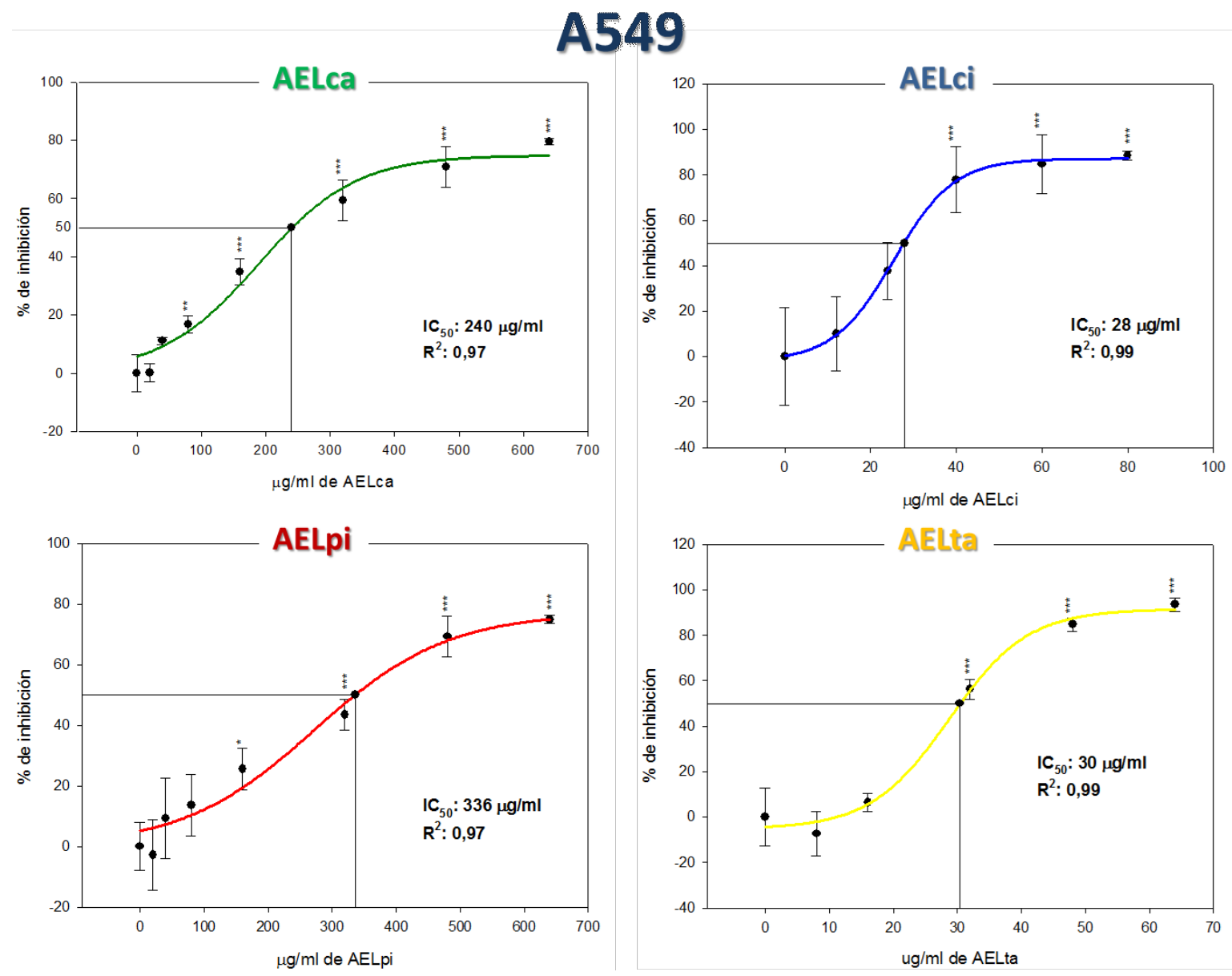

Figura A.5. Inhibición de la viabilidad celular mediada por AELs determinada por el ensayo de RN en células A549. Las células en fase exponencial de crecimiento fueron tratadas con concentraciones crecientes de cada AE durante 48 horas. La viabilidad celular se determinó por el ensayo de RN. Los datos se expresan como el promedio \pm DS $(n=4) ;{ }^{*} p<0,05 ; * *<<0,01 ; * * p<0,001$. 


\section{I.3 Ensayo de MTT en células tratadas con simvastatina.}

Células en fase exponencial de crecimiento fueron tratadas con concentraciones crecientes de Sv en medio de cultivo MEM suplementado con 10 \% SFB. A las 24 horas de tratamiento se reemplazó por medio fresco y las respectivas concentraciones de Sv y se incubaron las células por 24 horas más. La viabilidad celular fue determinada por el ensayo de MTT según lo descrito en la sección 3.B.4.1. A partir de los resultados obtenidos en los ensayos se elaboraron curvas dosis-respuesta utilizando el software SigmaPlot v. 10. Se muestran las curvas en las Figuras A.6.

A

HepG2

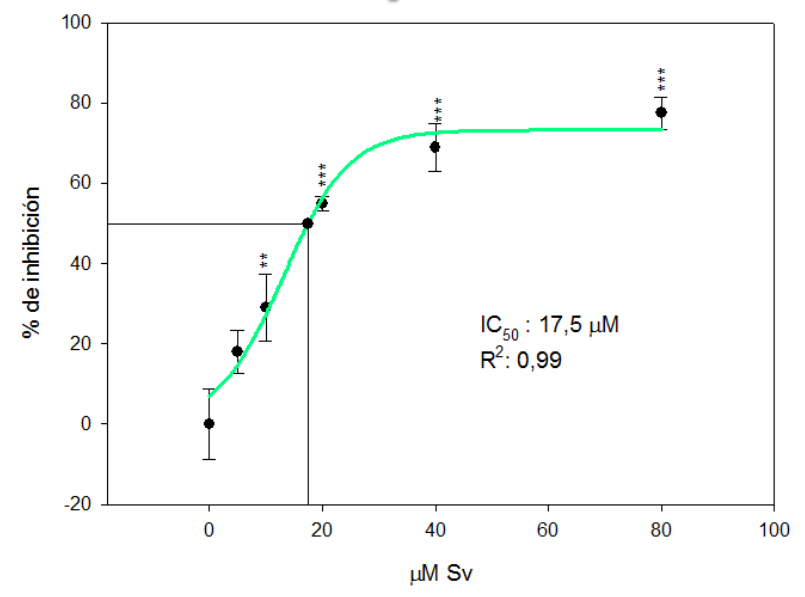

B

A549

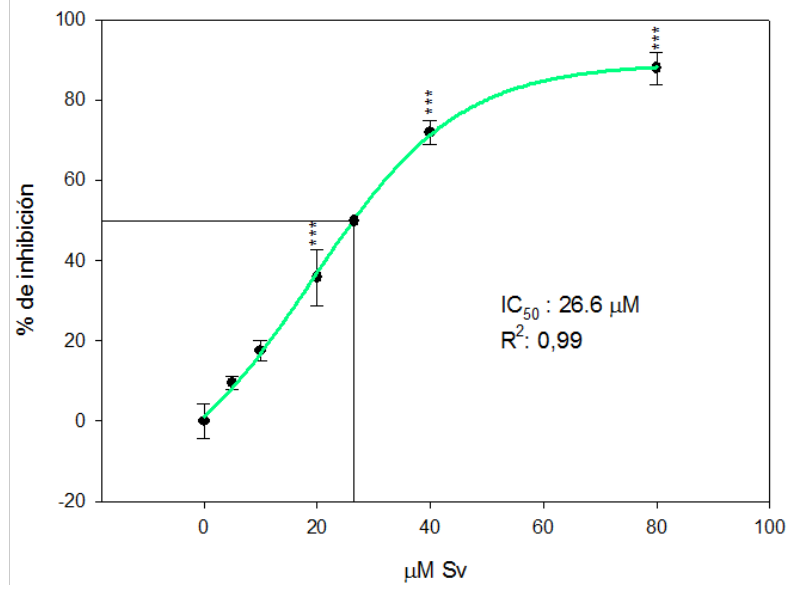

Figura A.6. Efecto de simvastatina sobre la viabilidad de células HepG2 y A549 determinada por el ensayo de $\mathbf{M T T}$. Las células en fase exponencial de crecimiento fueron tratadas con concentraciones crecientes de la estatina durante 48 horas. La viabilidad celular se determinó por el ensayo de MTT en las células HepG2 (panel A) y A549 (panel B). Los datos se expresan como el promedio \pm DS $(n=4) ;{ }^{*} p$ $<0,05 ;{ }^{* *} p<0,01 ;{ }^{* * *} \mathrm{p}<0,001$. 


\section{Determinación de apoptosis en células HepG2 por ensayo de TUNEL para 3 quimiotipos de Lippia alba}

Con el propósito de evaluar la existencia de un efecto pro-apoptótico en tres de los AEs de Lippia alba estudiados, se analizó la fragmentación de ADN nuclear por medio del ensayo de TUNEL. Para este ensayo se trataron células HepG2 creciendo sobre cubreobjetos de $24 \times 24 \mathrm{~mm}$ con las concentraciones correspondientes a los $\mathrm{IC}_{50}$ de AELca, AELci y AELpi durante 48 horas. Posteriormente las células fueron lavadas, fijadas, permeabilizadas y tratadas con el kit de detección de muerte celular in situ (TUNEL) de Roche ${ }^{\circledR}$ según lo detallado en la sección 3.B.6.1.

En la Figura A.7 puede observarse imágenes representativas obtenidas por microscopía de fluorescencia. Los resultados de la cuantificación de las imágenes obtenidas se muestran en la Tabla A.1 donde muy similar a lo observado en la sección 4.C.2.1. para AELta se observó que pese a encontrarse una diferencia significativa con respecto al control, el porcentaje de células en apoptosis es relativamente baja.
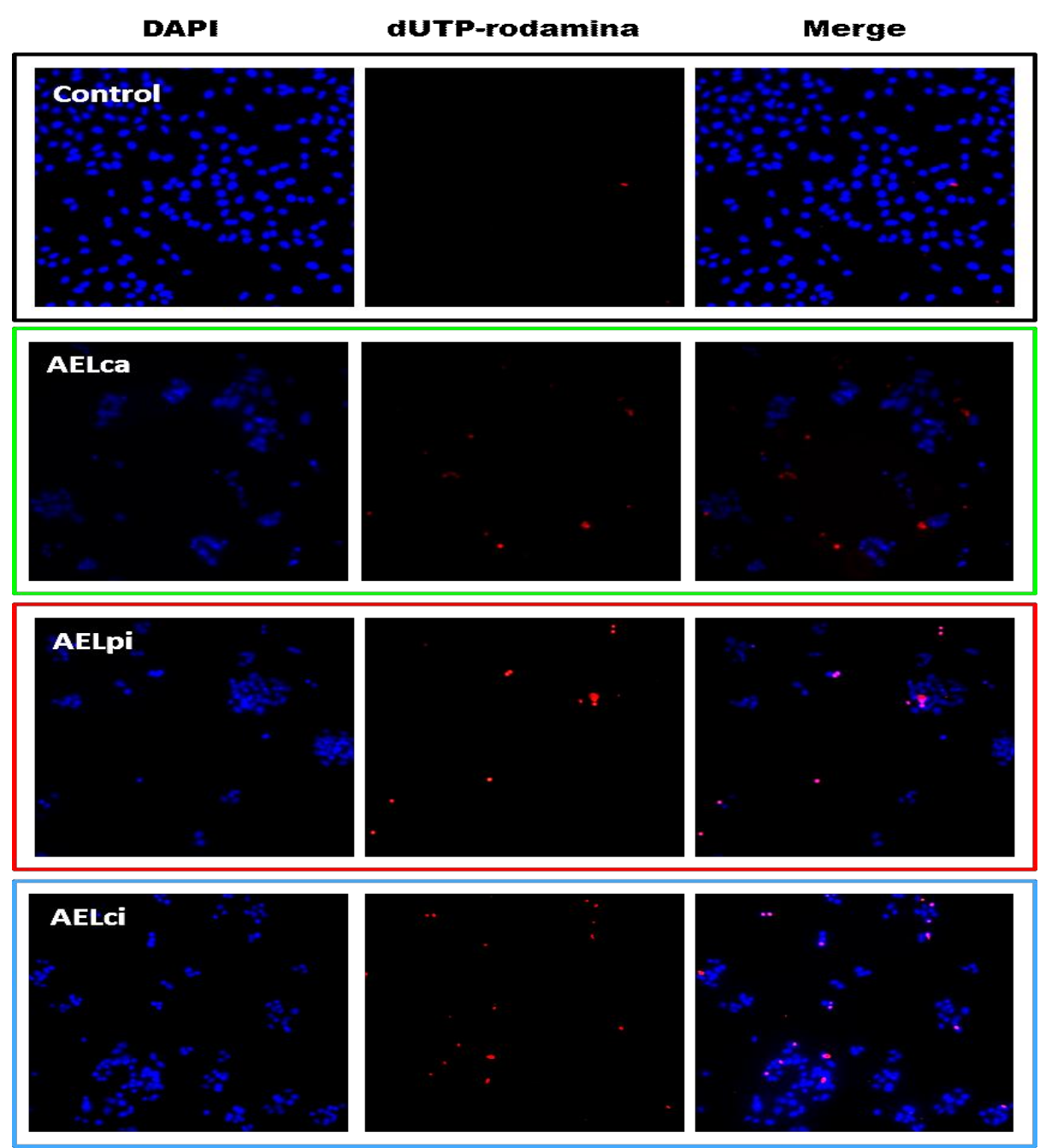

Figura A.7. Apoptosis determinada por ensayo de TUNEL en células HepG2. Imágenes de microscopía de fluorescencia (400X) de células tratadas con DMSO 0,2 \% (Control) y el $I_{50}$ de AELca, AELpi y AELci durante 48 horas. Se observa el núcleo teñido con DAPI, las células apoptóticas que incorporaron d-UTProdamina y la imagen combinada. 
Tabla A.1. Inducción de apoptosis en células HepG2 tratadas con quimiotipos de Lippia alba determinada por el ensayo TUNEL.

\begin{tabular}{cc}
\hline & Porcentaje células apoptóticas \\
\hline Control & $0,57 \pm 0,14$ \\
$1,0 \times I C_{50}$ AELca & $11,27 \pm 1,19 * * *$ \\
$1,0 \times I C_{50}$ AELpi & $9,21 \pm 2,06 * * *$ \\
$1,0 \times I C_{50}$ AELci & $9,56 \pm 2,56 * * *$
\end{tabular}

El porcentaje de células TUNEL positivas se determinó del conteo de 10 campos ópticos con 300 células/campo para cada condición experimental. Se expresan los valores como el promedio $\pm D S,(n=3) ; * * * p<0.001$. 


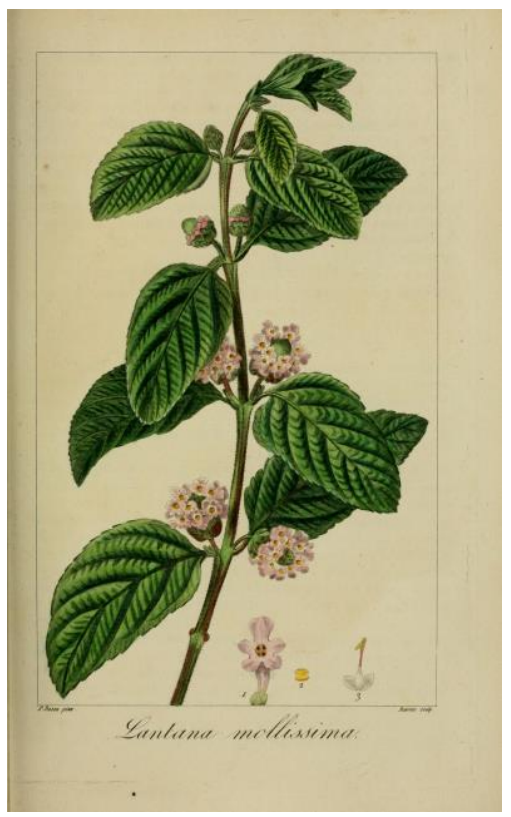

Foto portada y contraportada:

Lippia alba (Miller) N.E.Br. ex Britton \& P. Wilson. (como Lantana mollissima Desf)

Mordant De Launay,F; Loiseleur-Deslongchamps, JLA. Herbier general de l'amateur,vol 8: t.564 (1817)

Ilustración: Pancrase Bessa 


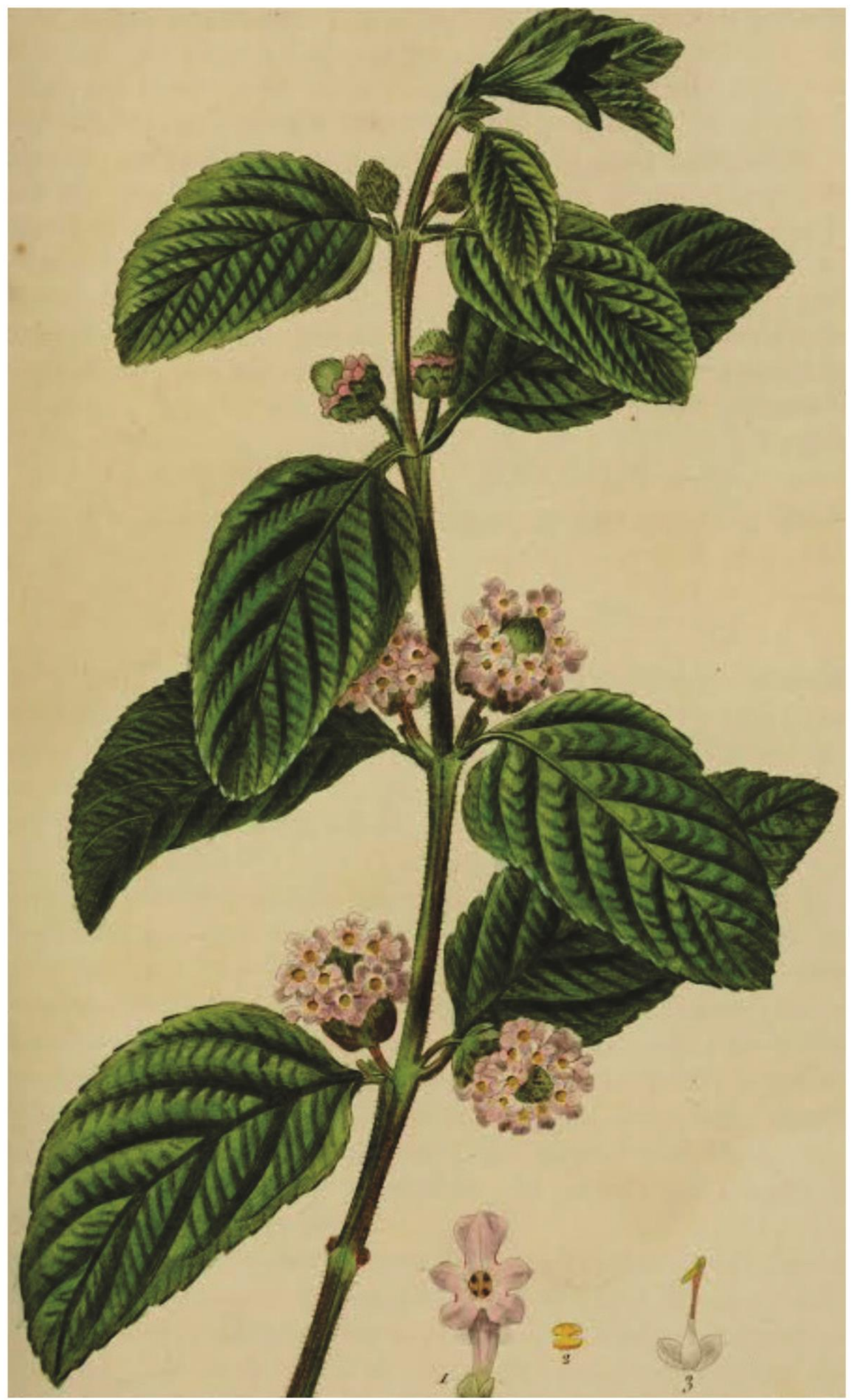

